A Final Technical Report Submitted to the

\begin{abstract}
U.S. Department of Energy
Nuclear Engineering Education Research (NEER) Program

By the

Office of Research and Graduate Programs

University of Florida

Gainesville, Florida 32611
\end{abstract}

For a project entitled

MicroCT-Based Skeletal Models for Use in Tomographic
Voxel Phantoms for Radiological Protection

Grant DE-FG07-07ID14773

Wesley Bolch, PhD, PE, CHP, Principal Investigator

Department of Nuclear and Radiological Engineering University of Florida

March 30, 2010 


\title{
9. Health Physics: \\ MicroCT-Based Skeletal Models for Use in Tomographic Voxel Phantoms for Radiological Protection
}

\author{
Wesley E. Bolch, PhD, PE, CHP \\ Professor of Radiological and Biomedical Engineering \\ University of Florida, Principal Investigator
}

\begin{abstract}
The University of Florida (UF) proposes to develop two high-resolution image-based skeletal dosimetry models for direct use by ICRP Committee 2's Task Group on Dose Calculation in their forthcoming Reference Voxel Male (RVM) and Reference Voxel Female (RVF) whole-body dosimetry phantoms. These two phantoms are CT-based, and thus do not have the image resolution to delineate and perform radiation transport modeling of the individual marrow cavities and bone trabeculae throughout their skeletal structures. Furthermore, new and innovative 3D microimaging techniques will now be required for the skeletal tissues following Committee 2's revision of the target tissues of relevance for radiogenic bone cancer induction. This target tissue had been defined in ICRP Publication 30 as a $10-\mu \mathrm{m}$ cell layer on all bone surfaces of trabecular and cortical bone. The revised target tissue is now a $50-\mu \mathrm{m}$ layer within the marrow cavities of trabecular bone only and is exclusive of the marrow adipocytes. Clearly, this new definition requires the use of $3 \mathrm{D}$ microimages of the trabecular architecture not available from past 2D optical studies of the adult skeleton. With our recent acquisition of two relatively young cadavers (males of age 18-years and 40-years), we will develop a series of reference skeletal models that can be directly applied to (1) the new ICRP reference voxel man and female phantoms developed for the ICRP, and (2) pediatric phantoms developed to target the ICRP reference children. Dosimetry data to be developed will include absorbed fractions for internal beta and alpha-particle sources, as well as photon and neutron fluence-to-dose response functions for direct use in external dosimetry studies of the ICRP reference workers and members of the general public.
\end{abstract}




\section{A. Project Objectives}

The International Commission on Radiological Protection (ICRP) is presently developing a revised set of radiological protection recommendations updating those given in ICRP Publication 60. Two very important decisions have been made regarding these revisions. First, ICRP Committee 2 was instructed to develop two tomographic voxel-based anatomic phantoms representing the ICRP 89 reference adult male and reference adult female. As these phantoms are based upon whole-body CT scans, limitations on image resolution preclude the ability to explicitly model the 3D micro-architecture of the bone trabeculae and marrow cavities within the skeletal regions of either phantom. Second, new information on the cells at risk for induction of radiogenic bone cancer have resulted in a revision of the $10-\mu \mathrm{m}$ endosteal layer originally defined in the ICRP 30 bone model. The new target tissue is now defined as all non-adipose bone marrow located within $50-\mu \mathrm{m}$ on the bone surfaces in trabecular bone (e.g., shallow active marrow). This new target tissue explicitly demands a 3D representation of not only the bone trabeculae by skeletal site, but also the active and inactive marrow tissues as a function of depth within the marrow cavities. The recent acquisition of two young cadavers at the University of Florida - an 18-year male and a 40-year male - provide us with a very unique and timely opportunity to significantly contribution to this ICRP effort. A 2-year comprehensive research project is thus proposed to DOE having the following three research objectives:

1. To construct a high-resolution skeletal dosimetry model for use with the ICRP Reference Voxel Male (RVM) and Reference Voxel Female (RVF) based upon CT and microCT images of skeletal specimens taken from the 18-year male. As the ICRP Publication 89 defines reference adults as between 20 and 50 years of age, this individual thus represents the lower end of the adult age range. Each bone and/or region of the skeleton will be modeled individually and will have two image-based descriptions. The first will be based on highresolution ex-vivo CT scans with regions of cortical bone and interior spongiosa explicitly segmented. The second will be based on one or more ex-vivo microCT scans of cored spongiosa with bone trabeculae and marrow cavities explicitly defined in the voxelized image. The resulting model will be used to develop absorbed fraction data for internal electron and alpha-particle dosimetry of the skeletal tissues, as well as fluence-to-dose response functions needed for both photon and neutron dosimetry in the ICRP phantoms.

2. To construct a high-resolution skeletal dosimetry model for use with the ICRP reference voxel phantoms based upon ex-vivo CT and microCT scanning of skeletal specimens taken from the 40-year male cadaver. This individual thus represents the upper end of the ICRP adult age range. Along with Task 1 , the ICRP will be able to report skeletal dosimetry values at each end of the adult age range, as well as average values for the median age of 35 years.

3. To construct high-resolution skeletal dosimetry models for use with UF and GSF series of pediatric phantoms for potential future use by the ICRP. In this task, we will rescale each of the ex-vivo CT skeletal images of the 18-year male cadaver of Task 1 to match the skeletal dimensions of the UF (9-mo M, 4-yr F, 8-yr F, 11-yr M, and 14-yr M) and GSF (2-mo F and $7-y r$ F) pediatric series. As existing chord-based models of electron transport in the skeleton do not account for energy loss to cortical bone, it is anticipated that Task 3 studies will significantly reduce conservative dose uncertainties in pediatric skeletal dosimetry as needed for dose reconstruction studies targeting members of the general public. 


\section{B. Graduate Students Supported}

\section{Masters Students}

1. Hasenauer, Deanna, MS (Health Physics - May 2006)

Thesis - Image-based techniques for beta particle skeletal dosimetry

2. Kielar, Kayla, MS (Health Physics - May 2006)

Thesis - A skeletal reference dosimetry model for the adult female

3. Hough, Matt, MS (Health Physics - May 2007)

Thesis - A skeletal reference dosimetry model for the 40-year male

\section{$\underline{\text { PhD Students }}$}

4. Kielar, Kayla PhD (Health Physics - August 2009)

Dissertation - Bone marrow dosimetry via microCT imaging and stem cell spatial mapping

5. Pafundi, Deanna PhD (Health Physics - August 2009)

Dissertation - Image-based skeletal models for the ICRP reference pediatric age series

\section{Meeting Presentations and Abstracts}

1. KN Kielar ${ }^{*}$, WE Bolch, and AP Shah, "A skeletal reference dosimetry model for the adult female", Transactions of the Computational Medical Physics Working Group - Workshop II - of the American Nuclear Society, Gainesville, Florida, October 1-3, 2007.

2. D Hasenauer ${ }^{*}, C$ Lee*, DL Lodwick", CJ Watchman, and WE Bolch, "Development of hybrid computational newborn phantom for dosimetry calculation: the skeleton" Transactions of the Computational Medical Physics Working Group - Workshop II - of the American Nuclear Society, Gainesville, Florida, October 1-3, 2007.

3. KN Kielar ${ }^{*}, \mathrm{AP}$ Shah, and WE Bolch, "A skeletal dosimetry model for the adult female", 2007 Annual Meeting of the Society of Nuclear Medicine, Washington, DC, June 3-6, 2007 [Supplement to J Nucl Med 48 (6) 297P (2007)].

4. KN Kielar ${ }^{*}$, AP Shah, and WE Bolch, "A skeletal reference dosimetry model for the adult female", 2007 Annual Meeting of the Health Physics Society, Portland, Oregon, July 8-12, 2007 [Supplement to Health Phys 93 (1) S46 (2007)].

5. M Hough ${ }^{*}$, and WE Bolch, "A skeletal reference dosimetry model for the 40-year male", 2007 Annual Meeting of the Health Physics Society, Portland, Oregon, July 8-12, 2007 [Supplement to Health Phys 93 (1) S46 (2007)]. 
6. D Hasenauer ${ }^{*}, \mathrm{C}$ Lee ${ }^{\star}, \mathrm{D}$ Lodwick${ }^{\star}, \mathrm{C}$ Watchman, and WE Bolch, "Development of hybrid computational newborn phantom for dosimetry calculations: The skeleton", 2007 Annual Meeting of the Health Physics Society, Portland, Oregon, July 8-12, 2007 [Supplement to Health Phys 93 (1) S47 (2007)].

7. C Lee*, D Lodwick*, J Hurtado*, D Pafundi", and WE Bolch, "Development of a series of hybrid computational phantoms and their applications to assessment of photon and electron specific absorbed fractions", 2008 Annual Meeting of the European Association of Nuclear Medicine, Munich, Germany, October 11-15, 2008. [Supplement to Eur J Nucl Med 35 (2) S202, 2008].

8. D Pafundi", C Lee*, DL Lodwick", A Shahlaee, and WE Bolch, "Image-based pediatric skeletal dosimetry for the UF hybrid computational phantom series", 2008 Annual Meeting of the European Association of Nuclear Medicine, Munich, Germany, October 11-15, 2008 [Supplement to Eur J Nucl Med 35 (2) S135, 2008].

9. D Hasenauer ${ }^{*}, C$ Lee*, D Lodwick ${ }^{*}, A$ Shahlaee, and WE Bolch, "Image-based pediatric skeletal dosimetry for the UF hybrid computational phantom series", 2008 Annual Meeting of the Society of Nuclear Medicine, New Orleans, LA, June 14-18, 2008. [Supplement to J Nucl Med 49 (5) 281P (2008)].

10. L Sinclair, D Pafundi, and W Bolch, "A skeletal model for marrow dosimetry in the ICRP reference adult female", 2009 Annual Meeting of the American Association of Physicists in Medicine, Anaheim, CA, July 26-30, 2009. [Supplement to Medical Physics 36 (6) 2450 (2009)].

11. A Bahadori, K Eckerman, D Jokisch, and W Bolch, "Skeletal neutron dose response functions development for use in proton therapy," 2009 Annual Meeting of the American Association of Physicists in Medicine, Anaheim, CA, July 26-30, 2009. [Supplement to Medical Physics 36 (6) 2668 (2009)].

12. D Pafundi", C Lee, C Watchman, V. Bourke, J. Aris, and WE Bolch, "Image-based skeletal dosimetry models for the ICRP reference pediatric series", Third International Symposium on Radionuclide Therapy and Radiopharmaceutical Dosimetry (ISRTRD), Toronto, Canada, June 13-17, 2009 [Supplement to J Nucl Med 50 (2) 70P (2009)].

\section{Journal Articles Published}

1. CJ Watchman, D Hasenauer ${ }^{\star}$, WE Bolch, "Derivation of site-specific skeletal masses within the current ICRP age series" Phys Med Biol 52 (11) 3133-3150 (2007).

2. WE Bolch, AP Shah, CJ Watchman, DW Jokisch, PW Patton, DA Rajon, M Zankl, N Petoussi-Henss, and KF Eckerman, "Skeletal absorbed fractions for electrons in the adult male - considerations of a revised $50-\mu \mathrm{m}$ definition of the bone endosteum" Radiat Prot Dosim (Adv Access June 7, 2007) 127 (1-4) 169-173 (2008). [Invited Paper]

3. CJ Watchman and WE Bolch, "Absorbed fractions for alpha particles in tissues of cortical bone" Phys Med Biol 54 6009-6027 (2009). 


\section{E. Journal Articles In Preparation for Submission}

1. A microCT-based skeletal dosimetry model for the reference adult male: Internal electron sources

Matt Hough, Didier Rajon, Perry Johnson, and Choonsik Lee

Physics in Medicine and Biology (in preparation)

2. Skeletal dose response functions: A comprehensive method for evaluating absorbed dose to active marrow and bone endosteum from external and internal photon sources

Perry Johnson, Amir Bahadori, Keith Eckerman, Choonsik Lee, and Wesley Bolch

Physics in Medicine and Biology (in preparation)

3. A microCT-based skeletal dosimetry model for the reference adult female: Internal electron sources

Lindsay Sinclair and Wesley Bolch

Physics in Medicine and Biology (in preparation)

4. A microCT-based skeletal dosimetry model for the reference 15-year adolescent: Internal electron sources

Deanna Pafundi and Wesley Bolch

Physics in Medicine and Biology (in preparation) 


\section{Appendix A}

\section{A Skeletal Reference Dosimetry Model for the 40-Year Male}




\title{
A Skeletal Reference Dosimetry Model for the 40-Year Male: Skeletal Masses
}

\author{
Matthew C Hough ${ }^{1}$ and Wesley Bolch ${ }^{1}$ \\ ${ }^{1}$ Department of Nuclear and Radiological Engineering \\ University of Florida, Gainesville, FL 32611
}

\begin{abstract}
Accurate estimates of absorbed dose to skeletal tissues (hematopoietic stem cells in active bone marrow and osteoprogenitor cells in shallow marrow) are essential in risk assessment in both occupational and medical dosimetry. Currently, the majority of skeletal reference models (SRMs) used in dosimetry utilizes chord-length data from a single 44-year male that was obtained in the late 1960s and early 1970s at the University of Leeds. Seeing a need for skeletal data for patients/workers at various ages, the University of Florida Bone Imaging and Dosimetry (UF BID) project set out to create scalable SRMs of male and female subjects representative of pediatric, adolescent, young adult, and geriatric ages that can be applied to patient/worker specific cases. Recently, the UF BID project has developed image-based SRMs of a 66-year male and a 64-year female, as representative of cancer patients undergoing radionuclide therapy. For this study, a 40-year male SRM is under development as representative of a typical radiation worker or cancer patient. A 40 year-old male cadaver was selected with a body-mass index of $28.6 \mathrm{~kg} \mathrm{~m}^{-2}$ and a cause of death precluding skeletal deterioration. In-vivo Computed Tomography (CT) images were acquired prior to removal of 38 bone sites, including 14 sites from the axial skeleton and 24 sites from the appendicular skeleton (proximal and distal sites of
\end{abstract}


the arm and leg bones). Next, high-resolution ex-vivo CT images of all skeletal sites were acquired from which volumes of both cortical bone and trabecular spongiosa were determined via image segmentation. Finally, samples of trabecular spongiosa from all bone sites were imaged at $30 \mu \mathrm{m}$ resolution utilizing microCT to determine the micro-structure and marrow volume fraction of the trabecular spongiosa. From knowledge of macrostructural information (ex-vivo CT contoured spongiosa volumes) and microstructural information (ex-vivo microCT marrow and bone volume fraction, cellularity, etc.) a skeletal mass database was created for the 40 year-old male. These reference masses are reported and compared to both the UF 66 year-old male and ICRP 70/89 Reference Man. 


\section{INTRODUCTION}

The skeleton is of critical interest in internal radiation dosimetry for both radiation protection and radionuclide therapy. Accurate absorbed dose estimates to the hematopoietic tissues in the active (red) bone marrow and osteogenic tissues in the shallow active bone marrow are of primary importance in order to better predict the short-term deterministic (myelotoxicity) and long-term stochastic (leukemia and/or osteosarcomas induction) effects of radiation exposure. Unlike many other organs of interest in internal dosimetry, however, the skeleton is composed of many bones with highly heterogeneous tissues: cortical and trabecular bone and hematopoietically active and inactive bone marrow. Explicit knowledge of each bone site's shape and volume of: (1) trabecular spongiosa (combination of trabecular bone and active and inactive marrow) and the exterior cortex of cortical bone (the hard compact bone that forms the dense but smooth external layer), or macrostructure, (2) trabecular bone (the spongy or cancellous bone that forms the honeycomb structure within the dense shell) distribution, or microstructure, (3) bone volume fraction and marrow volume fraction, (4) and marrow cellularity (the fraction of marrow present that is hematopoietically active) is paramount to accurately create Skeletal Reference Models (SRMs) used to calculate absorbed dose to both red bone marrow and osteogenic shallow marrow.

Currently, the majority of SRMs used in dosimetry utilizes chord-length data from a single 44-year male that was obtained in the late 1960s and early 1970s at the University of Leeds. This data forms an essential component of the International Commission on Radiological Protection's (ICRP) SRM published in ICRP Publications 30, 70, and 89. Unfortunately, this study only set out to describe the trabecular microstructure of seven bone sites and did not incorporate each bone sites' macrostructure. Ideally this model should have taken into account 
both the microscopic structure of the bone trabeculae and marrow cavities, as well as the macroscopic structure of the bone site itself. Indeed, for alpha emitters and low-energy beta emitters, only the microscopic characterization is needed to model each bone site and accurately predict its absorbed dose, as these particles typically expend their full emission energy within the trabecular spongiosa. However, for intermediate- to higher-energy beta emitters, energy loss to the exterior cortical bone or even particle escape from the bone site can be expected, especially at those skeletal sites with high spongiosa surface-to-volume ratios (flat bones such as the cranium and ribs). In the later cases, the SRMs based on the University of Leeds' data will overestimate skeletal absorbed dose, which could possibly lead to overly conservative treatment planning for radionuclide therapy patients.

Previous work by Shah et al. at the University of Florida (UF) created the Paired-Image Radiation Transport (PIRT) model, a means to account for both the macro- and microstructure of each individual bone site. PIRT allows particles to be tracked simultaneously through two segmented digital images: (1) an ex-vivo Computed Tomography (CT) scan of each individual bone site's macrostructure, and (2) a high-resolution microCT scan of each individual bone site's microstructure. This form of radiation transport allows for both energy losses to the exterior cortical bone as well as particle escape from the bone site, which leads to a much more accurate absorbed dose calculation for higher-energy beta emitters. Furthermore, the technique increases the prospects for expanded availability of SRMs for both genders and of individuals of varying stature and skeletal size.

In addition, while the University of Leeds' data has formed the backbone of all skeletal dosimetry for the past three decades, recent studies have shown that predictions of myelotoxicity must be based on patient/worker-specific skeletal absorbed doses. This is due to highly variable 
skeletal macro- and microstructures as well as marrow cellularities. An important example of this skeletal variability is osteoporosis in females over the age of 50. Osteoporosis, which is the most common bone disease in the United States, is a disorder which causes the rate of bone resorption to become much greater than that of bone formation. This leads to a much thinner trabecular structure, which greatly affects the microstructure and dosimetry of certain skeletal sites. Yet another variable is the shape and size of bone sites with age. Obviously, the skeletal structure of a teenage male is much different than that of a middle-aged male. Hence, trying to accurately predict myelotoxicity in a 65 year-old female Non-Hodgkin's Lymphoma patient or a 15 year-old male leukemia patient utilizing the University of Leeds' 44 year-old male skeletal data would be extremely difficult. For this reason, it is evident that the creation of SRMs that are able to be matched to patient-specific cases is essential. In fact, as radionuclide therapies such as radioimmunotherapy become more prevalent in everyday clinical practice, the need for patientspecific dosimetry intensifies.

Seeing a need for skeletal data for patients/workers at various ages, the University of Florida Bone Imaging and Dosimetry (UF BID) project set out to create scalable SRMs of male and female subjects representative of pediatric, adolescent, middle, and geriatric ages that can be applied to patient/worker-specific cases. Recently, the UF BID project has developed imagebased SRMs of a 66 year-old male and a 64 year-old female, as representative of cancer patients undergoing radionuclide therapy. Studies at UF have also established a methodology by which these voxel based SRMs can be converted to deformable polygon-mesh models via Non-Uniform Rational B-Spline (NURBS) technology in order to account for varying macrostructures. Also, linear regression models have been created to predict skeletal total spongiosa volumes from a 
few simple radiographic measurements. These advances will allow the age and gender dependent SRMs developed at UF to be scaled to patient/worker-specific cases.

In the current study, a 40-year male SRM is under development as representative of a typical radiation worker or cancer patient. Creation of an SRM is a two step process, in that radionuclide S-values require knowledge of both the absorbed fraction (AFs), the fractional energy deposited within a target region from a source region, as well as the mass of the target region. In this phase of the study, the later will be determined for the entire skeletal system and compared to the masses of the 66 year-old male SRM developed at UF and ICRP Reference Man.

\section{MATERIALS AND METHODS}

\section{Cadaver Selection}

A male candidate subject for this study was obtained through the State of Florida Anatomical Board located on the University of Florida (UF) campus. Cadaver selection criteria included (1) an age between $30-50$ years (representative of typical radiation worker or radionuclide therapy patient), (2) a body mass index close to between $18.5-25 \mathrm{~kg} \mathrm{~m}^{-2}$ (CDC recommended healthy range), and (3) a cause of death that would preclude significant skeletal deterioration. The subject identified was a 44 year-old male approximately $82 \mathrm{~kg}$ in total mass and $170 \mathrm{~cm}$ in total height at the time of death (BMI of $28.5 \mathrm{~kg} \mathrm{~m}^{-2}$ ). The subject died suddenly of complications associated with cardiopulmonary arrest due to myocardial infarction.

\section{In-Vivo Computed Tomography Scanning}

Prior to bone harvesting, the male cadaver was subjected to whole-body imaging via multi-slice helical $\mathrm{CT}$ at a pitch necessary to reconstruct contiguous 1-mm axial slices. The images were 
acquired on a Siemens Sensation 16 unit within the Department of Radiology at UF Shands Hospital. Image reconstruction was performed with a bone filter at a maximum in-plane pixel resolution of $977 \mu \mathrm{m} \times 977 \mu \mathrm{m}$. The CT image sets were then transferred to workstations within the Advanced Laboratory for Radiation Dosimetry Studies (ALRADS) in the UF Department of Nuclear \& Radiological Engineering for image processing and data storage. The in-vivo CT scans provided image data for (1) selecting the anatomical region from which the bone site would be harvested, and (2) constructing 3D anatomic models of skeletal sites where bone harvesting (and thus ex-vivo CT scanning) might be incomplete (e.g., facial bones of the skull and shafts of all long bones).

\section{Bone Harvesting and Ex-Vivo Computed Tomography Scanning}

Following detailed review of the whole-body in-vivo CT images, bone harvesting was conducted. Thirty-eight major skeletal sites were taken from the male cadaver: clavicles (2), cranium cap (2), distal and proximal femur (4), distal and proximal fibula (3 - the left distal fibula could not be excised due to the presence of a surgical pin), distal and proximal humerus (4), mandible (1), distal and proximal radius (4), lower rib (2), middle rib (2), upper rib (2), scapula (2), pelvis (1 - including osae coxae and sacrum), spinal column (1 - including lumbar, thoracic, and cervical vertebrae), sternum (1), distal and proximal tibia (3 - the left distal tibia could not be excised due to the presence of a surgical pin), and the distal and proximal ulna (4). Once each skeletal site was excised, it was cleaned of excess tissue, bagged, labeled, and stored frozen until ex-vivo CT imaging could be scheduled.

Ex-vivo CT imaging was again conducted with a Siemens Sensation 16 unit within the Department of Radiology at UF Shands Hospital utilizing the highest resolution permitted based on each samples' required field of view $(1.0 \mathrm{~mm}$ slice thickness with an in-plane resolution of 
$0.57 \mathrm{~mm} \times 0.57 \mathrm{~mm}$ for the pelvis, $0.11 \mathrm{~mm} \times 0.11 \mathrm{~mm}$ for the clavicles). The ex-vivo CT scans provided image data for (1) identifying the location and extent of trabecular spongiosa to be sectioned for microCT imaging; (2) quantifying both trabecular spongiosa and cortical bone volumes within the bone site; and (3) constructing 3D anatomic models of the bone site for subsequent paired-image radiation transport simulations ((2) and (3) were accomplished via detailed image segmentation).

\section{Micro- Computed Tomography Scanning}

After review of each bone site's ex-vivo CT scan, samples, or cores, of marrow intact spongiosa were strategically excised for imaging via microCT. Samples were taken to ensure that the largest volume of trabecular spongiosa possible would be imaged. Sample sizes were, however, limited to a maximum of $35 \mathrm{~mm}$ cubes due to restrictions of the microCT bore. Nonetheless, each sample was then shipped to Scanco Medical AG, in Bassersdorf, Switzerland for imaging with the $\mu \mathrm{CT} 80$ scanner at 30 micron resolution. It should be noted that in some cases, multiple samples were taken from each bone site (e.g. the cranium was split into the frontal, parietal, and occipital). Also, in an effort to include more samples from the long bones, only samples from the cadaver's right side were sent off for imaging.

\section{Post-acquisition Image Processing}

Image Segmentation of Spongiosa and Cortical Bone Regions from Ex-Vivo CT Scans

To create SRM tomographic anatomic models for use in internal dosimetry, boundaries must be delineated between each tissue region for which an independent dose assessment is to be made. For this reason, it is necessary to separate the cortical region of each bone site from the trabecular spongiosa region. Unfortunately, limitations of CT image acquisition results in an overlap of grayscale values for tissues of interest, which does not allow for simple automated 
methods of this boundary definition. For this reason, an in-house program called CT_Contours was adopted for use in segmenting the spongiosa and cortical bone within each ex-vivo or in-vivo CT image set. This program allows for a labeled contour file output in a variety of formats including binary files for EGSnrc and ASCII text for MCNP. In this program, the CT image data set is displayed in a two-dimensional array and the user can create colored overlays, or contours, to delineate the cortical from the spongiosa regions. An example of this program's user interface can be seen in Fig. 1.

Image Segmentation of Trabecular Spongiosa Regions from MicroCT Scans

In order to determine marrow volume fraction (MVF), trabecular shallow marrow volume fraction (SMVF), and trabecular bone volume fraction (BVF), multiple steps were applied to the microCT data sets. These steps included (1) extraction of a region of interest (ROI) to remove any intrusive cortical bone from the image; (2) applying a median filter to improve the signal-tonoise ratio (SNR); (3) determining a threshold to best classify the voxels as either bone or marrow; and (4) segmentation of the ROI into a binary image based on the threshold gray-level value. The thresholding technique used visual inspection of the image gradient magnitude in order to retrieve sample volume fractions at $30-\mu \mathrm{m}$ voxel resolution. An example of the user interface used to determine all microstructure data can be seen in Fig. 2.

\section{Comparison of Relative Spongiosa Volumes and Mass Calculations}

\section{Relative Spongiosa Volumes}

In an effort to quantify how well the 40 year-old male subject matched to average population parameters, relative spongiosa volumes, or the fraction of each bone site's spongiosa volume to the total spongiosa volume, were compared to those of the 66 year-old male SRM. Comparisons were also made to those of 19 other males, which were segmented in a previous study at UF. 


\section{Mass Calculations}

Mass estimates require both macrostructural volumetric information (obtained from the contours of segmented ex-vivo or in-vivo CT images), microstructural volume information (obtained from the filtered and segmented microCT spongiosa images), and the volume percentage of hematopoietically active versus inactive bone marrow for each skeletal site (marrow cellularity). It is important to note that marrow cellularity can vary from $0 \%$ (no active bone marrow) to $100 \%$ (no adipose tissue). For this reason, reference individuals could have a multitude of total active marrow masses, where the potential masses depend upon the marrow cellularity chosen. In an effort to create a SRM that is representative of average parameters, the reported masses utilize average age dependent cellularities provided by ICRP Publication 70 for a 40 year-old male, values of which can be seen in Table 1. Also, ICRU 46 tissue elemental compositions and densities, which can be seen in Table 2, were used for the appropriate skeletal regions.

Trabecular and Cortical Bone Masses in all Skeletal Sites

The mass of the Trabecular Bone Volume (TBV) was calculated as:

$$
\left(m_{T B V}\right)_{j}=(S V)_{j}(B V F)_{j}\left(\rho_{T B V}\right)
$$

where $\mathrm{SV}_{\mathrm{j}}$ is the spongiosa volume for skeletal site $\mathrm{j}, \mathrm{BVFj}$ is the Trabecular Bone Volume fractions at skeletal site $\mathrm{j}$, and $\rho_{\mathrm{TBV}}$ is the mass densities of the trabeculae bone $\left(1.92 \mathrm{~g} \mathrm{~cm}^{-3}\right)$.

The mass of the Cortical Bone Volume was calculated as:

$$
\left(m_{C B V}\right)_{j}=(C B V)_{j}\left(\rho_{C B V}\right)
$$

where $\mathrm{CBV}_{\mathrm{j}}$ is the cortical bone volume of skeletal site $\mathrm{j}$, and $\rho_{\mathrm{CBV}}$ is the density of cortical bone $\left(1.92 \mathrm{~g} \mathrm{~cm}^{-3}\right)$.

Marrow Masses in the Cortical Medullary Regions 
In the six skeletal long bones' (distal femur, distal fibula, distal humerus, distal radius, distal tibia, and distal ulna) cortical medullary regions, which lack active marrow (except in the upper half of the femur and humerus where $\mathrm{CF}$ is 0.25 ) and trabecular structure (i.e. $\mathrm{MVF}=1.0$ ), the inactive marrow masses were calculated using the following approach.

Unfortunately, the volume of the Cortical Medullary Inactive Shallow Marrow $\left(\mathrm{CIM}_{50}\right)$ is not easily attained from the segmented in-vivo images. For this reason, an approximation was made in which the cortical medullary region, or shafts, of the long bones were modeled as concentric cylinders. From these approximations, effective radii, which can be seen in Table 3, allowed the volume and mass of $\mathrm{CIM}_{50}$ to be calculated as:

$$
\begin{aligned}
& \left(V_{C M_{50}}\right)_{j}=1-\frac{R_{e f f .}-0.005 \mathrm{~cm}}{R_{e f f .}} \\
& \left(m_{C I M_{50}}\right)_{j}=\left(V_{C M_{50}}\right)_{j}(1-C F)_{j}\left(\rho_{C I M_{50}}\right)
\end{aligned}
$$

where $V_{\text {CIM } 50 \mathrm{j}}$ is the volume of Cortical Medullary Inactive Shallow Marrow of skeletal site $\mathrm{j}$, $\mathrm{CF}_{\mathrm{j}}$ is the cellularity factor for skeletal site $\mathrm{j}$, and $\rho_{\mathrm{CIM} 50}$ is the mass density of inactive marrow $\left(0.98 \mathrm{~g} \mathrm{~cm}^{-3}\right)$.

Marrow Masses in Skeletal Sites Containing Active and Inactive Marrow

For the thirteen skeletal sites that contain a relatively large portion of active marrow (clavicles, cranium and facial bones, proximal femur, proximal humerus, mandible, ribs, scapula, osae coxae, sacrum, lumbar vertebrae, thoracic vertebrae, cervical vertebrae, sternum), as well as the eight skeletal sites that contain minimal, if any, active marrow (distal femur, distal fibula, distal humerus, distal radius, distal tibia, distal ulna, hands, and feet),marrow masses were calculated using the following approach.

The mass of Trabecular Active Marrow (TAM) at skeletal site $j$ was calculated as: 


$$
\left(m_{T A M}\right)_{j}=(S V)_{j}(M V F)_{j}(C F)_{j}\left(\rho_{T A M}\right),
$$

where $\mathrm{SV}_{\mathrm{j}}$ is the spongiosa volume for skeletal site $\mathrm{j}, \mathrm{MVF}_{\mathrm{j}}$ is the marrow volume fraction for skeletal site $\mathrm{j}, \mathrm{CF}_{\mathrm{j}}$ is the cellularity factor for skeletal site $\mathrm{j}$, and $\rho_{\mathrm{TAM}}$ is the mass density of active marrow $\left(1.03 \mathrm{~g} \mathrm{~cm}^{-3}\right)$.

The mass of the Trabecular Inactive Marrow (TIM) was calculated as:

$$
\left(m_{T I M}\right)_{j}=(S V)_{j}(M V F)_{j}(1-C F)_{j}\left(\rho_{T I M}\right)
$$

where $\mathrm{SV}_{\mathrm{j}}$ is the spongiosa volume of skeletal site $\mathrm{j}, \mathrm{MVF}_{\mathrm{j}}$ is the marrow volume fraction of skeletal site $\mathrm{j}, \mathrm{CF}_{\mathrm{j}}$ is the cellularity factor for skeletal site $\mathrm{j}$, and $\rho_{\mathrm{TIM}}$ is the mass density of inactive marrow $\left(0.98 \mathrm{~g} \mathrm{~cm}^{-3}\right)$.

The mass of the Trabecular Marrow (TM), which includes both active and inactive marrow, was calculated as:

$$
\left(m_{T M}\right)_{j}=\left(m_{T A M}\right)_{j}+\left(m_{T I M}\right)_{j}
$$

The mass of the Trabecular Shallow Active Marrow $\left(\mathrm{TAM}_{50}\right)$, the 50 micron thick layer which contains the osteogenic tissues, was calculated as:

$$
\left(m_{T_{A M}{ }_{50}}\right)_{j}=(S V)_{j}(S M V F)_{j}(C F)_{j}\left(\rho_{\text {TAM }}\right)
$$

where $\mathrm{SV}_{\mathrm{j}}$ is the spongiosa volume for skeletal site $\mathrm{j}, \mathrm{SMVF}_{\mathrm{j}}$ is the shallow marrow volume fraction for skeletal site $\mathrm{j}, \mathrm{CF}_{\mathrm{j}}$ is the cellularity factor for skeletal site $\mathrm{j}$, and $\rho_{\text {TAM }}$ is the mass density of active marrow $\left(1.03 \mathrm{~g} \mathrm{~cm}^{-3}\right)$.

The mass of the Trabecular Shallow Inactive Marrow $\left(\mathrm{TAM}_{50}\right)$, was calculated as:

$$
\left(m_{\text {TIM }_{50}}\right)_{j}=(S V)_{j}(S M V F)_{j}(1-C F)_{j}\left(\rho_{T I M}\right)
$$


where $\mathrm{SV}_{\mathrm{j}}$ is the spongiosa volume for skeletal site $\mathrm{j}, \mathrm{SMVF}_{\mathrm{j}}$ is the shallow marrow volume fraction for skeletal site $\mathrm{j}, \mathrm{CF}_{\mathrm{j}}$ is the cellularity factor for skeletal site $\mathrm{j}$, and $\rho_{\mathrm{TIM}}$ is the mass density of inactive marrow $\left(0.98 \mathrm{~g} \mathrm{~cm}^{-3}\right)$.

The mass of the Trabecular Shallow Marrow $\left(\mathrm{TM}_{50}\right)$, which includes both active and inactive marrow, was calculated as:

$$
\left(m_{T M_{50}}\right)_{j}=\left(m_{T A M}\right)_{j}+\left(m_{T I M}\right)_{j}
$$

\section{RESULTS AND DISCUSSION}

\section{Relative Spongiosa Volumes}

The spongiosa volumes for all skeletal sites of the 40 year-old male can be seen in Table 4 . A comparison of the 13 active marrow skeletal sites' spongiosa volumes and relative spongiosa volumes as well as percent difference between the 40 year-old male and 66 year-old male's relative spongiosa volumes can be seen in Table 5. It is interesting to note the relatively large difference between the total skeletal spongiosa volumes of the 40 year-old male and the 66 yearold male; $1803.5 \mathrm{~cm}^{3}$ and $2413 \mathrm{~cm}^{3}$, respectively. This large difference, however, is not unexpected due to natural skeletal variations. Also of interest, is that the top three relative spongiosa volumes come from the same sites for both subjects: the osae coxae, proximal femurs, and the thoracic vertebrae. However, after this point some very large discrepancies begin to appear. For example, the percent differences between relative spongiosa volumes range from $51.19 \%$ in the cranium (the relative spongiosa volume of the cranium is much higher in the 44 year-old male than the 66 year-old) to $44.32 \%$ in the proximal femurs (even though they are the second largest relative contributor to total spongiosa volume, the 66 year-old male has a much 
higher relative spongiosa volume than the 44 year-old). These differences show the great variability in skeletal structure and spongiosa volumes that can occur between two individuals.

A comparison of the 13 active marrow skeletal sites' spongiosa volumes and relative spongiosa volumes as well as percent difference between the 40 year-old male and 19 other males' relative spongiosa volumes can be seen in Table 6. Again, large discrepancies can be seen between the relative spongiosa volumes of the 40 year-old male and nineteen other males. For example, percent differences range from $-27.0 \%$ in the ribs to $-40.0 \%$ in the mandible. These differences, however, are not to say that the 44 year-old male subject is not a good candidate for a SRM, but rather to highlight the significant errors that can be encountered when trying to utilize a single SRM's skeletal spongiosa volumes (and in turn skeletal masses) to accurately predict skeletal absorbed doses to other non-population average individuals.

In fact, these differences underscore the importance of the studies being performed by the UF BID project to develop scalable SRMs for use in patient/worker-specific cases. One such study, performed by Brindle et al., realized that marrow masses can easily be scaled from an SRM to patient/worker-specific cases by simply multiplying by the ratio of the patient/workerspecific total spongiosa volume to that of the SRMs total spongiosa volume. However, attaining such information on a patient/worker-specific case via manual image segmentation is quite labor intensive. Realizing this, Brindle et al. created a database of 20 cadaver (10 male and 10 female) total and relative spongiosa volumes as well as radiographic measurements of such parameters as osae coxae height and width. From this data, linear regression models were created to predict a patient/worker-specific total spongiosa volume from a few simple radiographic measurements. This total spongiosa volume can then be applied to more accurately predict patient/workerspecific active marrow masses and hence skeletal absorbed doses. Pichardo et al., recently 
extended this study to a data set of 40 cadavers (20 male and 20 female) and added a gender based component to the regression model to help improve the model's predictive accuracy.

\section{Marrow Volume Fractions}

The Marrow and Bone Volume Fractions (MVF and BVF, respectively) for all of the skeletal sites of which microstructural data was collected can be seen in Table 4. It should be noted, that as MVF and BVF are fractions of total spongiosa volumes, they must sum to 1. For this reason, only the MVF were used for comparison purposes between the 40 year-old male and the 66 yearold male.

A comparison of the 40 year-old male and the 66 year-old male's MVFs can be found in Table 7. There seems to be fairly good agreement between the MVFs as 17 of the 22 skeletal sites display relative percent differences of less than $10 \%$. The one extreme difference is for the occipital bone with a relative difference of $512 \%$. This is probably due to were the sample was taken for microstructural imaging. The comparisons are only made between the right side of the 40 year-old male and the 66 year-old male. If an average is taken for the left and right sides of the 66 year-old male the differences shown in Table 7 are drastically reduced. For example, the clavicles yield around a 9.1\% relative difference when comparing only the right side. However, if you compare an average, which can be seen in Table 8, of the right and left scapulae's MVF for the 66 year-old male and compare that to the 40 year-old male right scapula MVF, this relative difference is reduced to $0.2 \%$. This may seem insignificant for comparison purposes, as the comparison of the right sides seems more pertinent. However, when calculating the overall marrow volumes and masses comparing the right side of the 44 year-old male to the average of the 66 year-old male holds more weight. That is to say that in the case of the 66 year-old male, 
knowledge of the right and left side MVFs was used in conjunction with knowledge of the right and left side spongiosa volumes to explicitly calculate left and right side marrow volumes and masses. In the case of the 40 year-old male, only the right side MVF information is used along with the right and left side spongiosa volumes to calculate marrow volumes and masses. However, using the right side value only in the case of the 40 year-old male can be considered equivalent to using the average MVF for the 66 year-old male when it comes to calculating overall marrow volumes and masses. Hence, the fact that the average of the left and right side MVFs in the 66 year-old male are relatively close to those of the 40 year-old male demonstrates that explicit knowledge of both the left and right side MVFs for the 40 year-old male may not be necessary for accurate assessment of marrow volumes and masses.

Also, this lack of relatively large differences between the 40 year-old male and 66 yearold male, both of whom were considered to have normal skeletal structures (e.g. not osteoporetic), is of great importance. Studies by Hasenauer and Shah at UF have shown that microstructural differences do not demonstrate large differences in absorbed fraction calculations. In fact, differences in macrostructure seem to dominate absorbed fraction values at intermediate- to high-energy beta emitters. Therefore, explicit knowledge of each patient/worker's microstructure, which is practically impossible to attain, may not be necessary to accurately predict skeletal doses. These facts demonstrate, at least, that other factors such as spongiosa volumes and cellularity may have a much more direct impact on not only mass estimates but also absorbed fraction estimates. This is not to say, however, that patients/workers who demonstrate abnormal trabecular microstructure should be treated using the same microstructural data as a normal patient. Indeed, reference microstructural data for these 
patients/workers should be collected and assessed in order to more accurately estimate skeletal absorbed doses for their specific cases.

\section{Mass Calculations}

\section{Trabecular and Cortical Bone Masses in all Skeletal Sites}

Masses for trabecular and cortical bone in all skeletal sites can be seen in Table 9. Also, total mineral bone masses, the sum of trabecular and cortical bone, are given. The top three largest trabecular bone mass contributors in descending order are the craniofacial bones (199.6 g), the osae coxae $(73.5 \mathrm{~g})$, and the distal femora $(68.3 \mathrm{~g})$. The top three largest cortical bone mass contributors in descending order are the craniofacial bones (741.5 g), the ribs (427.6 g), and the osae coxae $(269.9 \mathrm{~g})$. Overall, the top three largest mineral bone mass contributors in descending order are the craniofacial bones $(941.1 \mathrm{~g})$, the ribs $(462.1 \mathrm{~g})$, and the osae coxae (343.4 g). It is interesting to note, that while the ribs do not contribute that much trabecular bone mass, $34.5 \mathrm{~g}$, their high cortical bone mass, $427.6 \mathrm{~g}$, allows them to be one of the top three total mineral bone mass contributors. The ribs, in particular, along with the craniofacial bones represent skeletal sites that have high surface-to-volume ratios. For this reason, these sites' absorbed fractions for intermediate to high beta energies are affected by macrostructural effects.

Comparisons of the trabecular, cortical, and total mineral bone masses between the 40 year-old male and ICRP Reference Man can be found at the bottom of the Table 9. It is evident that the 40 year-old male has much less trabecular, cortical, and total mineral bone mass than ICRP Reference Man with relative ratios of $0.76,0.82$, and 0.81 , respectively. This again, however, is not unexpected as skeletal structures and masses can be highly variable. The one important aspect that ensures the 40 year-old male's viability as a SRM is the relative fractions of trabecular and cortical bone mass. ICRP Reference Man displays a fractional $80 \%$ cortical 
bone mass and $20 \%$ trabecular bone mass, while the 40 year-old male displays a fractional $81 \%$ cortical bone mass and 19\% trabecular bone mass. Even though the 40 year-old male's total mineral bone mass is $81 \%$ that of ICRP Reference Man, the overall important factor is that he displays appropriate relative trabecular and cortical bone masses.

Active and Inactive Shallow Marrow Masses in all Skeletal Sites

Masses for active and inactive shallow marrow in all skeletal sites can be seen in Table 10. Also, the total shallow marrow mass, the sum of active and inactive shallow marrow, is given along with the relative percents of active and inactive shallow marrow. The top three largest inactive shallow marrow mass contributors in descending order are the distal femora $(33.0 \mathrm{~g})$, the feet $(32.5 \mathrm{~g})$, and the craniofacial bones $(19.7 \mathrm{~g})$. The top three largest active shallow marrow mass contributors in descending order are the osae coxae $(16.0 \mathrm{~g})$, the craniofacial bones $(12.7 \mathrm{~g})$, and the thoracic vertebrae (10.8 g). Overall, the top three largest shallow marrow mass contributors in descending order are the distal femora (33.0 g), the craniofacial bones (32.4 g), and the osae coxae $(32.4 \mathrm{~g})$.

Direct comparisons of skeletal site specific and total active and inactive shallow marrow between the 40 year-old male and ICRP Reference Man are not possible due to the lack of Reference Man data. Nonetheless, comparisons of the relative active and inactive shallow marrow masses of the 40 year-old male and the relative active and inactive marrow masses of Reference Man are possible. The 40 year-old male again shows good agreement with Reference Man on a relative scale with $69 \%$ inactive shallow marrow and $31 \%$ active shallow marrow compared to Reference Man's values of $68 \%$ inactive marrow and $32 \%$ active marrow. 
Masses for active and inactive marrow in all skeletal sites can be seen in Table 11. Also, the total marrow mass, the sum of active and inactive marrow, and relative percents of active and inactive marrow are shown. The top three largest inactive marrow mass contributors in descending order are the distal femora (241.0 g), the feet (237.7 g), and the osae coxae (176.6 g). The top three largest active marrow mass contributors in descending order are the osae coxae $(163.1 \mathrm{~g})$, the thoracic vertebrae $(132.7 \mathrm{~g})$, and the lumbar vertebrae $(112.0 \mathrm{~g})$. Overall, the top three largest marrow mass contributors in descending order are the osae coxae $(339.7 \mathrm{~g})$, the distal femora $(241.0 \mathrm{~g})$, and the feet $(237.7 \mathrm{~g})$.

Comparisons of total and relative active and inactive marrow masses for the 40 year-old male and ICRP Reference Man can be found at the bottom of Table 11. Again, it is evident that the 40 year-old male has much less inactive, active, and total bone marrow mass than ICRP Reference Man with relative ratios of $0.76,0.70$, and 0.74 , respectively. This again, however, is due to normal variability in skeletal structure and size. It is important to realize that the aspect that ensures the 40 year-old male's viability as a SRM is the relative fractions of inactive and active marrow mass. ICRP Reference Man displays a fractional 68\% inactive marrow mass and $32 \%$ active marrow mass, while the 40 year-old male displays a fractional $70 \%$ inactive marrow mass and $30 \%$ active marrow mass. Even though the 40 year-old male's total marrow mass is $74 \%$ that of ICRP Reference Man, the overall important factor is that he displays appropriate relative inactive and active marrow masses. These masses can easily be adjusted by the methods described by Brindle et al. and Pichardo et al. to match patient/worker specific cases. 


\section{CONCLUSION}

A complete skeletal mass database is presented for a 40 year-old male for use in internal radiation dosimetry for both radiation protection and radionuclide therapy. The masses reported are representative of those at ICRP 70/89's reference cellularity for a 40 year-old male for comparison purposes. However, the database presented includes all of the necessary data to recalculate patient/worker specific skeletal masses via scaling of spongiosa volumes and/or modification of skeletal site cellularities.

Overall, the 40 year-old male SRM masses presented were approximately $20-30 \%$ lower than that of ICRP Reference Man. This, however, does not represent any problems with the viability of the SRM to clinical use, as these differences are not unexpected. The subject chosen simply did not have as massive a skeletal system as Reference Man. Again, simple scaling to patient/worker cases can overcome this factor.

\section{FUTURE WORKS}

The ex-vivo CT, macrostructure, and microCT, microstructure, images will be combined utilizing PIRT as described by Shah et al to calculate Specific Absorbed Fractions (SAFs) for each skeletal site as well as skeletal averaged SAFs at cellularities ranging from $0-100 \%$. These skeletal absorbed dose estimates will complete the detailed skeletal reference model for the UF 40 year-old male.

\section{REFERENCES}

Aubin JE, Liu F, Malaval L, Gupta AK 1995 Osteoblast and chondroblast differentiation. Bone 17(2) 77S835

Beddoe $\mathrm{AH}$. The microstructure of mammalian bone in relation to the dosimetry of bone-seeking radionuclides [Thesis]. Leeds, UK: University of Leeds. 165 p; 1976. 
Beddoe AH, Darley PJ, and Spiers FW 1976 Measurements of trabecular bone structure in man. Phys. Med. Biol. 21(4) 589-607

Bianco P, Riminucci M, Gronthos S, Robey PG 2001 Bone marrow stromal stem cells: nature, biology, and potential applications. Stem Cells 19 180-192

Bouchet LG, Bolch WE, Howell RW, and Rao DV 2000 S values for radionuclides localized within the skeleton. J. Nucl. Med. 41(1) 189-212

Bovée JVMG, Cleton-Jansen AM, Taminiau AHM, Hogendoorn PCW 2005 Emerging pathways in the development of chondrosarcoma of bone and implications for targeted treatment. Lancet Oncology 6 599-607

Cristy M 1981 Active bone marrow distribution as a function of age in humans. Phys. Med. Biol. 26 389400

Cristy M, and Eckerman KF 1987 Specific absorbed fractions of energy at various ages from internal photon sources. Oak Ridge, TN: Oak Ridge National Laboratory. ORNL/TM-8381/Volumes I-VII.

Dominici M, Hofmann TJ, Horwitz EM 2001 Bone marrow mesenchymal cells: biological properties and clinical applications. J Biol Regul Homeost Agents 15 28-37

Eckerman KF Aspects of the dosimetry of radionuclides within the skeleton with particular emphasis on the active marrow. In: Proceedings of the Fourth International Radiopharmaceutical Dosimetry Symposium. Schlafke-Stelson AT, Watson EE, editors; 1985; Oak Ridge, Tennessee. Oak Ridge Associated Universities; 1985: p 514-534.

Eckerman KF, and Stabin MG 2000 Electron absorbed fractions and dose conversion factors for marrow and bone by skeletal regions. Health Phys. 78(2) 199-214

Fitzwater JE, Cabaud HE, Farr GH 1976 Irradiation-induced chondrosarcoma. A case report. J Bone \& Joint Surgery 58 1037-1039

Gossner W, Masse R, and Stather JW 2000 Cells at risk for dosimetric modeling relevant to bone tumour induction. Radiat Prot Dosimetry 92(1-3) 209-213

Gossner W 2003 Target cells in internal dosimetry. Radiat Prot Dosimetry 105(1-4) 39-42

ICRP 1979 Limits for intakes of radionuclides by workers. Oxford, UK: International Commission on Radiological Protection. ICRP Publication 30 (Part 1).

ICRP 1995 Basic anatomical and physiological data for use in radiological protection: the skeleton. Oxford, UK: International Commission on Radiological Protection. ICRP Publication 70.

Jokisch DW, Bouchet LG, Patton PW, Rajon DA, and Bolch WE 2001 Beta-particle dosimetry of the trabecular skeleton using Monte Carlo transport within 3D digital images. Med Phys 28(7) 1505-1518

Lee C, Lee C, Park SH, and Lee JK 2006b Development of the two Korean adult tomographic computational phantoms for organ dosimetry. Med Phys 33(2) 380-90

Lee C, Lee C, Shah AP, and Bolch WE in press An assessment of bone marrow and bone endosteum dosimetry methods for photon sources. Phys Med Biol

Mechanik N 1926 Studies of the weight of bone marrow in man. Zeitschrift fur die Gest. Anatomy 79 5899

Nagaoka T, Watanabe S, Sakurai K, Kunieda E, Taki M, and Yamanaka Y 2004 Development of realistic high-resolution whole-body voxel models of Japanese adult males and females of average height and weight, and application of models to radio-frequency electromagnetic-field dosimetry. Phys Med Biol 49(1) $1-15$

Parker RG, Berry HC 1976 Late effects of therapeutic irradiation on the skeleton and bone marrow. Cancer 37 1162-1171

Patton PW, Rajon DA, Shah AP, Jokisch DW, Inglis B, and Bolch WE 2002b Site-specific variability in trabecular bone dosimetry: considerations of energy loss to cortical bone. Med Phys 29(1) 6-14

Patton PW, Jokisch DW, Rajon DA, Shah AP, Myers SL, and Bolch WE 2002a Skeletal dosimetry via NMR microscopy: investigations of sample reproducibility and signal source. Health Phys 82(3) 316326

Peimer CA, Yuan HA, Sagerman RH 1976 Postirradiation chondrosarcoma. A care report. J Bone \& Joint Surgery 58 1033-1036

Petoussi-Henss N, Zankl M, Fill U and Regulla D 2002 The GSF family of voxel phantoms Phys. Med. Biol. 47 89-106

Piegl L 1991 On NURBS: A survey. IEEE Computer Graphics and Applications 11 55-71

Rajon D, Pichardo J, Brindle J, Kielar K, Jokisch D, Patton P, and Bolch W 2006 Image segmentation of trabecular spongiosa by visual inspection of the gradient magnitude. Phys Med Biol 51(16) 4447-67 
Roschger P, Grabner BM, Rinnerthaler S, Tesch W, Kneissel M, Berzlanovich A, Klaushofer K, Fratzl P 2001 Structural development of the mineralized tissue in the human L4 vertebral body. J Structural Biology 136 126-136

Shagina NB, Degteva MO, Tolstykh El, Anspaugh LR, and Napier BA 2005 Dosimetric Models for Strontium in the Human Bone: A Review of Available Data and Recommendations on Needed Research. Further Studies on Uncertainty and Validation of Doses in the Techa River Dosimetry System.: US-Russian Coordinating Committee on Radiation Effects Research - Project 1.1.

Shah AP, Jokisch D, Watchman C, Rajon D, Patton P, and Bolch W 2005a Chord-based versus voxelbased methods of electron transport in the skeletal tissues. Med Phys 32(10) 3151-3159

Shah AP, Rajon D, Jokisch D, Patton P, and Bolch W 2005b A comparison of skeletal chord-length distributions in the adult male. Health Phys 89(3) 199-215

Shah AP, Rajon D, Patton P, Jokisch D, and Bolch W 2005c Accounting for beta-particle energy loss to cortical bone via Paired-Image Radiation Transport (PIRT). Med Phys 32(5) 1354-1366

Shah AP, Patton PW, Rajon DA, and Bolch WE 2003 Adipocyte spatial distributions in bone marrow: Implications for skeletal dosimetry models. J Nucl Med 44(5) 774-783

Snyder WS, Ford MR, Warner GG, and Watson SB 1975 "S," absorbed dose per unit cumulated activity for selected radionuclides and organs. New York, NY: Society of Nuclear Medicine. MIRD Pamphlet No. 11.

Stabin MG, and Siegel JA 2003 Physical models and dose factors for use in internal dose assessment. Health Phys 85(3) 294-310

Tanaka C, and Kawamura H 1996 Anatomical and physiological characteristics for Asian reference man. National Institute of Radiological Sciences. NIRS-M-115.

Watchman CJ, Hasenauer D, Bolch WE 2007 in press Derivation of Site-Specific Skeletal Masses within the Current ICRP Age Series. Phys. Med. Biol.

Whitwell JR. Theoretical investigations of energy loss by ionizing particles in bone [Thesis]. Leeds, UK: University of Leeds. 268 p; 1973.

Whitwell JR, and Spiers FW 1976 Calculated beta-ray dose factors for trabecular bone. Phys. Med. Biol. 21(1) 16-38

Zankl M, and Wittmann A 2001 The adult male voxel model "Golem" segmented from whole-body CT patient data. Radiation and Environmental Biophysics 40(2) 153-162

Zubal IG, Harrell CR, Smith EO, Rattner Z, Gindi G, and Hoffer PB 1994 Computerized three-dimensional segmented human anatomy. Med Phys 21(2) 299-302 
Table 1. ICRP 70 marrow cellularities for a 40 year-old male. Marrow cellularity is the fraction of active bone marrow within the total marrow volume.

\begin{tabular}{lc}
\cline { 2 - 2 } \multicolumn{1}{c}{ Skeletal Sites } & $\begin{array}{c}\text { Cellularity } \\
\text { (\% of MV) }\end{array}$ \\
\hline Craniofacial Bones & $38 \%$ \\
Mandible & $38 \%$ \\
Scapulae & $38 \%$ \\
Clavicles & $33 \%$ \\
Sternum & $70 \%$ \\
Ribs & $70 \%$ \\
Cervical Vertebra & $70 \%$ \\
Thoracic Vertebra & $70 \%$ \\
Lumbar Vertebra & $70 \%$ \\
Sacrum & $70 \%$ \\
Os Coxae & $48 \%$ \\
Humeri, proximal & $25 \%$ \\
Femora, proximal & $25 \%$ \\
Humeri, shaft (upper 1/2) & $25 \%$ \\
Humeri, shaft (lower 1/2) & $0 \%$ \\
Humeri, distal & $0 \%$ \\
Ulnae, proximal & $0 \%$ \\
Ulnae, shaft & $0 \%$ \\
Ulnae, distal & $0 \%$ \\
Radii, proximal & $0 \%$ \\
Radii, shaft & $0 \%$ \\
Radii, distal & $0 \%$ \\
Hands & $0 \%$ \\
Femora, shaft (upper 1/2) & $25 \%$ \\
Femora, shaft (lower 1/2) & $0 \%$ \\
Femora, distal & $0 \%$ \\
Tibiae, proximal & $0 \%$ \\
Tibiae, shaft & $0 \%$ \\
Tibiae, distal & $0 \%$ \\
Fibulae, proximal & $0 \%$ \\
Fibulae, shaft & $0 \%$ \\
Fibulae, distal & $0 \%$ \\
Feet & $0 \%$ \\
\hline
\end{tabular}


Table 2. ICRU 46 skeletal tissue elemental compositions and mass densities used to calculate marrow and bone masses as well as for transport in PIRT.

\begin{tabular}{lcccccc} 
Tissue & $\mathbf{H}$ & $\mathbf{C}$ & $\mathbf{N}$ & $\mathbf{O}$ & Trace & $\begin{array}{c}\text { Mass Density } \\
\left(\mathbf{g ~ c m}^{-3}\right)\end{array}$ \\
\hline Red Bone Marrow (RBM) & 10.5 & 41.4 & 3.4 & 43.9 & $0.1 \mathrm{P}, 0.2 \mathrm{~S}, 0.2 \mathrm{Cl}, 0.2 \mathrm{~K}, 0.1 \mathrm{Fe}$ & 1.03 \\
Yellow Bone Marrow (YBM) & 11.5 & 64.4 & 0.7 & 23.1 & $0.1 \mathrm{Na}, 0.1 \mathrm{~S}, 0.1 \mathrm{Cl}$ & 0.98 \\
Trabecular Shallow Active Marrow $\left(\mathrm{TIM}_{50}\right)$ & 10.5 & 25.6 & 2.7 & 60.2 & $0.1 \mathrm{Na}, 0.2 \mathrm{P}, 0.3 \mathrm{~S}, 0.2 \mathrm{Cl}, 0.2 \mathrm{~K}$ & 1.03 \\
Trabecular Bone Volume (TBV) & 3.4 & 15.5 & 4.2 & 43.5 & $0.1 \mathrm{Na}, 0.2 \mathrm{Mg}, 10.3 \mathrm{P}, 0.3 \mathrm{~S}, 22.5 \mathrm{Ca}$ & 1.92 \\
Cortical Bone Volume (CBV) & 3.4 & 15.5 & 4.2 & 43.5 & $0.1 \mathrm{Na}, 0.2 \mathrm{Mg}, 10.3 \mathrm{P}, 0.3 \mathrm{~S}, 22.5 \mathrm{Ca}$ & 1.92 \\
Surrounding tissues & 10.5 & 25.6 & 2.7 & 60.2 & $0.1 \mathrm{Na}, 0.2 \mathrm{P}, 0.3 \mathrm{~S}, 0.2 \mathrm{Cl}, 0.2 \mathrm{~K}$ & 1.03 \\
\hline
\end{tabular}


Table 3. Values of the shaft marrow volume, cortical bone volume, and shaft length were obtained from segmentation and measurement of the in-vivo images of the long bones. The effective radii were calculated using the principle of concentric cylinders. These radii were then used to calculate the shallow marrow volume and shallow marrow masses for the cortical medullary regions of the long bones.

\begin{tabular}{|c|c|c|c|c|c|c|c|}
\hline & \multirow{2}{*}{$\begin{array}{l}\text { Shaft Marrow Volume } \\
\left(\mathrm{cm}^{3}\right)\end{array}$} & \multirow{2}{*}{$\begin{array}{l}\text { Cortical Bone Volume } \\
\qquad\left(\mathrm{cm}^{3}\right)\end{array}$} & \multirow{2}{*}{$\begin{array}{l}\text { Shaft Length } \\
\text { (cm) }\end{array}$} & \multicolumn{4}{|c|}{ Effective Radius (cm) } \\
\hline & & & & Shallow Marrow & Spongiosa & Cortical Shell & Total \\
\hline Humerus & 22.1 & 38.7 & 22.3 & 0.556 & 0.561 & 0.370 & 0.931 \\
\hline Radius & 5.2 & 10.5 & 19.6 & 0.287 & 0.292 & 0.214 & 0.506 \\
\hline Ulna & 3.2 & 13.9 & 23.7 & 0.204 & 0.209 & 0.271 & 0.480 \\
\hline Femur & 43.7 & 35.1 & 20.8 & 0.812 & 0.817 & 0.280 & 1.097 \\
\hline Tibia & 68.2 & 63.0 & 25.4 & 0.919 & 0.924 & 0.358 & 1.282 \\
\hline Fibula & 7.9 & 17.8 & 26.7 & 0.302 & 0.307 & 0.247 & 0.554 \\
\hline
\end{tabular}


Table 4. Spongiosa volumes, Marrow Volume Fractions, and Bone Volume Fractions for all skeletal sites of the 40 year-old male.

\begin{tabular}{|c|c|c|c|}
\hline & & & \\
\hline & $\begin{array}{c}\text { Spongiosa } \\
\text { Volume }\left(\mathrm{cm}^{3}\right) \\
\end{array}$ & $\begin{array}{c}\text { Trabecular Spo } \\
\text { Bone Volume } \\
\text { Fraction } \\
\text { (BVF) }\end{array}$ & $\begin{array}{c}\text { ngiosa Regions } \\
\text { Marrow Volume } \\
\text { Fraction } \\
\text { (MVF) }\end{array}$ \\
\hline Craniofacial Bones $^{d}$ & 185.48 & & \\
\hline Frontal & 40.34 & 0.445 & 0.555 \\
\hline Occipital & 54.94 & 0.912 & 0.088 \\
\hline Right Parietal / Temporal & 41.09 & 0.394 & 0.606 \\
\hline Left Parietal / Temporal & 41.09 & - & - \\
\hline Sphenoid, Ethmoid, Facial ${ }^{e}$ & 8.01 & - & - \\
\hline Mandible & 26.30 & 0.089 & 0.911 \\
\hline Scapulae & 108.22 & & \\
\hline Right & 55.69 & 0.153 & 0.847 \\
\hline Left & 52.53 & - & 0.847 \\
\hline Clavicles & 34.01 & & \\
\hline Right & 17.00 & 0.116 & 0.884 \\
\hline Left & 17.01 & - & - \\
\hline Sternum & 34.86 & 0.082 & 0.918 \\
\hline Ribs $^{d}$ & 148.60 & & \\
\hline Ribs 1-4 (Right) & 22.25 & 0.103 & 0.897 \\
\hline Ribs 5-8 (Right) & 35.40 & 0.142 & 0.858 \\
\hline Ribs 9-12 (Right) & 16.65 & 0.101 & 0.899 \\
\hline Ribs 1-4 (Left) & 22.25 & - & - \\
\hline Ribs 5-8 (Left) & 35.40 & - & - \\
\hline Ribs 9-12 (Left) & 16.65 & - & - \\
\hline Cervical Vertebra & 45.97 & & \\
\hline$C 1-C 3$ & 20.51 & 0.159 & 0.841 \\
\hline$C 4-C 7$ & 25.46 & 0.194 & 0.806 \\
\hline Thoracic Vertebra & 203.15 & & \\
\hline$T 1-T 4$ & 49.93 & 0.132 & 0.868 \\
\hline$T 5-T 8$ & 63.64 & 0.042 & 0.959 \\
\hline$T 9-T 12$ & 89.58 & 0.111 & 0.889 \\
\hline Lumbar Vertebra & 173.33 & & \\
\hline$\angle 1-\angle 3$ & 98.87 & 0.114 & 0.887 \\
\hline L4- L5 & 74.46 & 0.091 & 0.909 \\
\hline Sacrum & 132.19 & 0.118 & 0.882 \\
\hline Os Coxae & 384.93 & & \\
\hline Ilium & (n) & 0.100 & 0.901 \\
\hline Ischium & - & - & - \\
\hline Pubis & - & - & - \\
\hline Humeri, proximal & 109.03 & - & \\
\hline Right & 52.93 & 0.096 & 0.904 \\
\hline Left & 56.10 & - & - \\
\hline Femora, proximal & 223.07 & - & \\
\hline Right Head & 48.36 & 0.229 & 0.771 \\
\hline Right Neck & 67.82 & 0.103 & 0.897 \\
\hline Left Head & 50.98 & - & - \\
\hline Left Neck & 55.92 & - & - \\
\hline Totals: & 1809.14 & & \\
\hline & $\begin{array}{c}\text { Spongiosa } \\
\text { Volume }\left(\mathrm{cm}^{3}\right)\end{array}$ & $\begin{array}{c}\text { Bone Volume } \\
\text { Fraction } \\
\text { (BVF) }\end{array}$ & $\begin{array}{c}\text { Marrow Volume } \\
\text { Fraction } \\
\text { (MVF) }\end{array}$ \\
\hline Humeri, shaft & 44.12 & - & - \\
\hline Humeri, distal & 46.24 & 0.151 & 0.849 \\
\hline Ulnae, proximal & 29.94 & 0.161 & 0.839 \\
\hline Ulnae, shaft & 10.46 & - & - \\
\hline Ulnae, distal & 4.15 & 0.139 & 0.861 \\
\hline Radii, proximal & 12.53 & 0.089 & 0.911 \\
\hline Radii, shaft & 6.48 & - & - \\
\hline Radii, distal & 17.22 & 0.116 & 0.884 \\
\hline Hands & 44.29 & - & - \\
\hline Femora, shaft & 87.31 & - & - \\
\hline Femora, distal & 287.98 & 0.146 & 0.854 \\
\hline Tibiae, proximal & 213.66 & 0.115 & 0.885 \\
\hline Tibiae, shaft & 136.42 & - & - \\
\hline Tibiae, distal & 87.04 & 0.125 & 0.875 \\
\hline Fibulae, proximal & 16.06 & 0.078 & 0.922 \\
\hline Fibulae, shaft & 15.82 & - & - \\
\hline Fibulae, distal & 13.94 & 0.147 & 0.853 \\
\hline Feet & 284.04 & - & - \\
\hline Totals: & 1357.68 & & \\
\hline Total for UF Model: & 3166.82 & & \\
\hline
\end{tabular}


Table 5. Relative spongiosa volumes for all 13 active marrow containing skeletal sites for the 40 year-old male and 66 year-old male and comparison.

\begin{tabular}{|c|c|c|c|c|}
\hline \multirow[b]{2}{*}{ Skeletal Sites } & \multicolumn{2}{|c|}{$\begin{array}{l}\text { Relatvie Spongiosa Volumes } \\
\end{array}$} & \multirow{2}{*}{$\begin{array}{c}\text { Ratio } \\
\text { (40 YOM / } 66 \text { YOM) }\end{array}$} & \multirow[b]{2}{*}{ \% Difference } \\
\hline & 40 Year-old Male & 66 Year-old Male & & \\
\hline \multicolumn{5}{|l|}{ Pelvis } \\
\hline - Os Coxae & $21.34 \%$ & $23.14 \%$ & 0.922 & $8.41 \%$ \\
\hline - Sacrum & $7.33 \%$ & $6.61 \%$ & 1.109 & $-9.83 \%$ \\
\hline \multicolumn{5}{|l|}{$\overline{\text { Vertebrae }}$} \\
\hline - Cervical & $2.55 \%$ & $2.37 \%$ & 1.074 & $-6.86 \%$ \\
\hline - Thoracic & $11.26 \%$ & $12.10 \%$ & 0.931 & $7.45 \%$ \\
\hline - Lumbar & $9.61 \%$ & $9.83 \%$ & 0.977 & $2.31 \%$ \\
\hline \multicolumn{5}{|l|}{ Skull } \\
\hline - Cranium & $9.97 \%$ & $4.87 \%$ & 2.049 & $-51.19 \%$ \\
\hline - Mandible & $1.46 \%$ & $0.74 \%$ & 1.966 & $-49.14 \%$ \\
\hline Ribs & $8.24 \%$ & $8.06 \%$ & 1.023 & $-2.23 \%$ \\
\hline Clavicles & $1.89 \%$ & $1.07 \%$ & 1.757 & $-43.09 \%$ \\
\hline Scapulae & $6.00 \%$ & $4.78 \%$ & 1.256 & $-20.38 \%$ \\
\hline Sternum & $1.93 \%$ & $1.40 \%$ & 1.376 & $-27.32 \%$ \\
\hline Femora, proximal & $12.37 \%$ & $17.85 \%$ & 0.693 & $44.32 \%$ \\
\hline Humeri, proximal & $6.05 \%$ & $7.17 \%$ & 0.843 & $18.65 \%$ \\
\hline
\end{tabular}


Table 6. Relative spongiosa volume for all 13 active marrow containing skeletal sites for the 40 year-old male and nineteen other males from studies by Brindle et al. and Pichardo et al. and comparison.

\begin{tabular}{|c|c|c|c|c|}
\hline \multirow[b]{2}{*}{ Skeletal Sites } & \multicolumn{2}{|c|}{ Relatvie Spongiosa Volumes } & \multicolumn{2}{|l|}{ Ratio } \\
\hline & 40 Year-old Male & Nineteen Other Males & (40 YOM / 19 OM) & \% Difference \\
\hline \multicolumn{5}{|l|}{ Pelvis } \\
\hline - Os Coxae & $21.34 \%$ & $22.9 \%$ & 0.932 & $7.3 \%$ \\
\hline - Sacrum & $7.33 \%$ & $6.8 \%$ & 1.071 & $-6.6 \%$ \\
\hline \multicolumn{5}{|l|}{ Vertebrae } \\
\hline - Cervical & $2.55 \%$ & $2.5 \%$ & 1.018 & $-1.8 \%$ \\
\hline - Thoracic & $11.26 \%$ & $12.0 \%$ & 0.937 & $6.8 \%$ \\
\hline - Lumbar & $9.61 \%$ & $10.1 \%$ & 0.950 & $5.3 \%$ \\
\hline \multicolumn{5}{|l|}{ Skull } \\
\hline - Cranium & $9.97 \%$ & $7.0 \%$ & 1.432 & $-30.2 \%$ \\
\hline - Mandible & $1.46 \%$ & $0.9 \%$ & 1.667 & $-40.0 \%$ \\
\hline Ribs & $8.24 \%$ & $10.5 \%$ & 0.787 & $27.0 \%$ \\
\hline Clavicles & $1.89 \%$ & $1.6 \%$ & 1.165 & $-14.2 \%$ \\
\hline Scapulae & $6.00 \%$ & $4.6 \%$ & 1.305 & $-23.4 \%$ \\
\hline Sternum & $1.93 \%$ & $2.2 \%$ & 0.875 & $14.3 \%$ \\
\hline Femora, proximal & $12.37 \%$ & $13.0 \%$ & 0.952 & $5.0 \%$ \\
\hline Humeri, proximal & $6.05 \%$ & $5.9 \%$ & 1.027 & $-2.6 \%$ \\
\hline
\end{tabular}


Table 7. Marrow Volume Fractions sampled from all13 active marrow containing skeletal sites for the 40 year-old male and 66 year-old male and comparison of the right side Marrow Volume Fractions.

\begin{tabular}{|c|c|c|c|c|}
\hline Skeletal Sites & \multicolumn{2}{|c|}{$\begin{array}{c}\text { Trabecular Spongiosa Regions } \\
\text { Marrow Volume Fraction } \\
\text { (MVF) }\end{array}$} & $\begin{array}{c}\text { Ratio } \\
\text { (44 YOM / } 66 \text { YOM) }\end{array}$ & $\begin{array}{l}\text { Relative \% } \\
\text { Difference }\end{array}$ \\
\hline \multicolumn{5}{|l|}{ Cranium } \\
\hline Frontal & 0.555 & 0.596 & 0.931 & $7.4 \%$ \\
\hline Occipital & 0.0884 & 0.541 & 0.163 & $512.0 \%$ \\
\hline Right Parietal & 0.6062 & 0.643 & 0.943 & $6.1 \%$ \\
\hline Left Parietal & - & 0.656 & - & - \\
\hline Mandible & 0.9114 & 0.835 & 1.091 & $-8.4 \%$ \\
\hline \multicolumn{5}{|l|}{ Scapulae } \\
\hline Right & 0.8471 & 0.819 & 1.034 & $-3.3 \%$ \\
\hline Left & - & 0.877 & & - \\
\hline \multicolumn{5}{|l|}{ Clavicles } \\
\hline Right & 0.8844 & 0.804 & 1.100 & $-9.1 \%$ \\
\hline Left & - & 0.962 & & - \\
\hline Sternum & 0.9181 & 0.909 & 1.010 & $-1.0 \%$ \\
\hline \multicolumn{5}{|l|}{ Ribs } \\
\hline Upper Right & 0.8974 & 0.863 & 1.040 & $-3.8 \%$ \\
\hline Middle Right & 0.858 & 0.941 & 0.912 & $9.7 \%$ \\
\hline Lower Right & 0.8989 & 0.914 & 0.983 & $1.7 \%$ \\
\hline Upper Left & - & 0.929 & - & - \\
\hline Middle Left & - & 0.929 & - & - \\
\hline Lower Left & - & 0.942 & - & - \\
\hline \multicolumn{5}{|l|}{ Cervical Vertebra } \\
\hline C3 & 0.8411 & 0.894 & 0.941 & $6.3 \%$ \\
\hline C6 & 0.8059 & 0.859 & 0.938 & $6.6 \%$ \\
\hline \multicolumn{5}{|l|}{ Thoracic Vertebra } \\
\hline T3 & 0.868 & 0.9 & 0.964 & $3.7 \%$ \\
\hline T6 & 0.9585 & 0.924 & 1.037 & $-3.6 \%$ \\
\hline$T 11$ & 0.8892 & 0.762 & 1.167 & $-14.3 \%$ \\
\hline \multicolumn{5}{|l|}{ Lumbar Vertebra } \\
\hline$L 2$ & 0.8865 & 0.92 & 0.964 & $3.8 \%$ \\
\hline$L 4$ & 0.9092 & 0.771 & 1.179 & $-15.2 \%$ \\
\hline Sacrum & 0.8822 & 0.876 & 1.007 & $-0.7 \%$ \\
\hline \multicolumn{5}{|l|}{ Os Coxae } \\
\hline Ilium & 0.9005 & 0.887 & 1.015 & $-1.5 \%$ \\
\hline Ischium & - & 0.923 & - & - \\
\hline Pubis & - & 0.884 & - & - \\
\hline \multicolumn{5}{|l|}{ Humeri, proximal } \\
\hline Right & 0.904 & 0.837 & 1.080 & $-7.4 \%$ \\
\hline Left & - & 0.779 & - & - \\
\hline \multicolumn{5}{|l|}{ Femora, proximal } \\
\hline Right Head & 0.7709 & 0.647 & 1.191 & $-16.1 \%$ \\
\hline Right Neck & 0.8966 & 0.896 & 1.001 & $-0.1 \%$ \\
\hline Left Head & - & 0.707 & - & - \\
\hline Left Neck & - & 0.884 & - & - \\
\hline
\end{tabular}


Table 8. Marrow Volume Fractions sampled from all13 active marrow containing skeletal sites for the 40 year-old male and 66 year-old male and comparison of the average Marrow Volume Fractions.

\begin{tabular}{|c|c|c|c|c|}
\hline Skeletal Sites & \multicolumn{2}{|c|}{$\begin{array}{l}\text { Trabecular Spongiosa Regions } \\
\text { Average Marrow Volume Fraction }\end{array}$} & $\begin{array}{c}\text { Ratio } \\
\text { (44 YOM / } 66 \text { YOM) }\end{array}$ & $\begin{array}{l}\text { Relative \% } \\
\text { Difference } \\
\end{array}$ \\
\hline \multicolumn{5}{|l|}{ Cranium } \\
\hline Frontal & 0.555 & 0.596 & 0.931 & $7.4 \%$ \\
\hline Occipital & 0.0884 & 0.541 & 0.163 & $512.0 \%$ \\
\hline Parietal & 0.6062 & 0.6495 & 0.933 & $7.1 \%$ \\
\hline Mandible & 0.9114 & 0.835 & 1.091 & $-8.4 \%$ \\
\hline Scapulae & 0.8471 & 0.848 & 0.999 & $0.1 \%$ \\
\hline Clavicles & 0.8844 & 0.883 & 1.002 & $-0.2 \%$ \\
\hline Sternum & 0.9181 & 0.909 & 1.010 & $-1.0 \%$ \\
\hline \multicolumn{5}{|l|}{ Ribs } \\
\hline Upper & 0.8974 & 0.896 & 1.002 & $-0.2 \%$ \\
\hline Middle & 0.858 & 0.935 & 0.918 & $9.0 \%$ \\
\hline Lower & 0.8989 & 0.928 & 0.969 & $3.2 \%$ \\
\hline \multicolumn{5}{|l|}{ Cervical Vertebra } \\
\hline C3 & 0.8411 & 0.894 & 0.941 & $6.3 \%$ \\
\hline $\mathrm{C6}$ & 0.8059 & 0.859 & 0.938 & $6.6 \%$ \\
\hline \multicolumn{5}{|l|}{ Thoracic Vertebra } \\
\hline T3 & 0.868 & 0.9 & 0.964 & $3.7 \%$ \\
\hline T6 & 0.9585 & 0.924 & 1.037 & $-3.6 \%$ \\
\hline$T 11$ & 0.8892 & 0.762 & 1.167 & $-14.3 \%$ \\
\hline \multicolumn{5}{|l|}{ Lumbar Vertebra } \\
\hline$L 2$ & 0.8865 & 0.92 & 0.964 & $3.8 \%$ \\
\hline$\llcorner 4$ & 0.9092 & 0.771 & 1.179 & $-15.2 \%$ \\
\hline Sacrum & 0.8822 & 0.876 & 1.007 & $-0.7 \%$ \\
\hline Os Coxae & 0.9005 & 0.898 & 1.003 & $-0.3 \%$ \\
\hline Humeri, proximal & 0.904 & 0.808 & 1.119 & $-10.6 \%$ \\
\hline \multicolumn{5}{|l|}{ Femora, proximal } \\
\hline Head & 0.7709 & 0.677 & 1.139 & $-12.2 \%$ \\
\hline Neck & 0.8966 & 0.89 & 1.007 & $-0.7 \%$ \\
\hline
\end{tabular}


Table 9. Trabecular, cortical, and total mineral bone masses for all skeletal sites of the 40 year-old male and comparison with ICRP Reference Man.

\begin{tabular}{|c|c|c|c|}
\hline Skeletal Sites & $\begin{array}{c}\text { Trabecular Bone } \\
\text { Mass }(g)\end{array}$ & $\begin{array}{c}\text { Cortical Bone } \\
\text { Mass }(\mathrm{g})\end{array}$ & $\begin{array}{l}\text { Total Bone } \\
\text { Mass }(g)\end{array}$ \\
\hline Craniofacial Bones $^{d}$ & 199.6 & 741.5 & 941.1 \\
\hline Mandible & 4.5 & 54.1 & 58.5 \\
\hline Scapulae & 31.8 & 121.8 & 153.6 \\
\hline Clavicles & 7.5 & 45.3 & 52.8 \\
\hline Sternum & 5.5 & 32.2 & 37.7 \\
\hline Ribs & 34.5 & 427.6 & 462.1 \\
\hline Cervical Vertebra & 15.7 & 78.5 & 94.3 \\
\hline Thoracic Vertebra & 36.8 & 175.0 & 211.8 \\
\hline Lumbar Vertebra & 34.5 & 122.9 & 157.4 \\
\hline Sacrum & 29.9 & 98.8 & 128.7 \\
\hline Os Coxae & 73.5 & 269.9 & 343.4 \\
\hline Humeri, proximal & 20.1 & 38.8 & 58.9 \\
\hline \multirow[t]{3}{*}{ Femora, proximal } & 68.3 & 75.5 & 143.8 \\
\hline & 562.3 & 2282.0 & 2844.2 \\
\hline & $\begin{array}{c}\text { Trabecular Bone } \\
\text { Mass (g) }\end{array}$ & $\begin{array}{l}\text { Cortical Bone } \\
\text { Mass (g) }\end{array}$ & $\begin{array}{c}\text { Total Bone } \\
\text { Mass (g) }\end{array}$ \\
\hline Humeri, shaft & - & 148.7 & 148.7 \\
\hline Humeri, distal & 13.4 & 43.2 & 56.7 \\
\hline Ulnae, proximal & 9.3 & 28.8 & 38.0 \\
\hline Ulnae, shaft & - & 53.2 & 53.2 \\
\hline Ulnae, distal & 1.1 & 3.1 & 4.2 \\
\hline Radii, proximal & 2.1 & 10.8 & 13.0 \\
\hline Radii, shaft & - & 40.2 & 40.2 \\
\hline Radii, distal & 3.8 & 14.6 & 18.4 \\
\hline Hands & 12.9 & 131.7 & 144.6 \\
\hline Femora, shaft & - & 134.9 & 134.9 \\
\hline Femora, distal & 80.8 & 71.7 & 152.5 \\
\hline Tibiae, proximal & 47.3 & 48.5 & 95.9 \\
\hline Tibiae, shaft & - & 241.9 & 241.9 \\
\hline Tibiae, distal & 20.9 & 30.2 & 51.1 \\
\hline Fibulae, proximal & 2.4 & 8.7 & 11.1 \\
\hline Fibulae, shaft & - & 68.4 & 68.4 \\
\hline Fibulae, distal & 3.9 & 10.6 & 14.5 \\
\hline Feet & 79.7 & 248.0 & 327.7 \\
\hline Totals: & 277.8 & 1337.3 & 1615.0 \\
\hline Totals for UF Model: & 840 & 3619 & 4459 \\
\hline$\%$ mineral bone & $19 \%$ & $81 \%$ & - \\
\hline ICRP 89 Ref Male: & 1100 & 4400 & 5500 \\
\hline$\%$ mineral bone & $20 \%$ & $80 \%$ & - \\
\hline Ratio (UF / ICRP): & 0.76 & 0.82 & 0.81 \\
\hline
\end{tabular}


Table 10. Inactive, active, and total shallow marrow masses for all skeletal sites of the 40 year-old male.

\begin{tabular}{|c|c|c|c|}
\hline Skeletal Sites & $\begin{array}{c}\text { Shallow } \\
\text { Inactive Marrow } \\
\text { Mass }(g)\end{array}$ & $\begin{array}{c}\text { Shallow } \\
\text { Active Marrow } \\
\text { Mass }(g) \\
\end{array}$ & $\begin{array}{c}\text { Shallow } \\
\text { Total Marrow } \\
\text { Mass }(g) \\
\end{array}$ \\
\hline Craniofacial Bones & 19.7 & 12.7 & 32.4 \\
\hline Mandible & 1.0 & 0.6 & 1.6 \\
\hline Scapulae & 5.5 & 3.5 & 9.0 \\
\hline Clavicles & 1.6 & 0.8 & 2.4 \\
\hline Sternum & 0.8 & 1.9 & 2.6 \\
\hline Ribs & 4.0 & 9.9 & 13.9 \\
\hline Cervical Vertebra & 1.8 & 4.4 & 6.2 \\
\hline Thoracic Vertebra & 4.4 & 10.8 & 15.2 \\
\hline Lumbar Vertebra & 4.0 & 9.8 & 13.8 \\
\hline Sacrum & 3.2 & 7.8 & 11.0 \\
\hline Os Coxae & 16.5 & 16.0 & 32.4 \\
\hline Humeri, proximal & 4.7 & 1.6 & 6.3 \\
\hline \multirow[t]{3}{*}{ Femora, proximal } & 17.0 & 5.9 & 22.9 \\
\hline & 84.1 & 85.8 & 169.9 \\
\hline & $\begin{array}{c}\text { Shallow } \\
\text { Inactive Marrow } \\
\text { Mass }(g)\end{array}$ & $\begin{array}{c}\text { Shallow } \\
\text { Active Marrow } \\
\text { Mass }(g)\end{array}$ & $\begin{array}{c}\text { Shallow } \\
\text { Total Marrow } \\
\text { Mass }(g)\end{array}$ \\
\hline Humeri, distal & 4.3 & 0.0 & 4.3 \\
\hline Ulnae, proximal & 2.6 & 0.0 & 2.6 \\
\hline Ulnae, distal & 0.5 & 0.0 & 0.5 \\
\hline Radii, proximal & 0.6 & 0.0 & 0.6 \\
\hline Radii, distal & 1.6 & 0.0 & 1.6 \\
\hline Hands & 4.1 & 0.0 & 4.1 \\
\hline Femora, distal & 33.0 & 0.0 & 33.0 \\
\hline Tibiae, proximal & 15.9 & 0.0 & 15.9 \\
\hline Tibiae, distal & 5.8 & 0.0 & 5.8 \\
\hline Fibulae, proximal & 0.9 & 0.0 & 0.9 \\
\hline Fibulae, distal & 1.5 & 0.0 & 1.5 \\
\hline Feet & 32.5 & 0.0 & 32.5 \\
\hline Totals: & 103.3 & 0.0 & 103.3 \\
\hline Humeri, shaft (upper 1/2) & 0.3 & 0.1 & 0.3 \\
\hline Humeri, shaft (lower 1/2) & 0.4 & 0.0 & 0.4 \\
\hline Ulnae, shaft & 0.3 & 0.0 & 0.3 \\
\hline Radii, shaft & 0.3 & 0.0 & 0.3 \\
\hline Femora, shaft (upper 1/2) & 0.4 & 0.1 & 0.4 \\
\hline Femora, shaft (lower 1/2) & 0.5 & 0.0 & 0.5 \\
\hline Tibiae, shaft & 1.4 & 0.0 & 1.4 \\
\hline Fibulae, shaft & 0.5 & 0.0 & 0.5 \\
\hline Totals: & 4.2 & 0.2 & 4.2 \\
\hline $\begin{array}{l}\text { Totals for UF Model: } \\
\% \text { total shallow marrow: }\end{array}$ & $\begin{array}{c}191.5 \\
69 \%\end{array}$ & $\begin{array}{l}86.0 \\
31 \%\end{array}$ & 277.4 \\
\hline
\end{tabular}


Table 11. Inactive, active, and total marrow masses for all skeletal sites of the 40 yearold male and comparison with ICRP Reference Man.

\begin{tabular}{|c|c|c|c|}
\hline Skeletal Sites & $\begin{array}{c}\text { Inactive Marrow } \\
\text { Mass }(g)\end{array}$ & $\begin{array}{c}\text { Active Marrow } \\
\text { Mass }(g)\end{array}$ & $\begin{array}{c}\text { Total Marrow } \\
\text { Mass }(g)\end{array}$ \\
\hline Craniofacial Bones & 49.5 & 31.9 & 81.4 \\
\hline Mandible & 14.6 & 9.4 & 23.9 \\
\hline Scapulae & 55.7 & 35.9 & 91.6 \\
\hline Clavicles & 19.7 & 10.2 & 30.0 \\
\hline Sternum & 9.4 & 23.1 & 32.5 \\
\hline Ribs & 38.4 & 94.2 & 132.6 \\
\hline Cervical Vertebra & 11.1 & 27.2 & 38.3 \\
\hline Thoracic Vertebra & 54.1 & 132.7 & 186.8 \\
\hline Lumbar Vertebra & 45.7 & 112.0 & 157.7 \\
\hline Sacrum & 34.3 & 84.1 & 118.4 \\
\hline Os Coxae & 176.6 & 163.1 & 339.7 \\
\hline Humeri, proximal & 72.4 & 25.4 & 97.8 \\
\hline \multirow[t]{3}{*}{ Femora, proximal } & 137.8 & 48.3 & 186.1 \\
\hline & 719.4 & 797.3 & 1516.8 \\
\hline & $\begin{array}{c}\text { Inactive Marrow } \\
\text { Mass }(g)\end{array}$ & $\begin{array}{c}\text { Active Marrow } \\
\text { Mass }(g)\end{array}$ & $\begin{array}{c}\text { Total Marrow } \\
\text { Mass }(g)\end{array}$ \\
\hline Humeri, shaft (upper 1/2) & 16.2 & 5.7 & 21.9 \\
\hline Humeri, shaft (lower 1/2) & 21.6 & 0.0 & 21.6 \\
\hline Humeri, distal & 38.0 & 0.0 & 38.0 \\
\hline Ulnae, proximal & 24.6 & 0.0 & 24.6 \\
\hline Ulnae, shaft & 10.3 & 0.0 & 10.3 \\
\hline Ulnae, distal & 3.5 & 0.0 & 3.5 \\
\hline Radii, proximal & 11.2 & 0.0 & 11.2 \\
\hline Radii, shaft & 6.3 & 0.0 & 6.3 \\
\hline Radii, distal & 14.9 & 0.0 & 14.9 \\
\hline Hands & 36.8 & 0.0 & 36.8 \\
\hline Femora, shaft (upper 1/2) & 32.1 & 11.2 & 43.3 \\
\hline Femora, shaft (lower 1/2) & 42.8 & 0.0 & 42.8 \\
\hline Femora, distal & 241.0 & 0.0 & 241.0 \\
\hline Tibiae, proximal & 185.2 & 0.0 & 185.2 \\
\hline Tibiae, shaft & 133.7 & 0.0 & 133.7 \\
\hline Tibiae, distal & 74.6 & 0.0 & 74.6 \\
\hline Fibulae, proximal & 14.5 & 0.0 & 14.5 \\
\hline Fibulae, shaft & 15.5 & 0.0 & 15.5 \\
\hline Fibulae, distal & 11.7 & 0.0 & 11.7 \\
\hline Feet & 237.7 & 0.0 & 237.7 \\
\hline $\begin{array}{r}\text { Totals: } \\
\end{array}$ & 1172.2 & 16.9 & 1189.1 \\
\hline Totals for UF Model: & 1891.62 & 814.26 & 2705.9 \\
\hline$\%$ total marrow & 0.70 & 0.30 & - \\
\hline ICRP 89 Ref Male: & 2480.00 & 1170.00 & 3650.0 \\
\hline$\%$ total marrow & 0.68 & 0.32 & - \\
\hline Ratio (UF / ICRP): & 0.76 & 0.70 & 0.74 \\
\hline
\end{tabular}


Fig. 1. CT Contours graphic user interface. An ex-vivo CT image is overlaid with tag values to distinguish soft tissue, cortical bone, and spongiosa volumes.

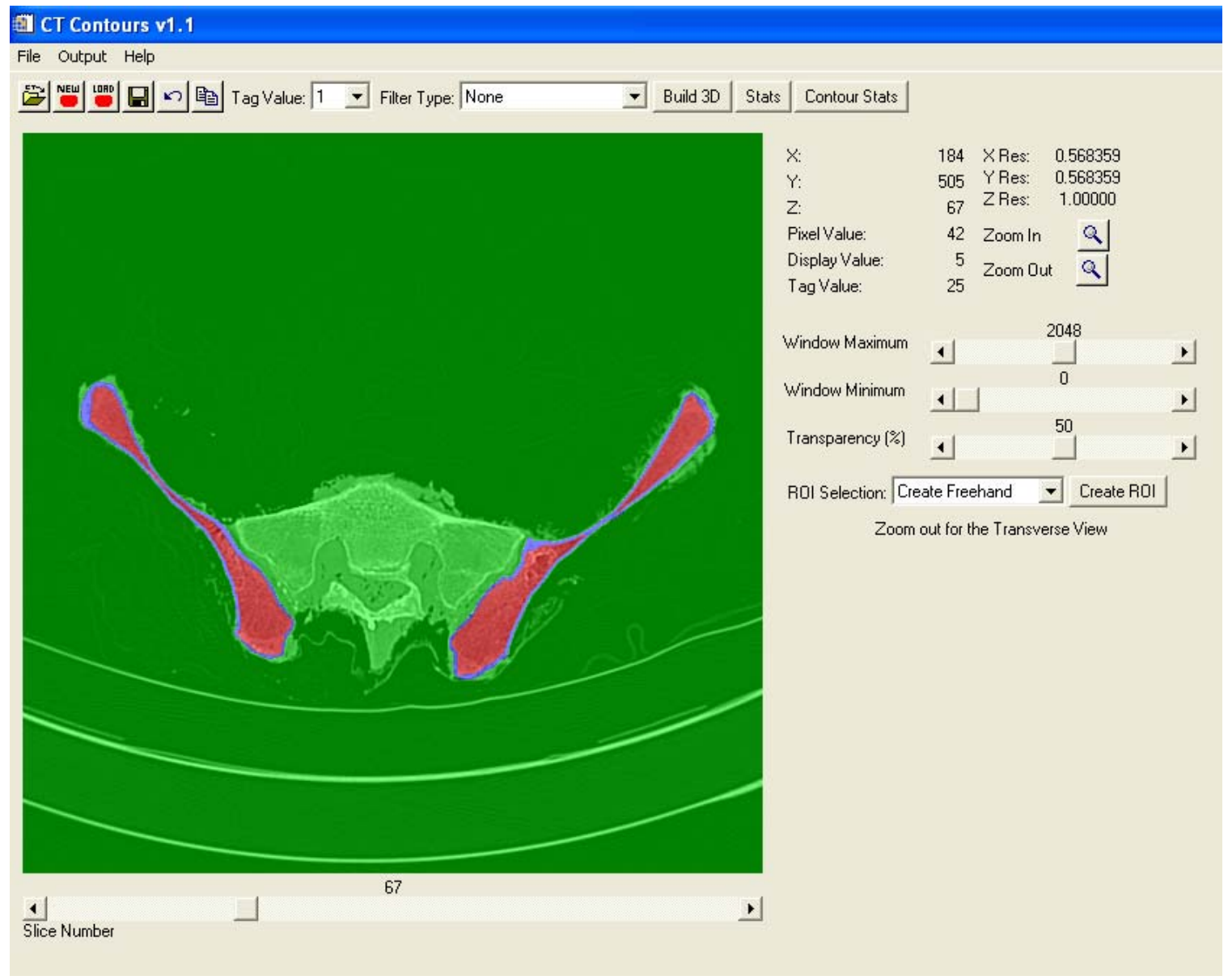


Fig. 2. BID graphic user interface. This program is used extract a region of interest from the trabecular spongiosa microCT image as well as to determine the appropriate threshold value and segment the image to contain only marrow (black) and trabecular bone (green).

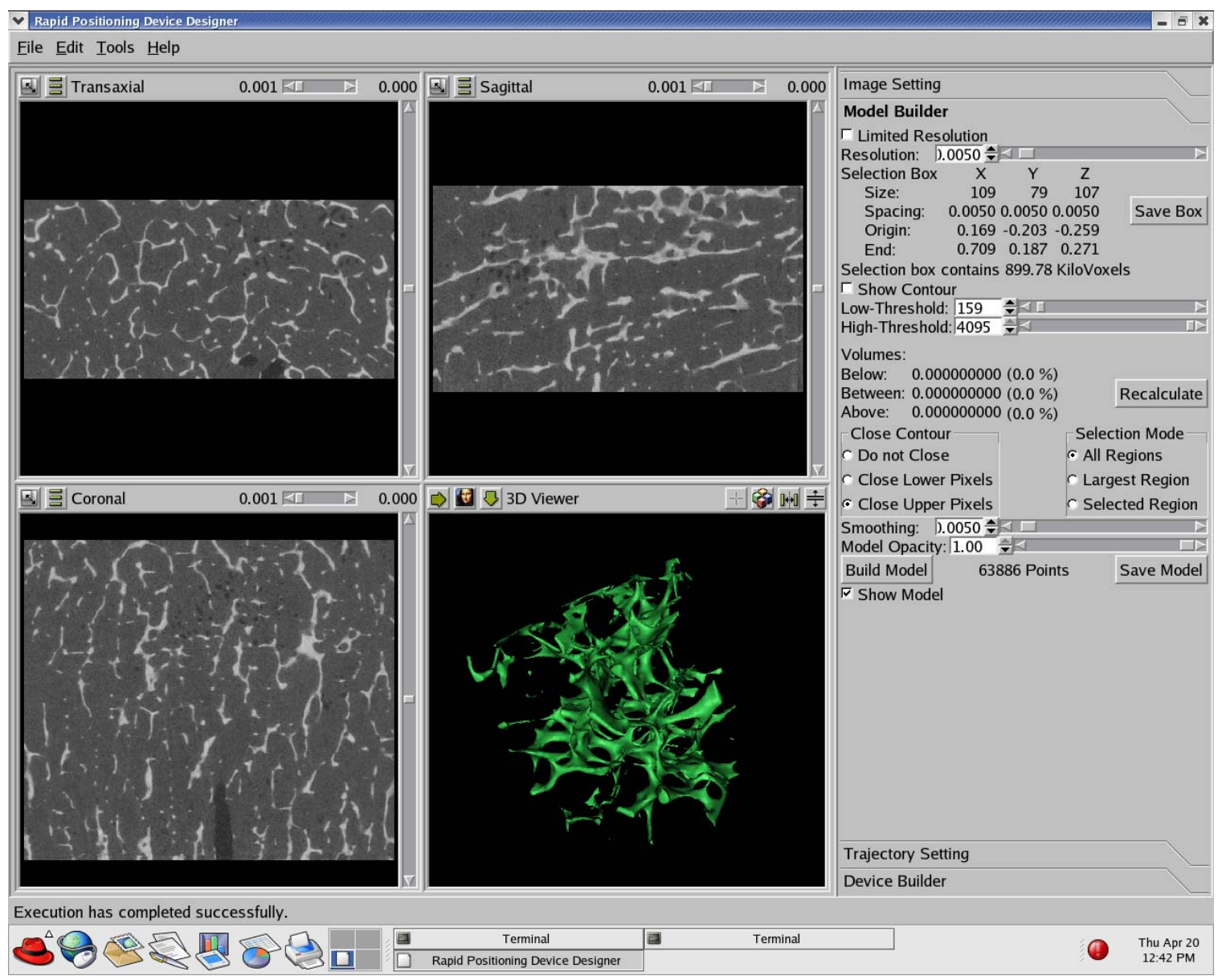




\section{Appendix B}

\section{A Skeletal Reference Dosimetry Model for the 15-Year Adolescent}




\section{CHAPTER 4 \\ AN IMAGE-BASED SKELETAL TISSUE AND DOSIMETRY MODEL FOR THE ICRP REFERENCE 15-YEAR MALE AND FEMALE}

\section{Introduction}

The goals of this chapter were to (1) develop and apply a methodology for the subsegmentation of the skeleton into all skeletal tissues by bone site within the hybrid computational 15 year-old male and female phantoms analogous to Chapter 2, and (2) implement the dosimetry methods utilized in Chapter 3 for dose assessment to active marrow and endosteal tissues for the 15 year-old female phantom of Lee et al. (2008). Detailed methods on the development of the homogeneous 15-year male and female hybrid phantoms are discussed in Lee et al. (2008). The methodology presented here targets total skeletal tissue masses for the reference 15 year-old male and female as defined in ICRP Publication 89 (ICRP 2002). However, the study further distributes those masses in a bone-specific manner based upon ICRP reference data, ex-vivo CT data from an 18 year-old male cadaver, microCT-based images of the 18 year-old male spongiosa from cadaver specimen collection, and the individual bone volumes defined within the UF hybrid 15-year male and female phantoms (Lee et al. 2008). The tissue masses presented here are thus offered as a revision to those given previously by Cristy (1981) for the 15-year active marrow distribution, and by Watchman et al. (2007) for all skeletal tissues. Electron dosimetry results are based on a large sample selection of 3D image data from an 18 year-old cadaver instead of limited 2D chord-distributions from 1.7-year and 9-year children. A glossary of acronyms for both tissue regions of the skeleton and model parameters used in this study is included at the beginning of this dissertation. 


\section{Materials and Methods}

\section{Cadaver Selection and Sample Acquisition}

The 66-year adult cadaver in Shah et al. (2005) was selected based on criteria including BMI $18.5-25 \mathrm{~kg} \mathrm{~m}^{-2}$ (CDC recommended healthy range), and cause of death that would preclude any significant skeletal deterioration. However, obtaining samples from children and young adults is rare due to limited availability and the sensitive nature in getting permission to acquire bone samples. After receiving IRB approval, the Florida State Anatomical Board and the University of Florida Shands Hospital was able to provide us with an 18 year-old male cadaver to be used as a surrogate for the 15 year-old male and female skeletal modeling in this study. Unlike the selection criteria for the adult, limited cadaver availability for this age group restricts the criteria. It was estimated that this cadaver was $180 \mathrm{lbs} .(81.6 \mathrm{~kg})$ in weight and 72 inches $(1.83 \mathrm{~m})$ in height, which is approximately a BMI of $24.4 \mathrm{~kg} \mathrm{~m}^{-2}$. It should be noted that the cause of death was due to complications from graft versys host disease (GVHD). It should also be noted that this individual was given total body irradiation (TBI) during the treatment of his leukemia, external beam treatment to the sternum, and a bone marrow transplant. The literature suggests that suppression of bone growth in children, along with bone marrow suppression could occur with TBI (Parker and Berry 1976). However, the skeleton is considered to be mature by 18 years of age. Therefore, it is assumed that significant changes in the trabecular microarchitecture from TBI are negligible for the dosimetry assessment. Bone marrow changes are taken into account during transport.

\section{In-vivo cadaver imaging, cadaver harvest, and ex-vivo bone sample imaging}

The cadaver was scanned, in-vivo, with the Siemens Sensation 16 unit in the Department of Radiology at UF Shands Hospital prior to the bone harvest. The cadaver was scanned at 1 mm slice thickness and reconstructed using both a bone filter and soft tissue filter. The in-plane 
resolution was selected as to maximize the resolution by minimizing the field-of-view (FOV) around the cadaver. $120 \mathrm{kVp}$ and 200-250 mA were chosen as the scanning protocols in order to maximize tissue contrast. The head and extremities were scanned separately for highest contrast and spatial resolution.

The bone tissue specimen collection from the 18 year-old male cadaver was performed on December 9, 2005. Representative samples from the entire skeleton were acquired during the bone harvest to further develop information on the relative cortical and spongiosa percentages, as well as 3D microstructure information of 18-year trabecular spongiosa for future transport. The following bone sites were acquired from the 18 year-old male: cranium, mandible, whole spine, sacrum, os coxae, mandible, right scapula, right clavicle, os coxae, sacrum, sternum, rib samples

from the $1^{\text {st }}, 6^{\text {th }}$ and $12^{\text {th }}$ right ribs, right proximal humerus, right proximal radius, right proximal ulna, right distal humerus, right distal radius, right distal ulna, right proximal femur, right proximal tibia, right proximal fibula, right distal femur, right distal tibia, and right distal fibula. These bone samples were then scanned, ex-vivo (outside the cadaver), in the same manner as the in-vivo imaging. Again, maximizing the in-plane resolution with the smallest scanning FOV, 1 mm slice thickness axial resolution, and both bone and soft tissue filter reconstruction, in order to obtain the best contrast resolution and spatial resolution necessary for accurate cortical bone and spongiosa segmentation.

\section{Spongiosa image analysis using microCT}

As done in Chapters 2 and 3 for the newborn, bone specimens from the 18 year-old were subjected to microCT imaging (Scanco Medical AG, Brüttisellen, Switzerland) at $30 \mu \mathrm{m}$ isotropic resolution. Prior to sample shipment, each bone was cut using a bone saw, and cored with a drill press in order to (1) maintain the microCT size restrictions of the bore $(4 \mathrm{~cm}$ height 
and $3.8 \mathrm{~cm}$ in-plane) and (2) obtain a large, representative sample of spongiosa. The resulting images were converted to binary format using techniques previously given in Rajon et al. (2006). Cored cranial samples from the parietal bone, occipital bone and frontal bone, cored vertebral samples from $\mathrm{C}_{3}, \mathrm{C}_{6}, \mathrm{~T}_{1}, \mathrm{~T}_{3}, \mathrm{~T}_{6}, \mathrm{~T}_{9}, \mathrm{~T}_{12}$ and $\mathrm{L}_{1}-\mathrm{L}_{5}$, manubrium cut from the sternum, cored samples from the proximal humerus and femur, cut samples from the distal femur and humerus, cut samples from both the proximal and distal fibula, ulna, radius and tibia, cored sample from the subscapular fossa region of the right scapula, cut sample of the sternal end to shaft region of the right clavicle, cored sample from the mandible body, cut sample of the shaft region in right rib-1, rib-6 and rib-12, cored sample of the right ilium from the os coxae, and cored sample from the medial sacral region were imaged.

\section{Segmentation of Skeletal Tissues from the 18-Year Male Cadaver CT and microCT Data}

As previously mentioned, the 15-year male and female skeleton developed in Lee et al. (2008) contain only homogeneous bone (no delineation between cortical bone and spongiosa). Similar to Chapter 2 for the newborn, skeletal tissue volume fractions are needed to partition the 15-year male and female homogeneous skeletons into detailed skeletal models. The CBVF and SVF were determined from manual image segmentation in $3 D-D O C T O R^{T M}$ (Able Software Corp., Lexington, MA) of the 18 -year male ex-vivo scans. The MVF and TBVF, with both in reference to the total volume of spongiosa (homogeneous bone exclusive of its cortical bone cortex), were determined based on image segmentation described in Chapter 2. The SMVF was derived though an image analysis software using EGSnrc, which is described in detail in Chapter 2. As previously discussed, the SMVF defines the fraction of spongiosa occupied by marrow space within $50-\mu \mathrm{m}$ of the bone trabeculae surfaces. This latter parameter is used to define the surrogate tissue region for the osteoprogenitor cells. 


\section{Skeletal Tissue Derivations for the UF 15-Year Male and Female Hybrid Phantoms}

Calculations of reference 15-year male and female site-specific skeletal tissue masses, elemental compositions, and mass densities were performed using data from three sources. The first were reference data given in ICRP Publications 70 (ICRP 1995) and 89 (ICRP 2002), ICRU Publication 44 (ICRU 1989), and ICRU Publication 46 (ICRU 1992). The second were CT and microCT images from skeletal specimens acquired from the 18 -year male cadaver. The third were homogeneous skeleton volumes defined within the UF 15-year male and female hybrid phantoms. The following is a list of overall assumptions and assumed bone surrogates made in this study:

1) Shafts of long bones have a MVF of 1.0 (no trabecular structures within the medullary cavities);

2) Rib MVF is assigned to the wrists/hands, patellae, and ankles/feet;

3) SVF and CBVF for the patella, wrist/hands, ankles/feet were determined by the in-vivo segmentation of the 18-year male cadaver;

4) Cellularity factors for the upper and lower half of the15-year male and female femur and humerus were partitioned in a gradient style into proximal, upper shaft, lower shaft, and distal, such that the linear average between proximal/upper shaft, and lower shaft/distal targeted the ICRP 70 reference cellularity for upper half and lower half (e.g. 55\% proximal, 35\% upper shaft, 20\% lower shaft, and $0 \%$ distal);

5) Medullary marrow volume fraction values for the upper shaft and lower shaft are assumed to be identical to that for whole segmented shaft from the in-vivo scans;

6) All volume fractions obtained by image segmentation are assumed to contain MST because these tissues can not be realized independently in the image. 
The following subsections are shortened due to the previous detailed analysis of skeletal tissue derivations in Chapter 2. Also, it should be noted that the tissue derivations below are considered the first iteration. Once this has been completed using the original image-based data, a second iteration must be done to match ICRP 89 total mineral bone $3700 \mathrm{~g}$ for the 15-year female and $4050 \mathrm{~g}$ for the 15 -year male, excluding MST. This mineral bone matching is done by uniformly increasing or decreasing the original image-based $C B V F$ from the 18-year male cadaver segmentation.

\section{Miscellaneous skeletal tissues}

As defined in ICRP Publication 89, miscellaneous skeletal tissues (MST) consist of blood vessels and periosteum, but exclude periarticular tissue and blood. Limitations on image contrast and spatial resolution do not allow for any visual delineation of miscellaneous skeletal tissues in the 18 year-old male CT dataset. Consequently, the reference volume of 15 -year male and female MST given in Table 9.2.15 of ICRP Publication 89 (male $-150.49 \mathrm{~cm}^{3}$ or $155 \mathrm{~g} / 1.03 \mathrm{~g}$ $\mathrm{cm}^{-1}$, female $-142.16 \mathrm{~cm}^{3}$ or $145 \mathrm{~g} / 1.02 \mathrm{~g} \mathrm{~cm}^{-1}$ ) was first distributed by bone site based solely on fractional homogeneous skeletal volumes (male $-4943.17 \mathrm{~cm}^{3}$, female $-4543.68 \mathrm{~cm}^{3}$ ) as shown in Chapter 2, Eq. 2-1. MST masses were calculated using the gender-specific soft tissue density of $1.03 \mathrm{~g} \mathrm{~cm}^{-3}$ for the male and $1.03 \mathrm{~g} \mathrm{~cm}^{-3}$ for the female given in ICRU Publication 46 (ICRU 1992). Once total MST volumes were assigned to each phantom skeletal site, $\mathrm{x}$, they were further partitioned into $M S T$ regions assigned to active marrow $\left(A M^{*}\right)$, inactive marrow $\left(I M^{*}\right)$, mineral bone $\left(M B^{*}\right)$, trabecular bone $\left(T B^{*}\right)$, and cortical bone $\left(C B^{*}\right)$, respectively, also according to their relative volumes. ${ }^{4}$

\footnotetext{
${ }^{4}$ The asterisks for the variables denote their inclusion of constituent miscellaneous skeletal tissue volumes. Variables with no asterisk denote their ICRP 89 reference values which are exclusive of miscellaneous skeletal tissues.
} 


$$
\begin{aligned}
& V_{M S T-A M}^{x}=\left(V_{M S T}^{x}\right)\left(S V F^{x}\right)\left(M V F^{x}\right)\left(C F^{x}\right) \\
& V_{M S T-I M}^{x}=\left(V_{M S T}^{x}\right)\left(S V F^{x}\right)\left(M V F^{x}\right)\left(1-C F^{x}\right) \\
& V_{M S T-M B}^{x}=\left(V_{M S T}^{x}\right)\left(\frac{V_{M B^{\star}}^{x}}{V_{H B^{\star}}^{x}}\right) \\
& V_{M S T-C B}^{x}=\left(V_{M S T-M B}^{x}\right)\left(\frac{V_{C B^{\star}}^{x}}{V_{M B^{\star}}^{x}}\right) \\
& V_{M S T-T B}^{x}=\left(V_{M S T-M B}^{x}\right)\left(\frac{V_{T B^{\star}}^{x}}{V_{M B^{*}}^{x}}\right)
\end{aligned}
$$

The derivation of site-specific tissue volumes are given below.

\section{Marrow masses and volumes}

Active bone marrow volumes in the 15-year male and female are derived using the same method in Chapter 2, Eq. 2-3. Inactive bone marrow volumes are obtained by replacing the CF term with (1-CF) in Eq. 2-3 in Chapter 2. Long bones in the 15-year phantoms were partitioned as was done with the newborn phantom. These subdivisions are necessary in the 15-year phantoms due to the varying cellularity gradient across the long bone regions. In this study, homogeneous bone volumes are taken directly from the 15-year male and female hybrid phantoms of Lee et al. (2008). The bone site-specific TAM and TAM* masses were calculated using Eq. 2-4 in Chapter 2, along with the ICRU Report 46 mass densities for active marrow $\left(\rho_{A M}=1.03 \mathrm{~g} \mathrm{~cm}^{-3}\right)$ and gender-specific soft tissue $\left(\rho_{S T-M A L E}=1.03 \mathrm{~g} \mathrm{~cm}^{-3}, \rho_{\text {ST }-F E M A L E}=1.02 \mathrm{~g}\right.$ $\mathrm{cm}^{-3}$ ) (ICRU 1992). For mass calculations in inactive marrow, a density, $\rho_{A M}$, of $0.98 \mathrm{~g} \mathrm{~cm}^{-3}$ and the calculated volume of $I M$ were used in place of the active marrow terms in Eq. 2-4 in Chapter 2. 


\section{Trabecular bone and cortical bone masses and volumes}

ICRP Publication 70, Table 10, provides cortical bone and trabecular bone percentages by bone site, but only for the adult. Instead of determining 15-year male and female cortical and trabecular bone volumes based on these adult partitions of mineral bone, values of $C B V F$ and TBVF were determined via image segmentation of the 18-year male cadaver CT images and autopsy microCT images, respectively. The mass and volumes for both cortical bone and trabecular bone were determined using the identical formulation in Eq. 2-5 through Eq. 2-8 in

Chapter 2. However, the $\rho_{C B}$ is the ICRP 89 density for 15 -year cortical bone $\left(1.80 \mathrm{~g} \mathrm{~cm}^{-3}\right)$, and it is assumed that 15-year trabecular bone has an identical mass density to 15-year cortical bone.

\section{$\mathrm{S} / \mathrm{V}$ ratios for the 15 -year male and female skeleton}

The cortical bone surface-to-volume $(\mathrm{S} / \mathrm{V})$ ratio is defined as the ratio of the Haversian canal surface area to the volume of ossified cortical bone, and is defined for dry bone (exclusive of periosteum and blood vessels). However, the trabecular bone S/V ratio is defined as the ratio of trabecular surface area to the volume of trabecular bone, and is also defined for dry bone. Reference values for S/V ratios of cortical bone and trabecular bone are presented in ICRP 70, Tables 11 and 12, respectively. ICRP Publication 89 suggests that a nominal reference value of $3 \mathrm{~mm}^{2} \mathrm{~mm}^{-3}$ be used for cortical bone at skeletal sites not indicated in their Table 11. Similarly, a default value of $18 \mathrm{~mm}^{2} \mathrm{~mm}^{-3}$ is given for the trabecular bone S/V ratio. In the present study, an EGSnrc subroutine was written to calculate (1) the total number of trabecular bone voxels and (2) the number of trabecular bone voxel surfaces adjacent to bone marrow voxels present in each 18-year male thresholded microCT-imaged skeletal site. The number of trabecular bone volume voxels was multiplied its unit volume to estimate the cumulative trabecular bone volume, while the number of bone voxel surfaces at the bone-marrow interface were multiplied by their unit 
area to estimate the total trabecular bone surface area. Dividing the trabecular bone surface area by the trabecular bone volume gives the $\mathrm{S} / \mathrm{V}$ ratios for each imaged skeletal site. For bone sites with multiple microstructures, a linear average was assumed for the overall reported value.

\section{Homogeneous spongiosa masses, volumes, densities, and elemental compositions}

Volumes, masses, and densities of the 15-year male and female homogeneous spongiosa are calculated with the same methodology as reported in Eq. 2-9 through 2-11 in Chapter 2, but with an $I M$ terms included in the expressions:

$$
\begin{aligned}
& V_{\text {spongiosa }}^{x}=V_{T A M^{*}}^{x}+V_{T I M^{*}}^{x}+V_{T B^{*}}^{x}=V_{T A M}^{x}+V_{T I M}^{x}+V_{T B}^{x}+V_{M S T-T A M}^{x}+V_{M S T-T I M}^{x}+V_{M S T-T B}^{x} \\
& V_{\text {spongiosa }}^{x}=V_{T A M}^{x}+V_{T I M}^{x}+V_{T B}^{x} \\
& m_{\text {spongiosa } a^{*}}^{x}=m_{T A M^{*}}^{x}+m_{T I M^{*}}^{x}+m_{T B^{*}}^{x}=m_{T A M}^{x}+m_{T I M}^{x}+m_{T B}^{x}+m_{M S T-T A M}^{x}+m_{M S T-T M}^{x}+m_{M S T-T B}^{x} \\
& m_{\text {spongiosa }}^{x}=m_{T A M}^{x}+m_{T I M}^{x}+m_{T B}^{x}
\end{aligned}
$$

It should be noted that the shafts of long bones in the newborn are assumed to contain only medullary marrow, and are thus devoid of trabecular bone and not included in the calculation of spongiosa volumes, masses, or densities. Once homogeneous spongiosa volumes were calculated, 15-year male and female site-specific spongiosa densities for each bone site, $\mathrm{x}$, as shown in Chapter 2, Eq. 2-10. The 15-year male and female site-specific spongiosa elemental compositions in percent by mass, $w_{\text {spongiosa }}^{x, k}$, were calculated as similarly to Eq. 2-11 in Chapter 2, but with the inclusion of $I M$ :

$$
w_{\text {spongiosa }}^{x, k}=\left[\frac{\left(w_{T A M^{*}}^{k}\right)\left(m_{T A M^{*}}^{x}\right)+\left(w_{T I M^{*}}^{k}\right)\left(m_{T I M^{*}}^{x}\right)+\left(w_{T B^{*}}^{k}\right)\left(m_{T B^{*}}^{x}\right)}{m_{\text {spongiosa }^{*}}^{x}}\right]
$$

where $k$ is the elemental index and $w$ is the mass percentage. There are no age-dependent reference elemental composition data for trabecular bone, and thus, for these calculations, it was 
assumed the 15-year male and female elemental compositions of trabecular bone were the same as that for cortical bone given in Table 13.4 of ICRP Publication 89. The elemental compositions of active and inactive marrow were taken to be that given in Table 13.4 in ICRP 89, independent of age and sex. The elemental compositions for MST were taken to be that of the male and female, gender-specific, values for ICRU-44 male and female average soft tissues as given in Table A1 of ICRU 46 (ICRU 1992).

\section{Shallow marrow masses and volumes}

As discussed in Bolch et al. (2007) and Gossner et al. (2000, 3003), the surrogate target regions defining the location of the osteoprogenitor cells are (1) a 50- $\mu \mathrm{m}$ layer of marrow surrounding the surfaces of bone trabeculae in regions of spongiosa, and (2) a 50- $\mu \mathrm{m}$ layer of marrow adjacent to cortical bone / medullary cavity boundary in the shafts of the long bones. These two tissue regions are defined as shallow active marrow $\left(A M_{50}\right)$ and shallow inactive marrow $\left(I_{50}\right)$, which include both the shallow marrow from the trabecular regions and the medullary marrow, , and are reported as a sum of total shallow marrow $\left(T M_{50}\right)$ for the total target region in the 15-year male and female. Again, a summary of all terms is given in the Glossary due to the extensive list of tissue definitions.

To assess the shallow marrow volumes and masses, values of shallow marrow volume fraction (SMVF) were obtained from Monte Carlo sampling of 3D point locations within thresholded microCT images of 18-year male spongiosa. The SMVF is defined as the fraction of spongiosa volume assigned to total bone marrow localized within $50 \mu \mathrm{m}$ of bone trabeculae surfaces. As such, volumes and masses of $T A M_{50} *$ for bone site $\mathrm{x}$ are obtained as:

$$
\begin{aligned}
& V_{T_{A M_{50}}^{*}}^{x}=\left(V_{\text {spongiosa }^{*}}^{x}\right)\left(S M V F^{x}\right)\left(C F^{x}\right) \\
& V_{T I M_{50} *}^{x}=\left(V_{\text {spongiosa }^{*}}^{x}\right)\left(S M V F^{x}\right)\left(1-C F^{x}\right)
\end{aligned}
$$




$$
\begin{aligned}
& m_{T A M_{50} *}^{x}=\left(V_{\text {spongiosa* }}^{x}\right)\left(S M N F^{x}\right)\left(C F^{x}\right)\left(\rho_{A M}\right)=\left(V_{T M_{50}}^{x}\right)\left(C F^{x}\right)\left(\rho_{A M}\right) \\
& m_{T M_{50} *}^{x}=\left(V_{\text {spongiosa* }}^{x}\right)\left(S M N F^{x}\right)\left(1-C F^{x}\right)\left(\rho_{I M}\right)=\left(V_{T M_{50} *}^{x}\right)\left(1-C F^{x}\right)\left(\rho_{I M}\right)
\end{aligned}
$$

To assess volumes and masses of $C M_{50} *$ or the sum of $C I M_{50} *$ and $C A M_{50} *$, the derived methods in Chapter 2, Eq. 2-13 and Eq. 2-14 were used. Cortical shallow marrow volume and active $\left(C A M_{50} *\right)$ and inactive $\left(C I M_{50} *\right)$ marrow masses were defined as:

$$
\begin{aligned}
& V_{C M_{50^{*}}}^{x}=\left(V_{\text {medullary marrow* }}^{x}\right)\left(S M V F_{\text {shaft }}^{x}\right) \\
& m_{C A M_{50^{*}}}^{x}=\left(V_{\text {medullary marrow }}^{x}\right)\left(S M N F_{\text {shaft }}^{x}\right)\left(C F^{x}\right)\left(\rho_{A M}\right)=\left(V_{C M_{50}^{*}}^{x}\right)\left(C F^{x}\right)\left(\rho_{A M}\right) \\
& m_{C M_{50^{*}}}^{x}=\left(V_{\text {medullary marrow }}^{x}\right)\left(S M N F_{\text {shaft }}^{x}\right)\left(1-C F^{x}\right)\left(\rho_{I M}\right)=\left(V_{C M_{50} 0^{*}}^{x}\right)\left(1-C F^{x}\right)\left(\rho_{I M}\right)
\end{aligned}
$$

\section{Homogeneous skeleton masses, volumes, densities, and elemental compositions}

In this study, as was done in Chapter 2 for the newborn, we have taken the noncartilaginous homogeneous skeleton of the UF hybrid 15-year male and female phantoms and sub-divided it into explicit regions of trabecular spongiosa, cortical bone, and for the long bones, medullary marrow. Homogenized skeleton volumes, masses, densities, and elemental compositions were computed using the derivations in Eq. 2-16 through Eq. 2-18 from Chapter 2, but with the inclusion of TIM or CIM contributions to the spongiosa and long bones, respectively.

\section{Electron Dosimetry Modeling for the 15-Year Female Hybrid Phantom}

In this study, electron dosimetry was performed for the 15-year female only. The transport methodology with PIRT, PIRTCartilage and PIRTCartilageLongBone and homogeneous bone segmentation are described in Chapter 3, and were applied to the computations involving the 15 year-old female skeletal model. The 18-year male microCT skeletal images were used as a surrogate for the 15-year skeleton, as discussed in the aforementioned sections. Any 
microstructure surrogate assignments were also previously identified. Electron energy deposition to cartilage (CAR) in the spine, ribs, and sternum is still reported as a surrogate target for the chondrocytes due to probabilistic incidence of chondrosarcoma. However, CAR sources are not performed during dosimetry analysis because the ossification process has been completed in the 15 year-old skeleton. Dosimetry results for the gender independent, skeletal sitedependent ICRP reference cellularities for the 15 year-old female were determined based on a linear averaged between the results at transported cellularities. There are significant differences in volume for the spongiosa, cortical bone, and medullary marrow between then male and female phantoms, but the same microstructure image sets would be used for the male dosimetry. Future studies are necessary to analyze the impact on marrow dosimetry regarding the overall electron escape fraction due to the larger volumes seen in the 15-year male skeletal model compared with the female.

Long bones require a separate modeling due to the variation in cellularity for the proximal, upper shaft, lower shaft, and distal regions. The modeling was performed such that the appropriate cellularity could be entered for the upper and lower shafts. For the 100\%-10\% cellularity cases, the same cellularity was placed in each region. For example, 50\% cellularity was placed in the proximal, upper shaft, lower shaft, and distal regions for a $50 \%$ cellularity case run. Given the ICRP reference cellularity of $0 \%$ for the tibia, fibula, ulna, and radius, the reference $A F$ and $S A F$ data for an $A M$ source did not need to be computed. Unlike the tibia, fibula, ulna and radius, the humerus and femur vary in ICRP reference cellularity between each of the four long bone regions. Therefore, the upper half and lower half of the humerus and femur were run separately with the ICRP reference cellularities in place and appropriate 
microstructures. The results were mathematically combined to emulate the results from a full long bone model.

\section{Results and Discussion}

\section{Homogeneous 15-Year Male and Female Skeletal Models}

The 15 year-old male and female skeletal models were developed from whole-cadaver CT image segmentation, polygon mesh or NURBS surface modeling, and hybrid phantom voxelization. Details of the latter are given in Lee et al. (2008). The voxel resolution chosen for each whole-body phantom was $0.1122 \mathrm{~cm}$ x $0.1122 \mathrm{~cm}$ x $0.1122 \mathrm{~cm}$ and $0.0997 \mathrm{~cm}$ x $0.0997 \mathrm{~cm}$ x $0.0997 \mathrm{~cm}$ for the male and female, respectively, based on reference skin thickness.

The site-specific homogeneous bone volumes, inclusive and exclusive of bone-associated cartilage, are shown in Table 4-1 for both the 15-year male and female skeletal models. The polygon mesh total homogeneous skeletal model volumes were approximately $1 \%$ and less than 1\% different compared to ICRP reference 15-year male and female, respectively. The volume of total segmented skeletal tissue (including all bone-associated cartilage) is $4806.20 \mathrm{~cm}^{3}$ and $5191.64 \mathrm{~cm}^{3}$ for the 15 -year female and male skeletons, respectively. It should be noted that the reported cranium volume does not include teeth, and was therefore not included in the dosimetry model. The teeth were thus treated as a separate tissue structure of the phantom.

Based on a volume-weighted average of ICRP reference densities for the constituent skeletal tissues $\left(1.03 \mathrm{~g} \mathrm{~cm}^{-3}\right.$ for active marrow, $0.98 \mathrm{~g} \mathrm{~cm}^{-3}$ for inactive marrow, $1.80 \mathrm{~g} \mathrm{~cm}^{-3}$ for mineral bone, and $1.03 \mathrm{~g} \mathrm{~cm}^{-3}$ for miscellaneous skeletal tissues), a value of $1.36 \mathrm{~g} \mathrm{~cm}^{-3}$ is estimated as the skeletal-averaged non-cartilaginous homogenous bone density for the 15 -year

male and female skeletons. This is less than the $1.41 \mathrm{~g} \mathrm{~cm}^{-3}$ reported for the newborn in Chapter 2 due to the large amounts of IM present in the 15 year-old skeletons. Utilizing the homogeneous skeletal density, total non-cartilaginous skeletal masses of $6180.02 \mathrm{~g}$ and 6743.09 
g were realized in the hybrid-NURBS/PM 15-year female and male phantoms, respectively.

These values are thus $-0.7 \%$ and $-0.3 \%$ different from the ICRP reference total skeletal masses of $6225 \mathrm{~g}$ and $6765 \mathrm{~g}$ for the 15 -year female and male, respectively. The total bone-associated cartilage masses for the hybrid-NURBS/PM 15-year female and male phantoms were $162.08 \mathrm{~g}$ and $152.33 \mathrm{~g}$, respectively, which are $-82 \%$ and $-87 \%$ different from the reference masses of 920 $\mathrm{g}$ and $1140 \mathrm{~g}$. Total cartilage volumes were not matched to ICRP reference value due to limited contrast resolution for the articular cartilage regions of the long bones and hyaline cartilage regions of the ears, larynx, trachea, extrapulmonary bronchi, and external nose. Only cartilage in the intervertebral disc, sternum, and ribs were directly segmented. However, an additional 26.75 $\mathrm{g}$ in the 15 -year female and $30.68 \mathrm{~g}$ in the 15 -year male is included for non-bone associated cartilage (external nose, trachea, larynx, extrapulmonary bronchi, and ears) based on the assumed distributions used in the newborn. The total 15-year male skeleton, excluding contributions from cartilage is approximately $8 \%$ larger, by volume, compared to the 15 year-old female. However, this percentage can vary by as much as $45 \%$ less in the 15 -year female sternum to as little as $11 \%$ less in the 15 -year thoracic vertebrae. It should be noted that female cervical vertebrae, lumbar vertebrae, sacrum, lower femur shaft, ribs, clavicles, os coxae, and scapula are larger, by volume, compared with the male by as little as $8 \%$ or as much as $27 \%$.

\section{Construction of the Heterogeneous 15-Year Male and Female Skeletal Models}

Once the UF homogeneous 15-year male and female skeletons were constructed to match ICRP reference masses to within a $1 \%$ tolerance, the constituent skeletal tissues of active marrow, inactive marrow, trabecular bone, cortical bone, and MST were distributed across individual bone sites. Similar to the newborn in Chapter 2, cortical bone and spongiosa volume fractions were obtained following complete segmentation of each ex-vivo CT scanned skeletal site, but from the 18-year male. Marrow and trabecular bone volume fractions, from the 18-year 
male microCT scanned harvested skeletal specimens, were then obtained through the image segmentation methods described in Chapter 2, and originated in Rajon et al. (2006). These volumes fractions are reported in Table 4-2. Column 1 and Column 4 are the original segmented values from the 18 year-old male of the $S V F, C B V F, M V F$, and TBVF. These values were used as the starting point for all subsequent calculations of skeletal tissues by bone site.

As discussed in the methods section, the calculations were performed as a first iteration with the original segmented values. It was determined that the ICRP reference total mineral bone would be the targeted value for development of the 15-year male and female skeletal. Consequently, the original microCT image analysis of the $M V F$ and $T B V F$ would be the final values used in the skeletal tissue calculations of trabecular bone and marrow. Compared with the original segmented 18-year male cadaver, the targeted 15-year female required a $2.1 \%$ uniform decrease in the $C B V F$, while the targeted 15 -year male require a $2.7 \%$ uniform decrease.

Therefore, all reported skeletal tissue values for both the 15 year-old male and female are based on the final iterative values of $S V F / C B V F$ to match ICRP reference total mineral bone. The 15year male has between $0.7 \%$ and $6 \%$ (lumbar vertebrae) larger CBVF (or smaller SVF) compared with the iterated 15-year female. Footnotes at the bottom of Table 4-2 indicate the corresponding standard deviations of the linearly-averaged MVF values from multiple microCT images from the same bone site (e.g. lumbar vertebrae).

\section{Miscellaneous skeletal tissue masses and volumes}

Table 4-3 and Table 4-4 give mass and volume distributions of miscellaneous skeletal tissues dispersed throughout the 15-year female and male skeletons, respectively, by skeletal site and constituent tissue. Again, these masses were calculated based on the assumption that the MST volume for a particular skeletal site is proportional to that bone site's total tissue volume (exclusive of bone-associated cartilage). This assumption was applied given the lack of literature 
data to the contrary. The MST volumes in the os coxae and cranium are the greatest as those skeletal sites are proportionally the largest in the 15-year male and female.

\section{Marrow masses and volumes}

$A M, I M, T M S$ (total marrow), and $A M^{*}, I M^{*}$, and $T M S^{*}$ volumes were calculated for every skeletal site as shown in Table 4-5 and Table 4-6 for the 15-year female and male, respectively. The calculated $A M$ and IM masses were approximately $+4 \%$ and $-5 \%$ for the 15 -year female, and $-3 \%$ and $+1 \%$ for the 15 -year male compared to the ICRP reference masses for these tissues. Active marrow distributions from this study are in fairly good agreement to those given by the non-imaged based methods of Watchman et al. (2007). The largest difference between then results in Watchman et al. (2007) and the current study was in the os coxae with a $73 \mathrm{~g}$ difference for the 15-year female, and $46 \mathrm{~g}$ in the 15-year male ribs. However, these sites have relatively large amounts of active marrow, which reduce any significance between the mass differences. Similarly for the $I M$, the largest differences were seen in the ankles/feet with $87 \mathrm{~g}$ and $62 \mathrm{~g}$ in the female and male, respectively. Again, this skeletal site contains the largest amount of $I M$ in the entire skeleton, thus the differences are not significant.

Table 4-7 lists the percent mass distribution of active marrow, including MST, by bone site for the 15-year female and male skeletons with comparisons to values given in Table 9.4 of ICRP Publication 89. The majority of skeletal sites in this study show absolute differences of less than 2\% with values in ICRP Publication 89. The 15-year female os coxae and 15-year male ribs have the highest percent differences, namely 6.02\%, $-4.07 \%$, respectively. Again, fairly good agreement compared with ICRP reference data.

\section{Cartilage masses and volumes}

A summary of 15-year female and male cartilage volumes are given in Table 4-8, along with calculated masses based on an ICRU Report 46 reference density of $1.10 \mathrm{~g} / \mathrm{cm}^{3}$. Only the 
sternum contains a layer of unossified bone. This bone is the last skeletal site to fully ossify, typically 18 years of age (White 2000). Table 4-8 next lists three major cartilage sites that were

manually segmented from the original CT images (costal, cranial, and intervertebral discs). Final bone-associated cartilage masses were calculated as $162.08 \mathrm{~g}$ (female) and $183.96 \mathrm{~g}$ (male), while total cartilage masses were calculated to be $187.83 \mathrm{~g}$ (female) and $214.64 \mathrm{~g}$ (male). The calculated total cartilage mass is $80 \%$ lower than the ICRP 89 reference value of $920 \mathrm{~g}$ (female) and $1140 \mathrm{~g}$ (male). The final column in Table 4-8 gives the percent mass distribution of cartilage by bone site. Costal cartilage connecting the ribs to the sternum accounts for the largest proportion of cartilage at 52\% in the 15-year female and 55\% in the male. As stated previously, cartilage mass and volume were not targeted to match ICRP reference due to limited contrast resolution.

\section{Trabecular bone and cortical bone masses and volumes}

Cortical and trabecular bone volumes and masses by skeletal site are listed in Table 4-9 and 4-10 for the 15-year female and male, respectively. Values of the 15-year female and male total trabecular bone mass (exclusive of MST) were calculated at $784.51 \mathrm{~g}$ and $869.43 \mathrm{~g}$, approximately 6\% and 7\%, respectively, more than reported in ICRP Publication 89. For cortical bone, the calculated masses for the female and male are 1619.72 and 1766.99g, a difference of only $2 \%$ less than the ICRP reference cortical bone masses for both genders. ICRP 89 reference values of cortical bone and trabecular bone are based on an assumed 80\% / 20\% partition of total mineral bone. Based on imaging data, this partition is approximately the same for the 15-year male and female skeletal models. These results are in contrast to the $40 \%$ cortical bone and 60\% trabecular found in the newborn analysis in Chapter 2 . The site-specific distribution of total mineral bone (excluding teeth) mass is shown in Table 4-11 for both the female and male skeletons, which shows the agreement with the targeted ICRP reference total 
skeletal mineral bone of $3700 \mathrm{~g}$ in the female and $4050 \mathrm{~g}$ in the male (2960 g CB + $740 \mathrm{~g}$ TB 15 year female; 3240 g CB + 810 g TB 15-year male). Compared to Watchman et al. (2007), the 15 year-old trabecular bone masses presented in this chapter can vary by bone site up to 8 times higher. In contrast, cortical bone masses can vary by bone site up to 3 times higher in the current study. In Watchman et al. (2007), this difference is noticeable in the inability to match total ICRP Publication 89 reference masses of trabecular bone by 15\% less and fair agreement in cortical bone by only $4 \%$ more.

Table 4-12 shows a comparison between the image-based newborn in Chapter 2, 15-year female and male in this study, and the ICRP Publication 89 adult reference percentages of cortical and trabecular bone. The 15-year skeletons appear to be in good agreement between cortical and trabecular percentages compared with ICRP reference values. However, the cortical percentage in the adult reference cranium appears to be overestimated, and the vertebrae almost appear to be in opposite agreement between the cortical and trabecular percentages. The percentage of mineral bone associated with cortical regions in the 15-year female and male range from a low of $50 \%$ and $48 \%$, respectively, in the lumbar spine to a high of $92 \%$ both male and female wrists/hands. It appears that mineral bone displays a more prominent appearance at birth in the form of bone trabeculae and then shifts to cortical bone as the bone matures. This ratio of CB:TB gradually shifts toward an adult 80:20 ratio as the skeleton matures during childhood and early adolescence.

\section{Shallow active marrow data}

Table 4-13 and Table 4-14 show a summary of the shallow marrow data for the 15-year female and male skeleton. All volumes and masses in this table include their MST contributions. Column 2 lists the shallow marrow volume fractions (percentage of spongiosa volume) for each skeletal site. For example, $14.76 \%$ of the spongiosa in the 15 -year male cervical vertebrae was 
computed as shallow marrow. The footnotes at the bottom of Table 4-13 and Table 4-14 denote the surrogate skeletal sites used where image data was not available, along with SMVF standard deviations for bone sites where linear averages were taken. The average measured shaft lengths are listed in column 2 of Table 4-15. The femur shaft length is the longest at $33.92 \mathrm{~cm}$ in the male and $28.75 \mathrm{~cm}$ in the female. In column 3 of Table 4-15, standard deviations were calculated based on the ten length measurements for each long bone shaft. Column 4 of Table 415 lists the calculated medullary marrow radius given in Chapter 2.

These values were then used in Eq. 2-14 in Chapter 2 to calculate the $S M V F_{\text {shaft }}$ for the long bone shafts, which are given in column 2 of Table 4-13 and Table 4-14. Column 3 of Table 4-13 and Table 4-14 list the percentage of total marrow space assigned to shallow marrow. On average, approximately $16 \%$ of the total marrow space in each bone site (excluding that in longbone shafts) is shallow marrow (50 $\mu \mathrm{m}$ from the trabecular surfaces) compared to the $20 \%$ in the newborn, while between $1.5 \%$ and $5 \%$ of the total medullary cavity volume is shallow marrow compared with $4 \%$ and $14 \%$ in the newborn. By multiplying the SMVF (column 2) by the spongiosa volume, or medullary marrow volume in the case of long bones, volumes of shallow marrow for each bone site were calculated and are listed in column 4 of Table 4-13 and Table 414. Corresponding shallow marrow masses at $100 \%$ cellularity (necessary for specific absorbed fraction calculations) are then given in column 5 of Table 4-13 and Table 4-14. The reference shallow inactive and active marrow masses are provided in columns 7 and 8 in both Table 4-13 and Table 4-14. Shallow active marrow values were determined by multiplying the shallow marrow volumes (column 4) by the reference cellularity and reference active marrow density. Likewise, the shallow inactive marrow masses were determined by multiplying the shallow marrow volume (column 4) by 1-CF and the reference inactive marrow density. In column 9 , the 
total reference shallow marrow mass based on the sum of columns 7 and 8 are listed. The total reference mass of shallow marrow throughout the entire skeleton was calculated to be $352.42 \mathrm{~g}$ for the 15 -year female and $395.34 \mathrm{~g}$ for the 15 -year male as compared to $333.7 \mathrm{~g}$ for the female and $365.2 \mathrm{~g}$ for the male estimated by Watchman et al. (2007). The estimate provided in Watchman et al. (2007) is in fairly good agreement with the image-based shallow marrow data provided in this study, with only $6 \%$ less for the female and $8 \%$ less for the male in the Watchman et al. (2007) study. The last column in Table 4-13 and Table 4-14 show the percent distribution of shallow marrow by bone site. The least amount of shallow marrow is found in the shafts of the long bones, while the greatest is found within the os coxae. This means that the long bone shafts must have fairly large medullary cavities.

\section{$\mathrm{S} / \mathrm{V}$ ratios for 15-year male and female hybrid phantoms}

Table 4-16 shows a comparison of the $\mathrm{S} / \mathrm{V}$ ratios computed for the hybrid newborn phantom (column 2), the gender-independent hybrid 15 year-old (column 3), the ICRP reference 15-year (column 4), and ICRP reference adult 44-year (column 5). The S/V ratio for all long bone shafts is equal to $0.0 \mathrm{~mm}^{2} \mathrm{~mm}^{-3}$ because these regions of the long bones do not contain bone trabeculae. Column 6 lists the ratios between then S/V values for the UF hybrid 15-year skeleton and the ICRP reference 15-year skeletal model. The 15-year in this study can have S/V ratios as low as half up to as much as twice the values reported for the ICRP reference 15-year. The largest difference is seen in the mandible and the largest is seen in the tibia. Compared with the ICRP adult S/V ratios, the image-based data from this study of the 15-year model are in fairly good agreement. This could be due to the fact that the imaging data was taken from an adult, 18year male cadaver. 


\section{Homogeneous spongiosa masses, volumes, densities, and elemental compositions}

Table 4-17 gives a summary of the 15-year female and male hybrid spongiosa masses, volumes and densities including MST for each of the 34 skeletal sites analyzed in this study. Table 4-17 also gives the summed spongiosa mass and volume data for the total skeleton, along with a volumetrically-weighted average spongiosa density for both female and male 15-year skeletal models. It appears that the majority of the 15-year female (487.01 g) and male (440.76

g) spongiosa resides in the os coxae, compared with the cranium for the hybrid newborn in Chapter 2. Similarly, the least amount of spongiosa mass is found in the distal ulna and proximal radius. The total skeleton spongiosa mass and volume were calculated as $3065.38 \mathrm{~g}$ and 2709.78 $\mathrm{cm}^{3}$ for the 15-year female, and $3316.72 \mathrm{~g}$ and $2925.46 \mathrm{~cm}^{3}$ for the 15 -year male skeletons, respectively. Compared with the ICRP 89 reference spongiosa masses of $3037.84 \mathrm{~g}$ for the female (sum of $974.09 \mathrm{~g}$ of TAM, $1250.98 \mathrm{~g}$ of TIM, $72.77 \mathrm{~g}$ of MST, and 740.0 $\mathrm{g}$ of TB), and $3259.93 \mathrm{~g}$ for the male (sum of $1048.04 \mathrm{~g}$ of TAM, $1324.98 \mathrm{~g}$ of TIM, $76.91 \mathrm{~g}$ of MST, and 810.0 g of $T B$ ), the calculated 15-year female and male spongiosa sum is less than $1 \%$ and $2 \%$ higher, respectively. ${ }^{5}$ Similar calculations can be performed with the spongiosa volumes and tissue constituent densities to show that the calculated 15-year female and male spongiosa sum across the skeleton is less than 1\% different that the ICRP 89 reference spongiosa volumes. This almost perfect agreement is directly related to the matched trabecular bone percentage of $20 \%$ in both the image-based data used for the 15-year hybrid and the ICRP reference 15-year skeletons. The agreement in the AM and IM marrow masses between the hybrid and reference skeletal models also contributes to the agreement in spongiosa.

\footnotetext{
${ }^{5}$ Reference spongiosa masses exclude contributions in the long bone shafts since this is not considered spongiosa.
} 
In Table 4-17, the 15-year female and male skeletal-averaged spongiosa density is estimated to be $1.13 \mathrm{~g} \mathrm{~cm}^{-3}$ and $1.12 \mathrm{~g} \mathrm{~cm}^{-3}$, respectively. The male is slightly lower than the female due to larger amounts of IM in the male. In ICRU Report 46, Table A1, the only reference spongiosa density listed is that for the adult, namely $1.18 \mathrm{~g} \mathrm{~cm}^{-3}$. For both the male and female 15 year-old, skeletal site-dependent spongiosa densities range from a low of $1.06 \mathrm{~g}$ $\mathrm{cm}^{-3}$ in the sacrum to a high of $1.25 \mathrm{~g} \mathrm{~cm}^{-3}$ in the cranium (largest proportion of trabecular bone). Despite the density range, the calculated skeletal-averaged spongiosa densities are in good agreement, only $4 \%$ for the female and $5 \%$ for the male lower, compared with the adult reference spongiosa density.

Table A1 of ICRU Report 46 lists reference elemental compositions of trabecular spongiosa, but only for the adult, and only for a fixed mixture of 33\% cortical bone, and 67\% marrow, which itself is comprised of 50\% IM and 50\% $A M$ (all percentages by mass). For comparison, the UF hybrid 15-year male and female contain a mixture of 55\% cortical bone and 45\% marrow, comprised of 56\% IM and 44\% AM. As shown in Table 4-18 (female) and Table 4-19 (male), the spongiosa elemental compositions including MST vary significantly between skeletal sites for some elements. For example, the mass percentage of carbon in the 15-year female cranium spongiosa is about $35 \%$, whereas approximately $63 \%$ is found the shafts of the long bones. Similarly, the shafts of the long bones does not contain any trabecular bone, therefore no Ca is present, compared to about $9 \%$ in the cranium. The total skeleton-averaged spongiosa elemental compositions for the 15 -year male and female are fairly represented by the adult reference spongiosa elemental compositions in ICRU 46.

\section{Homogeneous skeleton masses, volumes, densities, and elemental compositions}

The homogeneous skeleton masses and volumes including MST were calculated and are listed in Table 4-20 for both the female and male 15 year-old adolescent. The data of Table 4-20 
excludes cartilage mass and volume contributions to each bone site. Due to the length of this text, the data for homogeneous bone data including cartilage was not presented, but can be easily computed. Compared with the manually segmented NURBS/polygon mesh 15-year male and female phantoms, the derived total homogenous skeletal volume and mass are matched, which provides validation of the methods presented in this study.

The increased densities of homogeneous bone excluding cartilage compared to that in spongiosa regions is attributed to the contribution of cortical bone in the former. Density differences between site-specific homogeneous bones are similarly explained. The volumetricweighted skeletal averaged homogeneous bone density is $1.35 \mathrm{~g} \mathrm{~cm}^{-3}$ for both the male and female. As seen for bone site-specific spongiosa densities, homogeneous bone densities vary considerably across the newborn skeleton $\left(1.2 \mathrm{~g} \mathrm{~cm}^{-3}\right.$ to $\left.1.6 \mathrm{~g} \mathrm{~cm}^{-3}\right)$. Choosing a density specific to a given skeletal site of interest could provide additional improvements in the accuracy of dose estimates.

Homogeneous bone elemental compositions excluding cartilage for the 15 -year female and male were computed, and are shown in Table 4-21 and Table 4-22, respectively. Elemental data vary considerably across the skeleton. The ICRP reference data and calculated data appear to be in reasonably good agreement, except for the oxygen content, which is approximately $20 \%$ less than reference in absolute difference. Improved agreement is seen when the cartilage component is considered in the elemental composition of total homogeneous bone.

\section{5-Year Female Image Data for the Skeletal Macrostructure and Microstructure}

The voxel resolution and voxel array size for the 15-year female skeletal macrostructure and 18-year male microstructure are shown in the first set of columns in Table 4-23. Due to computer memory limitations large bone sites such as the ribs and os coxae were voxelized at $0.06 \mathrm{~cm}$ and $0.05 \mathrm{~cm}$, respectively, while a small bone site such as the clavicle was voxelized at 
$0.018 \mathrm{~cm}$. However, even at the lowest resolution of $0.06 \mathrm{~cm}$, differences less than $1 \%$ were achieved between the voxel volumes and polygon mesh volumes for the spongiosa and cortical bone tissues. Figure 4-1 A and Figure 4-1B illustrate the original polygon mesh and voxelized os coxae, respectively for the female (left) and male (right), while Figure 4-1 C and Figure 4-1 D illustrate the original and voxelized femur. The last three sets of columns in Table 4-23 are for the skeletal microstructure data obtained after filtering and thresholding the selected ROI for each bone sample. The largest ROI was selected for each microimage in order to obtain the best representative sample of spongiosa for transport. Voxel dimensions, marrow volume fractions $(M V F)$, and trabecular bone volume fractions $(T B V F)$ are all shown. Multiple regions were imaged for the cranium, lumbar vertebra, thoracic vertebra, cervical vertebra, proximal femur, and ribs. The average $M V F$ and $T B V F$ are indicated in Table 4-23 with the corresponding standard deviation. There are skeletal sites listed in the table which do not have a corresponding microimage due to the inability to obtain a sample from these skeletal regions during the bone harvest. As indicated in previously, surrogates for bone sites without microimages were assigned. These surrogates were then used for the microstructure image input into PIRTCartilage and PIRTCartilageLongBone. Finally, as indicated in Table 4-23, both the $M V F / T B V F$ values for the $30 \mu \mathrm{m}$ scan and $60 \mu \mathrm{m}$ re-sampled images are shown. Most relative differences between the $30 \mu \mathrm{m}$ and $60 \mu \mathrm{m}$ samples are less than $1 \%$. Therefore, no statistical difference can be seen between the original $30 \mu \mathrm{m}$ and re-sampled $60 \mu \mathrm{m}$ images.

\section{Bone-Site Dependent Specific Absorbed Fraction Data for the UF Hybrid 15-Year Female Phantom}

Tabular data for the 15-year female specific absorbed fractions are in Appendix H. The corresponding figures for the tabular data are in Appendices I - L. Specific absorbed fractions are calculated based on Chapter 3, Eq. 3-3. As previously mentioned, multiple sample sites from 
the cranium, ribs, lumbar vertebra, thoracic vertebra, femur, humerus, tibia, fibula, ulna, radius and cervical vertebra were transported. Average specific absorbed fraction data was obtained based on the methods in Chapter 3, Eq. 3-3 though Eq. 3-11. Likewise, data for the $C B V$ sources were linearly averaged.

Each of the 20 bone sites is listed as a set of two or three tables: $A M$ targets, $T M_{50}$ targets, and $C A R$ targets (only for intervertebral discs in the vertebrae, ribs, and sternum) for all bone tissue sources. Cellularity dependence for the specific absorbed fractions is only found when the electron source is in $A M$ and at low to intermediate electron energies. In the case of cellularityindependent specific absorbed fractions for the $T B V$, $T B S$, and $C B V$ electron sources, only input microstructures at $100 \%$ cellularity were run. However, for the $I M$ source, $50 \%$ cellularity was arbitrarily chosen for each case run, as was done in Chapter 3 for the newborn. The following sections discuss the specific absorbed fraction results for the three targets: $A M, T M_{50}$ and $C A R$ (intervertebral disc and costal cartilage targets only).

\section{Specific absorbed fractions for an active marrow target from a source in active marrow}

Specific absorbed fractions for electron sources in $A M$ irradiating $A M$ targets are shown in Appendix I based on the tabular data in Appendix H. Similar to the newborn in Chapter 3, this source-target combination exhibits a monotonically decreasing function for both the absorbed fraction and specific absorbed fraction quantities. As the electron energy increases, the electrons will eventually escape out of spongiosa, only depositing a fraction of the initial energy to marrow. The absorbed fraction approaches unity for an electron energy $10 \mathrm{keV}$ and below. Therefore, the corresponding specific absorbed fraction at low electron energies is proportional to the inverse target tissue mass. If the mass of the target tissue, $A M$, is held constant at $100 \%$ cellularity, then a decrease in the fractional cellularity will increase the overall specific absorbed fraction ratio. Once the electron energy has reached approximately $150 \mathrm{keV}$ to $1.5 \mathrm{MeV}$, as 
compared to the newborn energies of $500 \mathrm{keV}$ to $1 \mathrm{MeV}$, depending on the bone site, each curve collapses and becomes cellularity independent. This convergence is achieved once the electron energy has reached the point where a sufficient number of marrow cavities have been crossed and the electron range exceeds the dimensions of the spongiosa region. For low to intermediate electron energies, it is important to asses the accuracy of a marrow cellularity measurement in a patient given a factor of 10 difference in the specific absorbed fraction quantity in the most extreme case. The largest amount of energy deposition to $A M$ from an $A M$ source occurs in the os coxae compared to the newborn cranium, and least amount in the mandible as compared to the patella in the newborn, directly proportional to the amount of active marrow in these bone regions. SAF results at the ICRP reference cellularity are shown in the tables of Appendix H. Again, a linear average of the $S A F$ data at the transported cellularities was performed to compute the $S A F$ results at the ICRP reference cellularity.

As described in the methods section of this chapter, the long bones were run with the same cellularity across all regions for the incremental cellularity case runs. Both proximal and distal microstructure image data is available for these bone sites, but the transport code does not currently accept two microstructures due to memory constraints. Similarly to other bone sites, two sets of $A F$ data were computed. The first set was based on the proximal microstructure being placed in both proximal and distal spongiosa regions, and the second set was based on the distal microstructure being placed in the proximal and distal spongiosa regions. Similar to the methods in Chapter 3, for the incremental cellularity data, the averaged specific absorbed fractions were computed based on the mass fractional source distributions. However, the fractional source distributions for the proximal microstructure were based on the mass of the proximal and upper shaft source mass compared to the whole long bone source mass. Similarly, 
the fractional source distribution of the distal microstructure was based on the mass of the distal and lower shaft source mass compared to the entire mass of the source in the long bone. Consequently, the averaged absorbed fraction data has a higher weighting toward the higher fractional source mass.

A separate case run was performed for the ICRP reference long bones due to cellularity variations across the proximal, shaft, and distal regions. However, for the tibia, fibula, ulna and radius, the reference $A M$ mass is $0.0 \mathrm{~g}$. Therefore, the ICRP reference $S A F$ for an $A M$ target from an $A M$ source is 0.0 . The humerus and femur have different cellularity values for each region (55\% proximal, 35\% upper shaft, 20\% lower shaft, and 0\% distal). Therefore, the upper half (proximal and upper shaft) and lower half (lower haft and distal) were run separately for the two cases. Averaged results were again based on the fractional source contributions, but of the reference masses for the ICRP cellularity. Unfortunately, by running upper and lower half of the femur and humerus separately, cross-fire between then shaft regions is not neglected. A simple analysis was performed running the upper (with proximal microstructure) and lower (with distal microstructure) half of the humerus for a $100 \%$ cellularity case for an $A M, T B V, T B S$, and $C B V$ source to $A M$ target. $A F$ results from these two runs were then mathematically averaged as discussed above. These results were then compared with the averaged AF results from a full long bone run at $100 \%$ cellularity with the averaged proximal and distal microstructures. Neglecting cross-fire for an $A M$ source creates approximately 9.5\% difference for a $10 \mathrm{MeV}$ electron. This is the worst case scenario, as the lower half of the long bone does not contain as much $A M$ source mass as in the upper half. For a $C B V$ source, neglecting cortical bone cross fire between shaft regions into AM causes up to a 9\% difference at low to intermediate electron energies. Again, this is the maximum difference that would be seen, since ICRP reference 
cellularity in the shafts is less than $100 \%$. For the $T B V$ and $T B S$ sources, less than $5 \%$ difference is seen due to the fact that these sources are exclusively contained in the proximal and distal ends. Based on the CSDA range of approximately $10 \mathrm{~cm}$, a $10 \mathrm{MeV}$ electron in soft tissue will not cross the $9.8 \mathrm{~cm}$ shaft length unless the particles are starting close to the proximal/distal/shaft interface.

\section{Specific absorbed fractions for an active marrow target from all other bone sources}

Similarly to Appendix I, the specific absorbed fraction figures in Appendix $\mathrm{J}$ are for $A M$ targets, but from an $I M, T B S, T B V$, or $C B V$ source. As shown in Figure 3-2 in Chapter 3, the specific absorbed fractions for these sources are cellularity independent. As such, these sources were run at $100 \%$ cellularity, except in the case of the $I M$ source, which was run at an arbitrarily chosen $50 \%$ cellularity. As previously discussed, for a TBS source, $50 \%$ of the time electrons are emitted toward the marrow cavity, and $50 \%$ of the time electrons are emitted toward the trabecular bone. Therefore, the specific absorbed fraction for a TBS source to AM target is 50\% the product of the inverse target tissue mass at $100 \%$ cellularity and the $C F$ at low electron energies, or $50 \%$ of the specific absorbed fraction value for an $A M$ source to $A M$ target at the ICRP 15-year female site-specific reference cellularity. The addition of the $C F$ term in the denominator explains the larger difference in the 15-year female SAF data between the ICRP reference $A M$ source and $T B S$ source to $A M$ target compared with the newborn. Finally, similarly to the $A M$ source and target cellularity independence at high electron energies, the $T B S$, $T B V$, and $I M$ sources begin to converge at electron energies between $420 \mathrm{keV}$ and $3 \mathrm{MeV}$. Therefore, source independence occurs at these energies because the electrons have traveled through a large enough number of marrow cavities and space to effectively results in the same energy deposition. 
Energy deposition from an $I M$ and $T B V$ source continues to increase as electron energy increases until the electron energy reaches the point of electron escape out of spongiosa, as shown in the figures by the mound-shaped trend. A similar response is seen in the $C B V$ source. Electrons with enough energy will escape the cortical bone region and deposit energy into spongiosa, then exit the spongiosa once the energy corresponding to the spongiosa thickness has been reached, which causes a decrease in the energy deposition. Therefore, the lower the electron energy corresponding to the maximum energy deposition for a $C B V$ source, the thinner the cortical bone region. At a peak energy deposition of $4.0 \mathrm{MeV}$, the femur has the thickest cortical bone, probably as a result of the thick cortical shaft region, compared to $2.0 \mathrm{MeV}$ peak for the newborn femur. Similarly, the thinnest cortical bone can be found in the vertebrae, at a peak energy of $1.5 \mathrm{MeV}$, compared to the newborn patella at $0.5 \mathrm{MeV}$. Table 4-24 lists measured bone site-specific cortical bone thicknesses for the UF hybrid 15-year female phantom. These were estimated using the measurement tool in Rhinoceros ${ }^{\mathrm{TM}}$. For the $C B V$ source, the dosimetry results exactly correlate with measured cortical bone thickness. For an IM source the peak energy deposition occurs at a constant $80 \mathrm{keV}$ to100 $\mathrm{keV}$. This corresponds to the maximum distance an electron travels to reach the spongiosa boundary. For a $T B V$ source, the thickness of bone trabeculae, marrow cavity size, and $A M$ mass in combination determine the electron energy where maximum energy deposition occurs.

\section{Specific absorbed fractions for a shallow marrow target from all bone sources}

As reported for the newborn in Chapter 3, results for the $50-\mu \mathrm{m}$ target region definition are reported as total shallow marrow or $T M_{50}$. Appendix $\mathrm{K}$ illustrates the specific absorbed fractions from a source in $A M$ at reference cellularity, $I M, T B V, C B V$, and $T B S$ to target $T M_{50}$. As with previous results, these sources are cellularity independent, and therefore run at 100\% cellularity, except for the IM source, which was run with 50\% cellularity, as shown in Figure 4-2 A through 
Figure 4-2 D. Source independence occurs for the IM (at 50\% cellularity), and AM (at ICRP reference cellularity) sources, but not for the TBS source as was seen in the newborn. As was shown in Eq. 3-8 ad Eq. 3-9 in Chapter 3, the $A F$ and SAF data for an $A M$ source to $T M_{50}$ target is proportional to the $S M V F$ and ratio of the $S M V F$ and $T M_{50}$ target mass, respectively. For the newborn, the SMVF was approximately $50 \%$ for most bone sites. Therefore, since the AF data for the $T B S$ source to $T M_{50}$ target is also approximately $50 \%$ at low energies, the $T B S$ source also becomes source independent and converges with the AM and IM sources. However, for the 15year female, the SMVF values are less than 50\% (range between 5\% - 22\%), which means the IM and $A M$ sources will have source convergence, but at a value less than the TBS source. For example, the lumbar vertebra, cranium, and sacrum have a SMVF of approximately $0.14,0.20$, and 0.08 , respectively. After dividing by the shallow marrow mass for each bone site, the values become $0.005,0.004$, and 0.008 , respectively. The specific absorbed fraction results, as reported in Appendix $\mathrm{H}$ for $1 \mathrm{keV}$ are approximately 0.005, 0.006, and 0.008, respectively. The other skeletal sites follow this same pattern of cellularity independence

For a $T B V$ source, the source independence occurs between $150 \mathrm{keV}$ and $1.5 \mathrm{MeV}$, depending on the bone site, compared with $200 \mathrm{keV}$ to $700 \mathrm{keV}$ for the newborn in Chapter 3. The electron must have enough energy to exit the trabecular bone volume. Consequently, as with previous discussion, the convergence occurs at the electron energy for which the source particle has traversed enough marrow cavities to effectively deposit the same energy whether the particle began in $T B V, T B S, A M$, or $I M$.

\section{Specific absorbed fractions for a cartilage target from all bone sources}

Similar to the newborn, cellularity independence is shown for the AM source in Figure 4-3 A through Figure 4-3 D. Unlike the newborn, where every bone contains an ossification center surrounded by cartilage, the 15-year female is completely ossified except the sternum. 
Therefore, only CAR targets in the intervertebral discs, sternum, and costal regions are considered. Appendix L illustrates the specific absorbed fraction results by bone site for sources starting in $A M$ (at reference cellularity) $I M, T B S, T B V$, or $C B V$ sources depositing energy in the $C A R$ target. Electron sources in AM (ICRP reference cellularity), TBS, IM, and $T B V$ are source independent for the specific absorbed faction quantities. Electrons need enough energy to traverse the entire spongiosa and cortical bone regions to deposit any energy in the target cartilage region, regardless of the particle source.

The $C B V$ source converges with sources in cervical vertebrae and rib spongiosa, $A M, I M$, $T B S$, and $T B V$. As previously discussed, there reaches a point where the electron energy is source is high enough that regardless of the source, the same amount of energy is going to be deposited. However, for the thoracic vertebrae and lumbar vertebrae the sources in spongiosa deposit more electron energy into a $C A R$ target. This is due to the fact that these bones are not completely surrounded by a cartilage layer like in the newborn. The vertebrae are completely ossified by 15 years of age and do not contain a uniform cartilage layer. More energy deposition occurs from sources in spongiosa at higher energies due to cross-fire, which is why the energy deposition from spongiosa exceeds the $C B V$ at higher energies. Contributions of cross-fire for a CBV source occur at the intermediate electron energies. Convergence is expected to occur when the electron energy from sources in spongiosa significantly exceed the overall dimensions of the spine to avoid cross-fire dependence. The cervical spine converges due to the relative size compared with the thoracic and lumbar spine regions. The sternum appears to needs higher electron energy for convergence to occur. 


\section{Skeletal-Averaged Absorbed Fraction Comparisons for the UF Hybrid 15-Year Female Phantom and the 2003 15-Year Model}

The current Stabin and Siegel (2003) model does not contain absorbed fraction data by skeletal site. Instead, skeletal-averaged absorbed fraction data based on skeletal tissue masses tied to the ORNL stylized phantom are reported. Calculations of the skeletal-averaged absorbed fraction values are based on the formulations in Chapter 3. Values of $f_{s, i}$ are listed in Table 4-25, along with the ICRP reference cellularity by bone site for the 15-year female. Tabular data of the skeletal-averaged absorbed fraction data for the 15-year female are listed in Table 4-26. Figures 4-4 A-D illustrate the tabular data found in Table 4-26. For a TBS source to AM target, the PIRT skeletal-averaged absorbed fraction data are approximately $2 \%$ to $5 \%$ less than the 2003 model up to $100 \mathrm{keV}$. Between $100 \mathrm{keV}$ and $1 \mathrm{MeV}$, there is approximately 4\% to $15 \%$ difference between the two models. After $1 \mathrm{MeV}$, electron escape dominates the physics, and by $10 \mathrm{MeV}$ the infinite 2003 model overestimates the energy deposition to $A M$ by almost 4.0 times, assuming the infinite results for the $4 \mathrm{MeV}$ can be extended to $10 \mathrm{MeV}$. Similarly, the $2003 \mathrm{TBV}$ source for the 15 year-old overestimates between approximately $5 \%$ to $20 \%$ in the low to intermediate electron energy range due to the microstructural differences. Overestimations in the 2003 model due to the macrostructure occur after $500 \mathrm{keV}$, up to 3.98 times at $10 \mathrm{MeV}$. For an $A M$ source, the divergence begins at approximately $15 \mathrm{keV}$ to $1 \mathrm{MeV}$. Underestimations due to using 2D chord distributions from 9-year microstructural data for a 15 year-old in the 2003 model can be as high as $12 \%$. At electron energies above $1 \mathrm{MeV}$, the models diverge due to the PIRT modeling of electron escape from the macrostructure compared to the infinite transport modeling in the 2003 model. For comparison, newborn divergence due to electron escape begins at $400 \mathrm{keV}$ due to smaller bones. As before, extending the 2003 results out to $10 \mathrm{MeV}$ can show up to 3.5 times more energy deposition that in the PIRT model compared to 17.5 times in the 
newborn. In the 2003 model, energy deposition from a $C B V$ source to $A M$ target is zero. However, the skeletal-averaged PIRT model shows up to $6 \%$ energy deposition at $2 \mathrm{MeV}$, compared with $11 \%$ at $800 \mathrm{keV}$ for the newborn. Tabular results for $T M_{50}$ targets are reported, but are not compared with the 2003 model. As with the newborn, a fair comparison cannot be made between the two models because a $10-\mu \mathrm{m}$ endosteal layer of active marrow was utilized in the 2003 model, while a 50- $\mu \mathrm{m}$ shallow marrow target region of the summed active and inactive marrow was used in PIRT.

The current 2003 model uses overall cortical and trabecular bone percentages of $80 \% / 20 \%$, respectively. These percentages were confirmed in the study for the 15 -year male and female. Assuming a uniform mineral bone source (cortical bone plus trabecular bone), Figure 45 compares the skeletal-averaged absorbed fraction results between the 2003 model and PIRT model using a weighted cortical/trabecular bone percentage of $80 \% / 20 \%$. The 2003 model underestimates the energy deposition from electron sources in $M B$ to targets in $A M$ up to $25 \%$ for electron energies up to $4 \mathrm{MeV}$. Once electron escape is accounted for, the 2003 model overestimates the skeletal-averaged absorbed fraction by 1.65 times at $10 \mathrm{MeV}$. All differences are due to both the exclusion of cortical bone as a source and differences in the trabecular microstructure used in the 2003 model.

\section{Conclusions}

In this study, comprehensive skeletal tissue models were developed for the UF hybrid reference 15-year male and female. The model includes bone-specific masses and volumes of all relevant tissue components including active marrow, inactive marrow endosteal tissues, trabecular bone, cortical bone, miscellaneous skeletal tissues, and cartilage. Site-specific and skeletal-averaged tissue densities and elemental compositions are also derived. Model data sources included CT images of whole-cadaver 18-year male skeleton, along with the 
corresponding microCT images of the 18 -year male bone specimens. In this study, the 18 -year image sets served as surrogate data for the 15 -year male and female skeleton.

The site-specific distribution of active and inactive marrow compare reasonably well with that given for the reference 15-year male and female in ICRP Publication 89. In ICRP Publication 89,15 -year total mineral bone is partitioned as $20 \%$ trabecular and $80 \%$ cortical values accepted as averaged across the adult skeleton. In the present model, analysis of 18 -year whole-cadaver $\mathrm{CT}$ images and microCT images reveal the same percentage. These values, however, vary from $50 \%$ cortical and $50 \%$ trabecular to $90 \%$ cortical and $10 \%$ trabecular across the 15-year male and female skeletons, and thus a single skeletal-averaged value can be misleading when looking at a particular skeletal region. The 15-year male and female skeletal tissue model permits a sub-segmentation of the homogeneous bones in the UF hybrid 15-year male and female phantom into specific regions of cortical bone, spongiosa, and medullary marrow.

Similarly to the newborn, the results in this chapter show the importance of source-target combinations in terms of cellularity independence and source independence as a function of electron energy for specific absorbed fraction data. $I M, T B V, C B V$, and $T B S$ sources to $A M$ targets are all cellularity independent. Depending on the bone site, source independence from $I M, T B V$, and $T B S$ sources to $A M$ and $T M_{50}$ targets occurs at high electron energies. Cellularity independence also exists for an $A M$ source to $T M_{50}$ targets. Convergence of the various cellularity curves from $A M$ sources to $A M$ targets, depending on the bone site, occurs between $150 \mathrm{keV}$ and 1.5 MeV. Results also show relative thickness of spongiosa and cortical bone based on the energy for peak deposition. Therefore, it is often useful to analyze skeletal site- 
specific data variations, especially when exposing a certain region of the body to radiation (e.g. CAP exam).

When comparing skeletal-averaged absorbed fraction data for an $A M, I M, T B V$, or $T B S$ source to any target, the differences between then PIRT and 2003 models differ at low to intermediate electron energies due to microstructural differences between the 18-year 3D model in this study and the 9-year 2D chords used in the 2003 model, and consistently overestimates at energies greater than $4 \mathrm{MeV}$ due to electron escape. Microstructural differences between the newborn and the 2003 model are not as significant because 1.7-year data was used. Electron escape becomes significant after $1 \mathrm{MeV}$ for the 15 -year female, compared with $400 \mathrm{keV}$ for the newborn due to the size differences. Future studies will analyze any significant differences in electron escape between the 15-year male and female skeletal macrostructures. 


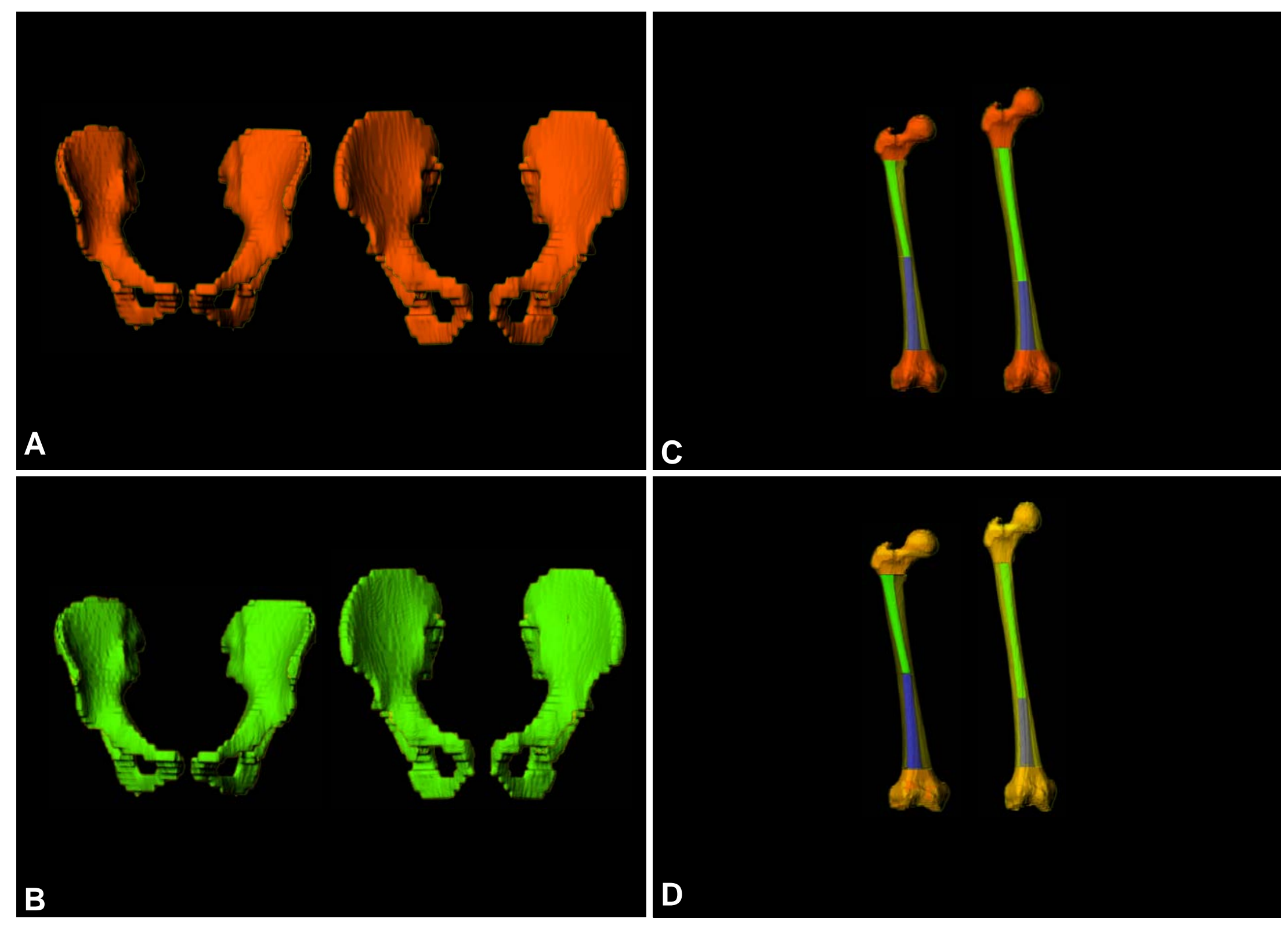

Figure 4-1. Comparison between the original rendered polygon mesh and segmented voxelized 15-year male (right) and 15-year female (left) (A) polygon mesh os coxae, (B) voxelized os coxae, (C) polygon mesh femur, and (D) voxelized femur. 

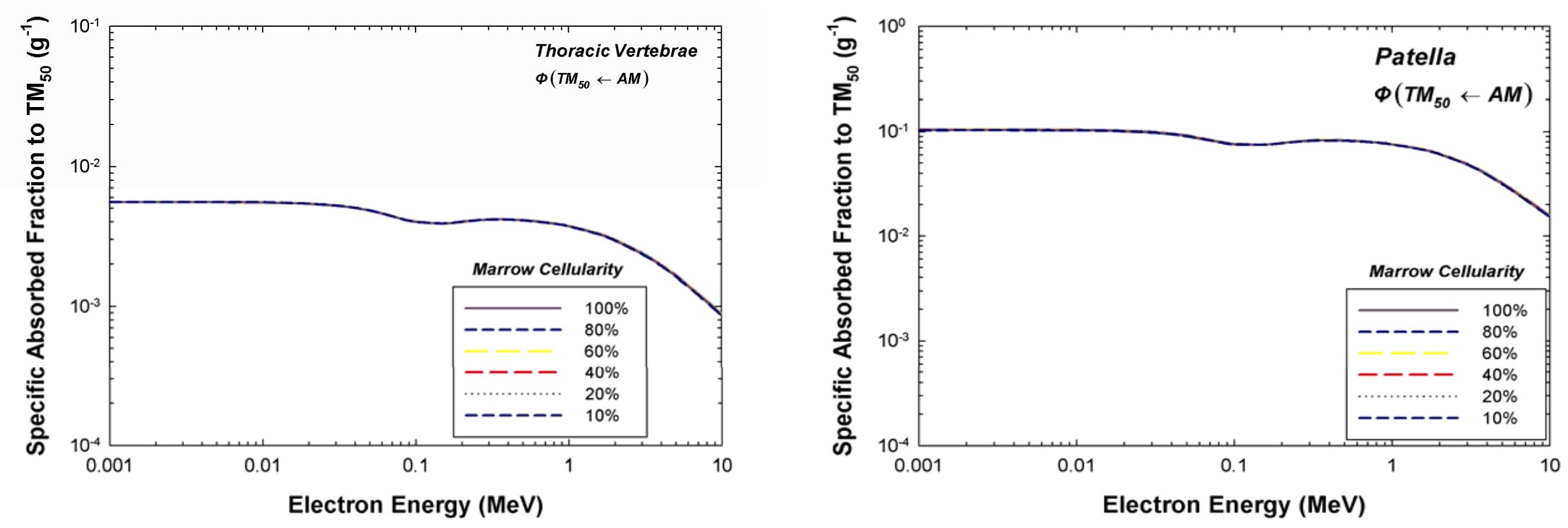

A

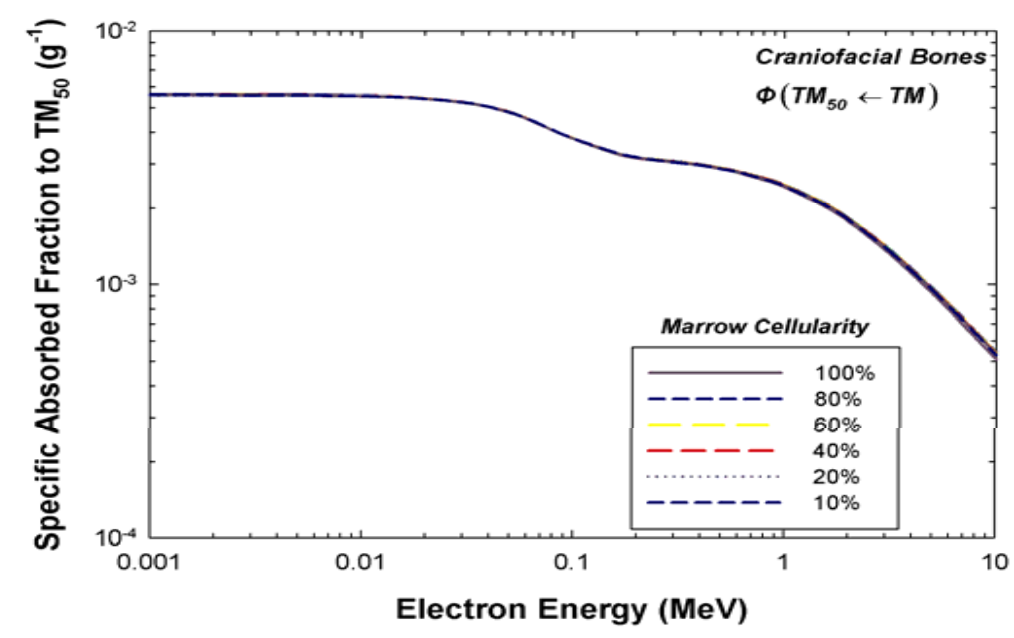

C

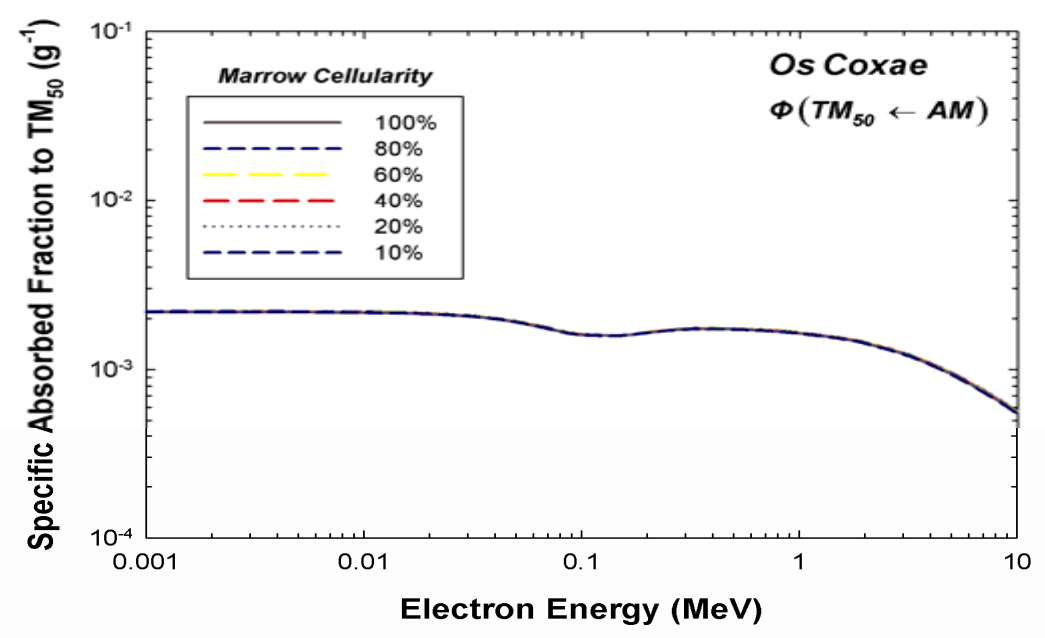

D

Figure 4-2. 15-year female specific absorbed fraction data from an $A M$ source to a $T M_{50}$ target at various cellularities for the (A) thoracic vertebrae, (B) patella, (C) craniofacial bones, and (D) os coxae. 


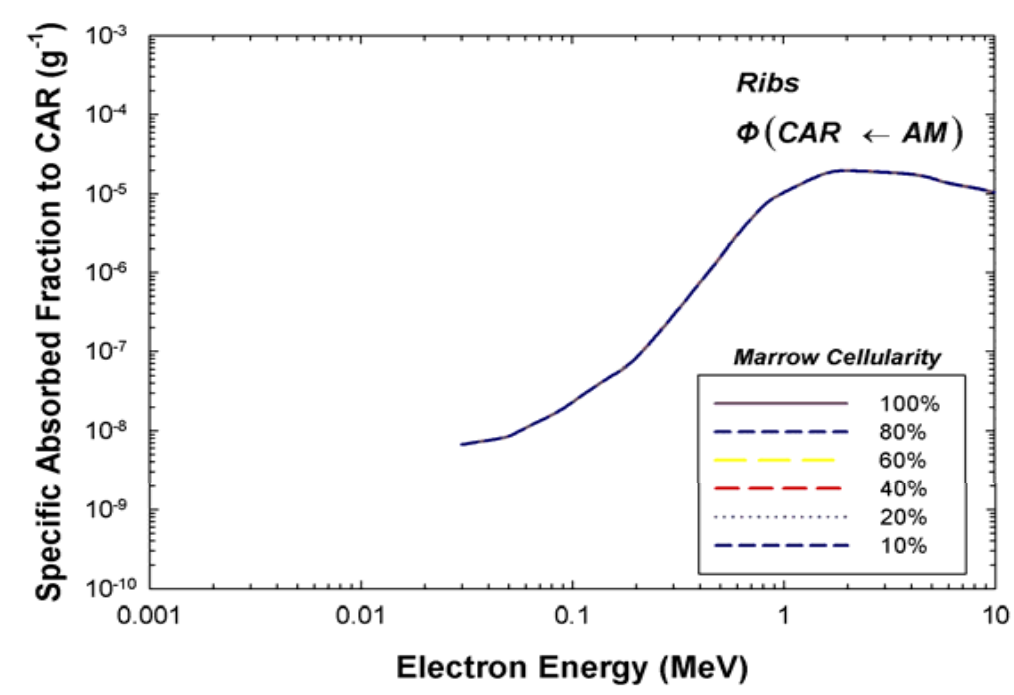

A

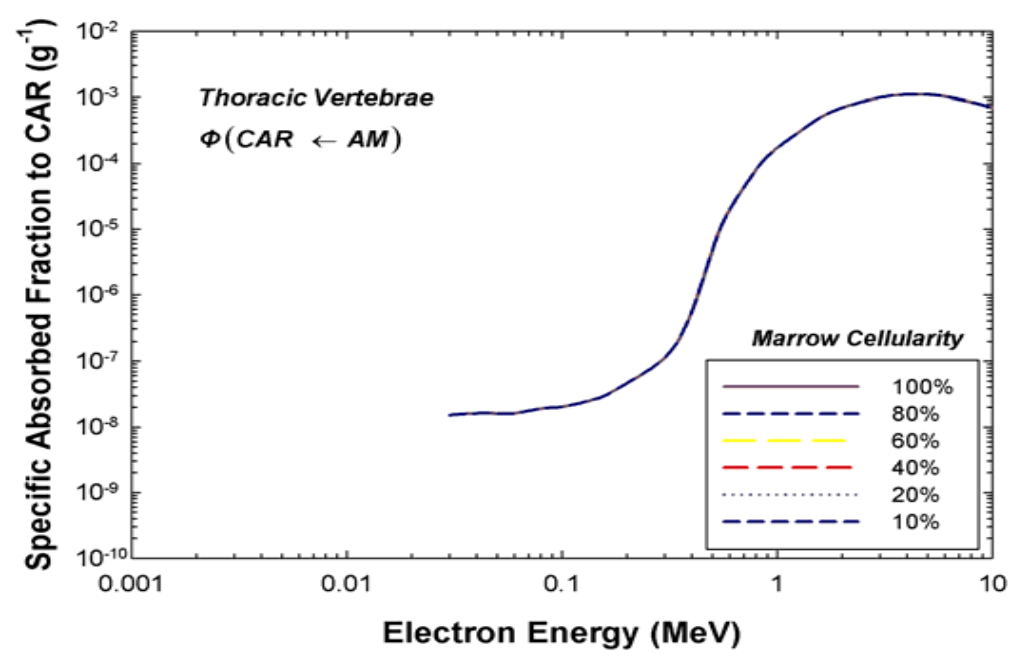

C

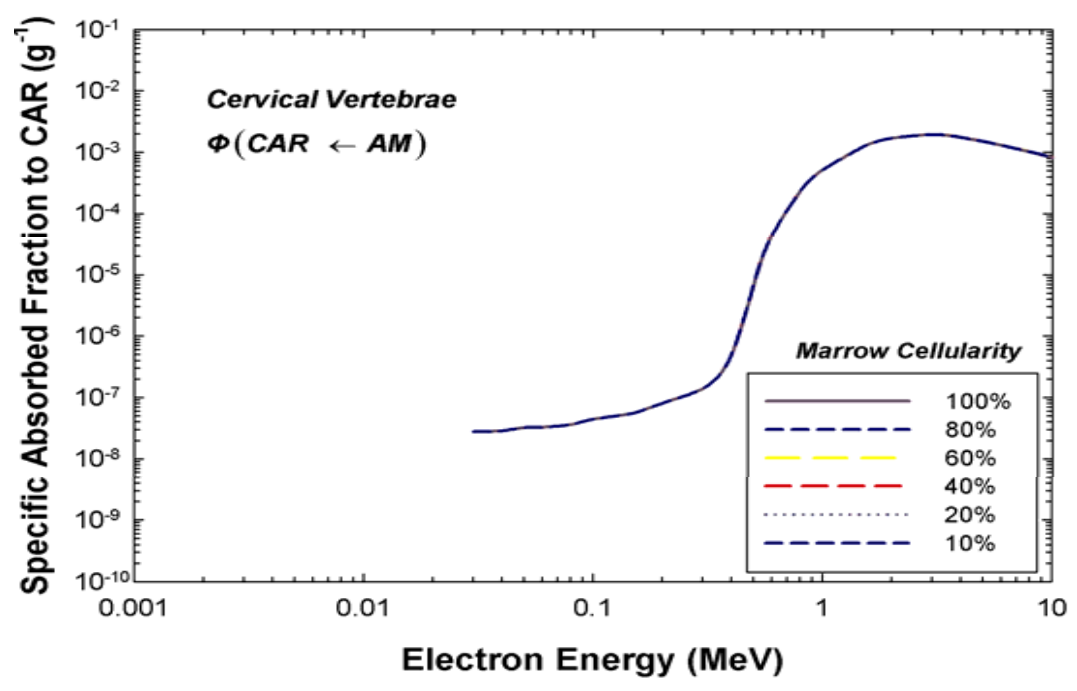

B

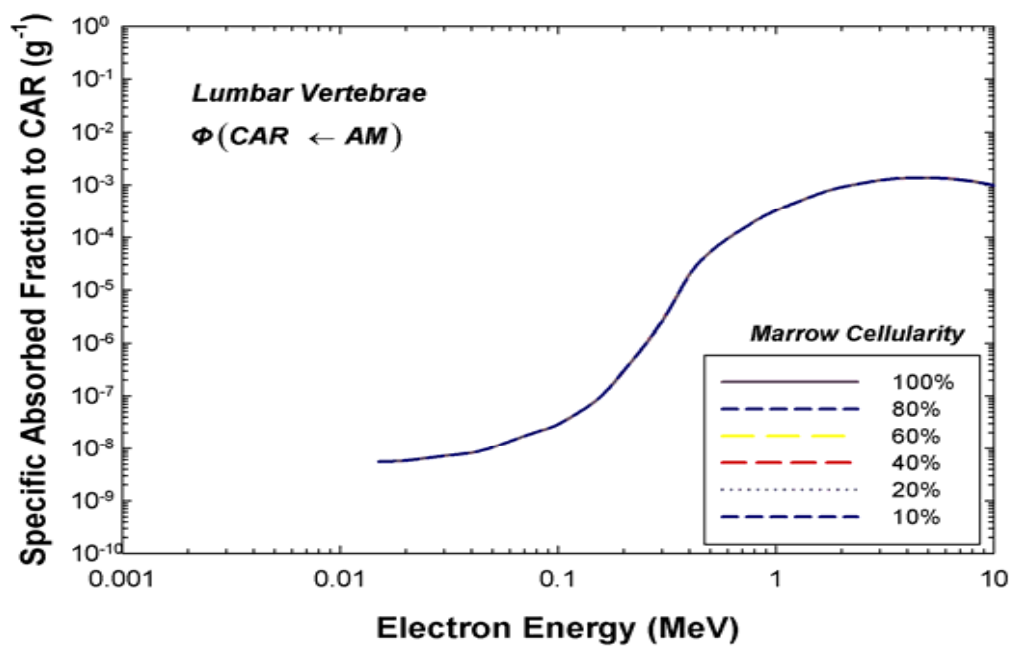

D

Figure 4-3. 15-year female specific absorbed fraction data from an AM source to a CAR target at various cellularities for the A) ribs, B) cervical vertebrae, C) thoracic vertebrae, and D) lumbar vertebrae. 


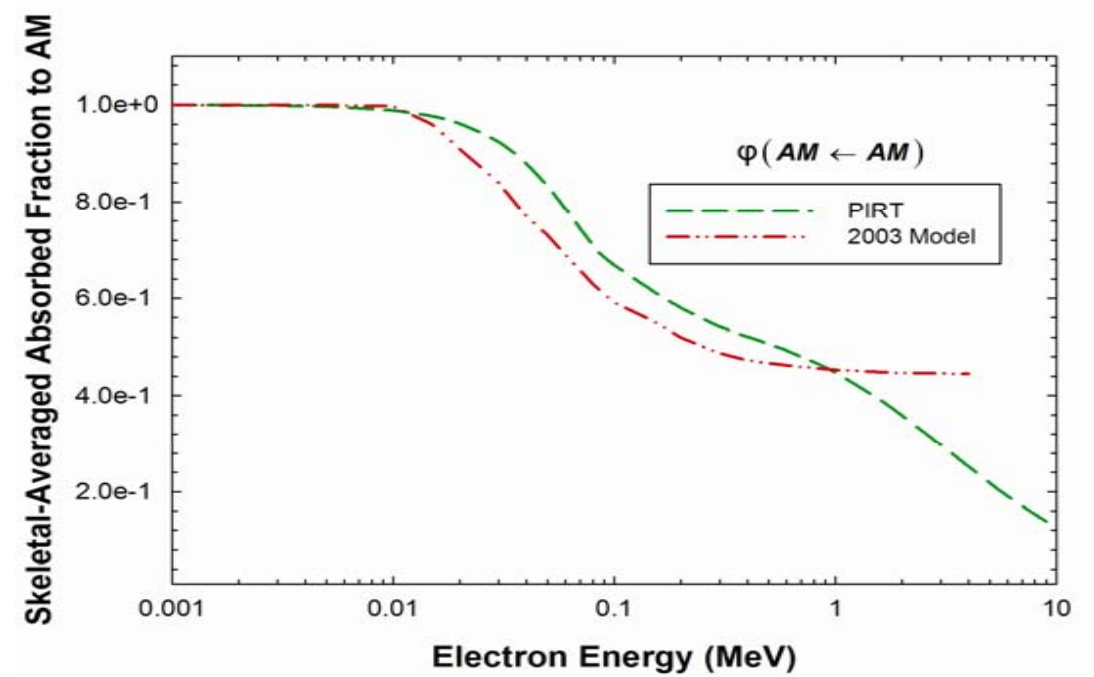

A

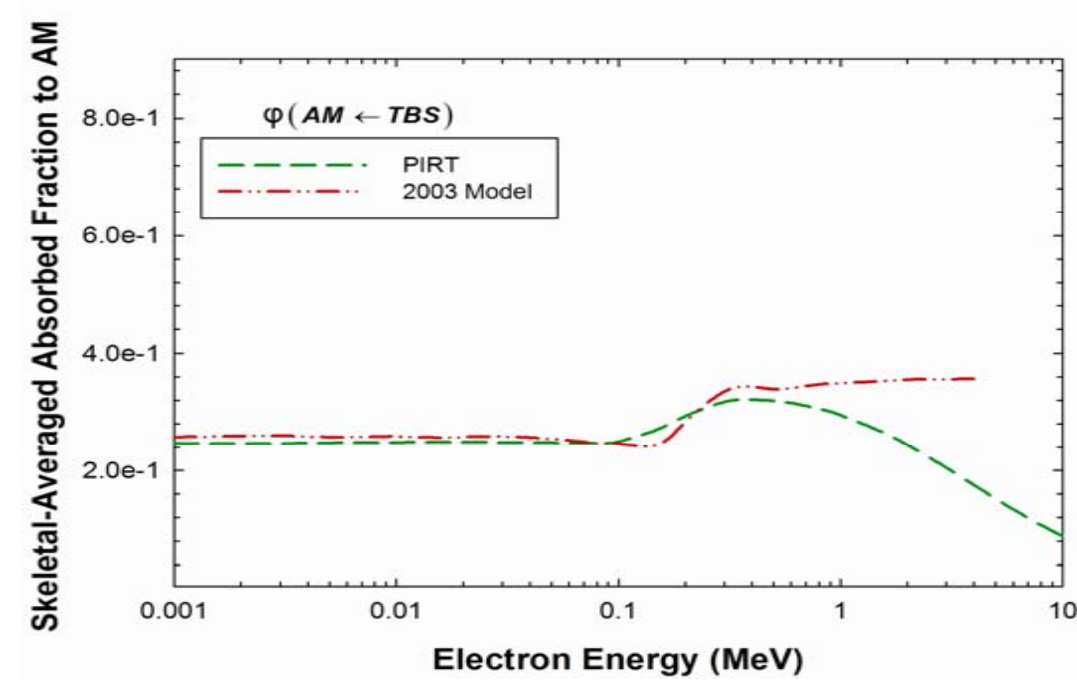

C

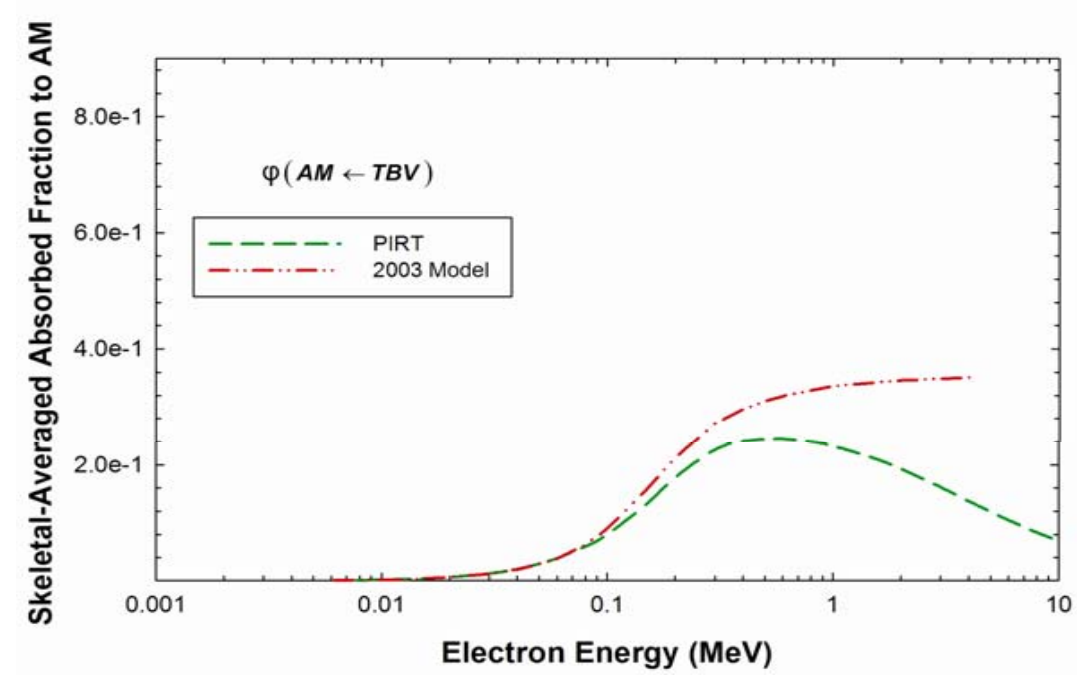

B

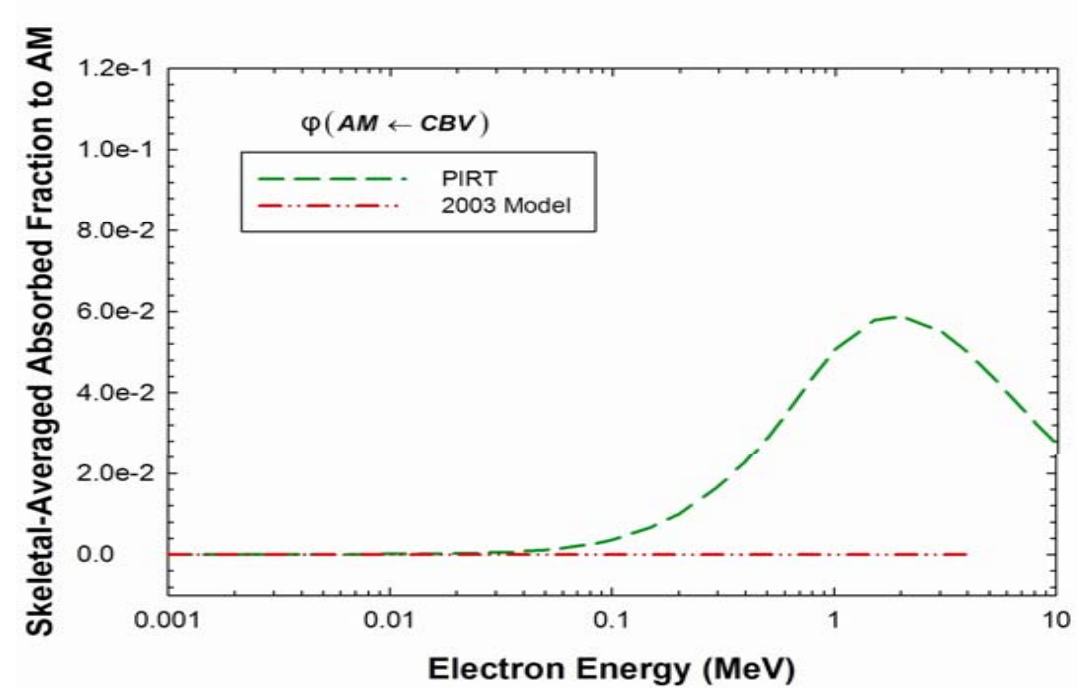

D

Figure 4-4. Comparison between the 2003 and PIRT 15 year-old female skeletal-averaged absorbed fraction data to an AM target at ICRP reference cellularity for the A) AM source, B) $T B V$ source, C) $T B S$ source, and D) $C B V$ source. 


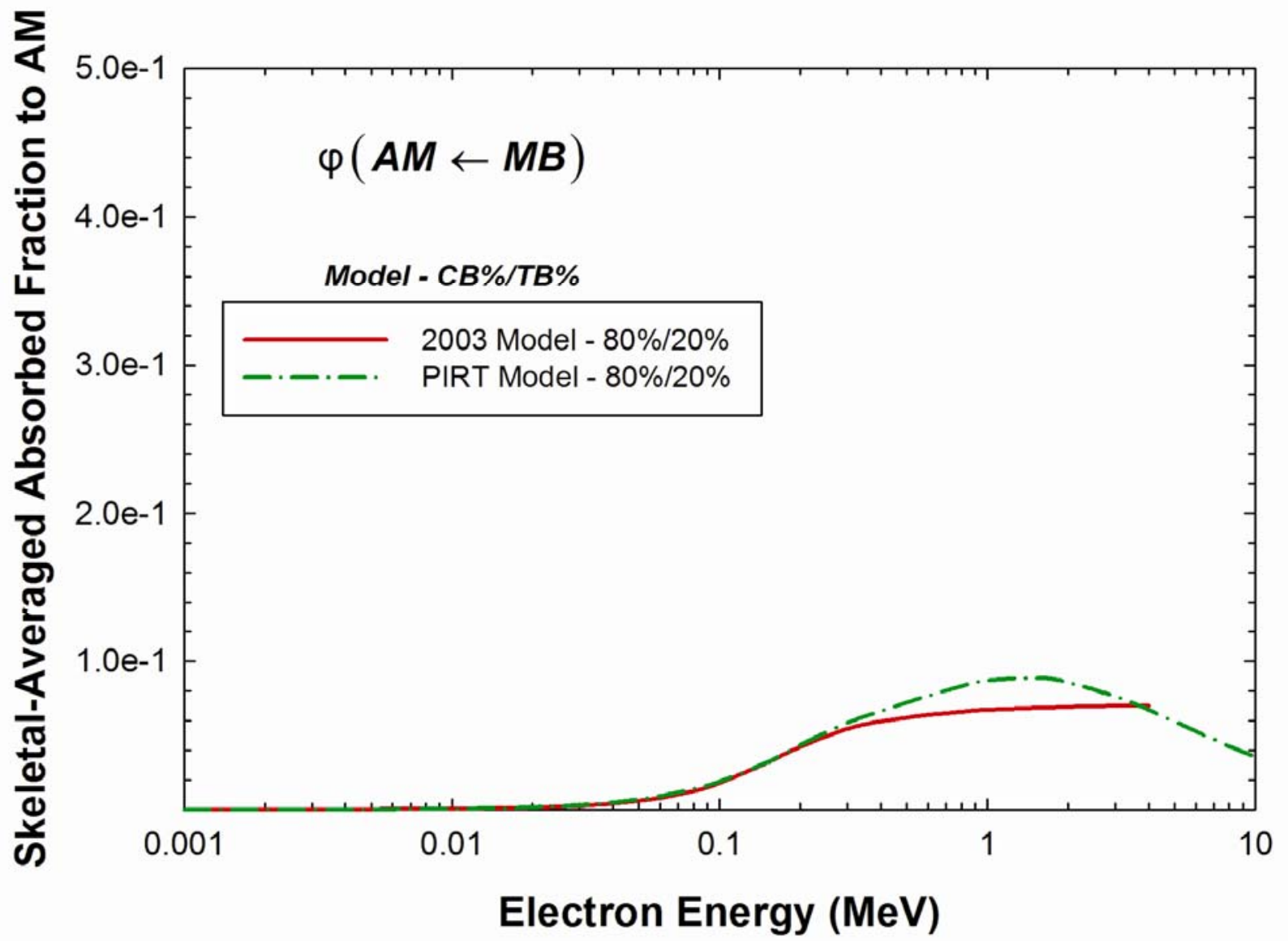

Figure 4-5. Comparison between the 2003 and PIRT 15 year-old female skeletal-averaged absorbed fraction data to an $A M$ target at ICRP reference cellularity from the mineral bone $(M B)$ source at $80 \%$ cortical and $20 \%$ trabecular bone. 
Table 4-1. Bone volumes given in the hybrid-NURBS/PM models and in the reconstructed hybrid-voxel models of the 15-year female (left) and male (right) skeletons for (1) the combined tissues of cortical bone and trabecular spongiosa, (2) outer layers of bone-associated cartilage, and (3) total volume of all tissues.

\begin{tabular}{|c|c|c|c|c|c|c|}
\hline \multirow[b]{2}{*}{ Skeletal Site } & \multicolumn{3}{|c|}{ Polygon Mesh/NURBS Volumes - Female } & \multicolumn{3}{|c|}{ Polygon Mesh/NURBS Volumes - Male } \\
\hline & $\begin{array}{c}\text { Cortical Bone }+ \\
\text { Spongiosa } \\
\left(\mathrm{cm}^{3}\right)\end{array}$ & $\begin{array}{c}\text { Cartilage } \\
\text { Bone-Associated } \\
\left(\mathrm{cm}^{3}\right) \\
\end{array}$ & $\begin{array}{c}{ }^{1} \text { Total } \\
\text { Homogeneous Bone } \\
\left(\mathrm{cm}^{3}\right)\end{array}$ & $\begin{array}{c}\text { Cortical Bone }+ \\
\text { Spongiosa } \\
\left(\mathrm{cm}^{3}\right)\end{array}$ & $\begin{array}{c}\text { Cartilage } \\
\text { Bone-Associated } \\
\left(\mathrm{cm}^{3}\right) \\
\end{array}$ & $\begin{array}{c}{ }^{1} \text { Total } \\
\text { Homogeneous Bone } \\
\left(\mathrm{cm}^{3}\right)\end{array}$ \\
\hline Cranium & 521.74 & 0.00 & 521.74 & 635.40 & 0.00 & 635.40 \\
\hline Mandible & 46.74 & 0.00 & 46.74 & 59.01 & 0.00 & 59.01 \\
\hline${ }^{1}$ Cervical & 75.77 & 0.00 & 79.63 & 60.47 & 0.00 & 63.38 \\
\hline${ }^{1}$ Thoracic & 226.16 & 0.00 & 254.69 & 250.64 & 0.00 & 283.41 \\
\hline${ }^{1}$ Lumbar & 237.23 & 0.00 & 263.97 & 216.64 & 0.00 & 240.13 \\
\hline${ }^{1}$ Sternum & 31.41 & 32.17 & 63.58 & 45.21 & 28.49 & 73.70 \\
\hline${ }^{1,2}$ Ribs & 266.19 & 0.00 & 322.24 & 244.50 & 0.00 & 295.32 \\
\hline Scapulae & 198.99 & 0.00 & 198.99 & 144.73 & 0.00 & 144.73 \\
\hline Clavicles & 52.13 & 0.00 & 52.13 & 39.89 & 0.00 & 39.89 \\
\hline Os coxae & 564.83 & 0.00 & 564.83 & 507.30 & 0.00 & 507.30 \\
\hline Sacrum & 165.40 & 0.00 & 165.40 & 135.42 & 0.00 & 135.42 \\
\hline Humeri, Proximal & 124.31 & 0.00 & 124.31 & 156.31 & 0.00 & 156.31 \\
\hline Humeri, Upper Shaft & 63.58 & 0.00 & 63.58 & 78.56 & 0.00 & 78.56 \\
\hline Humeri, Lower Shaft & 55.49 & 0.00 & 55.49 & 69.79 & 0.00 & 69.79 \\
\hline Humeri, Distal & 75.07 & 0.00 & 75.07 & 94.85 & 0.00 & 94.85 \\
\hline Radii, Proximal & 11.64 & 0.00 & 11.64 & 15.34 & 0.00 & 15.34 \\
\hline Radii, Shaft & 42.43 & 0.00 & 42.43 & 47.71 & 0.00 & 47.71 \\
\hline Radii, Distal & 21.25 & 0.00 & 21.25 & 28.03 & 0.00 & 28.03 \\
\hline Ulnae, Proximal & 39.98 & 0.00 & 39.98 & 51.38 & 0.00 & 51.38 \\
\hline Ulnae, Shaft & 50.45 & 0.00 & 50.45 & 58.23 & 0.00 & 58.23 \\
\hline Ulnae, Distal & 7.27 & 0.00 & 7.27 & 9.54 & 0.00 & 9.54 \\
\hline Wrists and Hands & 102.51 & 0.00 & 102.51 & 124.46 & 0.00 & 124.46 \\
\hline Femora, Proximal & 177.45 & 0.00 & 177.45 & 231.67 & 0.00 & 231.67 \\
\hline Femora, Upper Shaft & 126.58 & 0.00 & 126.58 & 172.52 & 0.00 & 172.52 \\
\hline Femora, Lower Shaft & 143.03 & 0.00 & 143.03 & 131.36 & 0.00 & 131.36 \\
\hline Femora, Distal & 240.98 & 0.00 & 240.98 & 270.05 & 0.00 & 270.05 \\
\hline Patellae & 25.32 & 0.00 & 25.32 & 31.29 & 0.00 & 31.29 \\
\hline Tibiae, Proximal & 190.51 & 0.00 & 190.51 & 219.28 & 0.00 & 219.28 \\
\hline Tibiae, Shaft & 167.83 & 0.00 & 167.83 & 201.16 & 0.00 & 201.16 \\
\hline Tibiae, Distal & 69.17 & 0.00 & 69.17 & 80.32 & 0.00 & 80.32 \\
\hline Fibulae, Proximal & 15.75 & 0.00 & 15.75 & 20.03 & 0.00 & 20.03 \\
\hline Fibulae, Shaft & 24.78 & 0.00 & 24.78 & 34.18 & 0.00 & 34.18 \\
\hline Fibulae, Distal & 15.17 & 0.00 & 15.17 & 19.32 & 0.00 & 19.32 \\
\hline Ankles and Feet & 366.55 & 0.00 & 366.55 & 458.56 & 0.00 & 458.56 \\
\hline Cranial Cartilage & N/A & 0.00 & 0.00 & N/A & 0.00 & 0.00 \\
\hline Costal Cartilage & $\mathrm{N} / \mathrm{A}$ & 56.06 & 56.06 & N/A & 50.82 & 50.82 \\
\hline CV Intervertebral Discs & N/A & 3.86 & 3.86 & N/A & 2.91 & 2.91 \\
\hline TV Intervertebral Discs & $\mathrm{N} / \mathrm{A}$ & 28.53 & 28.53 & N/A & 32.77 & 32.77 \\
\hline LV Intervertebral Discs & $\mathrm{N} / \mathrm{A}$ & 26.73 & 26.73 & N/A & 23.49 & 23.49 \\
\hline Total Skeleton $\left(\mathrm{cm}^{3}\right)$ & 4543.68 & 147.34 & 4806.20 & 4943.17 & 138.48 & 5191.64 \\
\hline Mass $(g)$ & 6180.02 & 162.08 & 6367.85 & 6743.09 & 152.33 & 6926.10 \\
\hline Reference Mass (g) & 6225.00 & 920.00 & 7145.00 & 6765.00 & 1140.00 & 7905.00 \\
\hline Ratio & 0.99 & 0.18 & 0.89 & 0.99676 & 0.13362 & 0.88 \\
\hline
\end{tabular}

${ }^{1}$ Total bone includes contributions of costal, intervertebral disc cartilage, bone-associated sternal, and all non-bone associated estimates.

${ }^{2}$ This volume is NURBS, while all others are polygon mesh 
Table 4-2. Comparison of the 18-year segmented and iterated 15-year male and female bone tissue volume fractions by bone site.

\begin{tabular}{|c|c|c|c|c|c|c|c|c|}
\hline \multirow[b]{2}{*}{ Skeletal Site } & \multicolumn{2}{|c|}{ 18-Year Old Male } & \multicolumn{2}{|c|}{ 15-Year Female } & \multicolumn{2}{|c|}{ 15-Year Male } & \multicolumn{2}{|c|}{ 18-Year Old Male } \\
\hline & SVF - Segmented & CBVF - Segmented & SVF - Iterated & CBVF - Iterated & SVF - Iterated & CBVF - Iterated & MVF & BVF \\
\hline${ }^{1}$ Cranium & 0.5006 & 0.4994 & 0.5221 & 0.4779 & 0.5279 & 0.4721 & 0.6807 & 0.3193 \\
\hline Mandible & 0.4189 & 0.5811 & 0.4404 & 0.5596 & 0.4462 & 0.5538 & 0.7173 & 0.2827 \\
\hline${ }^{2}$ Cervical & 0.6649 & 0.3351 & 0.6864 & 0.3136 & 0.6922 & 0.3078 & 0.8400 & 0.1601 \\
\hline${ }^{3}$ Thoracic & 0.7728 & 0.2272 & 0.7943 & 0.2057 & 0.8001 & 0.1999 & 0.8720 & 0.1280 \\
\hline $\begin{array}{l}{ }^{4} \text { Lumbar } \\
\text { Sternum }\end{array}$ & $\begin{array}{l}0.8823 \\
0.7023\end{array}$ & $\begin{array}{l}0.1177 \\
0.2977\end{array}$ & $\begin{array}{l}0.9038 \\
0.7238\end{array}$ & $\begin{array}{l}0.0962 \\
0.2762\end{array}$ & $\begin{array}{l}0.9096 \\
0.7296\end{array}$ & $\begin{array}{l}0.0904 \\
0.2704\end{array}$ & $\begin{array}{l}0.8940 \\
0.9066\end{array}$ & $\begin{array}{l}0.1060 \\
0.0934\end{array}$ \\
\hline${ }^{5}$ Ribs & 0.5910 & 0.4090 & 0.6125 & 0.3875 & 0.6183 & 0.3817 & 0.8792 & 0.1208 \\
\hline Right Scapula & 0.4985 & 0.5015 & 0.5200 & 0.4800 & 0.5258 & 0.4742 & 0.6935 & 0.3065 \\
\hline Right Clavicle & 0.3742 & 0.6258 & 0.3957 & 0.6043 & 0.4015 & 0.5985 & 0.8243 & 0.1757 \\
\hline${ }^{6}$ Os coxae & 0.7677 & 0.2323 & 0.7892 & 0.2108 & 0.7950 & 0.2050 & 0.8949 & 0.1051 \\
\hline Sacrum & 0.6890 & 0.3110 & 0.7105 & 0.2895 & 0.7163 & 0.2837 & 0.9437 & 0.0563 \\
\hline Humerii, Right Proximal & 0.8221 & 0.1779 & 0.8436 & 0.1564 & 0.8494 & 0.1506 & 0.8448 & 0.1552 \\
\hline${ }^{7}$ Humerii, Upper Shaft & 0.1979 & 0.8021 & 0.2194 & 0.7806 & 0.2252 & 0.7748 & 1.0000 & 0.0000 \\
\hline${ }^{7}$ Humerii, Lower Shaft & 0.1979 & 0.8021 & 0.2194 & 0.7806 & 0.2252 & 0.7748 & 1.0000 & 0.0000 \\
\hline Humerii, Right Distal & 0.5684 & 0.4316 & 0.5899 & 0.4101 & 0.5957 & 0.4043 & 0.7847 & 0.2153 \\
\hline Radii, Right Proximal & 0.6043 & 0.3957 & 0.6258 & 0.3742 & 0.6316 & 0.3684 & 0.7939 & 0.2061 \\
\hline Radii, Shaft & 0.1105 & 0.8895 & 0.1320 & 0.8680 & 0.1378 & 0.8622 & 1.0000 & 0.0000 \\
\hline Radii, Right Distal & 0.7225 & 0.2775 & 0.7440 & 0.2560 & 0.7498 & 0.2502 & 0.8035 & 0.1965 \\
\hline Ulna, Right Proximal & 0.6676 & 0.3324 & 0.6891 & 0.3109 & 0.6949 & 0.3051 & 0.7462 & 0.2538 \\
\hline Ulna, Shaft & 0.1163 & 0.8837 & 0.1378 & 0.8622 & 0.1436 & 0.8564 & 1.0000 & 0.0000 \\
\hline Ulna, Right Distal & 0.6516 & 0.3484 & 0.6731 & 0.3269 & 0.6789 & 0.3211 & 0.8140 & 0.1860 \\
\hline${ }^{8}$ Wrist and Hands & 0.3940 & 0.6060 & 0.4155 & 0.5845 & 0.4213 & 0.5787 & 0.8792 & 0.1208 \\
\hline${ }^{9}$ Femora, Proximal & 0.7728 & 0.2272 & 0.7943 & 0.2057 & 0.8001 & 0.1999 & 0.7936 & 0.2064 \\
\hline${ }^{7}$ Femora, Upper Shaft & 0.2343 & 0.7657 & 0.2558 & 0.7442 & 0.2616 & 0.7384 & 1.0000 & 0.0000 \\
\hline${ }^{7}$ Femora, Lower Shaft & 0.2343 & 0.7657 & 0.2558 & 0.7442 & 0.2616 & 0.7384 & 1.0000 & 0.0000 \\
\hline Femora, Distal & 0.8345 & 0.1655 & 0.8560 & 0.1440 & 0.8618 & 0.1382 & 0.7221 & 0.2779 \\
\hline${ }^{8}$ Patella & 0.5951 & 0.4049 & 0.6166 & 0.3834 & 0.6224 & 0.3776 & 0.8792 & 0.1208 \\
\hline Tibia, Proximal & 0.7194 & 0.2806 & 0.7409 & 0.2591 & 0.7467 & 0.2533 & 0.9050 & 0.0950 \\
\hline Tibia, Shaft & 0.2672 & 0.7328 & 0.2887 & 0.7113 & 0.2945 & 0.7055 & 1.0000 & 0.0000 \\
\hline Tibia, Distal & 0.8135 & 0.1865 & 0.8350 & 0.1650 & 0.8408 & 0.1592 & 0.8146 & 0.1854 \\
\hline Fibula, Proximal & 0.6282 & 0.3718 & 0.6497 & 0.3503 & 0.6555 & 0.3445 & 0.8485 & 0.1515 \\
\hline Fibula, Shaft & 0.2115 & 0.7885 & 0.2330 & 0.7670 & 0.2387 & 0.7613 & 1.0000 & 0.0000 \\
\hline Fibula, Distal & 0.6130 & 0.3870 & 0.6345 & 0.3655 & 0.6403 & 0.3597 & 0.7349 & 0.2651 \\
\hline${ }^{8}$ Ankles and Feet & 0.7114 & 0.2886 & 0.7329 & 0.2671 & 0.7387 & 0.2613 & 0.8792 & 0.1208 \\
\hline
\end{tabular}

${ }^{1}$ The MVF is a inear average between occipital, frontal, parietal $(+/-2.06 \%)$

${ }^{2}$ The MVF is a linear average between $\mathrm{C}_{3}$ and $\mathrm{C}_{6}(+/-2.23 \%)$

${ }^{3}$ The MVF is a linear average between $T_{1}, T_{3}, T_{6}, T_{9}$, and $T_{12}(+/-1.74 \%)$

${ }^{4}$ The MVF is a linear average between $\mathrm{L}_{1}, \mathrm{~L}_{2}, \mathrm{~L}_{3}, \mathrm{~L}_{4}$, and $\mathrm{L}_{5}(+/-2.01 \%)$

${ }^{5}$ The MVF is a linear average between the upper (rib-1), middle (rib-6), and lower right (rib-12) rib (+/- 3.04\%)

${ }^{6}$ The MVF was calculated from the right ilium

${ }^{7}$ The SVF for the upper shaft was segmented and assumed to be the same for the lower shaft

${ }^{8}$ The MVF for the rib was used as a surrogate

${ }^{9}$ The MVF is a linear average of the right and left head and neck $(+/-3.46 \%)$ 
Table 4-3. Masses and volumes of site-specific miscellaneous skeletal tissue in the 15-year female phantom. MST - miscellaneous skeletal tissue, $M B$ - mineral bone, $A M$ - active marrow, $I M$ - inactive marrow, $C B$ - cortical bone, $T B$ - trabecular bone.

\begin{tabular}{|c|c|c|c|c|c|c|c|c|c|c|c|c|}
\hline Skeletal Site & $\begin{array}{c}\text { Total MST } \\
\text { Volume }\left(\mathrm{cm}^{3}\right)\end{array}$ & $\begin{array}{l}\text { Total MST } \\
\text { Mass }(\mathrm{g})\end{array}$ & $\begin{array}{c}\text { MST In MB } \\
\text { Volume }\left(\mathrm{cm}^{3}\right)\end{array}$ & $\begin{array}{l}\text { MST In MB } \\
\text { Mass (g) }\end{array}$ & $\begin{array}{c}\text { MST In AM } \\
\text { Volume }\left(\mathrm{cm}^{3}\right)\end{array}$ & $\begin{array}{l}\text { MST In AM } \\
\text { Mass (g) }\end{array}$ & $\begin{array}{c}\text { MST In IM } \\
\text { Volume }\left(\mathrm{cm}^{3}\right)\end{array}$ & $\begin{array}{c}\text { MST In IM } \\
\text { Mass (g) }\end{array}$ & $\begin{array}{c}\text { MST In CB } \\
\text { Volume }\left(\mathrm{cm}^{3}\right)\end{array}$ & $\begin{array}{l}\text { MST In CB } \\
\text { Mass (g) }\end{array}$ & $\begin{array}{c}\text { MST In TB } \\
\text { Volume }\left(\mathrm{cm}^{3}\right)\end{array}$ & $\begin{array}{c}\text { MST In TB } \\
\text { Mass (g) }\end{array}$ \\
\hline Cranium & 16.32 & 16.65 & 10.52 & 10.73 & 3.19 & 3.25 & 2.61 & 2.66 & 7.80 & 7.96 & 2.72 & 2.78 \\
\hline Mandible & 1.46 & 1.49 & 1.00 & 1.02 & 0.25 & 0.26 & 0.21 & 0.21 & 0.82 & 0.83 & 0.18 & 0.19 \\
\hline Cervical & 2.37 & 2.42 & 1.00 & 1.02 & 1.03 & 1.05 & 0.34 & 0.35 & 0.74 & 0.76 & 0.26 & 0.27 \\
\hline Lumbar & 7.42 & 7.57 & 1.43 & 1.45 & 4.50 & 4.59 & 1.50 & 1.53 & 0.71 & 0.73 & 0.71 & 0.73 \\
\hline Sternum & 0.98 & 1.00 & 0.34 & 0.34 & 0.48 & 0.49 & 0.16 & 0.16 & 0.27 & 0.28 & 0.07 & 0.07 \\
\hline Ribs & 8.33 & 8.49 & 3.84 & 3.92 & 3.36 & 3.43 & 1.12 & 1.14 & 3.23 & 3.29 & 0.62 & 0.63 \\
\hline Scapulae & 6.23 & 6.35 & 3.98 & 4.06 & 1.23 & 1.26 & 1.01 & 1.03 & 2.99 & 3.05 & 0.99 & 1.01 \\
\hline Clavicles & 1.63 & 1.66 & 1.10 & 1.12 & 0.28 & 0.29 & 0.25 & 0.26 & 0.99 & 1.01 & 0.11 & 0.12 \\
\hline Sacrum & 5.17 & 5.28 & 1.71 & 1.74 & 2.22 & 2.26 & 1.25 & 1.27 & 1.50 & 1.53 & 0.21 & 0.21 \\
\hline Humeri, Proximal & 3.89 & 3.97 & 1.12 & 1.14 & 1.52 & 1.55 & 1.25 & 1.27 & 0.61 & 0.62 & 0.51 & 0.52 \\
\hline Humeri, Upper Shaft & 1.99 & 2.03 & 1.55 & 1.58 & 0.15 & 0.16 & 0.28 & 0.29 & 1.55 & 1.58 & 0.00 & 0.00 \\
\hline Humeri, Lower Shaft & 1.74 & 1.77 & 1.36 & 1.38 & 0.08 & 0.08 & 0.30 & 0.31 & 1.36 & 1.38 & 0.00 & 0.00 \\
\hline Humeri, Distal & 2.35 & 2.40 & 1.26 & 1.29 & 0.00 & 0.00 & 1.09 & 1.11 & 0.96 & 0.98 & 0.30 & 0.30 \\
\hline Radii, Proximal & 0.36 & 0.37 & 0.18 & 0.19 & 0.00 & 0.00 & 0.18 & 0.18 & 0.14 & 0.14 & 0.05 & 0.05 \\
\hline Radii, Shaft & 1.33 & 1.35 & 1.15 & 1.18 & 0.00 & 0.00 & 0.18 & 0.18 & 1.15 & 1.18 & 0.00 & 0.00 \\
\hline Radii, Distal & 0.66 & 0.68 & 0.27 & 0.27 & 0.00 & 0.00 & 0.40 & 0.41 & 0.17 & 0.17 & 0.10 & 0.10 \\
\hline Ulnae, Proximal & 1.25 & 1.28 & 0.61 & 0.62 & 0.00 & 0.00 & 0.64 & 0.66 & 0.39 & 0.40 & 0.22 & 0.22 \\
\hline Ulnae, Shaft & 1.58 & 1.61 & 1.36 & 1.39 & 0.00 & 0.00 & 0.22 & 0.22 & 1.36 & 1.39 & 0.00 & 0.00 \\
\hline Femora, Proximal & 5.55 & 5.66 & 2.05 & 2.09 & 1.92 & 1.96 & 1.57 & 1.61 & 1.14 & 1.16 & 0.91 & 0.93 \\
\hline Femora, Upper Shaft & 3.96 & 4.04 & 2.95 & 3.01 & 0.35 & 0.36 & 0.66 & 0.67 & 2.95 & 3.01 & 0.00 & 0.00 \\
\hline Femora, Lower Shaft & 4.48 & 4.56 & 3.33 & 3.40 & 0.23 & 0.23 & 0.92 & 0.93 & 3.33 & 3.40 & 0.00 & 0.00 \\
\hline Femora, Distal & 7.54 & 7.69 & 2.88 & 2.94 & 0.00 & 0.00 & 4.66 & 4.75 & 1.09 & 1.11 & 1.79 & 1.83 \\
\hline Patellae & 0.79 & 0.81 & 0.36 & 0.37 & 0.00 & 0.00 & 0.43 & 0.44 & 0.30 & 0.31 & 0.06 & 0.06 \\
\hline Tibiae, Proximal & 5.96 & 6.08 & 1.96 & 2.00 & 0.00 & 0.00 & 4.00 & 4.08 & 1.54 & 1.58 & 0.42 & 0.43 \\
\hline Tibiae, Shaft & 5.25 & 5.36 & 3.73 & 3.81 & 0.00 & 0.00 & 1.52 & 1.55 & 3.73 & 3.81 & 0.00 & 0.00 \\
\hline Tibiae, Distal & 2.16 & 2.21 & 0.69 & 0.71 & 0.00 & 0.00 & 1.47 & 1.50 & 0.36 & 0.36 & 0.34 & 0.34 \\
\hline Fibulae, Proximal & 0.49 & 0.50 & 0.22 & 0.23 & 0.00 & 0.00 & 0.27 & 0.28 & 0.17 & 0.18 & 0.05 & 0.05 \\
\hline Fibulae, Shaft & 0.78 & 0.79 & 0.59 & 0.61 & 0.00 & 0.00 & 0.18 & 0.18 & 0.59 & 0.61 & 0.00 & 0.00 \\
\hline Fibulae, Distal & 0.47 & 0.48 & 0.25 & 0.26 & 0.00 & 0.00 & 0.22 & 0.23 & 0.17 & 0.18 & 0.08 & 0.08 \\
\hline Ankles and Feet & 11.47 & 11.70 & 4.08 & 4.16 & 0.00 & 0.00 & 7.39 & 7.54 & 3.06 & 3.12 & 1.02 & 1.04 \\
\hline Total Skeleton & 142.16 & 145.00 & 66.39 & 67.72 & 32.48 & 33.13 & 43.29 & 44.16 & 52.31 & 53.36 & 14.08 & 14.36 \\
\hline $\begin{array}{c}\text { ICRP } 89 \text { Reference } \\
\text { Ratio }\end{array}$ & $\begin{array}{c}142.16 \\
1.00\end{array}$ & $\begin{array}{c}145.00 \\
1.00\end{array}$ & & & & & & & & & & \\
\hline
\end{tabular}


Table 4-4. Masses and volumes of site-specific miscellaneous skeletal tissue in the 15-year male phantom. MST - miscellaneous skeletal tissue, $M B$ - mineral bone, $A M$ - active marrow, $I M$ - inactive marrow, $C B$ - cortical bone, $T B$ - trabecular bone.

\begin{tabular}{|c|c|c|c|c|c|c|c|c|c|c|c|c|}
\hline Skeletal Site & $\begin{array}{c}\text { Total MST } \\
\text { Volume }\left(\mathrm{cm}^{3}\right) \\
\end{array}$ & $\begin{array}{c}\text { Total MST } \\
\text { Mass (g) }\end{array}$ & $\begin{array}{c}\text { MST In MB } \\
\text { Volume }\left(\mathrm{cm}^{3}\right)\end{array}$ & $\begin{array}{l}\text { MST In MB } \\
\text { Mass (g) }\end{array}$ & $\begin{array}{c}\text { MST In AM } \\
\text { Volume }\left(\mathrm{cm}^{3}\right)\end{array}$ & $\begin{array}{c}\text { MST In AM } \\
\text { Mass (g) }\end{array}$ & $\begin{array}{c}\text { MST In IM } \\
\text { Volume }\left(\mathrm{cm}^{3}\right)\end{array}$ & $\begin{array}{c}\text { MST In IM } \\
\text { Mass (g) }\end{array}$ & $\begin{array}{c}\text { MST In CB } \\
\text { Volume }\left(\mathrm{cm}^{3}\right)\end{array}$ & $\begin{array}{l}\text { MST In CB } \\
\text { Mass (g) }\end{array}$ & $\begin{array}{c}\text { MST In TB } \\
\text { Volume }\left(\mathrm{cm}^{3}\right)\end{array}$ & $\begin{array}{c}\text { MST In TB } \\
\text { Mass (g) }\end{array}$ \\
\hline Cranium & 19.34 & 19.92 & 12.39 & 12.76 & 3.82 & 3.94 & 3.13 & 3.22 & 9.13 & 9.41 & 3.26 & 3.36 \\
\hline Mandible & 1.80 & 1.85 & 1.22 & 1.26 & 0.32 & 0.33 & 0.26 & 0.27 & 0.99 & 1.02 & 0.23 & 0.23 \\
\hline Cervical & 1.84 & 1.90 & 0.77 & 0.79 & 0.80 & 0.83 & 0.27 & 0.28 & 0.57 & 0.58 & 0.20 & 0.21 \\
\hline Lumbar & 6.60 & 6.79 & 1.23 & 1.27 & 4.02 & 4.14 & 1.34 & 1.38 & 0.60 & 0.61 & 0.64 & 0.66 \\
\hline Sternum & 1.38 & 1.42 & 0.47 & 0.48 & 0.68 & 0.70 & 0.23 & 0.23 & 0.37 & 0.38 & 0.09 & 0.10 \\
\hline Ribs & 7.44 & 7.67 & 3.40 & 3.50 & 3.03 & 3.13 & 1.01 & 1.04 & 2.84 & 2.93 & 0.56 & 0.57 \\
\hline Scapulae & 4.41 & 4.54 & 2.80 & 2.88 & 0.88 & 0.91 & 0.72 & 0.74 & 2.09 & 2.15 & 0.71 & 0.73 \\
\hline Clavicles & 1.21 & 1.25 & 0.81 & 0.84 & 0.21 & 0.22 & 0.19 & 0.19 & 0.73 & 0.75 & 0.09 & 0.09 \\
\hline Os coxae & 15.44 & 15.91 & 4.46 & 4.59 & 7.03 & 7.24 & 3.96 & 4.07 & 3.17 & 3.26 & 1.29 & 1.33 \\
\hline Sacrum & 4.12 & 4.25 & 1.34 & 1.38 & 1.78 & 1.84 & 1.00 & 1.03 & 1.17 & 1.20 & 0.17 & 0.17 \\
\hline Humeri, Proximal & 4.76 & 4.90 & 1.34 & 1.38 & 1.88 & 1.93 & 1.54 & 1.58 & 0.72 & 0.74 & 0.63 & 0.65 \\
\hline Humeri, Upper Shaft & 2.39 & 2.46 & 1.85 & 1.91 & 0.19 & 0.19 & 0.35 & 0.36 & 1.85 & 1.91 & 0.00 & 0.00 \\
\hline Humeri, Lower Shaft & 2.12 & 2.19 & 1.65 & 1.70 & 0.10 & 0.10 & 0.38 & 0.39 & 1.65 & 1.70 & 0.00 & 0.00 \\
\hline Humeri, Distal & 2.89 & 2.97 & 1.54 & 1.58 & 0.00 & 0.00 & 1.35 & 1.39 & 1.17 & 1.20 & 0.37 & 0.38 \\
\hline Radii, Proximal & 0.47 & 0.48 & 0.23 & 0.24 & 0.00 & 0.00 & 0.23 & 0.24 & 0.17 & 0.18 & 0.06 & 0.06 \\
\hline Radii, Shaft & 1.45 & 1.50 & 1.25 & 1.29 & 0.00 & 0.00 & 0.20 & 0.21 & 1.25 & 1.29 & 0.00 & 0.00 \\
\hline Radii, Distal & 0.85 & 0.88 & 0.34 & 0.35 & 0.00 & 0.00 & 0.51 & 0.53 & 0.21 & 0.22 & 0.13 & 0.13 \\
\hline Ulnae, Proximal & 1.56 & 1.61 & 0.75 & 0.78 & 0.00 & 0.00 & 0.81 & 0.84 & 0.48 & 0.49 & 0.28 & 0.28 \\
\hline Wrists and Hands & 3.79 & 3.90 & 2.39 & 2.46 & 0.00 & 0.00 & 1.40 & 1.45 & 2.19 & 2.26 & 0.19 & 0.20 \\
\hline Femora, Proximal & 7.05 & 7.26 & 2.57 & 2.65 & 2.46 & 2.54 & 2.02 & 2.08 & 1.41 & 1.45 & 1.16 & 1.20 \\
\hline Femora, Upper Shaft & 5.25 & 5.41 & 3.88 & 3.99 & 0.48 & 0.50 & 0.89 & 0.92 & 3.88 & 3.99 & 0.00 & 0.00 \\
\hline Femora, Lower Shaft & 4.00 & 4.12 & 2.95 & 3.04 & 0.21 & 0.22 & 0.84 & 0.86 & 2.95 & 3.04 & 0.00 & 0.00 \\
\hline Femora, Distal & 8.22 & 8.47 & 3.10 & 3.20 & 0.00 & 0.00 & 5.12 & 5.27 & 1.14 & 1.17 & 1.97 & 2.03 \\
\hline Patellae & 0.95 & 0.98 & 0.43 & 0.44 & 0.00 & 0.00 & 0.52 & 0.54 & 0.36 & 0.37 & 0.07 & 0.07 \\
\hline Tibiae, Proximal & 6.68 & 6.88 & 2.16 & 2.23 & 0.00 & 0.00 & 4.51 & 4.65 & 1.69 & 1.74 & 0.47 & 0.49 \\
\hline Tibiae, Shaft & 6.12 & 6.31 & 4.32 & 4.45 & 0.00 & 0.00 & 1.80 & 1.86 & 4.32 & 4.45 & 0.00 & 0.00 \\
\hline Tibiae, Distal & 2.45 & 2.52 & 0.77 & 0.79 & 0.00 & 0.00 & 1.67 & 1.73 & 0.39 & 0.40 & 0.38 & 0.39 \\
\hline Fibulae, Proximal & 0.61 & 0.63 & 0.27 & 0.28 & 0.00 & 0.00 & 0.34 & 0.35 & 0.21 & 0.22 & 0.06 & 0.06 \\
\hline Fibulae, Shaft & 1.04 & 1.07 & 0.79 & 0.82 & 0.00 & 0.00 & 0.25 & 0.26 & 0.79 & 0.82 & 0.00 & 0.00 \\
\hline Fibulae, Distal & 0.59 & 0.61 & 0.31 & 0.32 & 0.00 & 0.00 & 0.28 & 0.29 & 0.21 & 0.22 & 0.10 & 0.10 \\
\hline Ankles and Feet & 13.96 & 14.38 & 4.89 & 5.04 & 0.00 & 0.00 & 9.07 & 9.34 & 3.65 & 3.76 & 1.25 & 1.28 \\
\hline Total Skeleton & 150.49 & 155.00 & 70.65 & 72.77 & 31.90 & 32.86 & 47.94 & 49.37 & 55.48 & 57.15 & 15.17 & 15.62 \\
\hline
\end{tabular}

Ratio

150.49

1.00 
Table 4-5. Site-specific active marrow volumes and masses of skeletal tissues in the 15-year female hybrid phantom including and then excluding contributions from miscellaneous skeletal tissues.

\begin{tabular}{|c|c|c|c|c|c|c|c|c|c|c|c|c|}
\hline \multirow[b]{3}{*}{ Skeletal Site } & \multicolumn{6}{|c|}{ Excluding MST } & \multicolumn{6}{|c|}{ Including MST } \\
\hline & TAM & TAM & TIM & TIM & TMS & TMS & TAM $^{*}$ & TAM* $^{*}$ & TIM* $^{*}$ & TIM* & TMS* & TMS* \\
\hline & Volume $\left(\mathrm{cm}^{3}\right)$ & Mass (g) & Volume $\left(\mathrm{cm}^{3}\right)$ & Mass (g) & Volume $\left(\mathrm{cm}^{3}\right)$ & Mass (g) & Volume $\left(\mathrm{cm}^{3}\right)$ & Mass (g) & Volume $\left(\mathrm{cm}^{3}\right)$ & Mass (g) & Volume $\left(\mathrm{cm}^{3}\right)$ & Mass (g) \\
\hline Cranium & 98.79 & 101.75 & 80.82 & 79.21 & 179.61 & 180.96 & 101.98 & 105.00 & 83.44 & 81.87 & 185.41 & 186.87 \\
\hline Mandible & 7.87 & 8.10 & 6.44 & 6.31 & 14.30 & 14.41 & 8.12 & 8.36 & 6.64 & 6.52 & 14.76 & 14.88 \\
\hline Thoracic & 113.82 & 117.23 & 37.94 & 37.18 & 151.76 & 154.41 & 117.49 & 120.98 & 39.16 & 38.43 & 156.66 & 159.41 \\
\hline Lumbar & 139.26 & 143.43 & 46.42 & 45.49 & 185.68 & 188.92 & 143.75 & 148.02 & 47.92 & 47.02 & 191.67 & 195.04 \\
\hline Sternum & 14.98 & 15.42 & 4.99 & 4.89 & 19.97 & 20.32 & 15.46 & 15.92 & 5.15 & 5.06 & 20.61 & 20.97 \\
\hline Ribs & 104.14 & 107.27 & 34.71 & 34.02 & 138.86 & 141.29 & 107.51 & 110.70 & 35.84 & 35.16 & 143.34 & 145.86 \\
\hline Scapulae & 38.24 & 39.38 & 31.28 & 30.66 & 69.52 & 70.04 & 39.47 & 40.64 & 32.29 & 31.69 & 71.76 & 72.33 \\
\hline Os coxae & 247.33 & 254.75 & 139.12 & 136.34 & 386.45 & 391.09 & 255.32 & 262.90 & 143.62 & 140.92 & 398.93 & 403.82 \\
\hline Sacrum & 68.75 & 70.82 & 38.67 & 37.90 & 107.43 & 108.72 & 70.97 & 73.08 & 39.92 & 39.17 & 110.90 & 112.26 \\
\hline Humeri, Proximal & 47.20 & 48.61 & 38.62 & 37.84 & 85.82 & 86.46 & 48.72 & 50.17 & 39.86 & 39.12 & 88.59 & 89.29 \\
\hline Humeri, Upper Shaft & 4.73 & 4.87 & 8.78 & 8.61 & 13.51 & 13.48 & 4.88 & 5.03 & 9.07 & 8.90 & 13.95 & 13.93 \\
\hline Humeri, Lower Shaft & 2.36 & 2.43 & 9.43 & 9.25 & 11.79 & 11.68 & 2.43 & 2.51 & 9.74 & 9.56 & 12.17 & 12.06 \\
\hline Humeri, Distal & 0.00 & 0.00 & 33.67 & 32.99 & 33.67 & 32.99 & 0.00 & 0.00 & 34.75 & 34.10 & 34.75 & 34.10 \\
\hline Radii, Proximal & 0.00 & 0.00 & 5.60 & 5.49 & 5.60 & 5.49 & 0.00 & 0.00 & 5.79 & 5.68 & 5.79 & 5.68 \\
\hline Radii, Shaft & 0.00 & 0.00 & 5.43 & 5.32 & 5.43 & 5.32 & 0.00 & 0.00 & 5.60 & 5.50 & 5.60 & 5.50 \\
\hline Radii, Distal & 0.00 & 0.00 & 12.30 & 12.06 & 12.30 & 12.06 & 0.00 & 0.00 & 12.70 & 12.46 & 12.70 & 12.46 \\
\hline Ulnae, Proximal & 0.00 & 0.00 & 19.91 & 19.51 & 19.91 & 19.51 & 0.00 & 0.00 & 20.56 & 20.17 & 20.56 & 20.17 \\
\hline Wrists and Hands & 0.00 & 0.00 & 36.28 & 35.55 & 36.28 & 35.55 & 0.00 & 0.00 & 37.45 & 36.75 & 37.45 & 36.75 \\
\hline Femora, Proximal & 59.60 & 61.39 & 48.76 & 47.79 & 108.36 & 109.17 & 61.52 & 63.35 & 50.34 & 49.39 & 111.86 & 112.74 \\
\hline Femora, Upper Shaft & 10.98 & 11.31 & 20.39 & 19.98 & 31.37 & 31.29 & 11.33 & 11.67 & 21.05 & 20.65 & 32.38 & 32.32 \\
\hline Femora, Lower Shaft & 7.09 & 7.30 & 28.36 & 27.79 & 35.45 & 35.09 & 7.32 & 7.54 & 29.27 & 28.72 & 36.59 & 36.26 \\
\hline Femora, Distal & 0.00 & 0.00 & 144.30 & 141.41 & 144.30 & 141.41 & 0.00 & 0.00 & 148.96 & 146.17 & 148.96 & 146.17 \\
\hline Patellae & 0.00 & 0.00 & 13.30 & 13.03 & 13.30 & 13.03 & 0.00 & 0.00 & 13.73 & 13.47 & 13.73 & 13.47 \\
\hline Tibiae, Proximal & 0.00 & 0.00 & 123.75 & 121.28 & 123.75 & 121.28 & 0.00 & 0.00 & 127.75 & 125.35 & 127.75 & 125.35 \\
\hline Tibiae, Shaft & 0.00 & 0.00 & 46.93 & 46.00 & 46.93 & 46.00 & 0.00 & 0.00 & 48.45 & 47.54 & 48.45 & 47.54 \\
\hline Tibiae, Distal & 0.00 & 0.00 & 45.58 & 44.67 & 45.58 & 44.67 & 0.00 & 0.00 & 47.05 & 46.17 & 47.05 & 46.17 \\
\hline Fibulae, Proximal & 0.00 & 0.00 & 8.41 & 8.24 & 8.41 & 8.24 & 0.00 & 0.00 & 8.68 & 8.52 & 8.68 & 8.52 \\
\hline Fibulae, Shaft & 0.00 & 0.00 & 5.59 & 5.48 & 5.59 & 5.48 & 0.00 & 0.00 & 5.77 & 5.66 & 5.77 & 5.66 \\
\hline Fibulae, Distal & 0.00 & 0.00 & 6.85 & 6.72 & 6.85 & 6.72 & 0.00 & 0.00 & 7.07 & 6.94 & 7.07 & 6.94 \\
\hline Ankles and Feet & 0.00 & 0.00 & 228.81 & 224.23 & 228.81 & 224.23 & 0.00 & 0.00 & 236.20 & 231.77 & 236.20 & 231.77 \\
\hline Total & 1005.42 & 1035.58 & 1340.55 & 1313.74 & 2345.97 & 2349.32 & 1037.90 & 1068.71 & 1383.84 & 1357.90 & 2421.74 & 2426.60 \\
\hline ICRP 89 Reference Values & 970.87 & 1000.00 & 1408.16 & 1380.00 & 2379.04 & 2380.00 & 1003.35 & 1033.13 & 1451.45 & 1424.16 & 2454.81 & 2457.28 \\
\hline Ratio & 1.04 & 1.04 & 0.95 & 0.95 & 0.99 & 0.99 & 1.03 & 1.03 & 0.95 & 0.95 & 0.99 & 0.99 \\
\hline
\end{tabular}


Table 4-6. Site-specific active marrow volumes and masses of skeletal tissues in the 15-year male hybrid phantom including and then excluding contributions from miscellaneous skeletal tissues.

\begin{tabular}{|c|c|c|c|c|c|c|c|c|c|c|c|c|}
\hline \multirow[b]{3}{*}{ Skeletal Site } & \multicolumn{6}{|c|}{ Excluding MST } & \multicolumn{6}{|c|}{ Including MST } \\
\hline & TAM & TAM & TIM & TIM & TMS & TMS & TAM $^{*}$ & TAM* $^{*}$ & TIM $^{*}$ & TIM* & TMS* & TMS* \\
\hline & Volume $\left(\mathrm{cm}^{3}\right)$ & Mass (g) & Volume $\left(\mathrm{cm}^{3}\right)$ & Mass (g) & Volume $\left(\mathrm{cm}^{3}\right)$ & Mass (g) & Volume $\left(\mathrm{cm}^{3}\right)$ & Mass (g) & Volume $\left(\mathrm{cm}^{3}\right)$ & Mass (g) & Volume $\left(\mathrm{cm}^{3}\right)$ & Mass (g) \\
\hline Cranium & 121.75 & 125.40 & 99.61 & 97.62 & 221.36 & 223.02 & 125.57 & 129.34 & 102.74 & 100.84 & 228.31 & 230.18 \\
\hline Mandible & 10.07 & 10.37 & 8.24 & 8.08 & 18.31 & 18.45 & 10.39 & 10.70 & 8.50 & 8.34 & 18.89 & 19.04 \\
\hline Thoracic & 127.16 & 130.98 & 42.39 & 41.54 & 169.55 & 172.52 & 131.16 & 135.09 & 43.72 & 42.91 & 174.88 & 178.00 \\
\hline Lumbar & 128.09 & 131.93 & 42.70 & 41.84 & 170.79 & 173.78 & 132.11 & 136.08 & 44.04 & 43.22 & 176.15 & 179.30 \\
\hline Sternum & 21.75 & 22.40 & 7.25 & 7.10 & 29.00 & 29.51 & 22.43 & 23.10 & 7.48 & 7.34 & 29.91 & 30.44 \\
\hline Ribs & 96.65 & 99.55 & 32.22 & 31.57 & 128.87 & 131.12 & 99.68 & 102.67 & 33.23 & 32.61 & 132.91 & 135.29 \\
\hline Scapulae & 28.14 & 28.99 & 23.03 & 22.57 & 51.17 & 51.55 & 29.03 & 29.90 & 23.75 & 23.31 & 52.78 & 53.21 \\
\hline Os coxae & 223.96 & 230.68 & 125.98 & 123.46 & 349.94 & 354.14 & 230.99 & 237.92 & 129.93 & 127.53 & 360.93 & 365.46 \\
\hline Sacrum & 56.80 & 58.50 & 31.95 & 31.31 & 88.75 & 89.81 & 58.58 & 60.34 & 32.95 & 32.34 & 91.53 & 92.68 \\
\hline Humeri, Proximal & 59.81 & 61.60 & 48.93 & 47.95 & 108.74 & 109.56 & 61.68 & 63.54 & 50.47 & 49.54 & 112.15 & 113.07 \\
\hline Humeri, Upper Shaft & 6.00 & 6.18 & 11.15 & 10.93 & 17.15 & 17.11 & 6.19 & 6.38 & 11.50 & 11.29 & 17.69 & 17.67 \\
\hline Humeri, Lower Shaft & 3.05 & 3.14 & 12.19 & 11.95 & 15.24 & 15.09 & 3.14 & 3.24 & 12.57 & 12.34 & 15.72 & 15.58 \\
\hline Humeri, Distal & 0.00 & 0.00 & 42.99 & 42.13 & 42.99 & 42.13 & 0.00 & 0.00 & 44.34 & 43.52 & 44.34 & 43.52 \\
\hline Radii, Proximal & 0.00 & 0.00 & 7.46 & 7.31 & 7.46 & 7.31 & 0.00 & 0.00 & 7.69 & 7.55 & 7.69 & 7.55 \\
\hline Radii, Shaft & 0.00 & 0.00 & 6.37 & 6.25 & 6.37 & 6.25 & 0.00 & 0.00 & 6.57 & 6.45 & 6.57 & 6.45 \\
\hline Radii, Distal & 0.00 & 0.00 & 16.37 & 16.05 & 16.37 & 16.05 & 0.00 & 0.00 & 16.89 & 16.58 & 16.89 & 16.58 \\
\hline Ulnae, Proximal & 0.00 & 0.00 & 25.83 & 25.31 & 25.83 & 25.31 & 0.00 & 0.00 & 26.64 & 26.15 & 26.64 & 26.15 \\
\hline Ulnae, Distal & 0.00 & 0.00 & 5.11 & 5.01 & 5.11 & 5.01 & 0.00 & 0.00 & 5.27 & 5.18 & 5.27 & 5.18 \\
\hline Wrists and Hands & 0.00 & 0.00 & 44.70 & 43.81 & 44.70 & 43.81 & 0.00 & 0.00 & 46.11 & 45.25 & 46.11 & 45.25 \\
\hline Femora, Proximal & 78.44 & 80.80 & 64.18 & 62.90 & 142.63 & 143.69 & 80.91 & 83.33 & 66.20 & 64.97 & 147.10 & 148.31 \\
\hline Femora, Upper Shaft & 15.32 & 15.78 & 28.44 & 27.87 & 43.76 & 43.65 & 15.80 & 16.27 & 29.34 & 28.79 & 45.13 & 45.06 \\
\hline Femora, Lower Shaft & 6.66 & 6.86 & 26.65 & 26.12 & 33.32 & 32.99 & 6.87 & 7.08 & 27.49 & 26.98 & 34.36 & 34.06 \\
\hline Femora, Distal & 0.00 & 0.00 & 162.94 & 159.69 & 162.94 & 159.69 & 0.00 & 0.00 & 168.06 & 164.96 & 168.06 & 164.96 \\
\hline Patellae & 0.00 & 0.00 & 16.60 & 16.27 & 16.60 & 16.27 & 0.00 & 0.00 & 17.12 & 16.81 & 17.12 & 16.81 \\
\hline Tibiae, Proximal & 0.00 & 0.00 & 143.67 & 140.80 & 143.67 & 140.80 & 0.00 & 0.00 & 148.19 & 145.45 & 148.19 & 145.45 \\
\hline Tibiae, Shaft & 0.00 & 0.00 & 57.44 & 56.29 & 57.44 & 56.29 & 0.00 & 0.00 & 59.24 & 58.14 & 59.24 & 58.14 \\
\hline Tibiae, Distal & 0.00 & 0.00 & 53.34 & 52.27 & 53.34 & 52.27 & 0.00 & 0.00 & 55.02 & 54.00 & 55.02 & 54.00 \\
\hline Fibulae, Proximal & 0.00 & 0.00 & 10.80 & 10.59 & 10.80 & 10.59 & 0.00 & 0.00 & 11.14 & 10.94 & 11.14 & 10.94 \\
\hline Fibulae, Shaft & 0.00 & 0.00 & 7.91 & 7.75 & 7.91 & 7.75 & 0.00 & 0.00 & 8.16 & 8.01 & 8.16 & 8.01 \\
\hline Fibulae, Distal & 0.00 & 0.00 & 8.82 & 8.64 & 8.82 & 8.64 & 0.00 & 0.00 & 9.09 & 8.92 & 9.09 & 8.92 \\
\hline Ankles and Feet & 0.00 & 0.00 & 288.75 & 282.98 & 288.75 & 282.98 & 0.00 & 0.00 & 297.82 & 292.32 & 297.82 & 292.32 \\
\hline Total & 1015.88 & 1046.35 & 1526.81 & 1496.27 & 2542.68 & 2542.62 & 1047.78 & 1079.21 & 1574.74 & 1545.64 & 2622.52 & 2624.86 \\
\hline ICRP 89 Reference Values & 1048.54 & 1080.00 & 1510.20 & 1480.00 & 2558.75 & 2560.00 & 1080.45 & 1112.86 & 1558.14 & 1529.37 & 2638.59 & 2642.23 \\
\hline Ratio & 0.97 & 0.97 & 1.01 & 1.01 & 0.99 & 0.99 & 0.97 & 0.97 & 1.01 & 1.01 & 0.99 & 0.99 \\
\hline
\end{tabular}

${ }^{*}$ Denotes inclusion of associated miscellaneous skeletal tissue volumes and masses 
Table 4-7. Comparison of site-specific active marrow distribution between the UF 15-year female (left) and male (right) hybrid phantoms and reference values given in ICRP Publication 89.

\begin{tabular}{|c|c|c|c|c|c|c|c|c|}
\hline \multirow[b]{2}{*}{ Skeletal Site } & \multicolumn{4}{|c|}{ Female } & \multicolumn{4}{|c|}{ Male } \\
\hline & $\begin{array}{c}\text { NURBS/Polygon Mesh } \\
(\%)\end{array}$ & $\begin{array}{c}\text { ICRP 89, Table } 9.4 \\
\text { (\%) }\end{array}$ & $\begin{array}{c}\text { Difference } \\
\text { (abs. \%) }\end{array}$ & $\begin{array}{c}\text { Ratio } \\
\text { NURBS/ICRP }\end{array}$ & $\begin{array}{c}\text { NURBS/Polygon Mesh } \\
\text { (\%) }\end{array}$ & $\begin{array}{c}\text { ICRP 89, Table } 9.4 \\
(\%) \\
\end{array}$ & $\begin{array}{l}\text { Difference } \\
\text { (abs. \%) }\end{array}$ & $\begin{array}{c}\text { Ratio } \\
\text { NURBS/ICRP } \\
\end{array}$ \\
\hline Cranium & 9.83 & 9.19 & 0.63 & 1.07 & 11.98 & 9.19 & 2.79 & 1.30 \\
\hline Mandible & 0.78 & 0.90 & -0.12 & 0.87 & 0.99 & 0.90 & 0.09 & 1.10 \\
\hline Cervical & 3.16 & 3.30 & -0.14 & 0.96 & 2.52 & 3.30 & -0.78 & 0.76 \\
\hline Thoracic & 11.32 & 13.69 & -2.37 & 0.83 & 12.52 & 13.69 & -1.17 & 0.91 \\
\hline Lumbar & 13.85 & 10.49 & 3.36 & 1.32 & 12.61 & 10.49 & 2.12 & 1.20 \\
\hline Sternum & 1.49 & 2.70 & -1.21 & 0.55 & 2.14 & 2.70 & -0.56 & 0.79 \\
\hline Ribs & 10.36 & 13.59 & -3.23 & 0.76 & 9.51 & 13.59 & -4.07 & 0.70 \\
\hline Scapulae & 3.80 & 3.30 & 0.51 & 1.15 & 2.77 & 3.30 & -0.53 & 0.84 \\
\hline Clavicles & 0.85 & 1.00 & -0.15 & 0.85 & 0.66 & 1.00 & -0.34 & 0.66 \\
\hline Os coxae & 24.60 & 18.48 & 6.12 & 1.33 & 22.05 & 18.48 & 3.56 & 1.19 \\
\hline Sacrum & 6.84 & 8.39 & -1.55 & 0.81 & 5.59 & 8.39 & -2.80 & 0.67 \\
\hline $\begin{array}{l}\text { Humeri, Proximal } \\
\text { Humeri, Upper Shaft }\end{array}$ & $\begin{array}{l}4.69 \\
0.47\end{array}$ & 3.10 & 2.07 & 1.67 & $\begin{array}{l}5.89 \\
0.59\end{array}$ & 3.10 & 3.38 & 2.09 \\
\hline Humeri, Lower Shaft & 0.23 & & & & 0.30 & & & \\
\hline Humeri, Distal & 0.00 & 0.70 & -0.46 & 0.34 & 0.00 & 0.70 & -0.40 & 0.43 \\
\hline Radii, Proximal & 0.00 & & & & 0.00 & & & \\
\hline Radii, Shaft & 0.00 & 0.00 & 0.00 & 1.00 & 0.00 & 0.00 & 0.00 & 1.00 \\
\hline Radii, Distal & 0.00 & & & & 0.00 & & & \\
\hline Ulnae, Proximal & 0.00 & & & & 0.00 & & & \\
\hline Ulnae, Shaft & 0.00 & 0.00 & 0.00 & 1.00 & 0.00 & 0.00 & 0.00 & 1.00 \\
\hline Ulnae, Distal & 0.00 & & & & 0.00 & & & \\
\hline Wrists and Hands & 0.00 & 0.00 & 0.00 & 1.00 & 0.00 & 0.00 & 0.00 & 1.00 \\
\hline $\begin{array}{l}\text { Femora, Proximal } \\
\text { Femora, Upper Shaft }\end{array}$ & $\begin{array}{l}5.93 \\
1.09\end{array}$ & 9.19 & -2.17 & 0.76 & $\begin{array}{l}7.72 \\
151\end{array}$ & 9.19 & 0.04 & 1.00 \\
\hline $\begin{array}{l}\text { Femora, Upper Shaft } \\
\text { Femora, Lower Shaft }\end{array}$ & $\begin{array}{l}1.09 \\
0.71\end{array}$ & & & & $\begin{array}{l}1.51 \\
0.66\end{array}$ & & & \\
\hline Femora, Distal & 0.00 & 2.00 & -1.29 & 0.35 & 0.00 & 2.00 & -1.34 & 0.33 \\
\hline Patellae & 0.00 & 0.00 & 0.00 & 1.00 & 0.00 & 0.00 & 0.00 & 1.00 \\
\hline Tibiae, Proximal & 0.00 & & & & 0.00 & & & \\
\hline Tibiae, Shaft & 0.00 & 0.00 & 0.00 & 1.00 & 0.00 & 0.00 & 0.00 & 1.00 \\
\hline Tibiae, Distal & 0.00 & & & & 0.00 & & & \\
\hline Fibulae, Proximal & 0.00 & & & & 0.00 & & & \\
\hline Fibulae, Shaft & 0.00 & 0.00 & 0.00 & 1.00 & 0.00 & 0.00 & 0.00 & 1.00 \\
\hline Fibulae, Distal & 0.00 & & & & 0.00 & & & \\
\hline Ankles and Feet & 0.00 & 0.00 & 0.00 & 1.00 & 0.00 & 0.00 & 0.00 & 1.00 \\
\hline Total & 100.00 & 100.00 & 0.00 & & 100.00 & 100.00 & 0.00 & \\
\hline
\end{tabular}


Table 4-8. Masses, volumes, and percent distribution of cartilage by bone site in the UF 15-year female (left) and male (right) phantoms.

\begin{tabular}{|c|c|c|c|c|c|c|}
\hline \multirow[b]{2}{*}{ Skeletal Site } & \multicolumn{3}{|c|}{ Female } & \multicolumn{3}{|c|}{ Male } \\
\hline & Cartilage Volume $\left(\mathrm{cm}^{3}\right)$ & Cartilage Mass (g) & \% Distribution & Cartilage Volume $\left(\mathrm{cm}^{3}\right)$ & Cartilage Mass (g) & \% Distribution \\
\hline Cranium & 0.00 & 0.00 & 0.00 & 0.00 & 0.00 & 0.00 \\
\hline Mandible & 0.00 & 0.00 & 0.00 & 0.00 & 0.00 & 0.00 \\
\hline Cervical & 0.00 & 0.00 & 0.00 & 0.00 & 0.00 & 0.00 \\
\hline Thoracic & 0.00 & 0.00 & 0.00 & 0.00 & 0.00 & 0.00 \\
\hline Lumbar & 0.00 & 0.00 & 0.00 & 0.00 & 0.00 & 0.00 \\
\hline Sternum & 32.17 & 35.39 & 18.84 & 28.49 & 31.33 & 14.60 \\
\hline Ribs & 0.00 & 0.00 & 0.00 & 0.00 & 0.00 & 0.00 \\
\hline Scapulae & 0.00 & 0.00 & 0.00 & 0.00 & 0.00 & 0.00 \\
\hline Clavicles & 0.00 & 0.00 & 0.00 & 0.00 & 0.00 & 0.00 \\
\hline Os coxae & 0.00 & 0.00 & 0.00 & 0.00 & 0.00 & 0.00 \\
\hline Sacrum & 0.00 & 0.00 & 0.00 & 0.00 & 0.00 & 0.00 \\
\hline Humeri, Proximal & 0.00 & 0.00 & 0.00 & 0.00 & 0.00 & 0.00 \\
\hline Humeri, Upper Shaft & 0.00 & 0.00 & 0.00 & 0.00 & 0.00 & 0.00 \\
\hline Humeri, Lower Shaft & 0.00 & 0.00 & 0.00 & 0.00 & 0.00 & 0.00 \\
\hline Humeri, Distal & 0.00 & 0.00 & 0.00 & 0.00 & 0.00 & 0.00 \\
\hline Radii, Proximal & 0.00 & 0.00 & 0.00 & 0.00 & 0.00 & 0.00 \\
\hline Radii, Shaft & 0.00 & 0.00 & 0.00 & 0.00 & 0.00 & 0.00 \\
\hline Radii, Distal & 0.00 & 0.00 & 0.00 & 0.00 & 0.00 & 0.00 \\
\hline Ulnae, Proximal & 0.00 & 0.00 & 0.00 & 0.00 & 0.00 & 0.00 \\
\hline Ulnae, Shaft & 0.00 & 0.00 & 0.00 & 0.00 & 0.00 & 0.00 \\
\hline Ulnae, Distal & 0.00 & 0.00 & 0.00 & 0.00 & 0.00 & 0.00 \\
\hline Wrists and Hands & 0.00 & 0.00 & 0.00 & 0.00 & 0.00 & 0.00 \\
\hline Femora, Proximal & 0.00 & 0.00 & 0.00 & 0.00 & 0.00 & 0.00 \\
\hline Femora, Upper Shaft & 0.00 & 0.00 & 0.00 & 0.00 & 0.00 & 0.00 \\
\hline Femora, Lower Shaft & 0.00 & 0.00 & 0.00 & 0.00 & 0.00 & 0.00 \\
\hline Femora, Distal & 0.00 & 0.00 & 0.00 & 0.00 & 0.00 & 0.00 \\
\hline Patellae & 0.00 & 0.00 & 0.00 & 0.00 & 0.00 & 0.00 \\
\hline Tibiae, Proximal & 0.00 & 0.00 & 0.00 & 0.00 & 0.00 & 0.00 \\
\hline Tibiae, Shaft & 0.00 & 0.00 & 0.00 & 0.00 & 0.00 & 0.00 \\
\hline Tibiae, Distal & 0.00 & 0.00 & 0.00 & 0.00 & 0.00 & 0.00 \\
\hline Fibulae, Proximal & 0.00 & 0.00 & 0.00 & 0.00 & 0.00 & 0.00 \\
\hline Fibulae, Shaft & 0.00 & 0.00 & 0.00 & 0.00 & 0.00 & 0.00 \\
\hline Fibulae, Distal & 0.00 & 0.00 & 0.00 & 0.00 & 0.00 & 0.00 \\
\hline Ankles and Feet & 0.00 & 0.00 & 0.00 & 0.00 & 0.00 & 0.00 \\
\hline Cranial Cartilage & 0.00 & 0.00 & 0.00 & 0.00 & 0.00 & 0.00 \\
\hline Costal Cartilage & 56.06 & 61.66 & 32.83 & 79.58 & 87.54 & 40.78 \\
\hline CV Intervertebral Discs & 3.86 & 4.24 & 2.26 & 2.91 & 3.20 & 1.49 \\
\hline TV Intervertebral Discs & 28.53 & 31.38 & 16.71 & 32.77 & 36.05 & 16.79 \\
\hline LV Intervertebral Discs & 26.73 & 29.40 & 15.65 & 23.49 & 25.84 & 12.04 \\
\hline${ }^{1}$ External Nose & 1.47 & 1.61 & 0.86 & 1.92 & 2.11 & 0.99 \\
\hline${ }^{2}$ Ears & 8.36 & 9.20 & 4.90 & 8.36 & 9.20 & 4.29 \\
\hline${ }^{3}$ Extrapulmonary Bronchi & 3.7 & 4.10 & 2.18 & 3.75 & 4.13 & 1.92 \\
\hline${ }^{3} \operatorname{Laryn} x$ & 7.04 & 7.74 & 4.12 & 10.34 & 11.37 & 5.30 \\
\hline${ }^{3}$ Trachea & 2.82 & 3.10 & 1.65 & 3.52 & 3.87 & 1.80 \\
\hline Total Skeleton (Only Bone-Associated Cartilage) & 147.34 & 162.08 & & 167.24 & 183.96 & 100.00 \\
\hline Total Skeleton (All Cartilage) & 170.76 & 187.83 & 100.00 & 195.13 & 214.64 & 100.00 \\
\hline ICRP 89 Reference & 836.36 & 920.00 & & 1036.36 & 1140.00 & \\
\hline Ratio (All Cartilage) & 0.20 & 0.20 & & 0.19 & 0.19 & \\
\hline
\end{tabular}

$33.3333 \%$ of total NURBS volume contains cartilage

${ }^{3} 50 \%$ of NURBS volume contains cartilage 
Table 4-9. Site-specific trabecular and cortical bone volumes and mass including and excluding MST in the 15-year female hybrid phantom.

\begin{tabular}{|c|c|c|c|c|c|c|c|c|}
\hline \multirow[b]{2}{*}{ Skeletal Site } & \multicolumn{4}{|c|}{$\begin{array}{l}\text { Including MST } \\
\end{array}$} & \multicolumn{4}{|c|}{ Excluding MST } \\
\hline & $\begin{array}{c}\text { Trabecular Bone* } \\
\text { Volume }\left(\mathrm{cm}^{3}\right)\end{array}$ & $\begin{array}{c}\text { Trabecular Bone* } \\
\text { Mass (g) }\end{array}$ & $\begin{array}{l}\text { Cortical Bone* } \\
\text { Volume }\left(\mathrm{cm}^{3}\right)\end{array}$ & $\begin{array}{l}\text { Cortical Bone } \\
\text { Mass (g) }\end{array}$ & $\begin{array}{c}\text { Trabecular Bone } \\
\text { Volume }\left(\mathrm{cm}^{3}\right)\end{array}$ & $\begin{array}{c}\text { Trabecular Bone } \\
\text { Mass (g) }\end{array}$ & $\begin{array}{l}\text { Cortical Bone } \\
\text { Volume }\left(\mathrm{cm}^{3}\right)\end{array}$ & $\begin{array}{c}\text { Cortical Bone } \\
\text { Mass (g) }\end{array}$ \\
\hline Cranium & 86.99 & 154.45 & 249.34 & 442.73 & 84.26 & 151.68 & 241.54 & 434.77 \\
\hline Mandible & 5.82 & 10.33 & 26.15 & 46.44 & 5.64 & 10.15 & 25.34 & 45.60 \\
\hline Cervical & 8.32 & 14.78 & 23.76 & 42.19 & 8.06 & 14.51 & 23.02 & 41.43 \\
\hline Thoracic & 22.99 & 40.82 & 46.51 & 82.59 & 22.27 & 40.09 & 45.06 & 81.11 \\
\hline Lumbar & 22.74 & 40.37 & 22.83 & 40.53 & 22.02 & 39.64 & 22.11 & 39.80 \\
\hline Sternum & 2.12 & 3.77 & 8.67 & 15.40 & 2.06 & 3.70 & 8.40 & 15.13 \\
\hline Ribs & 19.69 & 34.96 & 103.15 & 183.16 & 19.07 & 34.33 & 99.92 & 179.86 \\
\hline Scapulae & 31.72 & 56.32 & 95.51 & 169.59 & 30.72 & 55.30 & 92.52 & 166.54 \\
\hline Clavicles & 3.62 & 6.44 & 31.50 & 55.94 & 3.51 & 6.32 & 30.52 & 54.93 \\
\hline Os coxae & 46.85 & 83.19 & 119.05 & 211.38 & 45.39 & 81.70 & 115.32 & 207.58 \\
\hline Sacrum & 6.62 & 11.75 & 47.89 & 85.03 & 6.41 & 11.54 & 46.39 & 83.51 \\
\hline Humeri, Proximal & 16.27 & 28.90 & 19.45 & 34.53 & 15.77 & 28.38 & 18.84 & 33.91 \\
\hline Humeri, Upper Shaft & 0.00 & 0.00 & 49.63 & 88.12 & 0.00 & 0.00 & 48.08 & 86.54 \\
\hline Humeri, Lower Shaft & 0.00 & 0.00 & 43.31 & 76.90 & 0.00 & 0.00 & 41.96 & 75.52 \\
\hline Humeri, Distal & 9.54 & 16.93 & 30.79 & 54.66 & 9.24 & 16.63 & 29.82 & 53.68 \\
\hline Radii, Distal & 3.11 & 5.52 & 5.44 & 9.66 & 3.01 & 5.42 & 5.27 & 9.49 \\
\hline Ulnae, Proximal & 6.99 & 12.41 & 12.43 & 22.07 & 6.77 & 12.19 & 12.04 & 21.67 \\
\hline Ulnae, Shaft & 0.00 & 0.00 & 43.50 & 77.23 & 0.00 & 0.00 & 42.14 & 75.84 \\
\hline Ulnae, Distal & 0.91 & 1.62 & 2.37 & 4.22 & 0.88 & 1.59 & 2.30 & 4.14 \\
\hline Wrists and Hands & 5.14 & 9.13 & 59.91 & 106.38 & 4.98 & 8.97 & 58.04 & 104.46 \\
\hline Femora, Proximal & 29.10 & 51.66 & 36.49 & 64.80 & 28.19 & 50.74 & 35.35 & 63.63 \\
\hline Femora, Upper Shaft & 0.00 & 0.00 & 94.20 & 167.26 & 0.00 & 0.00 & 91.25 & 164.25 \\
\hline Femora, Lower Shaft & 0.00 & 0.00 & 106.44 & 189.00 & 0.00 & 0.00 & 103.11 & 185.60 \\
\hline Femora, Distal & 57.33 & 101.79 & 34.69 & 61.60 & 55.53 & 99.96 & 33.60 & 60.49 \\
\hline Patellae & 1.89 & 3.35 & 9.71 & 17.23 & 1.83 & 3.29 & 9.40 & 16.92 \\
\hline Tibiae, Proximal & 13.41 & 23.81 & 49.36 & 87.64 & 12.99 & 23.38 & 47.81 & 86.06 \\
\hline Tibiae, Shaft & 0.00 & 0.00 & 119.38 & 211.96 & 0.00 & 0.00 & 115.64 & 208.15 \\
\hline Tibiae, Distal & 10.71 & 19.01 & 11.41 & 20.26 & 10.37 & 18.67 & 11.06 & 19.90 \\
\hline Fibulae, Proximal & 1.55 & 2.75 & 5.52 & 9.79 & 1.50 & 2.70 & 5.34 & 9.62 \\
\hline Fibulae, Shaft & 0.00 & 0.00 & 19.01 & 33.75 & 0.00 & 0.00 & 18.41 & 33.14 \\
\hline Fibulae, Distal & 2.55 & 4.53 & 5.54 & 9.84 & 2.47 & 4.45 & 5.37 & 9.67 \\
\hline Ankles and Feet & 32.44 & 57.61 & 97.91 & 173.85 & 31.43 & 56.57 & 94.85 & 170.73 \\
\hline Total Skeleton & 449.92 & 798.87 & 1672.03 & 2968.85 & 435.84 & 784.51 & 1619.72 & 2915.49 \\
\hline
\end{tabular}

*Denotes inclusion of associated miscellaneous skeletal tissue volumes and masses 
Table 4-10. Site-specific trabecular and cortical bone volumes and mass including and excluding MST in the newborn 15-year male phantom.

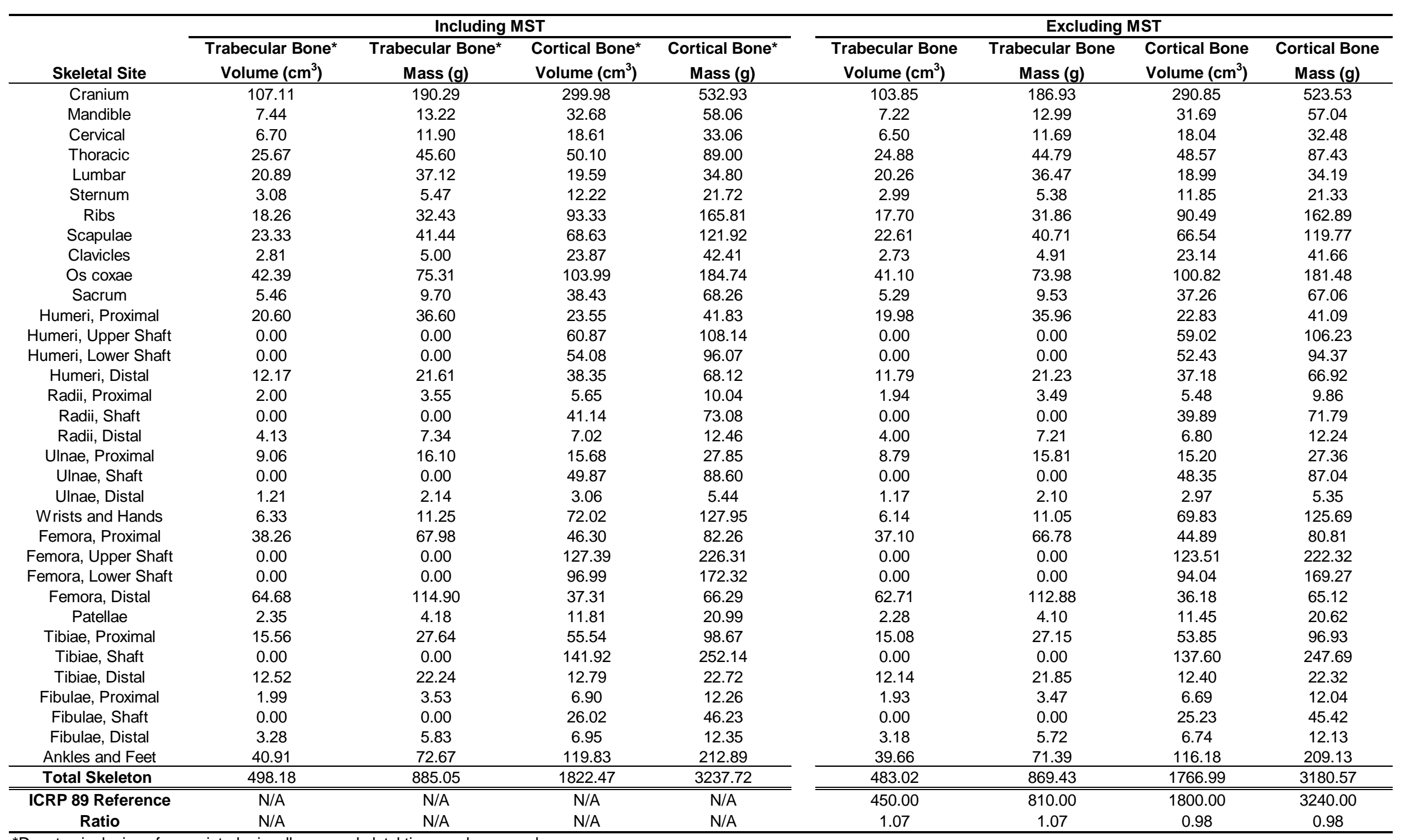

*Denotes inclusion of associated miscellaneous skeletal tissue volumes and masses 
Table 4-11. Site-specific total mineral bone volumes and mass including and excluding MST in the 15-year female (left) and male (right) hybrid phantoms.

\begin{tabular}{|c|c|c|c|c|}
\hline \multirow[b]{3}{*}{ Skeletal Site } & \multicolumn{4}{|c|}{ Female } \\
\hline & Total Mineral Bone & Total Mineral Bone & Total Mineral Bone* & Total Mineral Bone* \\
\hline & Volume $\left(\mathrm{cm}^{3}\right)$ & Mass (g) & Volume $\left(\mathrm{cm}^{3}\right)$ & Mass (g) \\
\hline Cranium & 325.80 & 586.45 & 336.33 & 597.18 \\
\hline Mandible & 30.97 & 55.75 & 31.97 & 56.77 \\
\hline Cervical & 31.08 & 55.94 & 32.08 & 56.97 \\
\hline Thoracic & 67.33 & 121.20 & 69.51 & 123.41 \\
\hline Lumbar & 44.14 & 79.45 & 45.56 & 80.90 \\
\hline Sternum & 10.46 & 18.83 & 10.80 & 19.17 \\
\hline Ribs & 119.00 & 214.20 & 122.84 & 218.12 \\
\hline Scapulae & 123.25 & 221.84 & 127.23 & 225.90 \\
\hline Clavicles & 34.03 & 61.25 & 35.13 & 62.37 \\
\hline Os coxae & 160.71 & 289.28 & 165.90 & 294.57 \\
\hline Sacrum & 52.80 & 95.04 & 54.51 & 96.78 \\
\hline Humeri, Proximal & 34.60 & 62.29 & 35.72 & 63.43 \\
\hline Humeri, Upper Shaft & 48.08 & 86.54 & 49.63 & 88.12 \\
\hline Humeri, Lower Shaft & 41.96 & 75.52 & 43.31 & 76.90 \\
\hline Humeri, Distal & 39.06 & 70.31 & 40.32 & 71.59 \\
\hline Radii, Proximal & 5.68 & 10.22 & 5.86 & 10.40 \\
\hline Radii, Shaft & 35.67 & 64.21 & 36.83 & 65.39 \\
\hline Radii, Distal & 8.28 & 14.90 & 8.55 & 15.18 \\
\hline Ulnae, Proximal & 18.81 & 33.86 & 19.42 & 34.48 \\
\hline Ulnae, Shaft & 42.14 & 75.84 & 43.50 & 77.23 \\
\hline Ulnae, Distal & 3.18 & 5.73 & 3.28 & 5.83 \\
\hline Wrists and Hands & 63.02 & 113.43 & 65.05 & 115.51 \\
\hline Femora, Proximal & 63.54 & 114.37 & 65.59 & 116.46 \\
\hline Femora, Upper Shaft & 91.25 & 164.25 & 94.20 & 167.26 \\
\hline Femora, Lower Shaft & 103.11 & 185.60 & 106.44 & 189.00 \\
\hline Femora, Distal & 89.14 & 160.45 & 92.02 & 163.39 \\
\hline Patellae & 11.23 & 20.21 & 11.59 & 20.58 \\
\hline Tibiae, Proximal & 60.80 & 109.44 & 62.77 & 111.45 \\
\hline Tibiae, Shaft & 115.64 & 208.15 & 119.38 & 211.96 \\
\hline Tibiae, Distal & 21.43 & 38.57 & 22.12 & 39.28 \\
\hline Fibulae, Proximal & 6.84 & 12.32 & 7.07 & 12.55 \\
\hline Fibulae, Shaft & 18.41 & 33.14 & 19.01 & 33.75 \\
\hline Fibulae, Distal & 7.84 & 14.12 & 8.10 & 14.37 \\
\hline Ankles and Feet & 126.28 & 227.30 & 130.35 & 231.46 \\
\hline Total Skeleton & 2055.56 & 3700.00 & 2121.94 & 3767.72 \\
\hline ICRP 89 Reference & 2055.56 & 3700.00 & 2121.94 & 3767.72 \\
\hline Ratio & 1.00 & 1.00 & 1.00 & 1.00 \\
\hline
\end{tabular}

\begin{tabular}{|c|c|c|c|}
\hline \multicolumn{4}{|c|}{ Male } \\
\hline Total Mineral Bone & Total Mineral Bone & Total Mineral Bone* & Total Mineral Bone \\
\hline Volume $\left(\mathrm{cm}^{3}\right)$ & Mass (g) & Volume $\left(\mathrm{cm}^{3}\right)$ & Mass (g) \\
\hline 394.70 & 710.46 & 407.09 & 723.22 \\
\hline 38.91 & 70.03 & 40.13 & 71.29 \\
\hline 24.54 & 44.17 & 25.31 & 44.96 \\
\hline 73.46 & 132.22 & 75.76 & 134.59 \\
\hline 39.25 & 70.66 & 40.49 & 71.92 \\
\hline 14.84 & 26.71 & 15.31 & 27.19 \\
\hline 108.19 & 194.75 & 111.59 & 198.24 \\
\hline 89.15 & 160.48 & 91.95 & 163.36 \\
\hline 25.87 & 46.57 & 26.69 & 47.41 \\
\hline 141.92 & 255.45 & 146.37 & 260.04 \\
\hline 42.55 & 76.59 & 43.89 & 77.97 \\
\hline 42.81 & 77.05 & 44.15 & 78.44 \\
\hline 59.02 & 106.23 & 60.87 & 108.14 \\
\hline 52.43 & 94.37 & 54.08 & 96.07 \\
\hline 48.97 & 88.15 & 50.51 & 89.73 \\
\hline 7.42 & 13.35 & 7.65 & 13.59 \\
\hline 39.89 & 71.79 & 41.14 & 73.08 \\
\hline 10.81 & 19.45 & 11.15 & 19.80 \\
\hline 23.98 & 43.17 & 24.74 & 43.95 \\
\hline 48.35 & 87.04 & 49.87 & 88.60 \\
\hline 4.14 & 7.45 & 4.27 & 7.58 \\
\hline 75.97 & 136.74 & 78.35 & 139.20 \\
\hline 81.99 & 147.59 & 84.57 & 150.24 \\
\hline 123.51 & 222.32 & 127.39 & 226.31 \\
\hline 94.04 & 169.27 & 96.99 & 172.32 \\
\hline 98.88 & 177.99 & 101.99 & 181.19 \\
\hline 13.73 & 24.72 & 14.16 & 25.16 \\
\hline 68.93 & 124.07 & 71.09 & 126.30 \\
\hline 137.60 & 247.69 & 141.92 & 252.14 \\
\hline 24.54 & 44.17 & 25.31 & 44.96 \\
\hline 8.62 & 15.52 & 8.89 & 15.79 \\
\hline 25.23 & 45.42 & 26.02 & 46.23 \\
\hline 9.92 & 17.85 & 10.23 & 18.17 \\
\hline 155.84 & 280.52 & 160.74 & 285.56 \\
\hline 2250.00 & 4050.00 & 2320.65 & 4122.77 \\
\hline 2250.00 & 4050.00 & 2320.65 & 4122.77 \\
\hline 1.00 & 1.00 & 1.00 & 1.00 \\
\hline
\end{tabular}


Table 4-12. Percentages of total mineral bone attributed to cortical bone and to trabecular bone by skeletal site in the newborn, 15-year female and male hybrid phantoms compared to the ICRP adult reference values.

\begin{tabular}{|c|c|c|c|c|c|c|c|c|}
\hline \multirow[b]{2}{*}{ Skeletal Site } & \multicolumn{2}{|c|}{ Newborn } & \multicolumn{2}{|c|}{15 Y Female } & \multicolumn{2}{|c|}{$15 \mathrm{Y}$ Male } & \multicolumn{2}{|c|}{ Adult } \\
\hline & Cortical & Trabecular & Cortical & Trabecular & Cortical & Trabecular & Cortical & Trabecular \\
\hline Cranium & 0.27 & 0.73 & 0.74 & 0.26 & 0.74 & 0.26 & 0.95 & 0.05 \\
\hline Mandible & 0.41 & 0.59 & 0.82 & 0.18 & 0.81 & 0.19 & 0.95 & 0.05 \\
\hline Cervical & 0.47 & 0.53 & 0.74 & 0.26 & 0.74 & 0.26 & 0.25 & 0.75 \\
\hline Thoracic & 0.57 & 0.43 & 0.67 & 0.33 & 0.66 & 0.34 & 0.25 & 0.75 \\
\hline Lumbar & 0.39 & 0.61 & 0.50 & 0.50 & 0.48 & 0.52 & 0.34 & 0.66 \\
\hline Sternum & 0.37 & 0.63 & 0.80 & 0.20 & 0.80 & 0.20 & 0.94 & 0.06 \\
\hline Ribs & 0.41 & 0.59 & 0.84 & 0.16 & 0.84 & 0.16 & 0.94 & 0.06 \\
\hline Scapula & 0.54 & 0.46 & 0.75 & 0.25 & 0.75 & 0.25 & 0.94 & 0.06 \\
\hline Clavicles & 0.54 & 0.46 & 0.90 & 0.10 & 0.89 & 0.11 & 0.94 & 0.06 \\
\hline Os coxae & 0.61 & 0.39 & 0.72 & 0.28 & 0.71 & 0.29 & 0.90 & 0.10 \\
\hline Sacrum & 0.39 & 0.61 & 0.88 & 0.12 & 0.88 & 0.12 & 0.75 & 0.25 \\
\hline Humeri, upper half & 0.50 & 0.50 & 0.81 & 0.19 & 0.80 & 0.20 & 0.90 & 0.10 \\
\hline Humeri, lower half & 0.55 & 0.45 & 0.89 & 0.11 & 0.88 & 0.12 & 0.90 & 0.10 \\
\hline Radii & 0.57 & 0.43 & 0.91 & 0.09 & 0.90 & 0.10 & 0.87 & 0.13 \\
\hline Ulna & 0.57 & 0.43 & 0.88 & 0.12 & 0.87 & 0.13 & 0.87 & 0.13 \\
\hline Wrist and Hands & 0.38 & 0.62 & 0.92 & 0.08 & 0.92 & 0.08 & 0.95 & 0.05 \\
\hline Femora, upper half & 0.54 & 0.46 & 0.82 & 0.18 & 0.82 & 0.18 & 0.77 & 0.23 \\
\hline Femora, lower half & 0.68 & 0.32 & 0.71 & 0.29 & 0.67 & 0.33 & 0.77 & 0.23 \\
\hline Patella & 0.38 & 0.62 & 0.84 & 0.16 & 0.83 & 0.17 & 0.77 & 0.23 \\
\hline Tibia & 0.55 & 0.45 & 0.88 & 0.12 & 0.88 & 0.12 & 0.83 & 0.17 \\
\hline Fibula & 0.60 & 0.40 & 0.88 & 0.12 & 0.88 & 0.12 & 0.89 & 0.11 \\
\hline Ankles and Feet & 0.38 & 0.62 & 0.75 & 0.25 & 0.75 & 0.25 & 0.65 & 0.35 \\
\hline
\end{tabular}


Table 4-13. Distribution of shallow marrow by skeletal site in the 15-year female hybrid phantom.

\begin{tabular}{|c|c|c|c|c|c|c|c|c|c|}
\hline Bone Site & $\begin{array}{l}\text { Shallow Marrow* } \\
\text { SMVF (\% of SV) }\end{array}$ & $\begin{array}{c}\text { Shallow Marrow* } \\
\text { (\% of MV) }\end{array}$ & $\begin{array}{l}\text { Shallow Marrow* } \\
\text { Volume }\left(\mathrm{cm}^{3}\right)\end{array}$ & $\begin{array}{l}\text { Shallow Marrow* } \\
\text { Mass (g) @100\% }\end{array}$ & $\begin{array}{c}\text { Shallow Marrow } \\
\text { Cellularity (\%) }\end{array}$ & $\begin{array}{c}\text { Shallow } \\
\text { Inactive Marrow* } \\
\text { Mass (g) }\end{array}$ & $\begin{array}{c}\text { Shallow } \\
\text { Active Marrow* } \\
\text { Mass (g) } \\
\end{array}$ & $\begin{array}{c}\text { Shallow Marrow* } \\
\text { Mass (g) @ Ref. Cell. }\end{array}$ & $\begin{array}{l}\text { Shallow } \\
\text { Marrow }^{*} \\
\text { \% of total }\end{array}$ \\
\hline $\begin{array}{l}{ }^{1} \text { Cranium } \\
\text { Mandible }\end{array}$ & $\begin{array}{l}13.84 \% \\
14.21 \%\end{array}$ & $\begin{array}{l}20.33 \% \\
19.81 \%\end{array}$ & $\begin{array}{c}37.70 \\
2.92\end{array}$ & $\begin{array}{c}38.83 \\
3.01\end{array}$ & $\begin{array}{l}55 \\
55\end{array}$ & $\begin{array}{c}16.63 \\
1.29\end{array}$ & $\begin{array}{c}21.36 \\
1.66\end{array}$ & $\begin{array}{c}37.98 \\
2.95\end{array}$ & $\begin{array}{c}10.78 \% \\
0.84 \%\end{array}$ \\
\hline${ }^{2}$ Cervical & $14.76 \%$ & $17.57 \%$ & 7.68 & 7.91 & 75 & 1.88 & 5.93 & 7.81 & $2.22 \%$ \\
\hline${ }^{3}$ Thoracic & $13.27 \%$ & $15.22 \%$ & 23.85 & 24.56 & 75 & 5.84 & 18.42 & 24.27 & $6.89 \%$ \\
\hline $\begin{array}{l}{ }^{4} \text { Lumbar } \\
\text { Sternum }\end{array}$ & $\begin{array}{l}12.20 \% \\
12.63 \%\end{array}$ & $\begin{array}{l}13.64 \% \\
13.93 \%\end{array}$ & $\begin{array}{c}26.15 \\
2.87\end{array}$ & $\begin{array}{c}26.94 \\
2.96\end{array}$ & $\begin{array}{l}75 \\
75\end{array}$ & $\begin{array}{l}6.41 \\
0.70\end{array}$ & $\begin{array}{c}20.20 \\
2.22\end{array}$ & $\begin{array}{c}26.61 \\
2.92\end{array}$ & $\begin{array}{l}7.55 \% \\
0.83 \%\end{array}$ \\
\hline${ }^{5}$ Ribs & $12.01 \%$ & $13.66 \%$ & 19.57 & 20.16 & 75 & 4.80 & 15.12 & 19.92 & $5.65 \%$ \\
\hline Right Scapula & $11.87 \%$ & $17.11 \%$ & 12.28 & 12.65 & 55 & 5.42 & 6.96 & 12.37 & $3.51 \%$ \\
\hline Right Clavicle & $10.43 \%$ & $12.66 \%$ & 2.15 & 2.22 & 53 & 0.99 & 1.17 & 2.17 & $0.61 \%$ \\
\hline${ }^{6}$ Os coxae & $12.78 \%$ & $14.29 \%$ & 56.99 & 58.70 & 64 & 20.11 & 37.57 & 57.67 & $16.37 \%$ \\
\hline Sacrum & $7.15 \%$ & $7.58 \%$ & 8.40 & 8.65 & 64 & 2.96 & 5.54 & 8.50 & $2.41 \%$ \\
\hline Humerii, Right Proximal & $13.28 \%$ & $15.73 \%$ & 13.93 & 14.35 & 55 & 6.14 & 7.89 & 14.04 & $3.98 \%$ \\
\hline${ }^{7}$ Humerii, Upper Shaft & $2.09 \%$ & $2.09 \%$ & 0.29 & 0.30 & 35 & 0.19 & 0.10 & 0.29 & $0.08 \%$ \\
\hline${ }^{7}$ Humerii, Lower Shaft & $2.26 \%$ & $2.26 \%$ & 0.27 & 0.28 & 20 & 0.22 & 0.06 & 0.27 & $0.08 \%$ \\
\hline Humerii, Right Distal & $13.57 \%$ & $17.30 \%$ & 6.01 & 6.19 & 0 & 5.89 & 0.00 & 5.89 & $1.67 \%$ \\
\hline Radii, Right Proximal & $13.54 \%$ & $17.05 \%$ & 0.99 & 1.02 & 0 & 0.97 & 0.00 & 0.97 & $0.27 \%$ \\
\hline Radii, Shaft & $4.39 \%$ & $4.39 \%$ & 0.25 & 0.25 & 0 & 0.24 & 0.00 & 0.24 & $0.07 \%$ \\
\hline Radii, Right Distal & $13.57 \%$ & $16.89 \%$ & 2.15 & 2.21 & 0 & 2.10 & 0.00 & 2.10 & $0.60 \%$ \\
\hline Ulna, Right Proximal & $15.16 \%$ & $20.32 \%$ & 4.18 & 4.30 & 0 & 4.09 & 0.00 & 4.09 & $1.16 \%$ \\
\hline Ulna, Shaft & $3.93 \%$ & $3.93 \%$ & 0.27 & 0.28 & 0 & 0.27 & 0.00 & 0.27 & $0.08 \%$ \\
\hline Ulna, Right Distal & $16.04 \%$ & $19.71 \%$ & 0.78 & 0.81 & 0 & 0.77 & 0.00 & 0.77 & $0.22 \%$ \\
\hline${ }^{8}$ Wrist and Hands & $12.01 \%$ & $13.66 \%$ & 5.11 & 5.27 & 0 & 5.01 & 0.00 & 5.01 & $1.42 \%$ \\
\hline${ }^{9}$ Femora, Proximal & $15.33 \%$ & $19.31 \%$ & 21.60 & 22.25 & 55 & 9.53 & 12.24 & 21.76 & $6.18 \%$ \\
\hline${ }^{7}$ Femora, Upper Shaft & $1.68 \%$ & $1.68 \%$ & 0.54 & 0.56 & 35 & 0.35 & 0.20 & 0.54 & $0.15 \%$ \\
\hline${ }^{7}$ Femora, Lower Shaft & $1.55 \%$ & $1.55 \%$ & 0.57 & 0.58 & 20 & 0.44 & 0.12 & 0.56 & $0.16 \%$ \\
\hline Femora, Distal & $15.64 \%$ & $21.66 \%$ & 32.26 & 33.23 & 0 & 31.62 & 0.00 & 31.62 & $8.97 \%$ \\
\hline${ }^{8}$ Patella & $12.01 \%$ & $13.66 \%$ & 1.87 & 1.93 & 0 & 1.84 & 0.00 & 1.84 & $0.52 \%$ \\
\hline Tibia, Proximal & $10.73 \%$ & $11.85 \%$ & 15.14 & 15.60 & 0 & 14.84 & 0.00 & 14.84 & $4.21 \%$ \\
\hline Tibia, Shaft & $1.75 \%$ & $1.75 \%$ & 0.85 & 0.87 & 0 & 0.83 & 0.00 & 0.83 & $0.24 \%$ \\
\hline Tibia, Distal & $15.14 \%$ & $18.59 \%$ & 8.75 & 9.01 & 0 & 8.57 & 0.00 & 8.57 & $2.43 \%$ \\
\hline Fibula, Proximal & $13.14 \%$ & $15.48 \%$ & 1.34 & 1.38 & 0 & 1.32 & 0.00 & 1.32 & $0.37 \%$ \\
\hline Fibula, Shaft & $5.02 \%$ & $5.02 \%$ & 0.29 & 0.30 & 0 & 0.28 & 0.00 & 0.28 & $0.08 \%$ \\
\hline Fibula, Distal & $16.32 \%$ & $22.20 \%$ & 1.57 & 1.62 & 0 & 1.54 & 0.00 & 1.54 & $0.44 \%$ \\
\hline${ }^{8}$ Ankles and Feet & $12.01 \%$ & $13.66 \%$ & 32.25 & 33.22 & 0 & 31.61 & 0.00 & 31.61 & $8.97 \%$ \\
\hline Total Skeleton & - & - & 351.85 & 362.40 & - & 195.67 & 156.75 & 352.42 & $100.00 \%$ \\
\hline
\end{tabular}

${ }^{1}$ The MVF is a inear average between occipital, frontal, parietal (+/- 2.06\%)

${ }^{2}$ The MVF is a linear average between $\mathrm{C}_{3}$ and $\mathrm{C}_{6}(+/-2.23 \%)$

${ }^{3}$ The MVF is a linear average between $T_{1}, T_{3}, T_{6}, T_{9}$, and $T_{12}(+/-1.74 \%)$

${ }^{4} T$ The MVF is a linear average between $L_{1}, L_{2}, L_{3}, L_{4}$, and $L_{5}(+/-2.01 \%)$

${ }^{5}$ The MVF is a linear average between the upper (rib-1), middle (rib-6), and lower right (rib-12) rib (+/- 3.04\%)

${ }^{6}$ The MVF was calculated from the right ilium

${ }^{7}$ The SVF for the upper shaft was segmented and assumed to be the same for the lower shaft

${ }^{8}$ The MVF for the rib was used as a surrogate

${ }^{9}$ The MVF is a linear average of the right and left head and neck (+/- 3.46\%) 
Table 4-14. Distribution of shallow marrow by skeletal site in the 15-year male hybrid phantom.

\begin{tabular}{|c|c|c|c|c|c|c|c|c|c|}
\hline Bone Site & $\begin{array}{l}\text { Shallow Marrow* } \\
\text { SMVF (\% of SV) }\end{array}$ & $\begin{array}{c}\text { Shallow Marrow }{ }^{*} \\
\text { (\% of MV) }\end{array}$ & $\begin{array}{l}\text { Shallow Marrow* } \\
\text { Volume }\left(\mathrm{cm}^{3}\right)\end{array}$ & $\begin{array}{l}\text { Shallow Marrow* } \\
\text { Mass (g) @ 100\% }\end{array}$ & $\begin{array}{l}\text { Shallow Marrow } \\
\text { Cellularity (\%) }\end{array}$ & $\begin{array}{c}\text { Shallow } \\
\text { Inactive Marrow* } \\
\text { Mass (g) }\end{array}$ & $\begin{array}{c}\text { Shallow } \\
\text { Active Marrow* } \\
\text { Mass (g) }\end{array}$ & $\begin{array}{c}\text { Shallow Marrow* } \\
\text { Mass (g) @ Ref. Cell. }\end{array}$ & $\begin{array}{l}\text { Shallow } \\
\text { Marrow* } \\
\text { \% of total }\end{array}$ \\
\hline $\begin{array}{l}{ }^{1} \text { Cranium } \\
\text { Mandible }\end{array}$ & $\begin{array}{l}13.84 \% \\
14.21 \%\end{array}$ & $\begin{array}{l}20.33 \% \\
19.81 \%\end{array}$ & $\begin{array}{c}46.42 \\
3.74\end{array}$ & $\begin{array}{c}47.81 \\
3.85\end{array}$ & $\begin{array}{l}55 \\
55\end{array}$ & $\begin{array}{c}21.52 \\
1.73\end{array}$ & $\begin{array}{c}26.30 \\
2.12\end{array}$ & $\begin{array}{c}47.81 \\
3.85\end{array}$ & $\begin{array}{c}12.09 \% \\
0.97 \%\end{array}$ \\
\hline${ }^{2}$ Cervical & $14.76 \%$ & $17.57 \%$ & 6.18 & 6.36 & 75 & 1.59 & 4.77 & 6.36 & $1.61 \%$ \\
\hline${ }^{3}$ Thoracic & $13.27 \%$ & $15.22 \%$ & 26.62 & 27.42 & 75 & 6.85 & 20.56 & 27.42 & $6.94 \%$ \\
\hline $\begin{array}{l}{ }^{4} \text { Lumbar } \\
\text { Sternum }\end{array}$ & $\begin{array}{l}12.20 \% \\
12.63 \%\end{array}$ & $\begin{array}{l}13.64 \% \\
13.93 \%\end{array}$ & $\begin{array}{c}24.03 \\
4.17\end{array}$ & $\begin{array}{c}24.75 \\
4.29\end{array}$ & $\begin{array}{l}75 \\
75\end{array}$ & $\begin{array}{l}6.19 \\
1.07\end{array}$ & $\begin{array}{c}18.57 \\
3.22\end{array}$ & $\begin{array}{c}24.75 \\
4.29\end{array}$ & $\begin{array}{l}6.26 \% \\
1.09 \%\end{array}$ \\
\hline${ }^{5}$ Ribs & $12.01 \%$ & $13.66 \%$ & 18.15 & 18.69 & 75 & 4.67 & 14.02 & 18.69 & $4.73 \%$ \\
\hline Right Scapula & $11.87 \%$ & $17.11 \%$ & 9.03 & 9.30 & 55 & 4.19 & 5.12 & 9.30 & $2.35 \%$ \\
\hline Right Clavicle & $10.43 \%$ & $12.66 \%$ & 1.67 & 1.72 & 53 & 0.81 & 0.91 & 1.72 & $0.44 \%$ \\
\hline $\begin{array}{c}{ }^{6} \text { Os coxae } \\
\text { Sacrum } \\
\text { Humerii. Riaht Proximal }\end{array}$ & $\begin{array}{c}12.78 \% \\
7.15 \% \\
13.28 \%\end{array}$ & $\begin{array}{c}14.29 \% \\
7.58 \% \\
15.73 \%\end{array}$ & $\begin{array}{c}51.56 \\
6.93 \\
17.64\end{array}$ & $\begin{array}{c}53.11 \\
7.14 \\
18.17\end{array}$ & $\begin{array}{l}64 \\
64 \\
55\end{array}$ & $\begin{array}{c}19.12 \\
2.57 \\
8.17\end{array}$ & $\begin{array}{c}33.99 \\
4.57 \\
9.99\end{array}$ & $\begin{array}{c}53.11 \\
7.14 \\
18.17\end{array}$ & $\begin{array}{c}13.43 \% \\
1.81 \% \\
4.60 \%\end{array}$ \\
\hline${ }^{7}$ Humerii, Upper Shaft & $\begin{array}{l}10.20 \% \\
1.89 \%\end{array}$ & $1.89 \%$ & 0.33 & 0.34 & 35 & 0.22 & 0.12 & 0.34 & $0.09 \%$ \\
\hline${ }^{7}$ Humerii, Lower Shaft & $2.07 \%$ & $2.07 \%$ & 0.33 & 0.34 & 20 & 0.27 & 0.07 & 0.34 & $0.08 \%$ \\
\hline Humerii, Right Distal & $13.57 \%$ & $17.30 \%$ & 7.67 & 7.90 & 0 & 7.90 & 0.00 & 7.90 & $2.00 \%$ \\
\hline Radii, Right Proximal & $13.54 \%$ & $17.05 \%$ & 1.31 & 1.35 & 0 & 1.35 & 0.00 & 1.35 & $0.34 \%$ \\
\hline Radii, Shaft & $4.07 \%$ & $4.07 \%$ & 0.27 & 0.28 & 0 & 0.28 & 0.00 & 0.28 & $0.07 \%$ \\
\hline Radii, Right Distal & $13.57 \%$ & $16.89 \%$ & 2.85 & 2.94 & 0 & 2.94 & 0.00 & 2.94 & $0.74 \%$ \\
\hline Ulna, Right Proximal & $15.16 \%$ & $20.32 \%$ & 5.41 & 5.58 & 0 & 5.58 & 0.00 & 5.58 & $1.41 \%$ \\
\hline Ulna, Shaft & $3.61 \%$ & $3.61 \%$ & 0.30 & 0.31 & 0 & 0.31 & 0.00 & 0.31 & $0.08 \%$ \\
\hline Ulna, Right Distal & $16.04 \%$ & $19.71 \%$ & 1.04 & 1.07 & 0 & 1.07 & 0.00 & 1.07 & $0.27 \%$ \\
\hline${ }^{8}$ Wrist and Hands & $12.01 \%$ & $13.66 \%$ & 6.30 & 6.48 & 0 & 6.48 & 0.00 & 6.48 & $1.64 \%$ \\
\hline${ }^{9}$ Femora, Proximal & $15.33 \%$ & $19.31 \%$ & 28.41 & 29.26 & 55 & 13.17 & 16.09 & 29.26 & $7.40 \%$ \\
\hline${ }^{7}$ Femora, Upper Shaft & $1.44 \%$ & $1.44 \%$ & 0.65 & 0.67 & 35 & 0.44 & 0.23 & 0.67 & $0.17 \%$ \\
\hline $\begin{array}{c}{ }^{7} \text { Femora, Lower Shaft } \\
\text { Femora. Distal }\end{array}$ & $\begin{array}{c}1.64 \% \\
15.64 \%\end{array}$ & $\begin{array}{c}1.64 \% \\
21.66 \%\end{array}$ & $\begin{array}{c}0.56 \\
36.40\end{array}$ & $\begin{array}{c}0.58 \\
37.49\end{array}$ & $\begin{array}{c}20 \\
0\end{array}$ & $\begin{array}{c}0.47 \\
37.49\end{array}$ & $\begin{array}{l}0.12 \\
0.00\end{array}$ & $\begin{array}{c}0.58 \\
37.49\end{array}$ & $\begin{array}{l}0.15 \% \\
9.48 \%\end{array}$ \\
\hline${ }^{8} \mathrm{Patella}$ & $12.01 \%$ & $13.66 \%$ & $\begin{array}{l}3.40 \\
2.34\end{array}$ & $\begin{array}{l}31.49 \\
2.41\end{array}$ & 0 & $\begin{array}{l}31.49 \\
2.41\end{array}$ & 0.00 & $\begin{array}{l}31.49 \\
2.41\end{array}$ & $0.61 \%$ \\
\hline Tibia, Proximal & $10.73 \%$ & $11.85 \%$ & 17.56 & 18.09 & 0 & 18.09 & 0.00 & 18.09 & $4.58 \%$ \\
\hline Tibia, Shaft & $1.60 \%$ & $1.60 \%$ & 0.95 & 0.98 & 0 & 0.98 & 0.00 & 0.98 & $0.25 \%$ \\
\hline Tibia, Distal & $15.14 \%$ & $18.59 \%$ & 10.23 & 10.53 & 0 & 10.53 & 0.00 & 10.53 & $2.66 \%$ \\
\hline Fibula, Proximal & $13.14 \%$ & $15.48 \%$ & 1.72 & 1.78 & 0 & 1.78 & 0.00 & 1.78 & $0.45 \%$ \\
\hline Fibula, Shaft & $4.29 \%$ & $4.29 \%$ & 0.35 & 0.36 & 0 & 0.36 & 0.00 & 0.36 & $0.09 \%$ \\
\hline Fibula, Distal & $16.32 \%$ & $22.20 \%$ & 2.02 & 2.08 & 0 & 2.08 & 0.00 & 2.08 & $0.53 \%$ \\
\hline${ }^{8}$ Ankles and Feet & $12.01 \%$ & $13.66 \%$ & 40.67 & 41.89 & 0 & 41.89 & 0.00 & 41.89 & $10.60 \%$ \\
\hline Total Skeleton & & -20.00 & 383.82 & 395.34 & 正 & 234.56 & 160.77 & 395.34 & $100.00 \%$ \\
\hline
\end{tabular}

${ }^{1}$ The MVF is a inear average between occipital, frontal, parietal (+/- 2.06\%)

${ }^{2}$ The MVF is a linear average between $C_{3}$ and $C_{6}(+/-2.23 \%)$

${ }^{3}$ The MVF is a linear average between $T_{1}, T_{3}, T_{6}, T_{9}$, and $T_{12}(+/-1.74 \%)$

${ }^{4}$ The MVF is a linear average between $L_{1}, L_{2}, L_{3}, L_{4}$, and $L_{5}(+/-2.01 \%)$

${ }^{5}$ The MVF is a linear average between the upper (rib-1), middle (rib-6), and lower right (rib-12) rib (+/- 3.04\%)

${ }^{6}$ The MVF was calculated from the right ilium

${ }^{7}$ The SVF for the upper shaft was segmented and assumed to be the same for the lower shaft

${ }^{8}$ The MVF for the rib was used as a surrogate

${ }^{9}$ The MVF is a linear average of the right and left head and neck (+/- 3.46\%) 
Table 4-15. Lengths and radii of the medullary cavities within the long bones of the 15-year female (left) and male (right) hybrid phantoms.

\begin{tabular}{|c|c|c|c|c|c|c|}
\hline \multirow[b]{2}{*}{ Bone site } & \multicolumn{2}{|c|}{$\begin{array}{l}\text { Measured Height (cm) } \\
\text { Medullary Marrow }\end{array}$} & \multicolumn{2}{|c|}{$\begin{array}{l}\text { Measured Height } \\
\text { Std. Dev. }(\mathrm{cm})\end{array}$} & \multicolumn{2}{|c|}{$\begin{array}{c}\text { Calculated Radius }(\mathrm{cm}) \\
\text { Medullary Marrow }\end{array}$} \\
\hline & Female & Male & Female & Male & Female & Male \\
\hline Humerii, Upper Shaft & 9.76 & 10.18 & 0.10 & 0.10 & 0.48 & 0.53 \\
\hline Humerii, Lower Shaft & 9.99 & 10.85 & 0.12 & 0.03 & 0.44 & 0.48 \\
\hline Radii, Shaft & 17.53 & 17.73 & 0.16 & 0.13 & 0.23 & 0.24 \\
\hline Ulna, Shaft & 17.44 & 17.67 & 0.03 & 0.17 & 0.25 & 0.27 \\
\hline Femora, Upper Shaft & 14.64 & 17.04 & 0.06 & 0.13 & 0.59 & 0.69 \\
\hline Femora, Lower Shaft & 14.11 & 16.88 & 0.05 & 0.05 & 0.64 & 0.61 \\
\hline Tibia, Shaft & 23.74 & 24.37 & 0.05 & 0.11 & 0.57 & 0.62 \\
\hline Fibula, Shaft & 23.76 & 24.42 & 0.05 & 0.07 & 0.20 & 0.23 \\
\hline
\end{tabular}

Table 4-16. Comparison of trabecular bone surface-to-volume (S/V) ratios $\left(\mathrm{mm}^{2} \mathrm{~mm}^{-3}\right)$ by skeletal site and age.

\begin{tabular}{|c|c|c|c|c|c|}
\hline Skeletal Site & $\begin{array}{c}\mathrm{mm}^{2} / \mathrm{mm}^{3} \\
{ }^{\mathrm{a}} \text { Hybrid Newborn }\end{array}$ & $\begin{array}{l}\mathrm{mm}^{2} / \mathrm{mm}^{3} \\
{ }^{\mathrm{b}} 15 \text {-year }\end{array}$ & $\begin{array}{c}\mathrm{mm}^{2} / \mathrm{mm}^{3} \\
{ }^{\prime} \text { ICRP 15-year }\end{array}$ & $\begin{array}{c}\mathrm{mm}^{2} / \mathrm{mm}^{3} \\
\text { ICRP-Adult }\end{array}$ & $\begin{array}{c}\text { Ratio } \\
\text { 15-year hybrid/ 15-year reference }\end{array}$ \\
\hline Cranium & 3.8 & 12.6 & 7.1 & 7.8 & 1.77 \\
\hline Mandible & 29.7 & 14.0 & 7.1 & 7.8 & 1.98 \\
\hline Cervical & 14.3 & 26.0 & 21.9 & 18.0 & 1.19 \\
\hline Thoracic & 13.8 & 28.1 & 21.9 & 18.0 & 1.28 \\
\hline Lumbar & 17.9 & 31.3 & 22.8 & 19.7 & 1.38 \\
\hline Sternum & 31.0 & 34.2 & 19.2 & 18.5 & 1.79 \\
\hline Ribs & 29.7 & 24.2 & 19.2 & 18.5 & 1.26 \\
\hline Scapulae & 25.3 & 10.1 & 21.4 & 18.5 & 0.47 \\
\hline Clavicles & 25.3 & 15.4 & 21.4 & 18.5 & 0.72 \\
\hline Os coxae & 25.3 & 31.2 & 20.0 & 17.2 & 1.56 \\
\hline Sacrum & 17.9 & 31.6 & 21.3 & 19.7 & 1.49 \\
\hline Humeri, Proximal & 17.9 & 23.8 & 18.0 & 18.0 & 0.66 \\
\hline Humeri, Upper Shaft & 0.0 & 0.0 & 10.0 & & 0.00 \\
\hline Humeri, Lower Shaft & 0.0 & 0.0 & 18.0 & 18.0 & 0.58 \\
\hline Humeri, Distal & 17.9 & 20.7 & 18.0 & 18.0 & 0.58 \\
\hline Radii, Proximal & 17.9 & 19.7 & & & \\
\hline Radii, Shaft & 0.0 & 0.0 & 18.0 & 18.0 & 0.72 \\
\hline Radii, Distal & 17.9 & 19.0 & & & \\
\hline Ulnae, Proximal & 17.9 & 16.9 & & & \\
\hline Ulnae, Shaft & 0.0 & 0.0 & 18.0 & 18.0 & 0.73 \\
\hline Ulnae, Distal & 17.9 & 22.3 & & & \\
\hline Wrists and Hands & 17.9 & 24.2 & 18.0 & 18.0 & 1.35 \\
\hline Femora, Proximal & 17.9 & 21.6 & 17.9 & 17.3 & 0.61 \\
\hline Femora, Upper Shaft & 0.0 & 0.0 & 17.9 & 17.3 & 0.61 \\
\hline Femora, Lower Shaft & 0.0 & 0.0 & 17.9 & 17.3 & 0.44 \\
\hline Femora, Distal & 17.9 & 15.9 & 17.9 & 17.3 & 0.44 \\
\hline Patellae & 17.9 & 24.2 & 18.0 & 18.0 & 1.35 \\
\hline Tibiae, Proximal & 17.9 & 29.7 & & & \\
\hline Tibiae, Shaft & 0.0 & 0.0 & 18.0 & 18.0 & 0.94 \\
\hline Tibiae, Distal & 17.9 & 21.3 & & & \\
\hline Fibulae, Proximal & 17.9 & 23.4 & & & \\
\hline Fibulae, Shaft & 0.0 & 0.0 & 18.0 & 18.0 & 0.74 \\
\hline Fibulae, Distal & 17.9 & 16.7 & & & \\
\hline Ankles and Feet & 17.9 & 24.2 & 18.0 & 18.0 & 1.35 \\
\hline
\end{tabular}

${ }^{a}$ Refer to Chapter 2 for detailed analysis.

b18-year male specimens serve as surrogate for 15-year male and female; see text for detailed microstructure data.

cvalues from Beddoe (1976). 
Table 4-17. Site-specific homogeneous spongiosa mass, volume, and density data, including MST, in the 15-year female (left) and male (right) hybrid phantoms.

\begin{tabular}{|c|c|c|}
\hline \multirow[b]{2}{*}{ Skeletal Site } & \multicolumn{2}{|c|}{$\begin{array}{c}\text { Homogeneous* }^{*} \\
\text { Spongiosa Mass (g) }\end{array}$} \\
\hline & Female & Male \\
\hline Cranium & 341.33 & 420.47 \\
\hline Mandible & 25.21 & 32.27 \\
\hline Cervical & 59.23 & 47.69 \\
\hline Thoracic & 200.24 & 223.60 \\
\hline Lumbar & 235.41 & 216.42 \\
\hline Sternum & 24.75 & 35.92 \\
\hline Ribs & 180.82 & 167.72 \\
\hline Scapulae & 128.65 & 94.65 \\
\hline Clavicles & 23.55 & 18.29 \\
\hline Os coxae & 487.01 & 440.76 \\
\hline Sacrum & 124.00 & 102.38 \\
\hline Humeri, Proximal & 118.18 & 149.68 \\
\hline Humeri, Distal & 51.03 & 65.13 \\
\hline Radii, Proximal & 8.34 & 11.10 \\
\hline Radii, Distal & 17.98 & 23.91 \\
\hline Ulnae, Proximal & 32.58 & 42.25 \\
\hline Ulnae, Distal & 5.52 & 7.32 \\
\hline Wrists and Hands & 45.88 & 56.50 \\
\hline Femora, Proximal & 164.41 & 216.29 \\
\hline Femora, Distal & 247.96 & 279.86 \\
\hline Patellae & 16.82 & 20.98 \\
\hline Tibiae, Proximal & 149.16 & 173.08 \\
\hline Tibiae, Distal & 65.18 & 76.24 \\
\hline Fibulae, Proximal & 11.27 & 14.47 \\
\hline Fibulae, Distal & 11.47 & 14.75 \\
\hline Ankles and Feet & 289.38 & 364.99 \\
\hline Total Skeleton & 3065.38 & 3316.72 \\
\hline \multicolumn{3}{|c|}{ Volume Weighted Average Density } \\
\hline ICRP 89 Reference & 3037.84 & 3259.93 \\
\hline Ratio & 0.99 & 0.98 \\
\hline $\begin{array}{l}\text { ICRU } 46 \text { Adult Densit } \\
\text { Ratio }\end{array}$ & & \\
\hline
\end{tabular}

\begin{tabular}{|c|c|}
\hline \multicolumn{2}{|c|}{ Spongiosa Volume $\left(\mathrm{cm}^{3}\right)$} \\
\hline Female & Male \\
\hline 272.40 & 335.42 \\
\hline 20.58 & 26.33 \\
\hline 52.01 & 41.86 \\
\hline 179.65 & 200.54 \\
\hline 214.41 & 197.05 \\
\hline 22.74 & 32.99 \\
\hline 163.03 & 151.17 \\
\hline 103.48 & 76.10 \\
\hline 20.63 & 16.01 \\
\hline 445.79 & 403.32 \\
\hline 117.51 & 97.00 \\
\hline 104.86 & 132.76 \\
\hline 44.29 & 56.50 \\
\hline 7.29 & 9.69 \\
\hline 15.81 & 21.02 \\
\hline 27.55 & 35.70 \\
\hline 4.89 & 6.48 \\
\hline 42.60 & 52.44 \\
\hline 140.96 & 185.37 \\
\hline 206.29 & 232.74 \\
\hline 15.61 & 19.47 \\
\hline 141.16 & 163.74 \\
\hline 57.76 & 67.54 \\
\hline 10.23 & 13.13 \\
\hline 9.63 & 12.37 \\
\hline 268.64 & 338.72 \\
\hline 2709.78 & 2925.46 \\
\hline 2717.65 & 2907.62 \\
\hline 1.00 & 0.99 \\
\hline
\end{tabular}

\begin{tabular}{|c|c|}
\hline \multicolumn{2}{|c|}{ Spongiosa Density $\left(\mathrm{g} / \mathrm{cm}^{3}\right)$} \\
\hline Female & Male \\
\hline 1.25 & 1.25 \\
\hline 1.22 & 1.23 \\
\hline 1.14 & 1.14 \\
\hline 1.11 & 1.11 \\
\hline 1.10 & 1.10 \\
\hline 1.09 & 1.09 \\
\hline 1.11 & 1.11 \\
\hline 1.24 & 1.24 \\
\hline 1.14 & 1.14 \\
\hline 1.09 & 1.09 \\
\hline 1.06 & 1.06 \\
\hline 1.13 & 1.13 \\
\hline 1.15 & 1.15 \\
\hline 1.14 & 1.15 \\
\hline 1.14 & 1.14 \\
\hline 1.18 & 1.18 \\
\hline 1.13 & 1.13 \\
\hline 1.08 & 1.08 \\
\hline 1.17 & 1.17 \\
\hline 1.20 & 1.20 \\
\hline 1.08 & 1.08 \\
\hline 1.06 & 1.06 \\
\hline 1.13 & 1.13 \\
\hline 1.10 & 1.10 \\
\hline 1.19 & 1.19 \\
\hline 1.08 & 1.08 \\
\hline 1.13 & 1.12 \\
\hline 1.18 & 1.18 \\
\hline 0.96 & 0.95 \\
\hline
\end{tabular}


Table 4-18. Site-specific homogeneous spongiosa elemental composition (\% by mass) in the 15-year female hybrid phantom.

\begin{tabular}{|c|c|c|c|c|c|c|c|c|c|c|c|c|}
\hline \multirow[b]{2}{*}{ Skeletal Site } & \multicolumn{12}{|c|}{ Element } \\
\hline & $\mathrm{H}$ & C & $\mathrm{N}$ & $\mathrm{O}$ & $\mathrm{Ca}$ & $\mathrm{Na}$ & $\mathrm{Mg}$ & $\mathrm{P}$ & $\mathrm{S}$ & $\mathrm{Cl}$ & $\mathrm{K}$ & $\mathrm{Fe}$ \\
\hline Cranium & 7.76 & 35.20 & 3.15 & 39.93 & 9.11 & 0.14 & 0.15 & 4.31 & 0.22 & 0.00 & 0.01 & 0.03 \\
\hline Mandible & 8.06 & 36.67 & 3.06 & 39.50 & 8.25 & 0.14 & 0.14 & 3.92 & 0.22 & 0.00 & 0.01 & 0.03 \\
\hline Cervical & 9.04 & 38.92 & 3.12 & 40.88 & 5.02 & 0.12 & 0.16 & 2.46 & 0.21 & 0.00 & 0.01 & 0.06 \\
\hline Thoracic & 9.35 & 40.30 & 3.05 & 40.61 & 4.10 & 0.12 & 0.16 & 2.04 & 0.20 & 0.00 & 0.01 & 0.06 \\
\hline Lumbar & 9.57 & 41.28 & 3.00 & 40.41 & 3.45 & 0.12 & 0.16 & 1.75 & 0.20 & 0.00 & 0.01 & 0.06 \\
\hline Sternum & 9.70 & 41.86 & 2.97 & 40.30 & 3.07 & 0.11 & 0.15 & 1.57 & 0.20 & 0.00 & 0.01 & 0.06 \\
\hline Ribs & 9.42 & 40.62 & 3.03 & 40.54 & 3.89 & 0.12 & 0.16 & 1.95 & 0.20 & 0.00 & 0.01 & 0.06 \\
\hline Scapulae & 7.86 & 35.71 & 3.12 & 39.78 & 8.81 & 0.14 & 0.15 & 4.17 & 0.22 & 0.00 & 0.01 & 0.03 \\
\hline Clavicles & 9.03 & 41.88 & 2.72 & 37.70 & 5.50 & 0.13 & 0.13 & 2.66 & 0.19 & 0.00 & 0.01 & 0.04 \\
\hline Os coxae & 9.66 & 43.29 & 2.77 & 38.61 & 3.44 & 0.12 & 0.14 & 1.73 & 0.19 & 0.00 & 0.01 & 0.05 \\
\hline Sacrum & 10.19 & 45.77 & 2.63 & 37.99 & 1.91 & 0.11 & 0.13 & 1.03 & 0.18 & 0.00 & 0.01 & 0.06 \\
\hline Humeri, Proximal & 9.21 & 42.39 & 2.72 & 37.86 & 4.92 & 0.12 & 0.13 & 2.40 & 0.19 & 0.00 & 0.01 & 0.04 \\
\hline${ }^{1}$ Humeri, Upper Shaft & 11.12 & 55.30 & 1.70 & 31.39 & 0.00 & 0.10 & 0.07 & 0.14 & 0.14 & 0.00 & 0.01 & 0.03 \\
\hline${ }^{1}$ Humeri, Lower Shaft & 11.27 & 58.71 & 1.30 & 28.31 & 0.00 & 0.10 & 0.04 & 0.12 & 0.12 & 0.00 & 0.01 & 0.02 \\
\hline Humeri, Distal & 8.97 & 47.72 & 1.92 & 31.18 & 6.68 & 0.13 & 0.07 & 3.17 & 0.17 & 0.00 & 0.01 & 0.00 \\
\hline Radii, Proximal & 9.06 & 48.29 & 1.88 & 30.92 & 6.43 & 0.13 & 0.06 & 3.05 & 0.17 & 0.00 & 0.01 & 0.00 \\
\hline${ }^{1}$ Radii, Shaft & 11.47 & 63.33 & 0.76 & 24.13 & 0.00 & 0.10 & 0.00 & 0.10 & 0.10 & 0.00 & 0.01 & 0.00 \\
\hline Radii, Distal & 9.16 & 48.90 & 1.83 & 30.64 & 6.18 & 0.13 & 0.06 & 2.93 & 0.16 & 0.00 & 0.01 & 0.00 \\
\hline Ulnae, Proximal & 8.59 & 45.40 & 2.09 & 32.22 & 7.67 & 0.14 & 0.07 & 3.62 & 0.18 & 0.00 & 0.01 & 0.00 \\
\hline${ }^{1}$ Ulnae, Shaft & 11.47 & 63.33 & 0.76 & 24.13 & 0.00 & 0.10 & 0.00 & 0.10 & 0.10 & 0.00 & 0.01 & 0.00 \\
\hline Ulnae, Distal & 9.26 & 49.57 & 1.78 & 30.34 & 5.89 & 0.13 & 0.06 & 2.80 & 0.16 & 0.00 & 0.01 & 0.00 \\
\hline Wrists and Hands & 9.97 & 53.96 & 1.45 & 28.36 & 4.01 & 0.12 & 0.04 & 1.94 & 0.14 & 0.00 & 0.01 & 0.00 \\
\hline Femora, Proximal & 8.73 & 39.98 & 2.87 & 38.55 & 6.33 & 0.13 & 0.14 & 3.04 & 0.20 & 0.00 & 0.01 & 0.04 \\
\hline${ }^{1}$ Femora, Upper Shaft & 11.12 & 55.30 & 1.70 & 31.39 & 0.00 & 0.10 & 0.07 & 0.14 & 0.14 & 0.00 & 0.01 & 0.03 \\
\hline${ }^{1}$ Femora, Lower Shaft & 11.27 & 58.71 & 1.30 & 28.31 & 0.00 & 0.10 & 0.04 & 0.12 & 0.12 & 0.00 & 0.01 & 0.02 \\
\hline Femora, Distal & 8.37 & 44.01 & 2.20 & 32.85 & 8.26 & 0.14 & 0.08 & 3.89 & 0.18 & 0.00 & 0.01 & 0.00 \\
\hline Patellae & 9.97 & 53.96 & 1.45 & 28.36 & 4.01 & 0.12 & 0.04 & 1.94 & 0.14 & 0.00 & 0.01 & 0.00 \\
\hline Tibiae, Proximal & 10.27 & 55.82 & 1.32 & 27.52 & 3.21 & 0.12 & 0.03 & 1.58 & 0.13 & 0.00 & 0.01 & 0.00 \\
\hline${ }^{1}$ Tibiae, Shaft & 11.47 & 63.33 & 0.76 & 24.13 & 0.00 & 0.10 & 0.00 & 0.10 & 0.10 & 0.00 & 0.01 & 0.00 \\
\hline Tibiae, Distal & 9.27 & 49.60 & 1.78 & 30.32 & 5.87 & 0.13 & 0.06 & 2.80 & 0.16 & 0.00 & 0.01 & 0.00 \\
\hline Fibulae, Proximal & 9.63 & 51.84 & 1.61 & 29.32 & 4.92 & 0.12 & 0.05 & 2.36 & 0.15 & 0.00 & 0.01 & 0.00 \\
\hline${ }^{1}$ Fibulae, Shaft & 11.47 & 63.33 & 0.76 & 24.13 & 0.00 & 0.10 & 0.00 & 0.10 & 0.10 & 0.00 & 0.01 & 0.00 \\
\hline Fibulae, Distal & 8.49 & 44.75 & 2.14 & 32.52 & 7.95 & 0.14 & 0.08 & 3.75 & 0.18 & 0.00 & 0.01 & 0.00 \\
\hline Ankles and Feet & 9.97 & 53.96 & 1.45 & 28.36 & 4.01 & 0.12 & 0.04 & 1.94 & 0.14 & 0.00 & 0.01 & 0.00 \\
\hline Total Skeleton Spongiosa & 9.28 & 44.31 & 2.49 & 36.05 & 4.99 & 0.12 & 0.11 & 2.42 & 0.18 & 0.00 & 0.01 & 0.03 \\
\hline
\end{tabular}

${ }^{1}$ Medullary marrow; contains marrow only 
Table 4-19. Site-specific homogeneous spongiosa elemental composition (\% by mass) in the 15 -year male hybrid phantom.

\begin{tabular}{|c|c|c|c|c|c|c|c|c|c|c|c|c|}
\hline \multirow[b]{2}{*}{ Skeletal Site } & \multicolumn{12}{|c|}{ Element } \\
\hline & $\mathrm{H}$ & C & $\mathrm{N}$ & $\mathrm{O}$ & $\mathrm{Ca}$ & $\mathrm{Na}$ & $\mathrm{Mg}$ & $\mathrm{P}$ & $\mathrm{S}$ & $\mathrm{Cl}$ & $\mathrm{K}$ & $\mathrm{Fe}$ \\
\hline Cranium & 7.75 & 35.05 & 3.16 & 40.06 & 9.11 & 0.14 & 0.15 & 4.31 & 0.22 & 0.01 & 0.01 & 0.03 \\
\hline Mandible & 8.05 & 36.53 & 3.07 & 39.63 & 8.25 & 0.14 & 0.14 & 3.92 & 0.22 & 0.01 & 0.01 & 0.03 \\
\hline Cervical & 9.03 & 38.77 & 3.13 & 41.02 & 5.03 & 0.12 & 0.16 & 2.46 & 0.21 & 0.01 & 0.01 & 0.06 \\
\hline Thoracic & 9.34 & 40.14 & 3.06 & 40.75 & 4.11 & 0.12 & 0.16 & 2.04 & 0.20 & 0.01 & 0.01 & 0.06 \\
\hline Lumbar & 9.56 & 41.12 & 3.01 & 40.56 & 3.45 & 0.12 & 0.16 & 1.75 & 0.20 & 0.01 & 0.01 & 0.06 \\
\hline Sternum & 9.69 & 41.69 & 2.98 & 40.45 & 3.07 & 0.11 & 0.15 & 1.57 & 0.20 & 0.01 & 0.01 & 0.06 \\
\hline Ribs & 9.42 & 40.46 & 3.04 & 40.69 & 3.89 & 0.12 & 0.16 & 1.95 & 0.20 & 0.01 & 0.01 & 0.06 \\
\hline Scapulae & 7.86 & 35.56 & 3.13 & 39.91 & 8.82 & 0.14 & 0.15 & 4.18 & 0.22 & 0.01 & 0.01 & 0.03 \\
\hline Clavicles & 9.03 & 41.72 & 2.73 & 37.84 & 5.50 & 0.13 & 0.13 & 2.66 & 0.20 & 0.01 & 0.01 & 0.04 \\
\hline Os coxae & 9.66 & 43.13 & 2.77 & 38.76 & 3.44 & 0.12 & 0.14 & 1.73 & 0.19 & 0.01 & 0.01 & 0.05 \\
\hline Sacrum & 10.18 & 45.60 & 2.64 & 38.14 & 1.91 & 0.11 & 0.13 & 1.04 & 0.18 & 0.01 & 0.01 & 0.06 \\
\hline Humeri, Proximal & 9.21 & 42.23 & 2.73 & 38.00 & 4.92 & 0.12 & 0.13 & 2.40 & 0.19 & 0.01 & 0.01 & 0.04 \\
\hline${ }^{1}$ Humeri, Upper Shaft & 11.12 & 55.13 & 1.71 & 31.55 & 0.00 & 0.10 & 0.07 & 0.14 & 0.14 & 0.01 & 0.01 & 0.04 \\
\hline${ }^{1}$ Humeri, Lower Shaft & 11.27 & 58.54 & 1.31 & 28.46 & 0.00 & 0.10 & 0.04 & 0.12 & 0.13 & 0.01 & 0.01 & 0.02 \\
\hline Humeri, Distal & 8.96 & 47.57 & 1.93 & 31.31 & 6.68 & 0.13 & 0.07 & 3.17 & 0.17 & 0.01 & 0.01 & 0.00 \\
\hline Radii, Proximal & 9.05 & 48.14 & 1.89 & 31.06 & 6.44 & 0.13 & 0.06 & 3.05 & 0.17 & 0.01 & 0.01 & 0.00 \\
\hline${ }^{1}$ Radii, Shaft & 11.47 & 63.16 & 0.76 & 24.29 & 0.00 & 0.10 & 0.00 & 0.10 & 0.11 & 0.01 & 0.01 & 0.00 \\
\hline Radii, Distal & 9.15 & 48.74 & 1.84 & 30.78 & 6.18 & 0.13 & 0.06 & 2.94 & 0.17 & 0.01 & 0.01 & 0.00 \\
\hline Ulnae, Proximal & 8.59 & 45.25 & 2.10 & 32.36 & 7.67 & 0.14 & 0.07 & 3.62 & 0.18 & 0.01 & 0.01 & 0.00 \\
\hline${ }^{1}$ Ulnae, Shaft & 11.47 & 63.16 & 0.76 & 24.29 & 0.00 & 0.10 & 0.00 & 0.10 & 0.11 & 0.01 & 0.01 & 0.00 \\
\hline Ulnae, Distal & 9.26 & 49.41 & 1.79 & 30.48 & 5.89 & 0.13 & 0.06 & 2.80 & 0.16 & 0.01 & 0.01 & 0.00 \\
\hline Wrists and Hands & 9.96 & 53.80 & 1.46 & 28.50 & 4.01 & 0.12 & 0.04 & 1.94 & 0.14 & 0.01 & 0.01 & 0.00 \\
\hline Femora, Proximal & 8.72 & 39.82 & 2.87 & 38.69 & 6.33 & 0.13 & 0.14 & 3.04 & 0.20 & 0.01 & 0.01 & 0.04 \\
\hline${ }^{1}$ Femora, Upper Shaft & 11.12 & 55.13 & 1.71 & 31.55 & 0.00 & 0.10 & 0.07 & 0.14 & 0.14 & 0.01 & 0.01 & 0.04 \\
\hline${ }^{1}$ Femora, Lower Shaft & 11.27 & 58.54 & 1.31 & 28.46 & 0.00 & 0.10 & 0.04 & 0.12 & 0.13 & 0.01 & 0.01 & 0.02 \\
\hline Femora, Distal & 8.37 & 43.87 & 2.20 & 32.98 & 8.27 & 0.14 & 0.08 & 3.89 & 0.19 & 0.01 & 0.01 & 0.00 \\
\hline Patellae & 9.96 & 53.80 & 1.46 & 28.50 & 4.01 & 0.12 & 0.04 & 1.94 & 0.14 & 0.01 & 0.01 & 0.00 \\
\hline Tibiae, Proximal & 10.26 & 55.66 & 1.32 & 27.67 & 3.22 & 0.12 & 0.03 & 1.58 & 0.14 & 0.01 & 0.01 & 0.00 \\
\hline${ }^{1}$ Tibiae, Shaft & 11.47 & 63.16 & 0.76 & 24.29 & 0.00 & 0.10 & 0.00 & 0.10 & 0.11 & 0.01 & 0.01 & 0.00 \\
\hline Tibiae, Distal & 9.27 & 49.45 & 1.79 & 30.46 & 5.88 & 0.13 & 0.06 & 2.80 & 0.16 & 0.01 & 0.01 & 0.00 \\
\hline Fibulae, Proximal & 9.62 & 51.68 & 1.62 & 29.46 & 4.92 & 0.12 & 0.05 & 2.36 & 0.15 & 0.01 & 0.01 & 0.00 \\
\hline${ }^{1}$ Fibulae, Shaft & 11.47 & 63.16 & 0.76 & 24.29 & 0.00 & 0.10 & 0.00 & 0.10 & 0.11 & 0.01 & 0.01 & 0.00 \\
\hline Fibulae, Distal & 8.49 & 44.60 & 2.15 & 32.65 & 7.95 & 0.14 & 0.08 & 3.75 & 0.18 & 0.01 & 0.01 & 0.00 \\
\hline Ankles and Feet & 9.96 & 53.80 & 1.46 & 28.50 & 4.01 & 0.12 & 0.04 & 1.94 & 0.14 & 0.01 & 0.01 & 0.00 \\
\hline Total Skeleton Spongiosa & 9.27 & 44.48 & 2.45 & 35.80 & 5.08 & 0.12 & 0.11 & 2.46 & 0.18 & 0.01 & 0.01 & 0.03 \\
\hline
\end{tabular}

${ }^{1}$ Medullary marrow; contains marrow only 
Table 4-20. Site-specific homogenized bone masses, volumes, and densities (excluding cartilage).

\begin{tabular}{|c|c|c|c|c|c|c|}
\hline & \multicolumn{3}{|c|}{ 15-Year Female } & \multicolumn{3}{|c|}{ 15-Year Male } \\
\hline & Homogeneous Bone & Homogeneous Bone & Homogeneous Bone & Homogeneous Bone & Homogeneous Bone & Homogeneous Bone \\
\hline Skeletal Site & Mass (g) & Volume (cm3) & Density (g/cm3) & Mass (g) & Volume (cm3) & Density $(\mathrm{g} / \mathrm{cm} 3)$ \\
\hline Cranium & 784.05 & 521.74 & 1.50 & 953.40 & 635.40 & 1.50 \\
\hline Mandible & 71.65 & 46.74 & 1.53 & 90.33 & 59.01 & 1.53 \\
\hline Cervical & 101.42 & 75.77 & 1.34 & 80.75 & 60.47 & 1.34 \\
\hline Thoracic & 282.83 & 226.16 & 1.25 & 312.60 & 250.64 & 1.25 \\
\hline Lumbar & 275.94 & 237.23 & 1.16 & 251.23 & 216.64 & 1.16 \\
\hline Sternum & 40.15 & 31.41 & 1.28 & 57.64 & 45.21 & 1.27 \\
\hline Ribs & 363.98 & 266.19 & 1.37 & 333.53 & 244.50 & 1.36 \\
\hline Scapulae & 298.24 & 198.99 & 1.50 & 216.57 & 144.73 & 1.50 \\
\hline Clavicles & 79.49 & 52.13 & 1.52 & 60.70 & 39.89 & 1.52 \\
\hline Os coxae & 698.39 & 564.83 & 1.24 & 625.50 & 507.30 & 1.23 \\
\hline Sacrum & 209.04 & 165.40 & 1.26 & 170.65 & 135.42 & 1.26 \\
\hline Humeri, Proximal & 152.71 & 124.31 & 1.23 & 191.51 & 156.31 & 1.23 \\
\hline${ }^{1}$ Humeri, Upper Shaft & 102.05 & 63.58 & 1.61 & 125.81 & 78.56 & 1.60 \\
\hline${ }^{1}$ Humeri, Lower Shaft & 88.97 & 55.49 & 1.60 & 111.65 & 69.79 & 1.60 \\
\hline Humeri, Distal & 105.69 & 75.07 & 1.41 & 133.25 & 94.85 & 1.40 \\
\hline Radii, Proximal & 16.08 & 11.64 & 1.38 & 21.14 & 15.34 & 1.38 \\
\hline${ }^{1}$ Radii, Shaft & 70.88 & 42.43 & 1.67 & 79.54 & 47.71 & 1.67 \\
\hline Radii, Distal & 27.64 & 21.25 & 1.30 & 36.38 & 28.03 & 1.30 \\
\hline Ulnae, Proximal & 54.65 & 39.98 & 1.37 & 70.10 & 51.38 & 1.36 \\
\hline${ }^{1}$ Ulnae, Shaft & 84.05 & 50.45 & 1.67 & 96.81 & 58.23 & 1.66 \\
\hline Ulnae, Distal & 9.74 & 7.27 & 1.34 & 12.76 & 9.54 & 1.34 \\
\hline Wrists and Hands & 152.26 & 102.51 & 1.49 & 184.45 & 124.46 & 1.48 \\
\hline Femora, Proximal & 229.21 & 177.45 & 1.29 & 298.55 & 231.67 & 1.29 \\
\hline${ }^{1}$ Femora, Upper Shaft & 199.58 & 126.58 & 1.58 & 271.38 & 172.52 & 1.57 \\
\hline${ }^{1}$ Femora, Lower Shaft & 225.26 & 143.03 & 1.57 & 206.38 & 131.36 & 1.57 \\
\hline Femora, Distal & 309.55 & 240.98 & 1.28 & 346.15 & 270.05 & 1.28 \\
\hline Patellae & 34.05 & 25.32 & 1.34 & 41.97 & 31.29 & 1.34 \\
\hline Tibiae, Proximal & 236.80 & 190.51 & 1.24 & 271.75 & 219.28 & 1.24 \\
\hline${ }^{1}$ Tibiae, Shaft & 259.51 & 167.83 & 1.55 & 310.28 & 201.16 & 1.54 \\
\hline Tibiae, Distal & 85.45 & 69.17 & 1.24 & 98.96 & 80.32 & 1.23 \\
\hline Fibulae, Proximal & 21.06 & 15.75 & 1.34 & 26.73 & 20.03 & 1.33 \\
\hline${ }^{1}$ Fibulae, Shaft & 39.41 & 24.78 & 1.59 & 54.24 & 34.18 & 1.59 \\
\hline Fibulae, Distal & 21.32 & 15.17 & 1.41 & 27.10 & 19.32 & 1.40 \\
\hline Ankles and Feet & 463.23 & 366.55 & 1.26 & 577.87 & 458.56 & 1.26 \\
\hline $\begin{array}{ll}\text { Total Skeleton } \\
\end{array}$ & 6194.32 & 4543.68 & & 6747.63 & 4943.17 & \\
\hline Volume Weighted Average Density & & & 1.35 & & & 1.35 \\
\hline Original 15-Year Hybrid Phantom & 6180.02 & 4543.68 & & 6743.09 & 4943.17 & \\
\hline Ratio & 1.00 & 1.00 & & 1.00 & 1.00 & \\
\hline
\end{tabular}


Table 4-21. Site-specific homogeneous bone elemental composition (excluding cartilage) in the 15-year female hybrid phantom (\% by mass).

\begin{tabular}{|c|c|c|c|c|c|c|c|c|c|c|c|c|}
\hline \multirow[b]{2}{*}{ Skeletal Site } & \multicolumn{12}{|c|}{ Element } \\
\hline & $\mathrm{H}$ & C & $\mathrm{N}$ & 0 & $\mathrm{Ca}$ & $\mathrm{Na}$ & $\mathrm{Mg}$ & $\mathrm{P}$ & $\mathrm{S}$ & $\mathrm{Cl}$ & $\mathrm{K}$ & $\mathrm{Fe}$ \\
\hline Cranium & 5.59 & 24.51 & 3.78 & 43.00 & 15.33 & 0.17 & 0.18 & 7.15 & 0.26 & 0.00 & 0.00 & 0.01 \\
\hline Mandible & 5.38 & 23.46 & 3.84 & 43.31 & 15.95 & 0.18 & 0.18 & 7.43 & 0.27 & 0.00 & 0.00 & 0.01 \\
\hline Cervical & 6.91 & 29.50 & 3.60 & 42.75 & 11.31 & 0.16 & 0.17 & 5.32 & 0.24 & 0.00 & 0.00 & 0.03 \\
\hline Thoracic & 7.76 & 33.29 & 3.41 & 42.00 & 8.78 & 0.14 & 0.17 & 4.17 & 0.23 & 0.00 & 0.01 & 0.04 \\
\hline Lumbar & 8.74 & 37.61 & 3.19 & 41.14 & 5.90 & 0.13 & 0.16 & 2.86 & 0.21 & 0.00 & 0.01 & 0.05 \\
\hline Sternum & 7.48 & 32.04 & 3.47 & 42.24 & 9.61 & 0.15 & 0.17 & 4.55 & 0.23 & 0.00 & 0.00 & 0.04 \\
\hline Ribs & 6.65 & 28.37 & 3.65 & 42.97 & 12.06 & 0.16 & 0.18 & 5.66 & 0.25 & 0.00 & 0.00 & 0.03 \\
\hline Scapulae & 5.62 & 24.66 & 3.77 & 42.96 & 15.25 & 0.17 & 0.18 & 7.11 & 0.26 & 0.00 & 0.00 & 0.01 \\
\hline Clavicles & 5.44 & 23.86 & 3.81 & 43.10 & 15.80 & 0.18 & 0.18 & 7.36 & 0.27 & 0.00 & 0.00 & 0.01 \\
\hline Os coxae & 7.92 & 35.11 & 3.22 & 40.66 & 8.49 & 0.14 & 0.16 & 4.03 & 0.22 & 0.00 & 0.01 & 0.04 \\
\hline Sacrum & 7.64 & 33.77 & 3.29 & 40.99 & 9.32 & 0.15 & 0.16 & 4.41 & 0.23 & 0.00 & 0.01 & 0.03 \\
\hline Humeri, Proximal & 8.02 & 36.48 & 3.07 & 39.56 & 8.36 & 0.14 & 0.15 & 3.97 & 0.22 & 0.00 & 0.01 & 0.03 \\
\hline${ }^{1}$ Humeri, Upper Shaft & 4.90 & 21.60 & 3.92 & 43.46 & 17.38 & 0.18 & 0.18 & 8.08 & 0.28 & 0.00 & 0.00 & 0.00 \\
\hline${ }^{1}$ Humeri, Lower Shaft & 4.92 & 22.03 & 3.86 & 43.06 & 17.40 & 0.18 & 0.18 & 8.08 & 0.27 & 0.00 & 0.00 & 0.00 \\
\hline Humeri, Distal & 6.36 & 31.46 & 3.13 & 38.52 & 13.64 & 0.17 & 0.13 & 6.36 & 0.24 & 0.00 & 0.00 & 0.00 \\
\hline Radii, Proximal & 6.59 & 32.89 & 3.03 & 37.87 & 13.02 & 0.16 & 0.13 & 6.07 & 0.23 & 0.00 & 0.00 & 0.00 \\
\hline${ }^{1}$ Radii, Shaft & 4.51 & 19.93 & 3.99 & 43.72 & 18.57 & 0.19 & 0.18 & 8.62 & 0.28 & 0.00 & 0.00 & 0.00 \\
\hline Radii, Distal & 7.33 & 37.50 & 2.68 & 35.79 & 11.05 & 0.15 & 0.11 & 5.17 & 0.21 & 0.00 & 0.00 & 0.00 \\
\hline Ulnae, Proximal & 6.71 & 33.64 & 2.97 & 37.53 & 12.70 & 0.16 & 0.12 & 5.93 & 0.23 & 0.00 & 0.00 & 0.00 \\
\hline${ }^{1}$ Ulnae, Shaft & 4.53 & 20.10 & 3.98 & 43.65 & 18.50 & 0.19 & 0.18 & 8.58 & 0.28 & 0.00 & 0.00 & 0.00 \\
\hline Ulnae, Distal & 6.95 & 35.15 & 2.86 & 36.85 & 12.06 & 0.16 & 0.12 & 5.63 & 0.22 & 0.00 & 0.00 & 0.00 \\
\hline Wrists and Hands & 5.74 & 27.63 & 3.42 & 40.24 & 15.27 & 0.17 & 0.15 & 7.11 & 0.25 & 0.00 & 0.00 & 0.00 \\
\hline Femora, Proximal & 7.37 & 33.28 & 3.26 & 40.48 & 10.23 & 0.15 & 0.15 & 4.82 & 0.23 & 0.00 & 0.00 & 0.03 \\
\hline${ }^{1}$ Femora, Upper Shaft & 5.09 & 22.60 & 3.85 & 43.11 & 16.87 & 0.18 & 0.18 & 7.84 & 0.27 & 0.00 & 0.00 & 0.01 \\
\hline${ }^{1}$ Femora, Lower Shaft & 5.10 & 23.11 & 3.79 & 42.62 & 16.89 & 0.18 & 0.17 & 7.85 & 0.27 & 0.00 & 0.00 & 0.00 \\
\hline Femora, Distal & 7.49 & 38.50 & 2.61 & 35.34 & 10.63 & 0.15 & 0.10 & 4.97 & 0.21 & 0.00 & 0.00 & 0.00 \\
\hline Patellae & 6.91 & 34.89 & 2.88 & 36.97 & 12.17 & 0.16 & 0.12 & 5.68 & 0.22 & 0.00 & 0.00 & 0.00 \\
\hline Tibiae, Proximal & 7.92 & 41.19 & 2.41 & 34.13 & 9.47 & 0.15 & 0.09 & 4.45 & 0.20 & 0.00 & 0.01 & 0.00 \\
\hline${ }^{1}$ Tibiae, Shaft & 5.31 & 24.90 & 3.62 & 41.48 & 16.44 & 0.18 & 0.16 & 7.64 & 0.26 & 0.00 & 0.00 & 0.00 \\
\hline Tibiae, Distal & 8.00 & 41.70 & 2.37 & 33.89 & 9.25 & 0.15 & 0.09 & 4.35 & 0.19 & 0.00 & 0.01 & 0.00 \\
\hline Fibulae, Proximal & 6.97 & 35.30 & 2.85 & 36.78 & 11.99 & 0.16 & 0.12 & 5.60 & 0.22 & 0.00 & 0.00 & 0.00 \\
\hline${ }^{1}$ Fibulae, Shaft & 5.01 & 23.04 & 3.76 & 42.32 & 17.24 & 0.18 & 0.17 & 8.01 & 0.27 & 0.00 & 0.00 & 0.00 \\
\hline Fibulae, Distal & 6.38 & 31.60 & 3.12 & 38.45 & 13.58 & 0.17 & 0.13 & 6.33 & 0.23 & 0.00 & 0.00 & 0.00 \\
\hline Ankles and Feet & 7.70 & 39.82 & 2.51 & 34.74 & 10.06 & 0.15 & 0.10 & 4.71 & 0.20 & 0.00 & 0.01 & 0.00 \\
\hline Total Skeleton & 6.71 & 30.87 & 3.34 & 40.52 & 12.25 & 0.16 & 0.15 & 5.73 & 0.24 & 0.00 & 0.00 & 0.02 \\
\hline
\end{tabular}

${ }^{1}$ Contains medullary marrow (no trabecular bone) and cortical bone only 
Table 4-22. Site-specific homogeneous bone elemental composition (excluding cartilage) in the 15-year male hybrid phantom (\% by mass).

\begin{tabular}{|c|c|c|c|c|c|c|c|c|c|c|c|c|}
\hline \multirow[b]{2}{*}{ Skeletal Site } & \multicolumn{12}{|c|}{ Element } \\
\hline & $\mathrm{H}$ & $C$ & $\mathrm{~N}$ & $\mathrm{O}$ & $\mathrm{Ca}$ & $\mathrm{Na}$ & $\mathrm{Mg}$ & $P$ & $\mathrm{~S}$ & $\mathrm{Cl}$ & $\mathrm{K}$ & $\mathrm{Fe}$ \\
\hline Cranium & 5.61 & 24.50 & 3.78 & 43.08 & 15.28 & 0.17 & 0.18 & 7.12 & 0.27 & 0.00 & 0.00 & 0.01 \\
\hline Mandible & 5.40 & 23.44 & 3.84 & 43.38 & 15.89 & 0.18 & 0.18 & 7.40 & 0.27 & 0.00 & 0.00 & 0.01 \\
\hline Cervical & 6.94 & 29.51 & 3.60 & 42.84 & 11.21 & 0.15 & 0.17 & 5.28 & 0.25 & 0.00 & 0.00 & 0.03 \\
\hline Thoracic & 7.80 & 33.32 & 3.40 & 42.10 & 8.67 & 0.14 & 0.17 & 4.12 & 0.23 & 0.01 & 0.01 & 0.04 \\
\hline Lumbar & 8.78 & 37.66 & 3.18 & 41.24 & 5.77 & 0.13 & 0.16 & 2.80 & 0.21 & 0.01 & 0.01 & 0.05 \\
\hline Sternum & 7.52 & 32.07 & 3.47 & 42.34 & 9.50 & 0.15 & 0.17 & 4.50 & 0.24 & 0.00 & 0.00 & 0.04 \\
\hline Ribs & 6.68 & 28.38 & 3.65 & 43.06 & 11.97 & 0.16 & 0.18 & 5.62 & 0.25 & 0.00 & 0.00 & 0.03 \\
\hline Scapulae & 5.64 & 24.64 & 3.77 & 43.04 & 15.19 & 0.17 & 0.17 & 7.08 & 0.27 & 0.00 & 0.00 & 0.01 \\
\hline Clavicles & 5.46 & 23.87 & 3.81 & 43.17 & 15.73 & 0.18 & 0.18 & 7.33 & 0.27 & 0.00 & 0.00 & 0.01 \\
\hline Os coxae & 7.96 & 35.16 & 3.22 & 40.74 & 8.37 & 0.14 & 0.16 & 3.98 & 0.22 & 0.01 & 0.01 & 0.04 \\
\hline Sacrum & 7.68 & 33.83 & 3.29 & 41.07 & 9.20 & 0.14 & 0.16 & 4.36 & 0.23 & 0.00 & 0.00 & 0.03 \\
\hline Humeri, Proximal & 8.05 & 36.54 & 3.07 & 39.63 & 8.25 & 0.14 & 0.14 & 3.92 & 0.22 & 0.01 & 0.01 & 0.03 \\
\hline${ }^{1}$ Humeri, Upper Shaft & 4.93 & 21.64 & 3.91 & 43.51 & 17.31 & 0.18 & 0.18 & 8.04 & 0.28 & 0.00 & 0.00 & 0.00 \\
\hline${ }^{1}$ Humeri, Lower Shaft & 4.94 & 22.08 & 3.86 & 43.09 & 17.33 & 0.18 & 0.17 & 8.05 & 0.28 & 0.00 & 0.00 & 0.00 \\
\hline Humeri, Distal & 6.38 & 31.52 & 3.13 & 38.55 & 13.56 & 0.17 & 0.13 & 6.32 & 0.24 & 0.00 & 0.00 & 0.00 \\
\hline Radii, Proximal & 6.61 & 32.95 & 3.02 & 37.90 & 12.94 & 0.16 & 0.13 & 6.04 & 0.23 & 0.00 & 0.00 & 0.00 \\
\hline${ }^{1}$ Radii, Shaft & 4.53 & 19.98 & 3.99 & 43.75 & 18.50 & 0.19 & 0.18 & 8.59 & 0.28 & 0.00 & 0.00 & 0.00 \\
\hline Radii, Distal & 7.36 & 37.58 & 2.67 & 35.81 & 10.96 & 0.15 & 0.11 & 5.13 & 0.21 & 0.00 & 0.00 & 0.00 \\
\hline Ulnae, Proximal & 6.73 & 33.70 & 2.96 & 37.56 & 12.63 & 0.16 & 0.12 & 5.89 & 0.23 & 0.00 & 0.00 & 0.00 \\
\hline${ }^{1}$ Ulnae, Shaft & 4.56 & 20.15 & 3.97 & 43.67 & 18.43 & 0.19 & 0.18 & 8.55 & 0.28 & 0.00 & 0.00 & 0.00 \\
\hline Ulnae, Distal & 6.98 & 35.23 & 2.85 & 36.87 & 11.97 & 0.16 & 0.12 & 5.59 & 0.22 & 0.00 & 0.00 & 0.00 \\
\hline Wrists and Hands & 5.77 & 27.70 & 3.41 & 40.27 & 15.20 & 0.17 & 0.15 & 7.07 & 0.25 & 0.00 & 0.00 & 0.00 \\
\hline Femora, Proximal & 7.40 & 33.30 & 3.26 & 40.56 & 10.13 & 0.15 & 0.15 & 4.78 & 0.23 & 0.00 & 0.00 & 0.03 \\
\hline${ }^{1}$ Femora, Upper Shaft & 5.11 & 22.64 & 3.85 & 43.15 & 16.79 & 0.18 & 0.18 & 7.81 & 0.27 & 0.00 & 0.00 & 0.01 \\
\hline${ }^{1}$ Femora, Lower Shaft & 5.13 & 23.16 & 3.78 & 42.66 & 16.81 & 0.18 & 0.17 & 7.82 & 0.27 & 0.00 & 0.00 & 0.00 \\
\hline Femora, Distal & 7.52 & 38.56 & 2.60 & 35.37 & 10.54 & 0.15 & 0.10 & 4.94 & 0.21 & 0.00 & 0.00 & 0.00 \\
\hline Patellae & 6.94 & 34.99 & 2.87 & 36.98 & 12.07 & 0.16 & 0.12 & 5.64 & 0.22 & 0.00 & 0.00 & 0.00 \\
\hline Tibiae, Proximal & 7.96 & 41.32 & 2.39 & 34.13 & 9.36 & 0.15 & 0.09 & 4.39 & 0.20 & 0.01 & 0.01 & 0.00 \\
\hline${ }^{1}$ Tibiae, Shaft & 5.33 & 24.98 & 3.61 & 41.50 & 16.36 & 0.18 & 0.16 & 7.61 & 0.26 & 0.00 & 0.00 & 0.00 \\
\hline Tibiae, Distal & 8.04 & 41.81 & 2.36 & 33.91 & 9.15 & 0.14 & 0.09 & 4.30 & 0.19 & 0.01 & 0.01 & 0.00 \\
\hline Fibulae, Proximal & 7.01 & 35.39 & 2.84 & 36.80 & 11.90 & 0.16 & 0.12 & 5.56 & 0.22 & 0.00 & 0.00 & 0.00 \\
\hline${ }^{1}$ Fibulae, Shaft & 5.03 & 23.11 & 3.75 & 42.34 & 17.16 & 0.18 & 0.17 & 7.97 & 0.27 & 0.00 & 0.00 & 0.00 \\
\hline Fibulae, Distal & 6.40 & 31.65 & 3.12 & 38.49 & 13.51 & 0.17 & 0.13 & 6.30 & 0.24 & 0.00 & 0.00 & 0.00 \\
\hline Ankles and Feet & 7.74 & 39.94 & 2.50 & 34.75 & 9.95 & 0.15 & 0.10 & 4.67 & 0.20 & 0.00 & 0.00 & 0.00 \\
\hline Total Skeleton & 6.70 & 30.90 & 3.33 & 40.44 & 12.31 & 0.16 & 0.15 & 5.76 & 0.24 & 0.00 & 0.00 & 0.02 \\
\hline
\end{tabular}

${ }^{1}$ Contains medullary marrow (no trabecular bone) and cortical bone only 
Table 4-23. Macrostructure for the 15-year female and microstructure imaging data for the 18-year male skeleton.

\begin{tabular}{|c|c|c|c|c|c|c|c|c|c|c|c|c|}
\hline & \multicolumn{2}{|c|}{ Macrostructure } & \multirow{2}{*}{\multicolumn{6}{|c|}{$\begin{array}{l}\text { Microstructure } \\
\text { Dimensions }\end{array}$}} & \multicolumn{2}{|c|}{ Microstructure } & \multicolumn{2}{|c|}{ Microstructure } \\
\hline & & & & & & & & & MVF & TBVF & MVF & TBVF \\
\hline & Voxel Size & \multirow{2}{*}{$\begin{array}{l}\text { Resolution } \\
\text { (cm) }\end{array}$} & \multicolumn{3}{|c|}{60 Microns } & \multicolumn{3}{|c|}{30 Microns } & \multirow{2}{*}{\multicolumn{2}{|c|}{ (260 Microns }} & \multirow{2}{*}{\multicolumn{2}{|c|}{30 Microns }} \\
\hline & $\begin{array}{lll}x & y & z\end{array}$ & & $x$ & $y$ & $z$ & $x$ & $y$ & $z$ & & & & \\
\hline Cranium (Average) & $408 \times 516 \times 459$ & 0.035 & & & & & & & $0.6793(+/-0.022)$ & $0.3207(+/-0.022)$ & $0.6807(+/-0.020)$ & $0.3193(+/-0.020)$ \\
\hline - Occipital & & & 39 & 407 & 147 & 78 & 815 & 294 & 0.6892 & 0.3108 & 0.6910 & 0.3090 \\
\hline - Frontal & & & 16 & 209 & 349 & 33 & 419 & 699 & 0.6540 & 0.3460 & 0.6570 & 0.3430 \\
\hline - Parietal & & & 19 & 409 & 246 & 39 & 818 & 493 & 0.6948 & 0.3052 & 0.6940 & 0.3060 \\
\hline Mandible & $351 \times 266 \times 243$ & 0.03 & & & & & & & 0.7184 & 0.2816 & 0.7173 & 0.2827 \\
\hline Sternum & $223 \times 345 \times 807$ & 0.02 & 97 & 454 & 426 & 195 & 909 & 852 & 0.9073 & 0.0927 & 0.9066 & 0.0934 \\
\hline Ribs (Average) & $439 \times 295 \times 554$ & 0.06 & & & & & & & $0.8788(+/-0.032)$ & $0.1212(+/-0.032)$ & $0.8792(+/-0.030)$ & $0.1208(+/-0.030)$ \\
\hline - Upper (Right Rib 1) & & & 23 & 117 & 299 & 47 & 234 & 599 & 0.8442 & 0.1558 & 0.8462 & 0.1538 \\
\hline - Middle (Right Rib 6) & & & 52 & 102 & 526 & 105 & 205 & 1052 & 0.9057 & 0.0943 & 0.9061 & 0.0939 \\
\hline - Lower (Right Rib 12) & & & 38 & 82 & 367 & 77 & 165 & 735 & 0.8866 & 0.1134 & 0.8854 & 0.1146 \\
\hline Scapula (Right) & $427 \times 301 \times 541$ & 0.03 & 36 & 128 & 270 & 73 & 257 & 541 & 0.6940 & 0.3060 & 0.6935 & 0.3065 \\
\hline Clavicle (Right) & $697 \times 594 \times 134$ & 0.018 & 126 & 286 & 211 & 253 & 572 & 423 & 0.8221 & 0.1779 & 0.8243 & 0.1757 \\
\hline \multicolumn{13}{|l|}{ Vertebrae } \\
\hline - Cervicle (Average) & $366 \times 324 \times 552$ & 0.02 & & & & & & & $0.8434(+/-0.021)$ & $0.1567(+/-0.021)$ & $0.8400(+/-0.022)$ & $0.1601(+/-0.022)$ \\
\hline$-18 Y \mathrm{C}_{3}$ & & & 150 & 208 & 155 & 301 & 417 & 310 & 0.8283 & 0.1717 & 0.8242 & 0.1758 \\
\hline$-18 Y C_{6}$ & & & 226 & 244 & 268 & 452 & 489 & 536 & 0.8584 & 0.1416 & 0.8557 & 0.1443 \\
\hline - Thoracic (Average) & $219 \times 288 \times 926$ & 0.03 & & & & & & & $0.8747(+/-0.018)$ & $0.1253(+/-0.018)$ & $0.8720(+/-0.018)$ & $0.1280(+/-0.018)$ \\
\hline$-18 \mathrm{Y}_{1}$ & & & 248 & 263 & 252 & 496 & 526 & 505 & 0.8523 & 0.1477 & 0.8502 & 0.1498 \\
\hline$-18 \mathrm{Y} \mathrm{T}_{3}$ & & & 242 & 261 & 271 & 484 & 523 & 543 & 0.8624 & 0.1376 & 0.8597 & 0.1403 \\
\hline$-18 \mathrm{Y} \mathrm{T}_{6}$ & & & 242 & 265 & 391 & 485 & 531 & 783 & 0.8761 & 0.1239 & 0.8735 & 0.1265 \\
\hline$-18 Y \mathrm{~T}_{9}$ & & & 314 & 341 & 369 & 629 & 682 & 739 & 0.8860 & 0.1140 & 0.8831 & 0.1169 \\
\hline$-18 \mathrm{Y} \mathrm{T}_{12}$ & & & 340 & 357 & 547 & 681 & 715 & 1094 & 0.8966 & 0.1034 & 0.8936 & 0.1064 \\
\hline - Lumbar Spine (Average) & $271 \times 323 \times 541$ & 0.03 & & & & & & & $0.8960(+/-0.020)$ & $0.1040(+/-0.022)$ & $0.8940(+/-0.020)$ & $0.1060(+/-0.020)$ \\
\hline$-18 Y L_{1}$ & & & 326 & 338 & 555 & 653 & 677 & 1111 & 0.9094 & 0.0906 & 0.9064 & 0.0936 \\
\hline$-18 Y \mathrm{~L}_{2}$ & & & 292 & 356 & 611 & 585 & 712 & 1222 & 0.9211 & 0.0789 & 0.9167 & 0.0833 \\
\hline$-18 Y L_{3}$ & & & 228 & 380 & 533 & 456 & 760 & 1066 & 0.9029 & 0.0971 & 0.9009 & 0.0991 \\
\hline$-18 Y \mathrm{~L}_{4}$ & & & 189 & 393 & 531 & 379 & 787 & 1062 & 0.8747 & 0.1253 & 0.8743 & 0.1257 \\
\hline$-18 Y L_{5}$ & & & 316 & 236 & 430 & 632 & 473 & 860 & 0.8720 & 0.1280 & 0.8715 & 0.1285 \\
\hline \multicolumn{13}{|l|}{ Pelvis } \\
\hline - Os Coxae (Right Ilium) & $499 \times 287 \times 399$ & 0.05 & 44 & 476 & 528 & 89 & 952 & 1057 & 0.8955 & 0.1045 & 0.8949 & 0.1051 \\
\hline - Sacrum & $333 \times 307 \times 363$ & 0.03 & 190 & 116 & 314 & 381 & 233 & 629 & 0.9441 & 0.0559 & 0.9437 & 0.0563 \\
\hline
\end{tabular}


Table 4-23. Continued.

\begin{tabular}{|c|c|c|c|c|c|c|c|c|c|c|c|c|c|c|}
\hline & \multicolumn{2}{|c|}{ Macrostructure } & \multirow{2}{*}{\multicolumn{6}{|c|}{$\begin{array}{c}\text { Microstructure } \\
\text { Dimensions } \\
\end{array}$}} & \multicolumn{2}{|c|}{ Microstructure } & \multicolumn{2}{|c|}{$\begin{array}{l}\text { Microstructure } \\
\end{array}$} & \multirow{2}{*}{\multicolumn{2}{|c|}{ Threshold Threshold }} \\
\hline & & & & & & & & & MVF & TBVF & MVF & TBVF & & \\
\hline & Voxel Size & \multirow{2}{*}{$\begin{array}{c}\text { Resolution } \\
(\mathbf{c m})\end{array}$} & \multicolumn{3}{|c|}{60 Microns } & \multicolumn{3}{|c|}{30 Microns } & \multirow{2}{*}{\multicolumn{2}{|c|}{60 Microns }} & \multirow{2}{*}{\multicolumn{2}{|c|}{30 Microns }} & Actual & Used \\
\hline & $\begin{array}{lll}x & y\end{array}$ & & $x$ & $y$ & $z$ & $x$ & $y$ & $z$ & & & & & & \\
\hline - Distal & & & & & & & & & & & & & & \\
\hline $\begin{array}{l}\text { - Right } \\
\text { - Proximal }\end{array}$ & & & 292 & 362 & 333 & 584 & 724 & 667 & $\begin{array}{c}0.7180 \\
0.7886(+/-0.047)\end{array}$ & $\begin{array}{c}0.2820 \\
0.2114(+/-0.047)\end{array}$ & $\begin{array}{c}0.7221 \\
0.7891(+/-0.0470)\end{array}$ & $\begin{array}{c}0.2779 \\
0.2109(+/-0.0470)\end{array}$ & 154.5 & 155 \\
\hline - Head & & & & & & & & & & & & & & \\
\hline $\begin{array}{l}\text { - Right } \\
\text { - Neck }\end{array}$ & & & 248 & 499 & 499 & 497 & 998 & 999 & 0.7553 & 0.2447 & 0.7559 & 0.2441 & 156.5 & 157 \\
\hline $\begin{array}{l}\text { - Right } \\
\text { Fibula (Right) }\end{array}$ & $145 \times 128 \times 1135$ & 0.03 & 329 & 357 & 420 & 659 & 715 & 841 & 0.8220 & 0.1780 & 0.8223 & 0.1777 & 155.5 & 156 \\
\hline $\begin{array}{l}\text { - Right } \\
\text { - Proximal }\end{array}$ & & & 276 & 180 & 282 & 552 & 361 & 565 & 0.7315 & 0.2685 & 0.7349 & 0.2651 & 156.5 & 157 \\
\hline $\begin{array}{l}\text { - Right } \\
\text { Tibia (Right) } \\
\text { - Distal }\end{array}$ & $275 \times 184 \times 1156$ & 0.03 & 295 & 178 & 341 & 591 & 356 & 682 & 0.8459 & 0.1541 & 0.8485 & 0.1515 & 153.5 & 154 \\
\hline $\begin{array}{l}\text { - Right } \\
\text { - Proximal }\end{array}$ & & & 416 & 394 & 260 & 833 & 789 & 521 & 0.8131 & 0.1869 & 0.8146 & 0.1854 & 155.5 & 156 \\
\hline $\begin{array}{r}\text { - Right } \\
\text { Humerus (Right) } \\
\text { - Distal }\end{array}$ & $292 \times 154 \times 789$ & 0.04 & 355 & 384 & 341 & 710 & 768 & 683 & 0.9060 & 0.0940 & 0.9050 & 0.0950 & 155.5 & 156 \\
\hline $\begin{array}{l}\text { - Right } \\
\text { - Proximal }\end{array}$ & & & 140 & 540 & 170 & 281 & 1081 & 340 & 0.7825 & 0.2175 & 0.7847 & 0.2153 & 156.5 & 157 \\
\hline $\begin{array}{l}\text { - Right } \\
\text { Radius (Right) } \\
\text { - Distal }\end{array}$ & $172 \times 282 \times 1176$ & 0.02 & 417 & 320 & 425 & 835 & 641 & 851 & 0.8462 & 0.1538 & 0.8448 & 0.1552 & 158.5 & 159 \\
\hline $\begin{array}{l}\text { - Right } \\
\text { - Proximal }\end{array}$ & & & 230 & 293 & 231 & 461 & 587 & 463 & 0.8030 & 0.1970 & 0.8035 & 0.1965 & 155.5 & 156 \\
\hline $\begin{array}{l}\text { - Right } \\
\text { Ulna (Right) } \\
\text { - Distal }\end{array}$ & $206 \times 178 \times 842$ & 0.03 & 105 & 498 & 107 & 544 & 141 & 434 & 0.7979 & 0.2021 & 0.7939 & 0.2061 & 161.5 & 162 \\
\hline $\begin{array}{l}\text { - Right } \\
\text { - Proximal }\end{array}$ & & & 121 & 339 & 135 & 242 & 679 & 270 & 0.8140 & 0.1860 & 0.814 & 0.186 & 155.5 & 156 \\
\hline - Right & & & 199 & 521 & 212 & 399 & 1042 & 424 & 0.7434 & 0.2566 & 0.7462 & 0.2538 & 156.5 & 157 \\
\hline Foot (Right) & $298 \times 807 \times 284$ & 0.03 & & & & & & & & & & & & \\
\hline $\begin{array}{l}\text { Hand (Right) } \\
\text { Patella (Riaht) }\end{array}$ & $150 \times 358 \times 553$ & 0.03 & & & & & & & & & & & & \\
\hline Patella (Right) & $445 \times 188 \times 367$ & 0.01 & & & & & & & & & & & & \\
\hline
\end{tabular}


Table 4-24. Cortical bone thickness estimates in the 15-year female skeleton.

\begin{tabular}{cc}
\hline Bone & 15Y Female Cortical Bone Thickness ESTIMATES $(\mathrm{cm})$ \\
\hline \hline Cranium & 0.13 \\
Mandible & 0.16 \\
Cervical Vertebrae & 0.08 \\
Thoracic Vertebrae & 0.07 \\
Lumbar Vertebrae & 0.04 \\
Sternum & 0.11 \\
Ribs & 0.07 \\
Scapulae & 0.17 \\
Clavicles & 0.24 \\
Os coxae & 0.11 \\
Sacrum & 0.13 \\
Humeri, Proximal & 0.15 \\
Humeri, Upper Shaft & 0.5 \\
Humeri, Lower Shaft & 0.45 \\
Humeri, Distal & 0.2 \\
Radii, Proximal & 0.2 \\
Radii, Shaft & 0.4 \\
Radii, Distal & 0.1 \\
Ulnae, Proximal & 0.15 \\
Ulnae, Shaft & 0.4 \\
Ulnae, Distal & 0.08 \\
Wrists and Hands & 0.15 \\
Femora, Proximal & 0.1 \\
Femora, Upper Shaft & 0.5 \\
Femora, Lower Shaft & 0.6 \\
Femora, Distal & 0.2 \\
Patellae & 0.13 \\
Tibiae, Proximal & 0.15 \\
Tibiae, Shaft & 0.5 \\
Tibiae, Distal & 0.1 \\
Fibulae, Proximal & 0.1 \\
Fibulae, Shaft & 0.3 \\
Fibulae, Distal & 0.1 \\
Ankles and Feet & 0.1 \\
\hline & \\
\hline & \\
\hline
\end{tabular}


Table 4-25. $A M, T B V, T B S$, and $C B V$ source f-values for the UF hybrid 15-year female skeleton.

\begin{tabular}{cccccc}
\hline & \multicolumn{5}{c}{ UF HYBRID 15Y FEMALE } \\
\cline { 2 - 6 } Skeletal Site & Cellularity & $\mathrm{f}_{\text {TAM }}$ & $\mathrm{f}_{\text {TBV }}$ & $\mathrm{f}_{\text {TBS }}$ & $\mathrm{f}_{\mathrm{CBV}}$ \\
\hline \hline Cranium & 55 & 0.108 & 0.193 & 0.121 & 0.149 \\
Mandible & 55 & 0.009 & 0.013 & 0.009 & 0.016 \\
Cervical & 75 & 0.035 & 0.019 & 0.024 & 0.014 \\
Thoracic & 75 & 0.124 & 0.051 & 0.071 & 0.028 \\
Lumbar & 75 & 0.152 & 0.051 & 0.078 & 0.014 \\
Sternum & 75 & 0.016 & 0.005 & 0.008 & 0.005 \\
Ribs & 75 & 0.114 & 0.044 & 0.053 & 0.062 \\
Scapula & 55 & 0.021 & 0.070 & 0.035 & 0.057 \\
Clavicles & 53 & 0.005 & 0.008 & 0.006 & 0.019 \\
Os coxae & 64 & 0.270 & 0.104 & 0.161 & 0.071 \\
Sacrum & 64 & 0.075 & 0.015 & 0.023 & 0.029 \\
Humeri, Proximal & 55 & 0.026 & 0.036 & 0.043 & 0.012 \\
Humeri, Upper Shaft & 35 & 0.003 & 0.000 & 0.000 & 0.030 \\
Humeri, Lower Shaft & 20 & 0.001 & 0.000 & 0.000 & 0.026 \\
Humeri, Distal & 0 & 0.000 & 0.021 & 0.022 & 0.018 \\
Radii, Proximal & 0 & 0.000 & 0.003 & 0.003 & 0.003 \\
Radii, Shaft & 0 & 0.000 & 0.000 & 0.000 & 0.022 \\
Radii, Distal & 0 & 0.000 & 0.007 & 0.007 & 0.003 \\
Ulnae, Proximal & 0 & 0.000 & 0.016 & 0.013 & 0.007 \\
Ulnae, Shaft & 0 & 0.000 & 0.000 & 0.000 & 0.026 \\
Ulnae, Distal & 0 & 0.000 & 0.002 & 0.002 & 0.001 \\
Wrists and Hands & 0 & 0.000 & 0.011 & 0.010 & 0.036 \\
Femora, Proximal & 55 & 0.033 & 0.065 & 0.069 & 0.022 \\
Femora, Upper Shaf1 & 35 & 0.006 & 0.000 & 0.000 & 0.056 \\
Femora, Lower Shaft & 20 & 0.004 & 0.000 & 0.000 & 0.064 \\
Femora, Distal & 0 & 0.000 & 0.127 & 0.100 & 0.021 \\
Patellae & 0 & 0.000 & 0.004 & 0.004 & 0.006 \\
Tibiae, Proximal & 0 & 0.000 & 0.030 & 0.044 & 0.030 \\
Tibiae, Shaft & 0 & 0.000 & 0.000 & 0.000 & 0.071 \\
Tibiae, Distal & 0 & 0.000 & 0.024 & 0.025 & 0.007 \\
Fibulae, Proximal & 0 & 0.000 & 0.003 & 0.004 & 0.003 \\
Fibulae, Shaft & 0 & 0.000 & 0.000 & 0.000 & 0.011 \\
Fibulae, Distal & 0 & 0.000 & 0.006 & 0.000 & 0.003 \\
Ankles and Feet & 0 & 0.000 & 0.072 & 0.064 & 0.059 \\
\hline & & & & & \\
\hline
\end{tabular}


Table 4-26. Skeletal-averaged absorbed fraction data for the UF hybrid 15-year female skeleton based on PIRT transport.

\begin{tabular}{|c|c|c|c|c|c|c|c|c|}
\hline $\begin{array}{c}\text { Energy } \\
\text { (MeV) }\end{array}$ & $\phi(A M<-A M)$ & $\phi(A M<-T B S)$ & $\phi(A M<-T B V)$ & $\phi(A M<-C B V)$ & $\phi\left(T M_{50}<-T B S\right)$ & $\phi\left(T M_{50}<-T B V\right)$ & $\phi\left(T M_{50}<-A M\right)$ & $\phi\left(T M_{50}<-C B V\right)$ \\
\hline 0.001 & $1.00 \mathrm{E}+00$ & $2.46 \mathrm{E}-01$ & $7.47 \mathrm{E}-07$ & $3.14 \mathrm{E}-08$ & $2.16 \mathrm{E}-01$ & 7.47E-07 & $1.37 \mathrm{E}-01$ & $0.00 \mathrm{E}+00$ \\
\hline 0.003 & 9.99E-01 & 2.46E-01 & 8.27E-05 & 8.08E-06 & 2.33E-01 & 8.65E-05 & 1.37E-01 & 1.36E-06 \\
\hline 0.005 & 9.97E-01 & 2.47E-01 & 3.06E-04 & 2.06E-05 & 2.34E-01 & 3.35E-04 & 1.37E-01 & 3.19E-06 \\
\hline 0.010 & 9.89E-01 & 2.48E-01 & 1.59E-03 & 6.70E-05 & 2.34E-01 & 1.67E-03 & 1.36E-01 & 1.06E-05 \\
\hline 0.015 & 9.77E-01 & 2.48E-01 & $3.72 \mathrm{E}-03$ & $1.41 E-04$ & 2.33E-01 & 3.74E-03 & 1.35E-01 & 2.23E-05 \\
\hline 0.020 & 9.62E-01 & $2.48 \mathrm{E}-01$ & $6.29 E-03$ & $2.32 \mathrm{E}-04$ & 2.31E-01 & $6.21 \mathrm{E}-03$ & 1.33E-01 & $3.66 \mathrm{E}-05$ \\
\hline 0.030 & $9.24 \mathrm{E}-01$ & 2.48E-01 & 1.27E-02 & 4.77E-04 & $2.26 \mathrm{E}-01$ & $1.24 \mathrm{E}-02$ & $1.29 \mathrm{E}-01$ & 7.40E-05 \\
\hline 0.040 & 8.80E-01 & 2.47E-01 & 2.05E-02 & 7.91E-04 & 2.19E-01 & 1.97E-02 & $1.24 \mathrm{E}-01$ & $1.22 \mathrm{E}-04$ \\
\hline 0.050 & 8.33E-01 & 2.47E-01 & 2.94E-02 & 1.16E-03 & 2.12E-01 & 2.77E-02 & 1.19E-01 & 1.79E-04 \\
\hline 0.060 & $7.86 \mathrm{E}-01$ & $2.46 \mathrm{E}-01$ & $3.90 \mathrm{E}-02$ & $1.56 \mathrm{E}-03$ & 2.03E-01 & $3.60 \mathrm{E}-02$ & $1.13 E-01$ & 2.49E-04 \\
\hline 0.080 & 7.10E-01 & $2.46 \mathrm{E}-01$ & 5.93E-02 & 2.51E-03 & $1.74 \mathrm{E}-01$ & 5.02E-02 & $1.04 \mathrm{E}-01$ & 3.93E-04 \\
\hline 0.10 & 6.68E-01 & 2.49E-01 & 8.02E-02 & 3.61E-03 & $1.44 \mathrm{E}-01$ & 5.81E-02 & 9.81E-02 & 5.42E-04 \\
\hline 0.15 & 6.14E-01 & 2.70E-01 & 1.33E-01 & $6.72 \mathrm{E}-03$ & 1.02E-01 & $6.28 \mathrm{E}-02$ & $9.40 \mathrm{E}-02$ & 9.72E-04 \\
\hline 0.20 & 5.80E-01 & 2.93E-01 & $1.78 \mathrm{E}-01$ & 9.95E-03 & 8.23E-02 & 5.92E-02 & 9.55E-02 & 1.42E-03 \\
\hline 0.30 & 5.41E-01 & 3.17E-01 & $2.26 \mathrm{E}-01$ & $1.66 \mathrm{E}-02$ & 6.48E-02 & 5.18E-02 & 9.80E-02 & 2.36E-03 \\
\hline 0.40 & $5.21 E-01$ & $3.21 E-01$ & $2.41 E-01$ & $2.29 \mathrm{E}-02$ & 5.82E-02 & 4.87E-02 & $9.75 \mathrm{E}-02$ & $3.29 E-03$ \\
\hline 0.50 & 5.06E-01 & 3.19E-01 & $2.45 E-01$ & $2.90 \mathrm{E}-02$ & 5.47E-02 & 4.69E-02 & 9.62E-02 & $4.20 \mathrm{E}-03$ \\
\hline 0.60 & 4.93E-01 & 3.15E-01 & $2.45 \mathrm{E}-01$ & 3.48E-02 & $5.22 \mathrm{E}-02$ & 4.55E-02 & 9.46E-02 & 5.05E-03 \\
\hline 0.80 & 4.69E-01 & 3.05E-01 & 2.40E-01 & 4.41E-02 & 4.84E-02 & 4.29E-02 & $9.11 \mathrm{E}-02$ & $6.46 \mathrm{E}-03$ \\
\hline 1.0 & 4.47E-01 & 2.95E-01 & 2.32E-01 & 5.07E-02 & 4.54E-02 & 4.07E-02 & 8.74E-02 & 7.48E-03 \\
\hline 1.5 & 3.99E-01 & 2.68E-01 & 2.12E-01 & 5.79E-02 & 3.98E-02 & 3.60E-02 & 7.87E-02 & 8.63E-03 \\
\hline 2.0 & 3.59E-01 & $2.44 \mathrm{E}-01$ & 1.93E-01 & 5.88E-02 & 3.55E-02 & 3.22E-02 & 7.13E-02 & 8.83E-03 \\
\hline 3.0 & $2.98 \mathrm{E}-01$ & $2.05 \mathrm{E}-01$ & $1.61 \mathrm{E}-01$ & 5.50E-02 & 2.91E-02 & 2.64E-02 & 5.93E-02 & $8.28 \mathrm{E}-03$ \\
\hline 4.0 & 2.53E-01 & $1.75 \mathrm{E}-01$ & 1.37E-01 & 4.96E-02 & $2.46 \mathrm{E}-02$ & $2.23 \mathrm{E}-02$ & 5.05E-02 & 7.46E-03 \\
\hline 5.0 & 2.18E-01 & $1.52 \mathrm{E}-01$ & 1.19E-01 & 4.44E-02 & $2.12 \mathrm{E}-02$ & $1.92 \mathrm{E}-02$ & 4.37E-02 & 6.67E-03 \\
\hline 6.0 & 1.91E-01 & $1.34 \mathrm{E}-01$ & $1.05 E-01$ & 3.97E-02 & 1.86E-02 & 1.68E-02 & 3.84E-02 & 5.97E-03 \\
\hline 8.0 & $1.52 \mathrm{E}-01$ & 1.07E-01 & 8.33E-02 & $3.24 \mathrm{E}-02$ & 1.48E-02 & 1.34E-02 & 3.06E-02 & 4.87E-03 \\
\hline 10.0 & $1.26 \mathrm{E}-01$ & 8.81E-02 & 6.87E-02 & 2.71E-02 & 1.22E-02 & 1.10E-02 & 2.52E-02 & 4.07E-03 \\
\hline
\end{tabular}




\section{Appendix C}

\section{A Skeletal Reference Dosimetry Model for the Adult Female}




\title{
An Image-based Skeletal Tissue Model for the ICRP Reference Adult Female
}

\author{
Lindsay Sinclair ${ }^{1}$, Deanna H. Pafundi ${ }^{2}$, and Wesley E. Bolch ${ }^{1}$ \\ ${ }^{1}$ Department of Nuclear and Radiological Sciences, University of Florida \\ ${ }^{2}$ Radiation Oncology Mayo Clinic, Rochester, MN
}

\begin{abstract}
Modeling of the unique macro and microstructure of the skeleton has shown to be a challenging aspect of skeletal dosimetry. The skeleton is comprised of two main radiosensitive cell populations, hematopoietic stem cells and osteoprogenitor cells. Hematopoietic stem cells are found within the active marrow regions of spongiosa, while osteoprogenitor cells are found on the bone endosteum. Skeletal tissues include mineral bone (cortical or trabecular in structure), active and inactive marrow, cartilage, periosteum, and blood vessels. The skeletal model described in this study seeks to accurately represent the structure and composition of all skeletal tissues within an adult female phantom.

The skeletal tissue masses presented in this paper were derived from four data sets. The first are the polygon mesh and NURBS skeletal volumes of the UF hybrid adult female phantom. The UFHADF skeleton was modeled so that total skeletal masses for each bone site were matched with ICRP reference data. Initially, the skeleton was composed as a homogeneous mixture of all skeletal tissues, including cortical bone, trabecular bone, red and yellow marrow, miscellaneous skeletal tissues, and teeth.

The second source of data for this skeletal model includes ICRP70 (1995), ICRP89 (2002), and ICRU46 (1992). The skeletal tissue reference masses and densities were obtained from the ICRP reports. ICRU46 served as a reference for the density of soft tissue for an adult female and for the elemental composition of spongiosa.

The last two sources of data were based on image data sets from a 45 year-old female cadaver. All pertinent skeletal sites were excised and imaged by standard CT and microCT in order to get valuable information on skeletal macrostructure and microstructure.

The end result of this study was the creation of a heterogeneous skeletal tissue model for the adult female that closely matched the reference total skeletal tissue masses given by the ICRP. Active and inactive marrow masses were both within one percent of the ICRP reference values. The cortical bone mass differed by three percent, while the trabecular bone percent difference was 13 . However, the CB/TB ratio from this model was $78 / 22$, which closely matches the ICRP $80 / 20$ ratio. In addition, the total skeletal mineral bone mass matched the ICRP reference value of $4000 \mathrm{~g}$ exactly.
\end{abstract}




\section{INTRODUCTION}

The composition of the skeleton is paramount in determining the effects of radiation exposure to the human body. The skeleton is comprised of two main radiosensitive cell populations, hematopoietic stem cells and osteoprogenitor cells. Hematopoietic stem cells are located in the active bone marrow, which can be found within trabecular spongiosa. Radiation exposures to these cells can be associated with leukemia risk. Osteoprogenitor cells are found on bone or endosteal surfaces. Stochastic effects such as bone cancer can be a result of radiation exposure to osteoprogenitor cells. When estimating the risk to radiosensitive regions of the skeleton, skeletal reference models are used to compute absorbed doses to these tissues. The skeletal tissue model presented here can be used to estimate radiation risk to a reference adult female.

Historically, the skeleton has been a challenging aspect to model in computational phantoms. This can be attributed to the highly variable and complex macrostructure and microstructure of the tissues which constitute the skeleton. Skeletal tissues include mineral bone, active and inactive marrow, cartilage, periosteum, and blood vessels. Mineral bone is an organic matrix composed mainly of the protein, collagen. This matrix is infused with inorganic material, calcium phosphate. (Triffitt 1980) The first step of bone formation is the creation of the organic matrix by osteoblasts, or bone-forming cells. The matrix is then mineralized, and then continually remodeled by osteoblasts and osteoclasts throughout life. (Frost 1980)

Mineral bone can generally be divided into either cortical or trabecular bone, based on structure. Cortical or compact bone forms the outer dense layer of osseous tissue throughout the skeleton. Cortical bone is found on the ends of bones surrounding trabecular bone and also 
as a thicker shell on the shafts of the long bones. The trabecular or spongy bone is porous in structure and has a much lower bone volume fraction than compact bone. Bone marrow is found within the cavities of trabecular bone. (Frost 1963a)

As mentioned earlier, the two main radiosensitive cell types are osteoprogenitor cells and hematopoietic stem cells. Osteoprogenitor cells are found on the surfaces of bone and within the bone cavities. In modeling the skeletal system, the endosteum is used as a surrogate target tissue for osteoprogenitor cells. This study sets a layer within 50 microns of trabecular and cortical bone surfaces to represent the endosteum. (Bolch et al. 2007) Hematopoietic stem cells are found within the active marrow regions of trabecular spongiosa. Active marrow is used as a surrogate to model these cells. The skeletal model described in this study seeks to accurately represent the structure and composition of all skeletal tissues within an adult female phantom.

When evaluating risk to patients, for either short-term effects or secondary cancer induction from radiation, absorbed dose estimates to critical tissues are vital. In order to complete this task within the skeleton, skeletal tissue masses must be calculated and then applied to a computational phantom. While a third generation hybrid phantom is used in this study, the majority of computational phantoms can be divided into two earlier modeling techniques, stylized or mathematical and voxel or tomographic phantoms.

The earliest form of computational phantoms used for dose assessment for internal and external radiation exposures are stylized phantoms. Stylized phantoms consist of geometric surface equations to represent regions of human anatomy. The most widely used skeletal tissue models are based on Oak Ridge National Laboratory (ORNL) mathematical phantoms 
developed in the late 1970 s and early 1980s. The skeleton within these phantoms consists of a homogeneous mixture of cortical bone and spongiosa. (Snyder et al. 1974, Cristy 1980, 1981) The phantoms were developed to be used with the MIRD (Medical Internal Radiation Dose) schema to evaluate organ doses from internal radiation sources. (Cristy and Eckerman 1987, Han et al. 2006)

The second generation of computational phantoms are voxel or tomographic phantoms. They are based on medical images of patients who have undergone CT (computed tomography) or MR (magnetic resonance) imaging. Segmentation allows for delineation of internal anatomy. Voxel phantoms are much more anatomically realistic than stylized phantoms, since they based on real patient images. However, the shape and size of organs cannot be easily changed within tomographic phantoms; the phantoms are only uniformly scalable. Furthermore, the majority of these phantoms have a homogeneous skeletal composition, and various correction factors must be applied in order to get absorbed dose estimates to the red bone marrow and endosteum targets.

Several of the available voxel phantoms that have been published are based on incomplete image sets of human anatomy. (Gibbs et al. 1984, Williams et al. 1986, Veit et al. 1989, Zubal et al. 1994, Caon et al. 1999) More recent attempts to utilize a heterogeneous skeleton have been documented. Xu et al. (2000) developed a tomographic phantom from color photographic images from the Visible Human Project. The skeleton in VIP-man is divided into separately tagged voxels of mineral bone and red marrow. However, there is no delineation between cortical and trabecular bone, and no representation of yellow marrow. Another approach to differentiating skeletal tissues in voxel phantoms was to tag voxels within 
the skeleton as cortical bone, spongiosa, and medullary marrow. (Zankl et al. 2007) Kramer et al. (2006a, 2006b) also utilized this approach in the MAX06 phantom. The distinction between cortical bone and spongiosa accounts for cortical bone shielding effects of marrow for transport involving low energy photons.

A third generation of computational phantoms called hybrid phantoms have been recently developed. Human anatomy within hybrid phantoms are made up of NURBS (NonUniform Rational B-Spline) and polygon mesh surfaces. They retain the anatomical realism of tomographic phantoms, and can also be easily modified to model different patient statures and weights. (Lee et al. 2007, Segars et al. 2008, Xu et al. 2007) A main contributor to the development of hybrid phantoms is the Bone Imaging \& Dosimetry research group at the University of Florida. They have published hybrid phantoms representing the ICRP89 reference newborn, 1 year, 5 year, 10 year, 15 year and adult male and female. (Lee et al. 2007, 2008, 2009, Hurtado 2008) The UFHADF (UF hybrid adult female) phantom will be used in this study to create a heterogeneous skeletal model for the adult female.

Models of skeletal dosimetry currently used in a clinical setting, such as MIRDOSE and its successors (Stabin 1996, Eckerman and Stabin 2000, Stabin and Siegel 2003) are limited by several factors. These models assume an infinite cylinder of spongiosa, which can result in an overestimation of dose because there is no allowance for energy escape. Secondly, the current model does not allow for beta particle cross-fire from cortical bone to active marrow. Furthermore, the skeletal microstructure, including that of trabecular bone and marrow, are widely based on studies done at the University of Leeds in the 1960's and 1970's in which chord-length distributions were measured through trabecular bone and marrow cavities for 7 
bone sites taken from a 44 year-old male. (Beddoe 1976) This data serves as a foundation for much of the skeletal attributes of ICRP reference man. (ICRP 1975)

The purpose of this study was to derive the masses of all the previously mentioned skeletal tissues in a bone site-specific manner, and then apply them to the UFHADF phantom. This allowed for significant improvements in the macro- and micro-architecture of the skeleton. For instance, spongiosa was modeled as a finite region within each bone site. Cross-fire effects were also taken into account from electron emissions in compact bone. The end result will be a heterogeneous skeleton from which a more accurate means of radiation transport can be implemented.

The skeletal tissue masses presented in this paper were derived from four data sets. The first are the polygon mesh and NURBS skeletal volumes of the UF hybrid adult female. The UFHADF skeleton was modeled so that total skeletal masses for each bone site were matched with ICRP reference data. Initially, the skeleton was composed as a homogeneous mixture of all skeletal tissues, including cortical bone, trabecular bone, red and yellow marrow, miscellaneous skeletal tissues, and teeth.

The second source of data for this skeletal model includes ICRP70 (1995), ICRP89 (2002), and ICRU46 (1992). The skeletal tissue reference masses and densities were obtained from the ICRP reports. ICRU46 served as a reference for the density of soft tissue for an adult female and for the elemental composition of spongiosa.

The last two sources of data were based on image data sets from a 45 year-old female cadaver. All pertinent skeletal sites were excised and imaged by standard CT and microCT in order to get valuable information on skeletal macrostructure and microstructure. 


\section{MATERIALS AND METHODS}

The purpose of this study is to develop a comprehensive skeletal tissue model for the ICRP reference adult female. This model will be implemented into UFHADF, the UF hybrid adult female phantom and later, coupled to radiation transport codes to obtain absorbed dose estimates to the active bone marrow and endosteum. The development of a skeletal reference model is a two-part process: 1 . skeletal tissue mass calculations and 2. skeletal dosimetry via radiation transport codes. This paper concentrates on the methodology behind calculating sitespecific skeletal tissue masses.

The methodology presented here is based on mass derivations from Pafundi et. al (2009) for the ICRP reference newborn hybrid phantom. However, modifications were made to account for differences in skeletal structure between the newborn and adult model.

\section{Image Acquisition and Analysis}

The adult female skeletal model was initiated when a 45-year old female cadaver was made available to us through the State of Florida Anatomical Board. It was confirmed that skeleton of the female had no deterioration before the study was continued. The cadaver was first subjected to whole-body in-vivo CT imaging within the Department of Radiology at UF Shands hospital with a 64-slice Toshiba CT scanner. The in-vivo CT images were transferred to imaging workstations within ALRADS (Advanced Laboratory for Radiation Dosimetry Studies) at the UF Department of Nuclear and Radiological Engineering. This was done so that we would 
have a complete data set of the subject available. The images were used when ex-vivo CT imaging of the skeletal site was not able to be performed (segmentation of the shafts of the long bones).

In order for ex-vivo CT imaging to take place a cadaver harvest was performed in which skeletal sites containing active marrow were excised. These bone sites included: the cranium, mandible, clavicles, scapulae, sternum, cervical, thoracic, and lumbar vertebrae, 2 upper, middle, and lower ribs, os coxae, sacrum, proximal and distal humeri, proximal and distal radii, proximal and distal ulnae, proximal and distal femorae, patellae, proximal and distal tibiae, and the proximal and distal fibulae. These major skeletal sites were harvested, cleaned, and then kept frozen for later use.

The next step performed was ex-vivo CT imaging of each skeletal site. These scans were completed at Shands at UF with the same CT scanner mentioned previously. Two scans for each bone were completed, one with a bone filter and one with a soft tissue filter in order to get optimal imaging of cortical bone and spongiosa boundaries, with $1 \mathrm{~mm}$ slices. Two vital parameters were extracted from these images, the cortical bone volume fraction (CBVF) and the spongiosa volume fraction (SVF). These fractions sum to one, as they represent the total volume of homogeneous bone in a given skeletal site. Segmentation of cortical bone and spongiosa boundaries was completed, and volumes were calculated using 3D-Doctor ${ }^{\mathrm{Tm}}$. These volume fractions will be later adjusted by an iterative process so that the total skeletal mineral bone mass matches the ICRP 89 (2002) value.

Following inspection of the ex-vivo scans, a region was selected within each bone to be imaged via microCT. The microCT imaging was completed by SCANCO (Scanco Medical AG, 
Bruttisellen, Switzerland) at 30 micron resolution. The microCT imaging allowed for two parameters of skeletal microstructure to be obtained through image analysis software for almost all skeletal sites. These included the marrow volume fraction (MVF) and the trabecular bone volume fraction (TBVF). These volume fractions also sum to one, and represent the volume of spongiosa within each skeletal site. The image analysis software, BIDUserInterface (Rajon et al. 2006) converts the images into a binary format by selecting a threshold value through gradient inspection. Four main steps are taken to get the final binary image: (1) a region of interest (ROI) is extracted to ensure that no cortical bone remains in the image; (2) a median filter is applied to improve the signal-to-noise ratio (SNR); (3) a threshold value is determined; and (4) the ROI is segmented into either bone or marrow voxels based on the threshold value.

The final volume fraction to be determined for mass calculations is the shallow marrow volume fraction (SMVF). This is the volume of spongiosa occupied by marrow within 50 microns of bone surfaces. As mentioned earlier, this parameter will be used to determine the surrogate target tissue for osteoprogenitor cells. The SMVF is calculated by importing the microCT images for each skeletal site into the PIRTSMVF code. (Shah et al. 2005)

\section{Mass Calculations}

\section{Miscellaneous Skeletal Tissues}

After obtaining all of the relevant volume fractions from the macro and microstructure, the next step is to distribute the miscellaneous skeletal tissue mass. Miscellaneous skeletal tissues (MST) include blood vessels and periosteum. (ICRP 2002) Since these tissues cannot be 
identified in CT data sets, they are just included in the homogeneous skeletal volumes of the adult female phantom. When comparing total skeletal tissue masses to that of ICRP 89, the MST must be taken out. Miscellaneous skeletal tissues are first distributed by volume to all skeletal sites, where $\mathrm{X}$ represents one skeletal site. (Equation 1)

$$
V_{M S T}^{X}=V_{M S T} *\left(\frac{V_{H B *}^{X}}{V_{H B *}^{T o t a l}}\right),
$$

The volumes marked with an asterisk represent those including MST. $\mathrm{V}_{\mathrm{HB}^{*}}$ refers to the volume of homogeneous bone already defined within the phantom. $V_{\text {MST }}$ was calculated by multiplying the mass of $160 \mathrm{~g}$, as given by ICRP89 as the total amount of MST within the skeleton, by the density of soft tissue for an adult female, 1.03. (ICRU46 1992)

Next they are further partitioned into skeletal tissues including active marrow ( $\left.\mathrm{AM}^{*}\right)$, inactive marrow $\left(\mathrm{IM}^{*}\right)$, and mineral bone $\left(\mathrm{MB}^{*}\right)$ including cortical $\left(\mathrm{CB}^{*}\right)$ and trabecular bone (TB*) volumes. (Equation 2)

$$
\begin{aligned}
& V_{M S T-A M}^{X}=V_{M S T}^{X} *\left(\frac{V_{A M *}^{X}}{V_{H B *}^{X}}\right), \\
& V_{M S T-I M}^{X}=V_{M S T}^{X} *\left(\frac{V_{I * *}^{X}}{V_{H B *}^{X}}\right) \\
& V_{M S T-M B}^{X}=V_{M S T}^{X} *\left(\frac{V_{M B *}^{X}}{V_{H B *}^{X}}\right) \\
& V_{M S T-C B}^{X}=V_{M S T-M B}^{X} *\left(\frac{V_{C B *}^{X}}{V_{M B *}^{X}}\right) \\
& V_{M S T-T B}^{X}=V_{M S T-M B}^{X} *\left(\frac{V_{T B *}^{X}}{V_{M B *}^{X}}\right)
\end{aligned}
$$

\section{Marrow Volumes and Masses}

In the adult, marrow can be found within spongiosa cavities or in the medullary cavities of the shafts of the long bones. In the medullary cavities of the long bones the marrow is 
assumed to be 100 percent inactive marrow, while active marrow remains in the proximal and distal ends of the bones. (ICRP 2002) The active and inactive marrow volumes are calculated from the NURBS homogeneous bone volumes, the spongiosa volume fraction (SVF), marrow volume fraction(MVF), and the cellularity factor, CF (fraction of marrow that is hematopoetically active). (ICRP 1995) (Equation 3)

$$
\begin{aligned}
& V_{T A M *}^{X}=V_{H B *}^{X} * S V F^{X} * M V F^{X} * C F^{X} \\
& V_{T I M *}^{X}=V_{H B *}^{X} * S V F^{X} * M V F^{X} *\left(1-C F^{X}\right) \\
& V_{T A M}^{X}=V_{T A M *}^{X}-V_{M S T-A M}^{X} \\
& V_{T I M}^{X}=V_{T I M *}^{X}-V_{M S T-I M}^{X}
\end{aligned}
$$

The subscripts TAM (trabecular active marrow) and TIM (trabecular inactive marrow) are adopted to distinguish between the inactive marrow located within trabecular cavities and the medullary marrow located within the shafts of the long bones. The medullary marrow volume is calculated in the same way as the trabecular inactive marrow volume, except the MVF is equal to 1 , since there is no trabeculation within the shafts. Since there was no microCT imaging completed for the hands and feet, and Whitwell (1973) conducted a study which showed comparable microstructure among the ribs and these bone regions, the MVF for the ribs was assigned to the wrists and hands and ankles and feet. The cellularity factors were obtained from Table 41 in ICRP70. For the inactive marrow, the volume is multiplied by (1-CF) instead of just CF, in order to obtain the fraction of marrow that hematopoietically inactive. The MST is then subtracted from the marrow volumes and multiplied by the correct ICRP density (1.03 for active marrow, 0.98 for inactive marrow) in order to compare to the active and inactive marrow masses from ICRP 89. 


\section{Mineral Bone Masses and Volumes}

Total mineral bone within the adult female skeleton is composed of trabecular and cortical bone. The equations used to calculate the mineral bone volumes including miscellaneous skeletal tissues are shown below. (Equation 4)

$$
\begin{aligned}
& V_{M B *}^{X}=V_{T B *}^{X}+V_{C B *}^{X} \\
& V_{T B *}^{X}=V_{H B *}^{X} * S V F^{X} * T B V F^{X} \\
& V_{C B *}^{X}=V_{H B *}^{X} * C B V F^{X}
\end{aligned}
$$

These volumes are based on the adult female phantom homogeneous bone volumes, as well as the macro and microstructure parameters determined from previous image processing techniques. The initial SVF and CBVF were obtained from manual image segmentation, and were adjusted through an iterative process until the total mineral bone mass matched the ICRP 89 (2002) value of $4000 \mathrm{~g}$. The equations for mineral bone volumes excluding MST are shown in Equation 5.

$$
\begin{aligned}
& V_{M B}^{X}=V_{M B *}^{X}-V_{M S T-M B}^{X} \\
& V_{T B}^{X}=V_{T B *}^{X}-V_{M S T-T B}^{X} \\
& V_{C B}^{X}=V_{C B *}^{X}-V_{M S T-C B}^{X}
\end{aligned}
$$

The masses of mineral bone, trabecular bone, and cortical bone are calculated from multiplying the equations above by the ICRP 89 (2002) density for mineral bone, $1.9 \mathrm{~g} / \mathrm{cm}^{3}$.

\section{Shallow Marrow Masses and Volumes}

As previously discussed, the shallow marrow volume or endosteum is used as a surrogate target tissue for osteoprogenitor cells. It encompasses a layer of cells 50 microns 
within trabecular bone surfaces or the cortical bone/medullary cavity interface in the shafts of the long bones. The target layer along trabecular bone surfaces is defined as TAM ${ }_{50}$, and the layer along the shafts on the long bones, $\mathrm{CIM}_{50}$. The equations for these volumes are shown below. (Equation 6 and 7)

$$
\begin{aligned}
& V_{T A M 50 *}^{X}=V_{\text {Spongiosa }}^{X} * S M V F^{X} * C F^{X} \\
& V_{\text {CIM50* }}^{X}=V_{\text {Medullarymarrow } *}^{X} * S M V F_{\text {Shaft }}^{X} *(1-C F)^{X}
\end{aligned}
$$

In equation 6 , the $V_{\text {Spongiosa }}^{X}$ refers to the volume of spongiosa for skeletal site, $\mathrm{X}$. It is the product of the phantom homogeneous bone volume and the spongiosa volume fraction. The $S M V F^{X}$ is calculated from the PIRTSMVF code by importing the microCT image into the code. In equation 7, since microCT images were not obtained for the shafts of the long bones, this volume must be calculated in a different manner. The shafts of the long bones were modeled

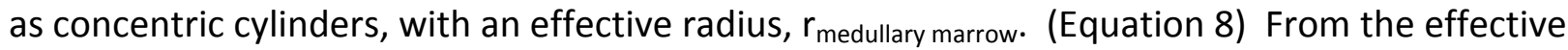
radius the shallow marrow volume fraction for the shafts was calculated. (Equation 9)

$$
\begin{aligned}
& r_{\text {medullary marrow }}=\sqrt{\frac{\frac{V_{\text {medullary marrow } *}^{X}}{2 * h}}{\pi}} \\
& S M V F_{\text {Shaft }}^{X}=1-\left(\frac{r_{\text {medullary marrow } *-0.005}^{X}}{r_{\text {medullary marrow } *}}\right)^{2}
\end{aligned}
$$

In equations 7 and $8, V_{\text {Medullary marrow* }}^{X}$ refers to the total volume of medullary marrow within the shafts. It is the product of the skeletal site volume from the female phantom and the medullary marrow volume fraction from segmentation in 3D-Doctor ${ }^{\mathrm{rm}}$. The $\mathrm{h}$ in equation 8 is the height of the shaft region, measured in Rhinoceros ${ }^{T M}$. 


\section{RESULTS AND DISCUSSION}

The volumes and masses of all skeletal tissues including active and inactive marrow, cortical and trabecular bone, and miscellaneous skeletal tissues were calculated based on 1) ICRP Reference skeletal tissue masses from ICRP70 and ICRP89, 2) the skeletal volumes from the ICRP-based UF hybrid adult female phantom, 3) in-vivo and ex-vivo CT images of all marrow-containing skeletal sites, and 4) microCT images of all active marrow-containing sites. This study targeted total skeletal tissue masses provided in ICRP 89 (2002), but distributed them among all marrow-containing skeletal sites based on volume ratios and imaging data.

\section{Volume fractions for Spongiosa, Marrow, Cortical and Trabecular Bone}

Table 1 shows the SVF (spongiosa volume fraction), CBVF (cortical bone volume fraction), TBVF (trabecular bone volume fraction) and MVF (marrow volume fraction) used to calculate all skeletal tissue masses. The SVF and CBVF were initially determined through manual image segmentation in 3D-Doctor ${ }^{\mathrm{TM}}$, and later adjusted through an iterative process to match ICRP reference masses. The values shown are the final volume fractions used in the mass calculations. The volume fractions for the cranium, all vertebral sites, and the proximal femur are averages of multiple samples obtained for that given bone site. The MVF and TBVF were determined by gradient inspection using BIDUserInterface. (Rajon et al. 2006) All of the MVFs for the shafts of the long bones are valued at 1.0, as there is no trabeculation, and all of the marrow in the medullary cavity is assumed to be inactive marrow. 


\section{Miscellaneous Skeletal Tissue Distribution}

Table 2 shows how the ICRP value of $160 \mathrm{~g}$ of miscellaneous skeletal tissue was partitioned. First, it was distributed to skeletal sites based on volume ratios of the homogeneous bones within the UFHADF phantom. Then, the volumes were further divided among all skeletal tissues: active and inactive marrow, and cortical and trabecular bone.

\section{Marrow Volumes and Masses}

Table 3 shows the trabecular active and inactive marrow volumes and masses for the adult female skeleton. These values do not include miscellaneous skeletal tissues. The entire skeleton was calculated to have an active marrow volume of $874.26 \mathrm{~cm}^{3}$ assuming the ICRP density of $1.03 \mathrm{~g} / \mathrm{cm}^{3}$ for active marrow. The total skeletal mass of active marrow came out to be $900.49 \mathrm{~g}$, almost equal to the ICRP reference mass of $900 \mathrm{~g}$. The ICRP reference mass for trabecular inactive marrow was $1800 \mathrm{~g}$. The final value for this skeletal tissue model was 1777.3, slightly over a 1 percent difference. The total volume was $1813.6 \mathrm{~cm}^{3}$, assuming the ICRP reference density of $0.98 \mathrm{~g} / \mathrm{cm}^{3}$ for inactive marrow. The largest mass of active marrow for a given bone site was found to be in the os coxae, which shows good agreement from the active marrow percent distribution table in ICRP 89.

\section{Mineral Bone Volumes and Masses}

Table 4 lists the masses for mineral bone and its constituents, trabecular and cortical bone. The values listed exclude the masses of miscellaneous skeletal tissues. These masses were calculated based on their respective volumes and the density of mineral bone, 0.98 , found 
in ICRP89. The mineral bone mass for the entire skeleton matched exactly with the ICRP reference mass of $4000 \mathrm{~g}$. The cortical and trabecular bone masses differed slightly from reference values, with the trabecular bone mass equaling $900.5 \mathrm{~g}$, and cortical bone mass being 3107.1 g. These values exhibit a 13 and 3 percent difference from ICRP. However, ICRP 89 clearly states that $80 \%$ of total mineral bone mass is cortical, and $20 \%$ is trabecular. The masses from this study indicate a very similar 78/22 percent distribution.

\section{Shallow Marrow Volumes and Masses}

The shallow marrow distribution by skeletal site is reported in Table 5 . The first column is the amount of spongiosa for a given bone site that was computed as shallow marrow. These values came directly from the PIRTSMVF code with the exception of all the shafts of the long

bones. Table 6 lists the average lengths of the shafts of the long bones. The longest shaft was found to be the femur at $28.7 \mathrm{~cm}$, and the shortest was the ulna, $17.4 \mathrm{~cm}$. Ten measurements were taken for each long bone shaft. The calculated medullary marrow radius was used to calculate the shallow marrow volume fraction for the shafts of the long bone listed in column 2 of table 5 . Column 3 is the percent of total marrow calculated as shallow marrow. Volumes and masses of shallow active and inactive marrow are listed in the last four columns. The total amount of shallow active marrow was around $147 \mathrm{~g}$.

\section{CONCLUSION}


The end result of this study was the creation of a heterogeneous skeletal tissue model for the adult female that closely matched the reference total skeletal tissue masses given by the ICRP. Active and inactive marrow masses were both within one percent of the ICRP reference values. The cortical bone mass differed by three percent, while the trabecular bone percent difference was 13 . However, the $\mathrm{CB} / \mathrm{TB}$ ratio from this model was $78 / 22$, which closely matches the ICRP $80 / 20$ ratio. In addition, the total skeletal mineral bone mass matched the ICRP reference value of $4000 \mathrm{~g}$ exactly. Shallow marrow volumes and masses were also calculated so that they can serve as a surrogate target region for osteoprogenitor cells.

In order to complete the skeletal dosimetry model for the adult female, the volumes from this study will be realized within the UFHADF. This subsegmentation of the skeleton is completed using the software, Rhinoceros ${ }^{T M}$ (McNeel North America, Seattle, WA). Utilizing Rhinoceros ${ }^{T M}$, cortical bone, spongiosa, and medullary marrow volumes will be targeted, completing the heterogeneous skeletal tissue model. The next step is to voxelize the phantom using an in-house MATLAB ${ }^{T M}$ (The Mathworks, Inc., Natick, MA) code, Voxelizer (Lee et al. 2007), so that radiation transport can be executed. An in-house IDL (ITT Visualization Solutions, Boulder, $\mathrm{CO}$ ) code Voxel_Counter will be used to verify that the voxel volumes are within one percent of the original volumes. Next, the voxelized version of UFHADF will be visually inspected using the program, ImageJ (National Institutes of Health Public Domain, Bethesda, MD). Radiation transport will be accomplished using PIRT (Paired Image Radiation Transport) (Shah et al. 2005). PIRT tracks the energy deposition of particles through the macrostructure and microstructure simultaneously. Finally, the skeletal tissue masses from this project will be 
used to obtain specific absorbed fraction data from the PIRT runs. When all of these steps are accomplished, the skeletal reference model for the ICRP adult female will be complete. 


\section{REFERENCES}

Beddoe AH, Darley PJ, and Spiers FW 1976 Measurements of trabecular bone structure in man. Phys.Med. Biol. 21(4) 589-607

Caon M, Bibbo G, and Pattison J 1999 An EGS4-ready tomographic computational model of a 14-year-old female torso for calculating organ doses from CT examinations.

Physics in Medicine and Biology 44(9) 2213-2225

Cristy, M. 1980. Mathematical phantoms representing children of various ages for use in estimates of internal dose. U.S. Nuclear Regulatory Commission Rep. NUREG/CR-1159 (also Oak Ridge National Laboratory Rep. ORNL/NUREG/TM-367).

Cristy, M. 1981. Active bone marrow distribution as a function of age in humans. Phys. Med. Biol.26: 389-400.

Cristy M and Eckerman K F 1987 Specific Absorbed Fractions of Energy at Various Ages from Internal Photon Sources vols 1-7 ORNL/TM-8381 (Oak Ridge, TN: Oak Ridge National Laboratory)

Eckerman K F and Stabin M G 2000 Electron absorbed fractions and dose conversion factors for marrow and bone by skeletal regions Health Phys. 78 199-214

Frost, H.M. (1980). Skeletal physiology and bone remodeling. In: Fundamental and clinical bone physiology, ed. By M.R. Urist. Philadelphia: J. B. Lippincott Co., 208-241

Frost, H.M. (1963a) Bone remodeling dynamics. Springfield, Illinois: Charles C. Thomas.

Gibbs SJ, Pujol A, Chen TS, Malcolm AW, and James AE 1984 Patient Risk from Interproximal Radiography. Oral Surgery Oral Medicine Oral Pathology Oral Radiology and Endodontics 58(3) 347-354

Han E, BolchWand Eckerman K 2006 Revisions to the ORNL series of adult and pediatric computational phantoms for use with the MIRD schema Health Phys. 90 337-56

Hurtado J L, Lee C, Lodwick D, Geode T, Williams J L and Bolch W E in press Hybrid computational phantoms representing the reference adult male and adult female: Construction and applications to retrospective dosimetry Health Phys

International Commission on Radiological Protection (ICRP) (1975) Publication 23, Report of the task group on reference man. Oxford: Pergamon Press.

ICRP (1995). Basic anatomical and physiological data for use in radiological protection: the skeleton. ICRP Publication 70, Ann. ICRP 25 (2). 
ICRP 2002 ICRP Publication 89: basic anatomical and physiological data for use in radiological protection-reference values Ann. ICRP 32 1-277

ICRU 1992 Photon, electron, proton and neutron interaction data for body tissues ICRU Report No 46 (Bethesda,MD: International Commission on Radiation Units and Measurements)

Kramer R, Khoury H J, Vieira J W and Kawrakow I 2006a Skeletal dosimetry in the MAX06 and the FAX06 phantoms for external exposure to photons based on vertebral 3D-microCT images Phys. Med. Biol. 51 6265-89

Kramer R, Khoury H J, Vieira J W and Lima V J 2006b MAX06 and FAX06: update of two adult human phantoms for radiation protection dosimetry Phys. Med. Biol. 51 3331-46

Lee C, Lodwick D, Hasenauer D, Williams J L, Lee C and Bolch W E 2007 Hybrid computational phantoms of the male and female newborn patient: NURBS-based whole-body models Phys. Med. Biol. 52 3309-33

Lee C, Lodwick D, Williams J L and Bolch W E 2008 Hybrid computational phantoms of the 15year male and female adolescent: applications to CT organ dosimetry for patients of variable morphometry Med Phys 35 2366-2382

Lee C, Lodwick D, Hurtado J, Pafundi D, Williams J, Bolch W 2009 The UF Family of Reference Hybrid Phantoms for Computational Radiation Dosimetry Phys Med Biol ?

Pafundi D, Lee C, Watchman C, Bourke V, Aris J, Shagina N, Harrison J, Fell T, Bolch W. 2009. An Image-based Skeletal Tissue Model for the ICRP Reference Newborn. Phys med Biol. 54: 44974531

Rajon D, Pichardo J, Brindle J, Kielar K, Jokisch D, Patton P and Bolch W 2006 Image segmentation of trabecular spongiosa by visual inspection of the gradient magnitude Phys. Med. Biol. 51 4447-67

Segars W P, Mahesh M, Beck T J, Frey E C and Tsui B M 2008 Realistic CT simulation using the 4D XCAT phantom Med Phys 35 3800-3808

Shah AP, Rajon D, Patton P, Jokisch D, and Bolch W 2005c Accounting for beta-particle energy loss to cortical bone via Paired-Image Radiation Transport (PIRT). Med Phys 32(5) 1354-1366

Segars W P, Mahesh M, Beck T J, Frey E C and Tsui B M 2008 Realistic CT simulation using the 4D XCAT phantom Med Phys 35 3800-3808

Shah AP, Rajon D, Patton P, Jokisch D, and Bolch W 2005c Accounting for beta-particle energy loss to cortical bone via Paired-Image Radiation Transport (PIRT). Med Phys 32(5) 1354-1366 
Snyder, W.S., Ford, M.R., Warner, G.G., and Watson, S.B. 1974. A tabulation of dose equivalent per microcurie-day for source and target organs of an adult for various radionuclides: Part 1. Oak Ridge National Laboratory Rep. ORNL-5000.

Stabin M G and Siegel J A 2003 Physical models and dose factors for use in internal dose assessment Health Phys 85 294-310

Stabin MG. MIRDOSE: personal computer software for internal dose assessment in nuclear medicine. J Nucl Med. 1996;37:538 -546.

Triffitt, J.T. (1980) The organic matrix of bone tissue. In: Fundamental and clinical bone physiology, ed. By M.R. Urist. Philadelphia: J.B. Lippincott Co., 45-82.

Veit R, Zankl M, Petoussi N, Mannweiler E, Williams G, and Drexler G 1989 Tomographic anthropomorphic models, Part I: Construction technique and description of models of an 8-week-old baby and a 7-year-old child. Neuherberg, Germany: GSF-National Research Center for Environment and Health.

Williams G, Zankl M, Abmayr W, Veit R, and Drexler G 1986 The calculation of dose from external photon exposures using reference and realistic human phantoms and Monte-Carlo methods. Physics in Medicine and Biology 31(4) 449-452

Xu X G, Taranenko V, Zhang J and Shi C 2007 A boundary-representation method for designing whole-body radiation dosimetry models: pregnant females at the ends of three gestational periods--RPI-P3, -P6 and -P9 Phys Med Biol 52 7023-7044

Xu XG, Chao TC, and Bozkurt A 2000 VIP-man: An image-based whole-body adult male model constructed from color photographs of the visible human project for multiparticle Monte Carlo calculations. Health Physics 78(5) 476-486

Zankl M, Eckerman K F and Bolch W E 2007 Adult male and female voxel-based models representing the ICRP

reference adult -the skeleton Radiat. Prot. Dosim. 127 174-86

Zubal IG, Harrell CR, Smith EO, Rattner Z, Gindi G, and Hoffer PB 1994 Computerized 3-Dimensional Segmented Human Anatomy. Medical Physics 21(2) 299-302 
Table 1. Skeletal Site-Specific Volume Fractions

\begin{tabular}{|l|ll|ll|}
\hline Skeletal Site & MVF & TBVF & SVF & CBVF \\
\hline Cranium & 0.3160 & 0.6840 & 0.4125 & 0.58749 \\
Mandible & 0.8502 & 0.1498 & 0.4965 & 0.50345 \\
Cervical & 0.8205 & 0.1795 & 0.6415 & 0.35853 \\
Thoracic & 0.8856 & 0.1144 & 0.7890 & 0.21102 \\
Lumbar & 0.8728 & 0.1272 & 0.8488 & 0.15119 \\
Sternum & 0.9173 & 0.0827 & 0.7385 & 0.26153 \\
Ribs & 0.9096 & 0.0904 & 0.5706 & 0.42943 \\
Scapulae & 0.9461 & 0.0539 & 0.6082 & 0.39179 \\
Clavicles & 0.9211 & 0.0789 & 0.5638 & 0.43617 \\
Os coxae & 0.9529 & 0.0471 & 0.7698 & 0.23017 \\
Sacrum & 0.8476 & 0.1524 & 0.7423 & 0.25772 \\
Humeri, Proximal & 0.9071 & 0.0929 & 0.8811 & 0.11886 \\
Humeri, Upper Shaft & 1.0000 & 0.0000 & 0.3468 & 0.65322 \\
Humeri, Lower Shaft & 1.0000 & 0.0000 & 0.3468 & 0.65322 \\
Humeri, Distal & 0.8291 & 0.1709 & 0.7644 & 0.23555 \\
Radii, Proximal & 0.8805 & 0.1195 & 0.7448 & 0.25519 \\
Radii, Shaft & 1.0000 & 0.0000 & 0.3353 & 0.66472 \\
Radii, Distal & 0.8671 & 0.1329 & 0.8253 & 0.17471 \\
Ulnae, Proximal & 0.7312 & 0.2688 & 0.8120 & 0.18795 \\
Ulnae, Shaft & 1.0000 & 0.0000 & 0.3338 & 0.66623 \\
Ulnae, Distal & 0.9620 & 0.0380 & 0.8184 & 0.18158 \\
Wrists and Hands & 0.9096 & 0.0904 & 0.3482 & 0.65181 \\
Femora, Proximal & 0.77275 & 0.2273 & 0.9008 & 0.09917 \\
Femora, Upper Shaft & 1.0000 & 0.0000 & 0.5230 & 0.47701 \\
Femora, Lower Shaft & 1.0000 & 0.0000 & 0.5230 & 0.47701 \\
Femora, Distal & 0.7966 & 0.2034 & 0.8558 & 0.14419 \\
Patellae & 0.8135 & 0.1865 & 0.8588 & 0.14116 \\
Tibiae, Proximal & 0.8417 & 0.1583 & 0.8830 & 0.11698 \\
Tibiae, Shaft & 1.0000 & 0.0000 & 0.4708 & 0.52919 \\
Tibiae, Distal & 0.8284 & 0.1716 & 0.8509 & 0.14909 \\
Fibulae, Proximal & 0.8780 & 0.1220 & 0.8344 & 0.16564 \\
Fibulae, Shaft & 1.0000 & 0.0000 & 0.3058 & 0.69422 \\
Fibulae, Distal & 0.8185 & 0.1815 & 0.7428 & 0.25724 \\
Ankles and Feet & 0.9096 & 0.0904 & 0.6812 & 0.31877 \\
\hline
\end{tabular}


Table 2. Miscellaneous Skeletal Tissue Volume and Mass Distribution

\begin{tabular}{|c|c|c|c|c|c|c|c|c|c|c|c|c|}
\hline Skeletal Site & MST - Total Vol & MST - Total Mass & MST - Mineral Bone Vol & MST - Mineral Bone Mass & MST - TAM Vol & MST - TAM Mass & MST - TIM Vol & MST - TIM Mass & MST - CBV Vol & MST - CBV Mass & MST - TBV Vol & MST - TBV Mass \\
\hline \begin{tabular}{|l|} 
Cranium \\
\end{tabular} & 18.35 & 18.71 & 15.96 & 16.28 & 0.91 & 0.93 & 1.48 & 1.51 & 10.78 & 10.99 & 4.31 & 4.40 \\
\hline Mandible & 1.53 & 1.56 & 0.89 & 0.90 & 0.25 & 0.25 & 0.40 & 0.41 & 0.77 & 0.79 & 0.09 & 0.09 \\
\hline Cervical & 2.54 & 2.59 & 1.20 & 1.23 & 0.94 & 0.95 & 0.40 & 0.41 & 0.91 & 0.93 & 0.21 & 0.22 \\
\hline Thoracic & 7.28 & 7.43 & 2.19 & 2.24 & 3.56 & 3.63 & 1.53 & 1.56 & 1.54 & 1.57 & 0.42 & 0.43 \\
\hline Lumbar & 8.60 & 8.78 & 2.23 & 2.27 & 4.46 & 4.55 & 1.91 & 1.95 & 1.30 & 1.33 & 0.56 & 0.57 \\
\hline Sternum & 1.23 & 1.26 & 0.40 & 0.41 & 0.58 & 0.60 & 0.25 & 0.26 & 0.32 & 0.33 & 0.06 & 0.06 \\
\hline Ribs & 9.80 & 10.00 & 4.71 & 4.81 & 3.56 & 3.63 & 1.53 & 1.56 & 4.21 & 4.29 & 0.33 & 0.34 \\
\hline Scapulae & 9.70 & 9.90 & 4.12 & 4.20 & 2.12 & 2.16 & 3.46 & 3.53 & 3.80 & 3.88 & 0.23 & 0.24 \\
\hline Clavicles & 1.62 & 1.65 & 0.78 & 0.80 & 0.28 & 0.28 & 0.56 & 0.58 & 0.71 & 0.72 & 0.05 & 0.05 \\
\hline Os coxae & 20.27 & 20.68 & 5.40 & 5.51 & 7.14 & 7.28 & 7.73 & 7.89 & 4.67 & 4.76 & 0.50 & 0.51 \\
\hline Sacrum & 6.16 & 6.29 & 2.29 & 2.33 & 1.86 & 1.90 & 2.02 & 2.06 & 1.59 & 1.62 & 0.50 & 0.51 \\
\hline Humeri, Proximal & 4.03 & 4.11 & 0.81 & 0.82 & 1.13 & 1.15 & 2.09 & 2.13 & 0.48 & 0.49 & 0.25 & 0.25 \\
\hline Humeri, Upper Shaft & 2.14 & 2.18 & 1.39 & 1.42 & 0.11 & 0.11 & 0.63 & 0.64 & 1.39 & 1.42 & 0.00 & 0.00 \\
\hline Humeri, Lower Shaft & 1.88 & 1.92 & 1.23 & 1.25 & 0.00 & 0.00 & 0.65 & 0.67 & 1.23 & 1.25 & 0.00 & 0.00 \\
\hline Humeri, Distal & 2.56 & 2.62 & 0.94 & 0.96 & 0.00 & 0.00 & 1.63 & 1.66 & 0.60 & 0.62 & 0.23 & 0.23 \\
\hline Radii, Proximal & 0.40 & 0.41 & 0.14 & 0.14 & 0.00 & 0.00 & 0.26 & 0.27 & 0.10 & 0.10 & 0.02 & 0.02 \\
\hline Radii, Shaft & 1.49 & 1.51 & 0.99 & 1.01 & 0.00 & 0.00 & 0.50 & 0.51 & 0.99 & 1.01 & 0.00 & 0.00 \\
\hline Radii, Distal & 0.72 & 0.74 & 0.21 & 0.21 & 0.00 & 0.00 & 0.52 & 0.53 & 0.13 & 0.13 & 0.06 & 0.06 \\
\hline Ulnae, Proximal & 1.36 & 1.38 & 0.55 & 0.56 & 0.00 & 0.00 & 0.81 & 0.82 & 0.25 & 0.26 & 0.21 & 0.21 \\
\hline Ulnae, Shaft & 1.76 & 1.80 & 1.17 & 1.20 & 0.00 & 0.00 & 0.59 & 0.60 & 1.17 & 1.20 & 0.00 & 0.00 \\
\hline Ulnae, Distal & 0.25 & 0.26 & 0.05 & 0.05 & 0.00 & 0.00 & 0.20 & 0.20 & 0.05 & 0.05 & 0.00 & 0.00 \\
\hline Wrists and Hands & 3.65 & 3.73 & 2.50 & 2.55 & 0.00 & 0.00 & 1.16 & 1.18 & 2.38 & 2.43 & 0.09 & 0.09 \\
\hline Femora, Proximal & 5.76 & 5.88 & 1.75 & 1.79 & 1.40 & 1.43 & 2.61 & 2.66 & 0.57 & 0.58 & 0.75 & 0.77 \\
\hline Femora, Upper Shaft & 3.97 & 4.05 & 1.89 & 1.93 & 0.31 & 0.32 & 1.76 & 1.80 & 1.89 & 1.93 & 0.00 & 0.00 \\
\hline Femora, Lower Shaft & 4.53 & 4.62 & 2.16 & 2.20 & 0.00 & 0.00 & 2.37 & 2.42 & 2.16 & 2.20 & 0.00 & 0.00 \\
\hline Femora, Distal & 7.52 & 7.67 & 2.39 & 2.44 & 0.00 & 0.00 & 5.12 & 5.23 & 1.08 & 1.11 & 1.06 & 1.08 \\
\hline Patellae & 0.81 & 0.82 & 0.24 & 0.25 & 0.00 & 0.00 & 0.56 & 0.58 & 0.11 & 0.12 & 0.10 & 0.10 \\
\hline Tibiae, Proximal & 5.96 & 6.08 & 1.53 & 1.56 & 0.00 & 0.00 & 4.43 & 4.52 & 0.70 & 0.71 & 0.65 & 0.66 \\
\hline Tibiae, Shaft & 5.31 & 5.41 & 2.81 & 2.86 & 0.00 & 0.00 & 2.50 & 2.55 & 2.81 & 2.86 & 0.00 & 0.00 \\
\hline Tibiae, Distal & 2.19 & 2.23 & 0.65 & 0.66 & 0.00 & 0.00 & 1.54 & 1.58 & 0.33 & 0.33 & 0.26 & 0.26 \\
\hline Fibulae, Proximal & 0.50 & 0.51 & 0.13 & 0.14 & 0.00 & 0.00 & 0.37 & 0.37 & 0.08 & 0.08 & 0.03 & 0.03 \\
\hline Fibulae, Shaft & 0.81 & 0.82 & 0.56 & 0.57 & 0.00 & 0.00 & 0.25 & 0.25 & 0.56 & 0.57 & 0.00 & 0.00 \\
\hline Fibulae, Distal & 0.49 & 0.50 & 0.19 & 0.20 & 0.00 & 0.00 & 0.30 & 0.30 & 0.13 & 0.13 & 0.05 & 0.05 \\
\hline Ankles and Feet & 11.68 & 11.92 & 4.44 & 4.53 & 0.00 & 0.00 & 7.24 & 7.39 & 3.72 & 3.80 & 0.36 & 0.37 \\
\hline Total Skeleton & 156.86 & 160.00 & 68.90 & 70.28 & 28.61 & 29.18 & 59.35 & 60.54 & 53.52 & 54.59 & 11.38 & 11.61 \\
\hline ICRP 89 Reference & 156.86 & 160.00 & & & & & & & & & & \\
\hline
\end{tabular}


Table 3. Trabecular Active and Inactive Marrow Volumes and Masses

\begin{tabular}{|c|c|c|c|c|}
\hline Skeletal Site & $\begin{array}{c}\text { TAM } \\
\text { Volume }(\mathrm{cm} 3)\end{array}$ & $\begin{array}{c}\text { TAM } \\
\text { Mass (g) }\end{array}$ & $\begin{array}{c}\text { TIM } \\
\text { Volume } \\
\text { (cm3) }\end{array}$ & $\begin{array}{c}\text { TIM } \\
\text { Mass (g) }\end{array}$ \\
\hline Cranium & 27.77 & 28.60 & 45.31 & 44.40 \\
\hline Mandible & 7.52 & 7.74 & 12.27 & 12.02 \\
\hline Cervical & 28.61 & 29.47 & 12.26 & 12.02 \\
\hline Thoracic & 108.85 & 112.12 & 46.65 & 45.72 \\
\hline Lumbar & 136.33 & 140.42 & 58.43 & 57.26 \\
\hline Sternum & 17.85 & 18.39 & 7.65 & 7.50 \\
\hline Ribs & 108.78 & 112.04 & 46.62 & 45.69 \\
\hline Scapulae & 64.84 & 66.78 & 105.79 & 103.67 \\
\hline Clavicles & 8.50 & 8.75 & 17.25 & 16.91 \\
\hline Os coxae & 218.10 & 224.64 & 236.27 & 231.55 \\
\hline Sacrum & 56.89 & 58.59 & 61.63 & 60.40 \\
\hline Humeri, Proximal & 34.42 & 35.45 & 63.92 & 62.64 \\
\hline Humeri, Upper Shaft & 3.39 & 3.50 & 19.23 & 18.85 \\
\hline Humeri, Lower Shaft & 0.00 & 0.00 & 19.94 & 19.54 \\
\hline Humeri, Distal & 0.00 & 0.00 & 49.67 & 48.67 \\
\hline Radii, Proximal & 0.00 & 0.00 & 7.99 & 7.83 \\
\hline Radii, Shaft & 0.00 & 0.00 & 15.22 & 14.91 \\
\hline Radii, Distal & 0.00 & 0.00 & 15.77 & 15.46 \\
\hline Ulnae, Proximal & 0.00 & 0.00 & 24.61 & 24.12 \\
\hline Ulnae, Shaft & 0.00 & 0.00 & 17.96 & 17.60 \\
\hline Ulnae, Distal & 0.00 & 0.00 & 6.07 & 5.95 \\
\hline Wrists and Hands & 0.00 & 0.00 & 35.34 & 34.64 \\
\hline Femora, Proximal & 42.91 & 44.20 & 79.70 & 78.10 \\
\hline Femora, Upper Shaft & 9.51 & 9.79 & 53.89 & 52.81 \\
\hline Femora, Lower Shaft & 0.00 & 0.00 & 72.36 & 70.91 \\
\hline Femora, Distal & 0.00 & 0.00 & 156.57 & 153.44 \\
\hline Patellae & 0.00 & 0.00 & 17.26 & 16.91 \\
\hline Tibiae, Proximal & 0.00 & 0.00 & 135.34 & 132.63 \\
\hline Tibiae, Shaft & 0.00 & 0.00 & 76.36 & 74.83 \\
\hline Tibiae, Distal & 0.00 & 0.00 & 47.19 & 46.25 \\
\hline Fibulae, Proximal & 0.00 & 0.00 & 11.20 & 10.98 \\
\hline Fibulae, Shaft & 0.00 & 0.00 & 7.53 & 7.38 \\
\hline Fibulae, Distal & 0.00 & 0.00 & 9.11 & 8.92 \\
\hline Ankles and Feet & 0.00 & 0.00 & 221.24 & 216.82 \\
\hline Total Skeleton & 874.26 & 900.49 & 1813.58 & 1777.31 \\
\hline ICRP 89 Reference & & 900.00 & & 1800.00 \\
\hline Ratio & & 1.00 & & 0.99 \\
\hline
\end{tabular}


Table 4. Cortical, Trabecular, and Mineral Bone Masses

\begin{tabular}{|c|c|c|c|}
\hline \multirow[b]{2}{*}{ Skeletal Site } & \multicolumn{3}{|c|}{ Excluding MST } \\
\hline & $\begin{array}{c}\text { Trabecular Bone } \\
\text { Mass (g) }\end{array}$ & $\begin{array}{c}\text { Cortical Bone } \\
\text { Mass (g) }\end{array}$ & $\begin{array}{c}\text { Total Mineral } \\
\text { Bone Mass }\end{array}$ \\
\hline Cranium & 302.22 & 625.80 & 926.38 \\
\hline Mandible & 6.67 & 44.83 & 51.45 \\
\hline Cervical & 17.14 & 52.89 & 69.88 \\
\hline Thoracic & 38.63 & 89.23 & 127.40 \\
\hline Lumbar & 54.65 & 75.52 & 129.46 \\
\hline Sternum & 4.40 & 18.71 & 23.08 \\
\hline Ribs & 29.68 & 244.30 & 273.65 \\
\hline Scapulae & 18.63 & 220.73 & 239.20 \\
\hline Clavicles & 4.23 & 41.09 & 45.28 \\
\hline Os coxae & 43.11 & 270.87 & 313.54 \\
\hline Sacrum & 40.86 & 92.24 & 132.73 \\
\hline Humeri, Proximal & 19.29 & 27.79 & 46.92 \\
\hline Humeri, Upper Shaft & 0.00 & 80.98 & 80.98 \\
\hline Humeri, Lower Shaft & 0.00 & 71.35 & 71.35 \\
\hline Humeri, Distal & 19.66 & 35.07 & 54.52 \\
\hline Radii, Proximal & 2.08 & 5.91 & 7.97 \\
\hline Radii, Shaft & 0.00 & 57.32 & 57.32 \\
\hline Radii, Distal & 4.64 & 7.32 & 11.91 \\
\hline Ulnae, Proximal & 17.36 & 14.80 & 32.00 \\
\hline Ulnae, Shaft & 0.00 & 68.13 & 68.13 \\
\hline Ulnae, Distal & 0.46 & 2.66 & 3.11 \\
\hline Wrists and Hands & 6.72 & 138.21 & 144.88 \\
\hline Femora, Proximal & 69.33 & 33.19 & 101.70 \\
\hline Femora, Upper Shaft & 0.00 & 109.87 & 109.87 \\
\hline Femora, Lower Shaft & 0.00 & 125.40 & 125.40 \\
\hline Femora, Distal & 76.43 & 62.92 & 138.88 \\
\hline Patellae & 7.58 & 6.63 & 14.14 \\
\hline Tibiae, Proximal & 48.72 & 40.47 & 88.83 \\
\hline Tibiae, Shaft & 0.00 & 163.07 & 163.07 \\
\hline Tibiae, Distal & 18.70 & 18.96 & 37.54 \\
\hline Fibulae, Proximal & 3.00 & 4.81 & 7.77 \\
\hline Fibulae, Shaft & 0.00 & 32.49 & 32.49 \\
\hline Fibulae, Distal & 3.87 & 7.32 & 11.16 \\
\hline Ankles and Feet & 42.46 & 216.25 & 258.03 \\
\hline Total Skeleton & 900.48 & 3107.12 & 4000.00 \\
\hline ICRP 89 Reference & 800.00 & 3200.00 & 4000.00 \\
\hline Ratio & 1.13 & 0.97 & 1.00 \\
\hline
\end{tabular}


Table 5. Distribution of Shallow Marrow by Skeletal Site

\begin{tabular}{|c|c|c|c|c|c|c|c|}
\hline Skeletal Site & $\begin{array}{c}\text { SMVF } \\
\text { (\% of SV) }\end{array}$ & $\begin{array}{c}\text { SMVF } \\
\text { (\% of } \\
\text { Marrow) }\end{array}$ & $\begin{array}{l}\text { Shallow } \\
\text { Inactive } \\
\text { Marrow } \\
\text { Volume }\end{array}$ & $\begin{array}{c}\text { Shallow } \\
\text { Inactive } \\
\text { Marrow } \\
\text { Mass }\end{array}$ & $\begin{array}{c}\text { Shallow } \\
\text { Active } \\
\text { Marrow } \\
\text { Volume }\end{array}$ & $\begin{array}{c}\text { Shallow } \\
\text { Active } \\
\text { Marrow } \\
\text { Mass }\end{array}$ & $\begin{array}{c}\text { Shallow } \\
\text { Marrow } \\
\text { (\% of } \\
\text { Total) }\end{array}$ \\
\hline Cranium & 16.92 & 53.55 & 25.06 & 24.56 & 15.36 & 15.82 & 10.78 \\
\hline Mandible & 23.54 & 27.69 & 3.51 & 3.44 & 2.15 & 2.21 & 1.51 \\
\hline Cervical & 13.38 & 16.31 & 2.06 & 2.02 & 4.82 & 4.96 & 1.87 \\
\hline Thoracic & 13.84 & 15.63 & 7.53 & 7.38 & 17.57 & 18.10 & 6.80 \\
\hline Lumbar & 8.46 & 9.69 & 5.85 & 5.73 & 13.65 & 14.06 & 5.29 \\
\hline Sternum & 16.12 & 17.57 & 1.39 & 1.36 & 3.24 & 3.34 & 1.25 \\
\hline Ribs & 17.46 & 19.20 & 9.24 & 9.06 & 21.57 & 22.22 & 8.35 \\
\hline Scapulae & 14.78 & 15.62 & 17.06 & 16.72 & 10.46 & 10.77 & 7.34 \\
\hline Clavicles & 11.67 & 12.66 & 2.26 & 2.21 & 1.11 & 1.14 & 0.90 \\
\hline Os coxae & 15.03 & 15.77 & 38.48 & 37.71 & 35.52 & 36.59 & 19.84 \\
\hline Sacrum & 10.76 & 12.70 & 8.08 & 7.92 & 7.46 & 7.68 & 4.17 \\
\hline Humeri, Proximal & 10.81 & 11.91 & 7.86 & 7.71 & 4.23 & 4.36 & 3.22 \\
\hline Humeri, Upper Shaft & 0.02 & 0.02 & 0.00 & 0.00 & 0.00 & 0.00 & 0.00 \\
\hline Humeri, Lower Shaft & 0.02 & 0.02 & 0.00 & 0.00 & 0.00 & 0.00 & 0.00 \\
\hline Humeri, Distal & 11.36 & 13.70 & 7.03 & 6.89 & 0.00 & 0.00 & 1.84 \\
\hline Radii, Proximal & 10.72 & 12.18 & 1.00 & 0.98 & 0.00 & 0.00 & 0.26 \\
\hline Radii, Shaft & 0.03 & 0.03 & 0.00 & 0.00 & 0.00 & 0.00 & 0.00 \\
\hline Radii, Distal & 11.02 & 12.70 & 2.07 & 2.03 & 0.00 & 0.00 & 0.54 \\
\hline Ulnae, Proximal & 11.24 & 15.38 & 3.91 & 3.83 & 0.00 & 0.00 & 1.02 \\
\hline Ulnae, Shaft & 0.02 & 0.02 & 0.00 & 0.00 & 0.00 & 0.00 & 0.00 \\
\hline Ulnae, Distal & 7.01 & 7.29 & 0.46 & 0.45 & 0.00 & 0.00 & 0.12 \\
\hline Wrists and Hands & 9.59 & 10.55 & 3.85 & 3.77 & 0.00 & 0.00 & 1.01 \\
\hline Femora, Proximal & 9.70 & 12.55 & 10.33 & 10.13 & 5.56 & 5.73 & 4.23 \\
\hline Femora, Upper Shaft & 0.01 & 0.01 & 0.01 & 0.01 & 0.00 & 0.00 & 0.00 \\
\hline Femora, Lower Shaft & 0.01 & 0.01 & 0.01 & 0.01 & 0.00 & 0.00 & 0.00 \\
\hline Femora, Distal & 7.16 & 8.98 & 14.52 & 14.23 & 0.00 & 0.00 & 3.80 \\
\hline Patellae & 6.12 & 7.52 & 1.34 & 1.31 & 0.00 & 0.00 & 0.35 \\
\hline Tibiae, Proximal & 13.11 & 15.57 & 21.77 & 21.33 & 0.00 & 0.00 & 5.70 \\
\hline Tibiae, Shaft & 0.01 & 0.01 & 0.01 & 0.01 & 0.00 & 0.00 & 0.00 \\
\hline Tibiae, Distal & 13.80 & 16.66 & 8.12 & 7.96 & 0.00 & 0.00 & 2.13 \\
\hline Fibulae, Proximal & 11.42 & 13.01 & 1.50 & 1.47 & 0.00 & 0.00 & 0.39 \\
\hline Fibulae, Shaft & 0.04 & 0.04 & 0.00 & 0.00 & 0.00 & 0.00 & 0.00 \\
\hline Fibulae, Distal & 18.89 & 23.07 & 2.17 & 2.13 & 0.00 & 0.00 & 0.57 \\
\hline Ankles and Feet & 10.20 & 11.21 & 25.62 & 25.11 & 0.00 & 0.00 & 6.71 \\
\hline Total Skeleton & & & 232.13 & 227.49 & 142.70 & 146.99 & 100.00 \\
\hline
\end{tabular}


Table 6. Height and Radii of the Medullary Cavities within the long bone of UFHADF

\begin{tabular}{|c|c|c|c|}
\hline Skeletal Site & $\begin{array}{c}\text { Measured Height }(\mathrm{cm}) \\
\text { Medullary Marrow }\end{array}$ & $\begin{array}{c}\text { Measured Height } \\
\text { Std. Dev. (cm) }\end{array}$ & $\begin{array}{c}\text { Calculated Radius (cm) } \\
\text { Medullary Marrow }\end{array}$ \\
\hline Humerii, Upper Shaft & 9.755 & 0.095 & 0.617 \\
Humerii, Lower Shaft & 9.995 & 0.117 & 0.573 \\
Radii, Shaft & 17.532 & 0.159 & 0.378 \\
Ulna, Shaft & 17.443 & 0.032 & 0.411 \\
Femora, Upper Shaft & 14.642 & 0.065 & 0.844 \\
Femora, Lower Shaft & 14.108 & 0.048 & 0.918 \\
Tibia, Shaft & 23.744 & 0.050 & 0.727 \\
Fibula, Shaft & 23.761 & 0.054 & 0.228 \\
\hline
\end{tabular}

